Portland State University

PDXScholar

$1-1-1983$

\title{
An exploratory functional-structural analysis of American urban traditional and alternative secondary public schools
}

Mary Ellen Sweeney

Portland State University

Follow this and additional works at: https://pdxscholar.library.pdx.edu/open_access_etds Let us know how access to this document benefits you.

\section{Recommended Citation}

Sweeney, Mary Ellen, "An exploratory functional-structural analysis of American urban traditional and alternative secondary public schools" (1983). Dissertations and Theses. Paper 709.

https://doi.org/10.15760/etd.709

This Dissertation is brought to you for free and open access. It has been accepted for inclusion in Dissertations and Theses by an authorized administrator of PDXScholar. Please contact us if we can make this document more accessible: pdxscholar@pdx.edu. 
AN EXPLORATORY FUNCTIONAL-STRUCTURAL ANALYSIS OF AMERICAN URBAN TRADITIONAL AND ALTERNATIVE SECONDARY PUBLIC SCHOOLS

by

MARY ELLEN SWEENEY

A dissertation submitted in partial fulfillment of the requirements for the degree of

\section{DOCTOR OF PHILOSOPHY \\ in}

URBAN STUDIES

Portland State University

1983 
TO THE OFFICE OF GRADUATE STUDIES AND RESEARCH

The members of the Committee approve the dissertation of

Mary Ellen Sweeney presented December 2, 1983.
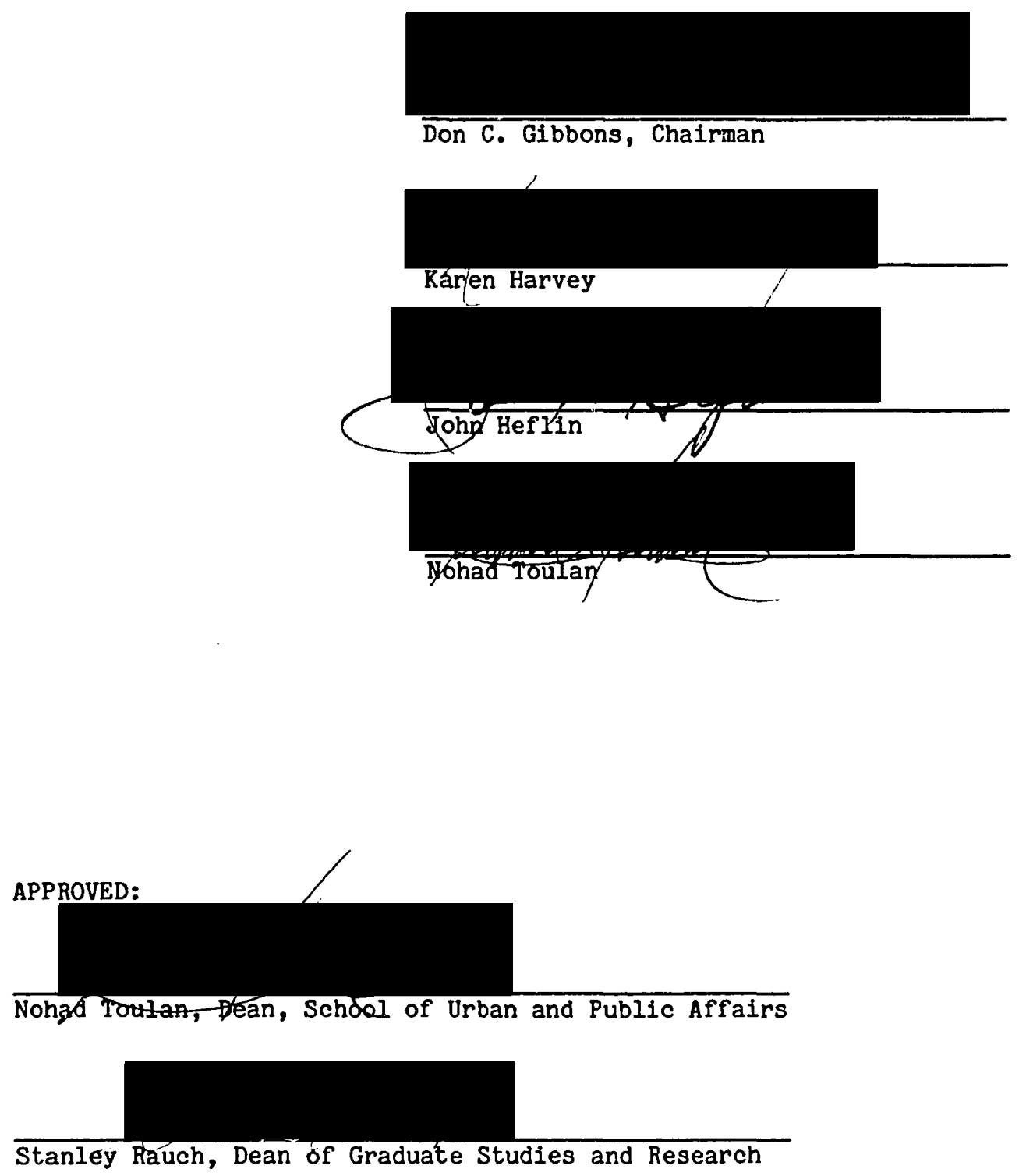
AI ABSTRACT OF THE DISSERTATION OF Mary Ellen Sweeney for the Doctor of Philosophy in Urban Studies presented December 2, 1983.

Title: An Exploratory Structural-Functional Analysis of American Urban Traditional and Alternative Public Secondary Schools. APPROVED BY MEMBERS OF THE DISSERTATION COMMITTEE:

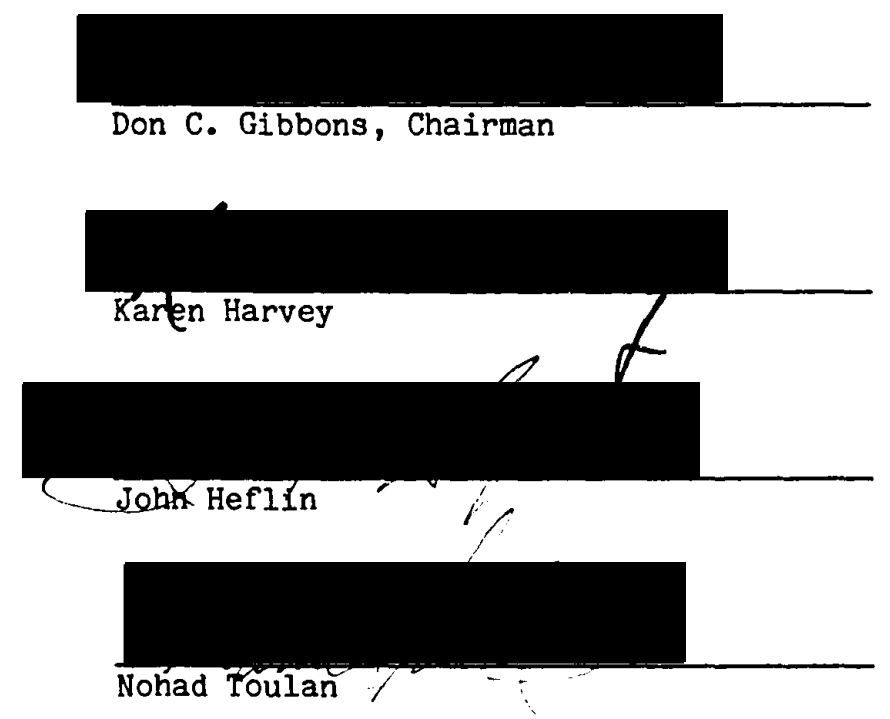

This study investigates the way traditional and alternative secondary public school organizations are structured to impact youths. Some studies have found that traditional secondary schools utilize inappropriate and outdated organizational elements and arrangements. Alternative schools with different organizational arrangements have been initiated in public school districts to institute school reform measures. 
The three goals of this study are to: (1) collate a large share of the literature on the function, social context and organizational characteristics of conventional and alternative secondary public school organizations, (2) explicate a theoretical framework or interrelated set of propositions of organizational principles regarding modern organizations, including secondary schools, and (3) describe and analyze one alternative high school in Colorado. The theoretical exploration of the literature and case study will address the following questions: (1) what organizational models do conventional and alternative high schools utilize? (2) What are the organizational elements of conventional and alternative secondary public schools? (3) What types of conventional and alternative secondary schools exist in urban areas? (4) How do conventional and alternative high school organizations bear up to the charges leveled against secondary education in America? (5) What are the organizational characteristics of the alternative school in Colorado? (6) What type of alternative school is Mountain Open High School (MOHS)? (7) How does MOHS measure up to the charges leveled against American secondary education? (8) How is MOHS simflar or dissimilar to public secondary schools reviewed in the literature?

Data for the exploration of the organizational characteristics of traditional and alternative secondary public schools include the following sources: (1) consultation with experts in the field, (2) in-depth literature review, and (3) historical and document analysis. Data for the case study include the following sources: (1) in-depth 
interviews with 13 student volunteers, the prircipal, and other staff, (2) field observations, and (3) historical and document analysis. The results show that traditional secondary public schools utilize a bureaucratic organizational framework but organizational characteristics of schools vary according to their function and student body composition. Also, alternative secondary schools exist under bureaucratic principles but differ according to their function and organizational arrangements. The case study of MOHS demonstrates one model with instituted school reform measures. 
The completion of this endeavor is testimony to the fact that "With God all things are possible." I am especially indebted to my Dissertation Committee: Dr. Don Gibbons, my Chairperson, for his leadership and hours of editing, Dr. Karen Harvey for her moral support and writing mechanics guidance, Dr. John Heflin for his theoretical expertise and perserverance, and Dr. Nohad Toulan, Dean of the School of Urban and Public Affairs, for his belief in me.

I have been blessed with a multitude of significant others to whom I am appreciative including my family, relatives, friends, and fellow graduate students. In particular, my parents have made the completion of this effort possible.

The trust and cooperation of all persons at Mountain Open High School, especially student interviewees, has enabled me to investigate and document the interpersonal, effective, and quality education provided at MOHS. My interest in alternative schools is rooted in my teaching experience in a magnet school, Martin Luther King Middle School, in Omaha, Nebraska and by Dr. William T. Pink during my graduate studies in Urban Education at the University of Nebraska at Omaha. This study is dedicated to all of my students, in the past and the future, and to all of American youths as attempts are made in educational institutions to discover better ways to prepare them for a successful transition to adulthood and for self-actualization as workplace participants and contributing members of our democratic society. 
ACKNOWLEDGEMENTS . . . . . . . . . . . . . . . . . iii

LIST OF FIGURES . . . . . . . . . . . . . . . . . ix

INTRODUCTION

Statement of the Problem ............ 1

Importance of the Study .............. 1

Conceptual Framework for the Research . . . . . . 3

Organization of this Dissertation ......... 4

PART I - MODERN ORGANIZATIONAL THEORY: APPLICATION TO PUBLIC SCHOOL ORGANIZATIONS

\section{CHAPTER}

I MODERN ORGANIZATIONAL STRUCTURES: HISTORICAL EMERGENCE AND THEORETICAL ANALYSIS . . . . . . . . 7

Historical Emergence of Modern Organizational

Structures ................. 7

Modern Organizational Theory . . . . . . . 10

Organizational Elements . . . . . . . 13

Organizational Typologies . . . . . . . 18

The Human Size Side of Organizations . . . . . 20

Secondary Public Schools as Modern Social

Organizations .............. 24

Summary . . . . . . . . . . . . . 29

Methodology .............. 30

Operational Definitions ........... 32 
Limitations of this study . . . . . . . 32

Data Sources . . . . . . . . . . . 33

Contributions . . . . . . . . . 35

PART II - CONVENTIONAL PUBLIC SECONDARY SCHOOLS: THE STATE OF THE ART

II THE COMPREHENSIVE HIGH SCHOOL: AN OVERVIEW . . . . 38

Historical Emergence of the Comprehensive

High School ............. 38

A Functional Typology of Secondary Schools . . . 43

The Socioeconomic-Geographical Patterning of

Secondary Schools .. . . . . . . . . 49

Criticisms of the Conventional Secondary School

Organization ............... 68

III COMPREHENSIVE HIGH SCHOOLS: AN EXAMINATION OF ORGANIZATIONAL CHARACTERISTICS . . . . . . . . . 74

Goals.................. . . 74

Participatory Goal Setting

Preferred Secondary School Goals

Technologies of Conventional High Schools . . . . 92

Curriculum

Curriculum: Social Studies

Curriculum: Science and Mathematics

Curriculum: English

School Size

Academic Tracking

Effective Schools

Effective Schools: The Rutter Study

Formal Structures . . . . . . . . . . . 126

Informal Structures . . . . . . . . 137

Ecological Influences .......... 148 
IV SUMMARY STATEMENTS: THE STATUS OF CONVENTIONAL SECONDARY SCHOOL ORGANIZATIONS . . . . . . . 150

Conventional Secondary Public School

Summary Statements . . . . . . . 150

Conventional Secondary Public School Concluding

Statements ................. 153

PART III - ALTERNATIVE SCHOOLS: EDUCATIONAL ORGANIZATIONS OF CHOICE

V ALTERNATIVE SCHOOLS: AN OVERVIEW . . . . . . 160

Origins ............................. 161

The Matter of a Definition . . . . . . 164

The Growth of Alternative Schools . . . . . 165

Alternative School Typologies . . . . . . 167

Alternative School Populations ......... 183

VI ORGANIZATIONAL CHARACTERISTICS OF ALTERNATIVE SCHOOLS • 186

Goals .................. 186

Technologies (............. 190

Curriculum

Teaching Strategies

Size

Cost

Grading

Evaluation, Flexibility, and Change

Free Choice

Alternative School Formal Structures . . . . 201

Governance

Administrators in Alternative Schools

Teachers in Alternative Schools

Informal Structures of Alternative Schools . . . 209

Advisory Systems

Student Gains

Alternative Schools as Effective Schools 
Ecological Influences . . . . . . . . . 217

A Summary: School Reform and Alternative

Schooling ................. 217

VII THE STATUS OF ALTERNATIVE SECONDARY SCHOOL

ORGANIZATIONS: SUMMARY STATEMENTS . . . . . . . . 219

Alternative School Summary Statements . . . . . 219

Charges Against Secondary Schools--The Alternative

School Response .............. . 222

PART IV - MOUNTAIN OPEN HIGH SCHOOL: A CASE STUDY OF ONE ALTERNATIVE PUBLIC HIGH SCHOOL

VIII AN OVERVIEW OF MOUNTAIN OPEN HIGH SCHOOL . . . . . 228

Location and Physical Facilities . . . . . . 229

History ................ 232

Student Population . . . . . . . . . . 236

IX MOUNTAIN OPEN HIGH SCHOOL'S ORGANIZATIONAL

CHARACTERISTICS . . . . . . . . . . . . 240

MOHS' Goals . . . . . . . . . . . . 240

Technologies . . . . . . . . . . . . 243

Phase I--Beginnings

Phase II--Pre-Walkabout

Phase III--Passages

Other MOHS Technologies

MOHS' Formal Structure . . . . . . . . . 262

Arnie: The Principal

Governance

Teachers

Informal Structure . . . . . . . . 270

Community Influences . . . . . . . . . . 272 


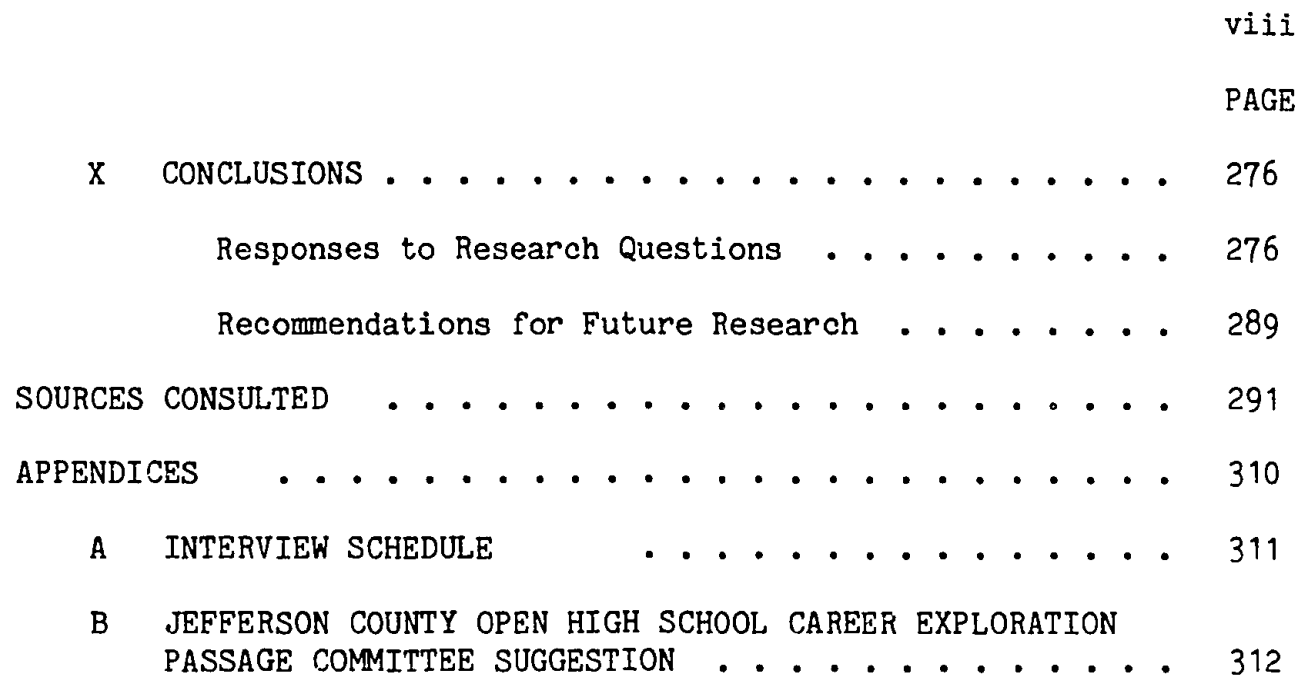




\section{LIST OF FIGURES}

FIGURE

PAGE

1. An Example of the Functional Types of Secondary

Schools . . . . . . . . . . . . 43

2. An Example of the Organizational Characteristics of

Different Socioeconomic High School Types . . . . 51

3. An Example of the Levels of Alternative Education

Programs .................... 170

4. Bureaucratic Organizational Characteristics of

Traditional and Alternative Secondary Schools

and MOHS . . . . . . . . . . . . 277 
INTRODUCTION

\section{Statement of the Problem}

This study examines the organizational characteristics of one urban social institution, in this case secondary public schools, to analyze the ways they are organized to have an impact on youths.

\section{Importance of the Study}

Why is this examination of high schools important and significant? The education of 16 million American youths and their adequate preparation for adulthood as participants in the world of work and as contributors to a democratic society has political, social, and economic implications and ramifications for other urban social institutions.

Economically, a thriving economy and strong Gross National Product can only be sustained by the availability of large numbers of skilled and capable individuals. The worker in the current labor market must be prepared with technical skills and the capacity to learn new skills. Socially, young adults must possess and sustain a strong self-concept so they can effectively relate to and interact with an increasing diverse and pluralistic larger community. Politically, young adults should be experienced in the workings of a democracy and analytical enough to examine and vote competently upon complicated issues such as nuclear disarmament and nuclear power. 
Urban social organizations like social service agencies, job training corps, unemployment agencies, drug and alcohol rehabilitation programs, law enforcement agencies, and the armed forces are effected directly by the way secondary schools are structured successfully or unsuccessfully to educate and train students for the future.

Historically, there have been two types of conventional secondary public high schools. Numerous studies over the past twenty years claim that something is wrong with these educational organizations because they are failing some youths. There are indicators that something is amiss and evidence to support this fact in academic areas include: (1) internationally, when compared by nineteen academic tests, American students were never first or second, but were last seven times, (2) 13 percent of youths 17 years of age in the U.S. are functionally illiterate with as many as 40 percent of minority youths being in this predicament, (3) academic achievement of high school students is lower on standardized tests than 26 years ago when Sputnik was launched, (4) 50 percent of gifted students in high schools do not achieve to appropriate levels in schools, (5) SAT scores have dropped since 1963 with the average Verbal and Math scores declining 50 and 40 points, respectively, (6) superior SAT scores of a 650 composite have declined sharply, and (7) dropout rates are as high as 40 percent in some schools.

Testimony that verifies problems in social areas in high schools includes: (1) higher incidences of vandalism, fighting, and disruptive student behavior, (2) increased school suspensions and expulsions, and (3) reported increases in drug and alcohol use in 
schools by students. Political symptoms of the ills of high schools include: (1) students reporting feelings of powerlessness and alienation, and (2) student involvement in decision-making practices in the schools has declined.

There are public school organizations which have directly addressed the recommendations of educational theorists over the past twenty year period by instituting numerous reform measures in their organizational arrangements, namely alternative schools. A first type of alternative school offers an education for homogenous or target populations of students such as disgruntled and alienated youths, dropouts, the behaviorally disruptive student, and pregnant teenagers. A second type of alternative school funtions with no additional costs to school districts, exists within public school districts, and attracts heterogenous populations. In addition, this second type of alternative school endeavors to institute within their programs educational reform measures advocated by educational theorists and researchers.

Conceptual Framework for the Research

The impact of traditional and alternative secondary public schools and their organizational patterns upon youths is investigated in this study. The threefold purpose of this study is to: (1) collate a large body of the literature on the function, social context and organizational characteristics of conventional and alternative secondary public school organizations, (2) explicate a theoretical framework or interrelated set of propositions of organizational 
principles regarding modern organizations, including secondary schools, and (3) describe and analyze one alternative high school in Colorado. The exploration of the literature and case study will address the following questions:

1) What organizational model do conventional and alternative high schools utilize?

2) What are the organizational elements of conventional and alternative secondary public schools?

3) What types of conventional and alternative secondary schools exist in urban areas?

4) How do conventional and alternative high school organizations measure up to the charges leveled against secondary education in America?

5) What are the organizational characteristics of the alternative school in Colorado?

6) What type of alternative school is Mountain Open High School?

7) How does Mountain Open High School (MOHS) measure up to the charges leveled against American secondary education?

8) How is MOHS similar or dissimilar to public secondary schools reviewed in the literature?

\section{Organization of this Dissertation}

This dissertation consists of four parts. First, Part I presents a general historical trace of the organizational model adapted by schools in the $1880^{\prime} \mathrm{s}$. The methodology utilized to direct this research endeavor is also described in Part I. Second, Part II presents an overview of the state of the art of conventional secondary sducation in America. Summary conclusion statements are provided and the charges leveled against secondary education are addressed by the evidence which evolved from the literature reviewed in this study. 
Third, Part III is similar to Part II but alternative secondary schools in America are the subject of the historical analysis of this section. Finally, Part IV describes and details a case study of one alternative secondary school. The final chapter of Part IV presents responses to the eight general questions which guide this dissertation. Finally, areas for future research are also discussed in the last chapter. 
PART I

MODERN ORGANIZATIONAL THEORY: APPLICATION TO PUBLIC SCHOOL ORGANIZATIONS 
CHAPTER I

MODERN ORGANIZATIONAL STRUCTURES: HISTORICAL EMERGENCE AND THEORETICAL ANALYSIS

Part I begins with a discussion of modern (Post Industrial Revolution) organizational theory applied to public school organizations. Chapter I first examines the historical emergence of modern organizational structures in Western societies. This chapter then comments upon modern organizational theory, including the basic components and elements of organizations, and discusses briefly organizational typologies. The bureaucratic theory outlined by Max Weber (1947) is also presented in this section. Next, human consequences and political concerns posed by large scale modern organizations in a democratic society are discussed. Then, organizational theory is applied to public school organizations, providing the reader with insight into the ways schools are similar to, and divergent from, other organizations. Summary statements concerning organizational theory and the ways schools exist as social institutions are enumerated in the closing section of this chapter. Finally, the research design and methodology for this study are offered in the final section of Part I.

HISTORICAL EMERGENCE OF MODERN ORGANIZATIONAL STRUCTURES

Cities have existed for over 5,000 years, but prior to the eighteenth century, human settlements were often military or religious 
societies in which the chief figures were priests, warriors, and feudal lords. Early advances in agriculture and transportation provided food surplus and raw materials as well as some specialization (Childe, 1977; Sjoberg, 1960). That situation accelerated in the Western world with the Agricultural and Industrial Revolutions in the late 1800 's, involving among other things, the application of scientific methods to the processes of production and distribution. These changes in production led, in turn, to an expanded division of labor and further increases in productivity. The necessity of large numbers of workers living in close proximity to industrial establishments accelerated the country-to-city migration and urban growth which is still in progress today. New developments and technologies in Iong distance transportation and communication systems also were integral elements in supporting the lives and work of large concentrations of people in such enterprises.

The growth of cities was particularly pronounced in the decade between 1880 and 1890, both in Europe and the United States. Martindale (1958:12) has noted how the population of many cities doubled in this decade:

In the $1880^{\prime} \mathrm{s}$, for example, Prussion cities grew up two million; those of France by a million; the cities of England and Wales increased by three quarters of a million and by 1890 London and Paris had more than doubled their populations as of the mid-century while the population of Berlin had increased fourfold. In America the same population lived in towns of four thousand or more inhabitants. Between 1880 and 1890 the number of cities with from 12 to 20 thousand population had increased in number from 45 to 91 ; cities of from 45 to 75 thousand population had increased from 23 to 39 . 
The increase in urban populations was due, in part, to the Industrial Revolution. Changes occurred in the means of production and in forms of human associations. Peasants and workers no longer produced goods within primary group settings, but often left their village communities to live and work in urban areas among secondary associations. Specialized demands, including those for public services, were made by these dense urban concentrations of people. The public services listed by Martindale (1958:13) included: " . . streets, public sewage systems, garbage disposal, police protection, fire protection, playgrounds, civic centers, schools, libraries, transportation systems."

Newly formed factories producing large quantities of goods, as well as organizations performing other types of human services, did in fact arise, patterned after the hierarchical organizational structures similar to the feudal military and religious structures in existence at the onset of the Industrial Revolution.

Henri de Saint-Simon (1760-1825), one of the Fathers of modern sociology, was one of the first theorists to write about modern organizations during the period following the French Revolution. He asserted that the emerging industrial society would be ruled by the engineers and the entrepreneurs of production, not by lords and kings, and administrative authority would be based on expertise and skill in the industrial enterprise; not on coercion, force, or privilege of birth, as in the case of feudal times (Gouldner, 1959). August Comte, a student of Saint-Simon, argued for less formal planning in the 
formation of organizations (Gouldner, 1959). A new order for administering large-scale organizations in industrial times was predicted by both of these theorists.

So much for a brief look at the rise of urbanism and of large scale organizations. Insights into organizations offered by modern social theorists are examined next.

\section{MODERN ORGANIZATIONAL THEORY}

The first order of business in the analysis of organizational theory is to agree upon a definition of organization. Parson's definition is used here: social units with specific goals (Parsons, 1956). Caplow (1964) stated that factories, prisons, hospitals, offices, newspapers, and schools are examples of organizations but races, ethnic groups, and social classes are not organizations because they are not agreed upon goals or demonstration of a network of interaction between members of such aggregates (Caplow, 1964). One particularly prominent organizational phenomenon in the Western world for the past century or so has been the growth of bureaucratic structures. Blau (1961:14) defined bureaucracies as: "The type of organization designed to accomplish large-scale administrative tasks by systematically coordinating the work of many individuals. " Blau (1961:19) enumerated the central characteristics of bureaucracies as ". . specialization, a hierarchy of authority, a system of rules, and impersonality." Factories and governmental agencies became organized around these four stated characteristics so that they would be operated efficiently on a large scale. 
The work of Max Weber, the renowned German sociologist whose writings were translated and published in America in the 1940's, acts even today as a significant departure point for the discussion of bureaucratic theory. Weber (1947) stressed the central function of bureaucracies: the promotion of efficiency and rationality. At least from a formal, technical point of view, bureaucracies are the most efficient and rational way to produce and regulate subunits of goods or people. But, while Saint-Simon viewed modern organizations in general as a positive, liberating force for modern man, Weber warned of the social and political consequences of bureaucracies, a point which will be discussed in a subsequent section of this chapter. Perrow (1970) criticized Weber's bureaucratic theory on the grounds that Weber was describing an ideal type of organization, while Perrow questioned the existence of such an ideal type. Perrow argued that humans do not live totally within the organization where they work and they have social selves. If it were not for Western world values, with their emphasis upon efficiency and being on time, bureaucracies would not exist, so Perrow's debate went. Finally, he maintained that bureaucracies created rules and regulations to control the environmental influences of the social self. For these reasons, Perrow argued that the ideal type of organization described by Weber and not recognizing man's social self, did not exist.

Somewhat differently, Blau (1969:389) stated that organizations needed Western world socialization processes to impart efficiency values: 
In different cultures, different social arrangements will prove most suitable for these purposes. When an authoritarian orientation toward social relationships prevails in the family and in the society generally and when lack of education limits the qualification of subaltern officials, as in Germany at Weber's time, strict hierarchical control may be the most efficient method of bureaucratic operation. However, when equality in social relationships is highly valued and when a much higher level of popular education has been reached, as in the United States today, permitting junior officials considerable discretion in discharging their responsibilities may be a more efficiert system of administration. Similarly, in a culture where people are oriented toward century-old traditions, bureaucratic efficiency probably requires less change in organization than in a young culture where progress is a central value.

Blau indicated that bureaucracies are bound by culture and time. For example, within an American Indian culture, where there was no adherence to a time orientation and craftsmen create artifacts in primary group settings, a bureaucratic model would be ineffective and inapplicable.

Other arguments have been leveled against Weber's bureaucratic theory. Weber supplied a functional analysis of bureaucracy, but according to Blau (1961), the dysfunctions of bureaucracy needed closer scrutiny. He reasoned that Weber's functional explanation meant that a bureaucratic social structure was explained by examining how each of its elements contributed to efficient and rational operations. However, Blau argued that emphasis on efficiency can have negative effects on general operations. For example, the strict exercise of authority by formal administrators or higher-ups in a factory situation may cause workers to conceal defects in operational processes because the latter want to be thought well of by their superiors. Blau also argued that Weber placed too much importance on the formal organization of bureaucracies. He criticized Weber on the 
grounds that it was necessary to study more than the formal elements of an organization. According to Blau (1969), a free exchange of ideas and open communication between the formal and informal structure of a bureaucracy would cause maximum efficiency in operations. Finally, Blau (1969:388) criticized Weber for offering only untested hypotheses for his functional theory of bureaucratic efficiency:

Weber's discussion may be interpreted in one of two ways. Either he defined bureaucracy by specifying formal characteristics and hypothesized its superior operating efficiency; or he intended to define it as any administrative apparatus that maximizes efficiency and advanced hypotheses about organizational attributes that would typically have this effect.

It is not the purpose of this essay to exhaust the literature concerning theories of modern organizations, rather, it is to highlight some of the basic premises of general organizational theory. Stated differently, the discussion here provides a road map for the exploration of organizational theory as it applies to conventional and alternative secondary schools. The components of organizations are presented next.

\section{ORGANIZATIONAL ELEMENTS}

Stanley Udy (1965) has enumerated five basic components or elements of an organization: (1) objectives, (2) administrative system, (3) internal organization, (4) technology, and (5) environment. Objectives or goals are the general statements which give an organization direction, while administrative systems or the formal structure of an organization define the roles of all participants and determine how they relate to one another. The 
internal organization or the informal patterns and norms interact with the formal or administrative structure to determine what really goes on in an organization. The mode of production (i.e., assembly practices, instructional approaches, therapy programs, etc.) employed to reach objectives or goals are the technologies of an organization, while its environment or social setting consists of all the variables and outside organizations that it must confront in order to carry out principle tasks and services.

Particular emphasis has been given in the sociological literature to the various elements or components of organizations, but various theorists have accentuated specific elements of organizations as the important ones: i.e., goal orientation or function (Parsons, 1956; Udy, 1969); formal structures (Etzioni, 1961; Goffman, 1969; Merton, 1969; Meyer and Rowan, 1977); informal structures (Blau, 1961; Selznick, 1969).

Parsons (1956) discussed organizations in relation to goal primacy, maintaining that the value pattern of any social system is the central point of reference for analyzing any social structure. Concerning matters of legitimacy, Parsons (1956:36) argued that the values and goals of the subsystem must be subvalues of the super-organization, or the soclety at large where the sidbsystem exists. This means that the goal of an organization must be a legitimate one and one that is accepted by the larger society. For example, the mining of the radioactive element plutonium is congruent with the values of the society at large as long as there is an interest in the development of atomic energy for defense or energy 
reasons. But if the super-structure of the larger society should rule the development of atomic energy as unlawful or dangerous to human life then the mining of plutonium would be considered an illegitimate organizational goal.

Along this same line, Udy (1969:481) acknowledged that organizations evolve around "empirical objectives" that are culturally universal or legitimate according to the standards of other organizations. While Parsons and Udy emphasize the goal orientations or functions of organizations, both acknowledged the interdependence of organizational elements. In particular, Udy (1969:481) stressed goals and technologies in his definition of a formal organization:

One may define a formal organization as any social group engaged in pursuing explicit announced empirical objectives through manifestly coordinated effort and, at the same time, describe an entity that appears to be culturally universal.

For various reasons, Etzioni (1961), Goffman (1969), Merton (1969), and Meyer and Rowan (1977) stressed the formal structures of organizations. Etzioni classified organizations according to the forms of compliance the formal structure of each organization commanded from its participants or workers. Merton (1969) noted that formal structures existed in a different capacity than described by Etzioni but acted to resist internal friction inside organizations. According to Merton, the hierarchical ordering of offices and the establishment of rules and regulations were instituted by organizations in an attempt to define patterns of activity. Such formality in an organization was rationalized by Merton (1969:47) to be "functionally related to the purposes of that organization." 
Goffman also stressed the role of the formal structure particularly speaking of total institutions. Total institutions, such as prisons and mental hospitals, have the responsibilities of complete surveillance and service of their wards' needs. According to Goffman (1969:314) these duties of the formal structure mean that:

- all phases of the day's activities are tightly scheduled, with one activity leading to a prearranged time into the next, the whole circle of activities being imposed from above through a system of explicit formal rulings and a body of officials. (Goffman, 1969:314)

Meyer and Rowan (1977) differed from Goffman regarding their explanation of the importance of formal structures witrin organizations. According to them, the rules, positions, and regulations of the formal structure have little impact on the daily routine within an organization. Formal structures exist for purposes of ritual: i.e., they identify relational networks with other organizations and they rationalize means of production to other organizations. In other words, within an organization, formal structures serve to define the goals and purposes of the particular organizational structure and provide legitimacy with other organizations. Meyer and Rowan deemphasized the importance of formal structures and the formal rules and regulations within organizations, but stressed the role of these formal aspects for matters of legitimacy and survival with other organizations and external influences. For example, they noted that in mental hospitals the administrators endeavor to protect the reputation of the organization from external or outside influences but do not markedly regulate the hospital employees. Thus, formal structures have been described as 
maintaining an institutional myth or ritual (Meyer and Rowan, 1977) and as monitoring internal conformity (Etzioni, 1961; Merton, 1969).

Blau (1961) and Selznick (1969) accentuated the informal

structure of organizations. Blau argued that open communication and a continual exchange of ideas must flow between the formal and informal structures of an organization for maximum efficiency of goods production. Blau (1961:59) asserted: "Unless the members of the organizations have the freedom and initiative to deal with operating problems as they come up, efficiency will suffer." Selznick (1969) presented an argument similar to Blau's when he recommended a cooperative flow of ideas between the formal and informal structures within an organization. Selznick (1969:23) described what informal coalitions within an organization could accomplish:

The deviations tend to force a shift away from the purely formal system as the effective determinant of behavior to (1) a condition in which informal patterns buttress the formal, as through the manipulation of sentiment within the organization in favor of established authority; or (2) a condition wherein the informal controls effect a consistent modification of formal goals, as in the case of some bureaucratic patterns. (Selznick, 1969:23)

He stressed the importance of informal coalitions within an organization and emphasized the importance of studying such groups to understand how they function. For example, youth groups and subcultures have been studied in depth as informal structures that possibly subvert the goals of the informal structure or administration in a school setting.

It should be apparent from the preceding discussion that organizations are complex and that their components are interdependent 
elements within the whole organizational structure. A discussion is now ensued of organizational typologies, that is, the way organizations are defined according to the emphasized elements.

ORGANIZATIONAL TYPOLOGTES

This discussion would not be complete without some mention of typologies of modern organizations. Typologies have been based upon various elements of organizational structures. For example, the degree of formal authority exerted by the formal administrative structures was stressed in the classification schemes of Gouldner (1959), Drabek (1974), and Etzioni (1961), while goals and functions of organizations were the focus of Parson's (1956) classification scheme.

Etzioni (1961) classified organizations according to the amount of compliance the formal structure of each organization commanded, with three patterns of compliance being identified: coercive, utilitarian, and normative. Examples of coercive organizations included prisons, concentration camps, and mental hospitals. Offices, mines, and factories are examples of utilitarian organizations. Hospitals, churches, and schools are examples of normative organizations. Similarly, Gouldner (1959:403) identified two models of bureaucracies based on voluntary versus forced or punishment-centered authority:

The representative bureaucracy is, in part, characterized by authority based upon knowledge and expertise. It also entails collaborative rules by the parties involved; the rules are justified by the participants on the grounds they they are means to desired ends, and persuasion and education are used 
to obtain compliance with them. The punishment-centered bureaucracy is characterized by authority based on incumbency in office, and by the unilateral initiation of organizational rules which are enforced through punishments.

Drabek (1974:55) identified four types of organizations: ". authoritarian, democratic, total, and voluntary." The authoritarian organization he described was focused highly on formal rules, with precision in technology with little stimulation of creativity. High member influence and less rigid rules were specified as central characteristics of democratic organizations. Drabek listed around the clock surveillance, standardized scheduling of activities, and confiscation of personal property as characteristics of total organizations. Drabek (1974:61) explained that voluntary organizations are unlike other organizations, for they have "segmental participation" and are monopolies because there is no competition from external environments. Examples of voluntary organizations include public school systems and fire departments.

Parsons (1956) on the other hand, stressed goals and functions rather than formal structures in his classification scheme of organizational types. He identified organizations oriented to economic production, organizations arranged for political goals, integrative organizations which contribute to efficiency and the adjustment of conflicts, and finally, pattern maintenance organizations with cultural, educational, and expressive functions. However, Perrow (1970:36) pointed out that the goals stressed in various types of organizations are a matter of degree or emphasis: - - within the same "type" or organization--in this case a
"people changing institution" a wide variety of techniques, 
structures, and goals can be used. In order to understand these differences it is important to find out how an organization conceives its task and its raw material, how interdependent is its system, how closely controlled it must be.

In summary, this review has demonstrated that service organizations arose when large concentrations of people settled in urban areas. In particular, bureaucratic structures were devised as the most efficient and rational way to serve large numbers of people. There are bureaucratic classification schemes which stress various organizational elements. There are human consequences as a result of bureaucratic organizations and this issue is discussed next.

THE HUMAN SIZE SIDE OF ORGANIZATION

Some mention of the human concerns of large scale organizations should be made in a historical analysis of modern organizations. First, it should be noted that Weber (1947) was sensitive to the social and politial aspects of bureaucratic structures, for he was concerned about the depersonalization of individuals and the misuse of authority by management figures in the hierarchical or bureaucratic administrative structure. One social consequence Weber (1947:340) predicted was formalistic impersonality:

- . the dominance of a spirit of formalistic, "Sine ira et studio," without hatred or passion, and hence without affection or enthusiasm. The dominant norms are concepts of straightforward duty without regard to personal considerations. Everyone is subject to formal equality of treatment; that is, everyone in the same empirical situation. This is the spirit in which the ideal official conducts his office.

Within a bureaucracy, Weber voiced concern for the possible deterioration of an individual's personality through dehumanizing 
regimentation. Also, explaining that the bureaucratic organizational structure would be based on knowledge and expertise, rather than birth privilege or heritage, Weber feared that nonrational elements could influence the exercise of authority. For example, authority figures might misuse obedience for the sake of the position they held and for ego gratifying reasons, and not for the expertise the office was intended to represent. Merton (1969), too, was troubled about the nature of individual work and the depersonalization process in a bureaucracy. Because of the emphasis on efficiency, the bureaucratic structure threatened to eliminate personal relationships at the work place. Bureaucracies were viewed by Merton as secondary and impersonal groups where man was controlled by the means of production. Merton (1969:49) stated: "With increasing bureaucratization, it becomes plain to all who would see that man is to a very important degree controlled by his social relations to the instruments of production." He recommended that in-depth research be initiated to study personality formation in social organizations like bureaucracies.

On a more positive note, Selznick (1969) and Blau (1961) advocated a cooperative organizational system where the informal system acted to reinforce the goals and values of the formal structure through an open exchange of ideas. Selznick discussed the importance of the formal structure of a bureaucracy working in cooperation with the informal structure for the development of the whole person in a formal 
organization. A recognition of the influence and impact of the informal system was acknowledged by Selznick (1969:23) in the following statement:

The deviations tend to force a shift away from the purely formal systems as the effective determinant of behavior to (1) a condition in which informal patterns buttress the formal, as through the manipulation of sentiment within the organization in favor of established authority; or (2) a condition wherein the informal controls effect a consistent modification of formal goals, as in the case of some bureaucratic patterns.

Similarly, Blau (1969) stressed the importance of including the worker in the change process in which bureacracies should be involved. Blau (1969:391) maintained the need for communication, flexibility, and change in a bureaucracy:

Maximum rationality in the organization, therefore, depends on the ability of operating officials to assume the initiative in establishing operational difficulties as they occur. This ability, in turn, presupposes the absence of acute feelings of inequality among the members of the bureaucracy.

Blau argued that in order to enhance administrative efficiency, the formal structure of a bureaucracy must take into account the importance of social relations within the organization. He reasoned that it was more efficient to link the abilities and motivations of workers to the goals of the organization than to control them with detailed rules and job descriptions.

On a less critical note, Blau (1969) commented on some of the social, economic, and political gains that the bureaucratic structure had contributed to society including: (1) a higher standard of living, (2) the social justice movement of the previous two decades had made headway, 1.e., standardized hiring practices initiated by bureaucracies had assured minorities a more equal chance of obtaining 
employment, and (3) the efficiency of bureaucracies had allowed employees more leisure time and also more opportunities to involve themselves in the political activities of their government. However, he addressed the political contradictions of bureaucracies in a democratic society. He maintained that efficiency and conformity is stressed by bureaucracies, while participation in a democratic system requires free expression of opinion. Blau (1969:107) strongly stated this point:

Bureaucratic and democratic structures can be distinguished, then, on the basis of the dominant organizing principles: efficiency or freedom of dissent. Each of these principles is suited for one purpose and not for another.

Moreover, decision policies which affect many individuals were in the hands of a few, usually unelected officials. While Blau noted many criticisms concerning the policies of regulation and coordination in a bureaucracy, the social inequalities inherent in the hierarchical structure of organizations were his greatest concern. Blau argued for (1969:80) cooperation and communication between all organizational members:

\footnotetext{
- . the lower echelons of a bureaucracy have several effects that are detrimental for operations. They inhibit identification with the organization and its objectives, lessen interest in performing tasks to the best of one's abilities, kill initiative and reduce the chances that emergent operating problems will be readily met. Unless employees consider themselves partners in a common enterprise rather than tools in the hands of manangement, they are not prone willingly to assume responsibilities of their own.
}

Although there existed social concerns for bureaucratic organizations, public schools adopted the bureaucratic model. The bureaucratization of secondary public schools is now traced. 
SECONDARY PUBLIC SCHOOLS AS MODERN SOCIAL ORGANIZATIONS

Until the $1890^{\prime} \mathrm{s}$, American schools were most often of the one-room variety and under lay influence. The bureaucratization of school organizations followed the urbanization of the cities in the 1890's (Tyack, 1974). Schools were one of the public services that were needed for the great concentrations of populations of people in the cities that developed during this period. Martindale (1958:13) commented on the public services that were in demand:

The crowding of people into small space bears with it a tremendous increase in specialized demands. People need streets, public water supplies, public sewage systems, garbage disposal, police protection, fire protection, playgrounds, civic centers, schools, libraries, transportation systems.

In an effort to meet these needs, schools were developed with the corporate model of bureaucracy serving as the organizational pattern (Corwin and Edelfelt, 1977; Tyack, 1974). The business corporation model was used to structure large urban school districts. Tyack claimed that the efforts of the educational reformers of the early 1900's replaced community and lay persons with professional bureaucrats. Tyack (1974:42) explained that the philosophical ideals of educational professionals resulted in the centralization of the city-wide districts in the early 1900 's and liberal principles were based on the provision of equal opportunity for all students:

To those who feared the whims of a decentralized politics of education such a meritocracy has a strong appeal. While it is possible to see in retrospect that school bureaucracy reinforced racial, religious, and class privilege in many cases, its liberal advocates believed that a strong and rational system 
of education could eliminate corporal punishment, offer new opportunities for women, equalize educational expenditures between rich and poor sections of a city, and provide a system of instruction which was impartially efficient for all classes of the population.

In fact, Tyack (1974:29) argued that the bureaucratization of city school systems was a necessary precursor for the industrialization of modern society:

Schooling was essential because it adapted people to the new discipline and incentives of the urban-industrial order and supplied the "directive intelligence" and specialists required in a complex society. In effect, some saw the school as a critical means of transforming the pre-industrial culture-values and attitudes, work habits, time orientation, even recreations-of citizens in a modernizing society.

Schools are complex organizations. They share the elements of bureaucratic organizations: goals, technologies, formal structures, informal structures, and environments. They are complex because they are interdependent and interrelated with other organizations. Lortie (1977:22) listed some of the other organizations that effect schools:

Schools and school system fit into an individual network of educational activities in local, state, and federal governments, institutions, accreditation groups, the court system, taxpayers associations, international unions, and chambers of commerce, to list only some.

To expand upon this point, it can be noted that federal and local political moods affect the schools in issues such as control and funding. For example, feelings of political powerlessness during the 1960's prompted local citizen advocacy groups, especially in inner city areas, to move toward decentralized school districts and to push for local community control of neighborhood schools. Currently, conservative federal spending in social programs under the Reagan administration has threatened cut-backs or the elimination 
of compensatory educational programs such as Title I and Headstart. Schools are influenced by political moods and other organizations. Because they were usually a collection of individual classrooms, schools are also simple organizations. They are also complex, interdependent, and interrelated organizations. Teaching occurs in cellular, single classroom units and is labor-intensive (Lortie, 1977). Elementary students are frequently taught by individual teachers in self-contained classrooms. Schools have been influenced by the computer but they have replaced classroom teachers and Gross (1959) insisted that the student-teacher relationship is the most important social dimension of the schools.

Educational theorists have argued that public schools can be defined as social organizations because: (1) their participants are interdependent, (2) the roles of individuals within the system are promulgated and enforced, and (3) schools exist with a service function (Bany and Johnson, 1975; Bidwell, 1965; Brookover and Erickson, 1969; Katz, 1964; Sieber and Wilder, 1973; Wallar, 1932). Within schooling systems, students are dependent on teachers, teachers are subordinate to build-ing administrators, building administrators as well as grade level and subject area superintendents are subject to district-wide assistant superintendents, district-wide superintendents are accountable to local school boards, and district-wide superintendents are responsible to local taxpayers and voters. Thus, while members of school organizations experience varying degrees of autonomy in decision making, all participants are accountable and interdependent with other participants and community members outside of the school system. 
Schools are social organizations and their formal structure defines roles for all members of this hierarchically structured organization. Students, teachers, administrators, and all school personnel have clearly defined roles within the school structure and are managed by rules and regulations. On this point, Bidwell (1965) has expounded upon the dichotomy between student and staff roles, explaining that students are mandated to participate in the schooling enterprise while teachers and staff members enter such a system voluntarily.

Schools are client-serving social organizations with a service function. Bidwell (1965:973) observed: "First, it is assumed that school systems are client-serving organizations, that is, that they are social units specifically vested with a service function, in this case the moral and technical socialization of the young." The degree to which schools socialize students for particular values is open to debate but the fact that schools exist as social units with a service function is incontrovertible. The various goals that secondary schools hold for students will be enumerated in Parts II and III of this study.

Schools resemble other organizations in terms of the five elements or components discussed in this chapter (Gross, 1968; Udy, 1965; Weber, 1947). Their goals are general statements of purpose which give them direction while technologies are instructional practices, approaches, and programs that are employed to reach these goals. The formal structure of the school defines the roles of students, administrators, teachers, and parents, and stipulates how 
participants are to relate to one another. The informal patterns and norms of a school inieract with the formal structure to determine how the school actually functions. The ecological influences consist of everything external to a school: parent, community, and other organizations that a school interacts with in order to carry on its principle tasks or services.

Schools share many of the same elements and characteristics of other bureaucratic organizations such as factories, military units, mental hospitals, and prisons, although the degree that certain elements are emphasized and controlled varies. For example, schools allow individual teachers more autonomy when making decisions for individual students than that enjoyed by corrections officers in dealing with individual offenders in prisons (Corwin and Edelfelt, 1977; Katz, 1964). Lortie (1977:26-27) listed the similarities of schools with other organizations: (1) they are public institutions, (2) they are involved in people work, (3) they consist of large numbers of people, (4) the clients of school organizations are students and parents, and (5) school organizations have compulsory and mandatory attendance rules for their clients.

Schools resemble other organizations, but they are somewhat unique because they have high public visibility and vague criteria to evaluate their efficacy or end product (Tumin, 1977; Wallar, 1932). For example, many school studies have utilized quantitative measures such as students' grade point averages, attendance and truancy rates, amount of school vandalism, number of expulsions and suspensions, student-teacher ratios or library books per child to indicate the 
atmosphere or climate of the school and make assessments between schools concerning their end products. Other studies have initiated in-depth case analysis or qualitative research methodologies to examine outcome variables, all of which suggests that schools have vague criteria to measure the success of their organizational patterns on students' development.

\section{SUMMARY}

This chapter has indicated that modern organizational structures date back to the early eighteenth century, or to the emergence of the Industrial Revolution in Western civilization. Bureaucracies, a type of organizational structure, were a consequence of the new type of organization deemed to be the most rational and efficient for the larger numbers of people in urban areas. Five basic elements or components of bureaucratic structures were discussed, and typologies of organizations were found to be based on a particular emphasis of singular elements. The social and political consequences affecting individuals in modern organizational structures were also noted. Organizational theory has been applied to school structures, with schools being viewed as complex, yet simple social institutions. School professionals adapted the corporate bureaucratic model. The five elements or components of a bureaucratic organization can be applied to school organizations, but they also have their own unique characteristics. The preceding discussion was designed to reveal to the reader the organizational model that centralized schools adopted and the ways that schools were structured according to modern 
organizational theory. The remaining section of this chapter reviews the particular research design and methodology employed for this study.

METHODOLOGY

This study involves a historical analysis or theoretical exploration of conventional and alternative secondary school organizations. Historical research is supported by various theorists (Drake, 1973; Kerlinger, 1973). A weakness of historical research is that the facts of the past are interpreted by the researcher which leaves room for personal bias and the possibility of omission of evidence pertinent to the analysis of events (McCoy, 1974). Nevertheless, historical research is the most appropriate methodology to address the questions posed by this investigation. Primary and secondary data sources of past events in the evolution of secondary public school organizations are analyzed. The theoretical framework produced by this historical research reveals the issues and relationships between variables relevant to the way secondary schools are organized.

After establishing an historical perspective of secondary public school organizational patterns, a case study of one alternative high school is described utilizing the theoretical framework generated by the historical analysis.

A naturalistic case study is the methodology selected for the description of the alternative high school. Because school organizations, especially alternative school organizations vary considerably in characteristics such as student body population, curricula, 
governance system, size, funding and sponsorship, and advisory systems, the naturalistic methodology was employed to discover and then verify the organizational characteristics of MOHS (Guba, 1978; Rist, 1978). This method was selected so that the observed school could be studied in its natural setting. A strength of naturalistic research, claimed by its supporters, is its holistic or heuristic qualities (Guba, 1978; Stake, 1978; Webb et al., 1966). The researcher discovers the phenomenon under study, free of preconceptions or hypotheses, and gathers data from the participants' or actors' point of view. Mixed research triangulation is employed in the case study. Triangulation allows the cross-checking of one group of datum against various other sources (Guba, 1978). Guba (1978), Douglas (1976), and Webb et al. (1966) support a multi-method approach to cross check data. The case study of MOHS was obtained through various techniques-direct observation, interviewing, questionnaires, and historical and document analysis. Before reaching conclusions about findings, this researcher looked for common relationships and themes reported through a combination of sources.

In addition to utilizing mixed strategies to describe the organizational characteristics of the alternative school, the charges and propositions that emerged from the empirical findings of the major reviewed studies will serve as a theoretical basis against which to analyze the case study of the open high school. 
OPERATIONAL DEFINITIONS

Specific terms used throughout this study are defined as follows:

(1) Exploratory. Historical research is utilized to uncover theory concerning the organizational characteristic of public secondary schools.

(2) Structural. The elements of a bureaucracy (goals, technologies, formal structure, informal structure, and ecological influences) will be the theoretical framework which guides this investigation.

(3) Functional. The educational purpose of a schooling institution is its function.

(4) American. Schools within the 50 states of the United States of America are included in this examination of secondary public schools.

(5) Urban. Schools in the central city and surrounding areas of a city are included in this study.

(6) Public. This term refers to free tax-supported schools controlled by local and state governmental authority.

(7) Traditional. Schools with norms and beliefs which have remained stable and unchanged over time are traditional. Traditional and conventional are terms which are used in a synonymous way in this dissertation.

(8) Alternative. This term refers to schools which offer choice and organizational features which are arranged differently from traditional schools.

(9) Secondary. This term refers to grades 9 through 12, or grades 10 through 12 .

\section{LIMITATIONS OF THIS STUDY}

There are two limitations to this study. First, ecological influences are assumed to be significant external forces and influences which affect school organizations. A complete and in-depth 
investigation of this organizational characteristic would warrant another major study and will only be mentioned in this dissertation. Second, because of the major change in the evolution of the student subculture in and out of school, the discussion of the informal structure in this study primarily focuses on students. The role of parents and teachers is discussed in a more general sense than the youth subculture which is detailed in depth.

DATA SOURCES

As already indicated, a major portion of this study centered around the systematic analysis of the organization and functioning of secondary schools in American society. The data consists of primary and secondary sources including: review of the literature, and historical and document analysis. The major studies of conventional and alternative public secondary schools that have been conducted primarily over the past ten-year period will be examined. The case study includes the following primary and secondary data sources: (1) newspaper accounts of MOHS betwen 1975-1981; (b) the Self Study Report prepared by the MOHS staff for the North Central Accreditation Association, March, 1980; (c) Pilot Study Audit Reports prepared by the MOHS school district for the three years 1975-1978; and (d) taped interviews with the principal and other staff persons concerning the history of MOHS.

Additionally, field observation notes of MOHS have been gathered by this researcher who spent September of 1980 discovering the 
organizational elements of MOHS, a preliminary step in naturalistic studies recommended by Lofland (1976) and Sackett (1978). In addition, three weeks were spent from February 28, 1981 to March 20, 1981 traveling to Baja in Mexico on an extended school trip documenting the characteristics and stages of group development as experienced by an MOHS group of 16 persons. Daily observation notes were recorded. Interviews and field observation notes also provided descriptive material for this case study.

In-depth interviews with students were conducted between September, 1980 and June, 1981. Thirteen student volunteers were questioned regarding their opinions of various MOHS characteristics. An interview guide was used for all interviews (see Appendix A). Interviews were taped and notes were taken during each interview. At the conclusion of each interview, a brief summary was recorded. Information from one interview was utilized to verify or obtain opinions from subsequent interviewees. Student volunteer interviewees were sought during a September, 1980 all-school Governance Meeting. The first 13 student volunteers who came forward were accepted as interviewees: 8 males and 5 females. The group contained six tenth graders, three eleventh graders and four twelfth graders. Each volunteer was interviewed on 7 topics, with interview times varying from 15 minutes to 2 hours. All student interviewees were guaranteed confidentiality. For this reason the names of student volunteers are not indicated in this study.

The Director of the Research and Evaluation Department of the Jefferson County School District and the Mountain Area Superintendent 
were also interviewed concerning their knowledge and opinion of the school. These interviews provided background information of the time period 1975-1981. This study primarily focused on the sixth year of MOHS, 1980-1981.

CONTRIBUTIONS

First, in the area of theory development in education, this study provides an in-depth examination, analysis, and summary of numerous studies concerning the social context, function, and organizational characteristics of public traditional and alternative secondary schools. This study provides a theoretical framework from which traditional and alternative schools and other youth organizations can analyze their programs so they can incorporate effective organizational arrangements in order to positively effect youths.

Second, concerning issue resolution in education, this study demonstrates how alternative structural arrangements are patterned differently to meet the needs of alienated and academically stifled students who are not adequately served by conventional high schools or the "one best system" (Katz, 1968; Tyack, 1974). The review of alternative schools provides demonstrated ways that reform measures in education can be implemented in schools organizational structures to effect academic and affective gains on the part of students. Some of the myths about alternative schools are also dispelled by this study. This study contributes to the field of Urban Studies as it provides an in-depth examination of one urban youth social 
institution, namely secondary public schools. This study provides the social scientist, others in the youth business, and the public a theoretical framework which could be utilized to assess the organizational structures of other urban youth social institutions. Such an effort could allow social workers, youth counselors, and other concerned professionals preliminary steps for examining their organizational characteristics to discover more effective arrangements to positively impact youths in the city. 
PART II

CONVENTIONAL PUBLIC SECONDARY SCHOOLS:

THE STATE OF THE ART 
CHAPTER II

THE COMPREHENSIVE HIGH SCHOOL: AN OVERVIEW

This chapter discusses the American comprehensive high school and describes the historical context of its emergence on the American educational scene. Furthermore, high schools are classified by their functions and socio-geographical characteristics. Finally, the major criticisms that have been leveled against the comprehensive high school are examined. That commentary is now undertaken.

HISTORICAL EMERGENCE OF THE COMPREHENSIVE HIGH SCHOOL

Following World War I, there was widespread debate concerning whether American secondary schools should be patterned after the dual system in Europe which provided separate schooling for the elite and working classes. At that time, schooling for the elite was highly academic, with college preparation as the main emphasis. On the other hand, the working class school concentrated on vocational training for immediate employment following high schnol graduation.

The proposal for the institution of a dual educational system in America was met with opposition. Around World War I, as early as 1915, John Dewey spoke out against the adaption of the dual system (Tanner, 1979). His criticisms centered on the following argument: students would be segregated according to social class and educational 
opportunities would be influenced by social class distinctions. For example, only those students from elite families would be presented an academic or liberal arts education.

Many years after Dewey argued against the dual system, James Conant, a professor of chemistry who was commissioned by the Carnegie Corporation of New York, wrote in 1959 in favor of institutionalizing a comprehensive high school system. Considering Dewey's objections against the dual system's premises of segregation and inequality of opportunity, Conant's proposal reflected an awareness of the weaknesses of the dual system. His proposal was based on the following six principles. First, because a general education could be offered all students in one facility, Conant (1959:17) supported comprehensive high schools over a dual system of academic and vocational specialized schools:

To repeat, the three main objectives of a comprehensive high school are: first, to provide a general education for all the future citizens; second, to provide good elective programs for those who wish to use their acquired skills immediately upon graduation; third, to provide satisfactory programs for those whose vocations will depend on subsequent education in a college or university.

The social integration and equal educational opportunities provided students in the comprehensive high school were additional benefits promised by Conant's plan (Passow, 1977). Conant's 1959 work was spurred by the Space race and the fear that Russia would outdistance America in science and technology. In effect, Americans supported Conant's comprehensive high school model because of the intensive curricula offered, a third aspect of his proposal. Many 
agreed that the comprehensive high school would adequately prepare

students for the technological race (Conant, 1967).

The fourth and fifth aspects of Conant's proposal maintained

that consolidation for financial efficiency and larger student body

size were specific strategies comprehensive high schools should employ

(Conant, 1967). He insisted that, if possible, schools should enroll

at least 750 students since larger student bodies would not only allow

social integration situations but would also provide schools with

greater budgetary support.

Social and political ideals based on democratic principles of equality were the sixth item of Conant's plan. In the foreword of The American High School Today authored by Conant in 1959, John Gardner, the president of the Carnegie Corporation of New York, echoed the emphasis on comprehensive high schools and commented on the democratic and general education for all that high schools were called upon to discharge in a single building:

The comprehensive high school is a peculiarly American phenomenon. It is called comprehensive because it offers, under one administration and under one roof (or series of roofs), secondary education for almost all the high school age children of one town or neighborhood. It is responsible for educating the boy who will be an atomic scientist and the girl who will marry at eighteen; the prospective captain of a ship and the future captain of industry. It is responsible, in sum, for providing good and appropriate education, both academic and vocational, for all young people within a democratic environment which the American people believe serves the princples they cherish. (p. 3)

Conant's ideas for comprehensive high schools did not go unchallenged. For example, Barker and Gump's Big Schools, Small Schools: High School Size and Student Behavior (1964) focused on the 
effects of school size upon the social behavior and experiences of the individual student and groups of students. Data were collected on 52 high schools, ranging in size from 18 to 2,287 students. A number of behavioral domains were studied: educational behavior areas, athletic games and contests, and extracurricular settings (Barker and Gump, 1964:54). The study discovered that student participation in extracurricular activities was 3 to 20 times greater in high schools with enrollments between 61 and 150 students than in larger schools (Barker and Gump, 1964:196). Overall, students in the smaller schools were engaged in twice as many extracurricular activities as students in the larger ones. The results of the Barker and Gump (1964:62) study implied that there were different ways of life in the two types of schools:

To an outside observer, a school with many students is impressive: its imposing physical dimensions, its seemingly endless halls and numberless rooms, its hundreds of microscopes, its vast auditorium and great audiences, its sweeping tides of students, all carry the message of power, movement, vitality, purpose, achievement, certainty. In contrast, a small school with its commonplace building, its few microscopes, its dual-purpose gym-auditorium half-filled with students who assemble and depart, not in tides but in a tangle of separate channels, is not impressive. The members of the field-work team never ceased to marvel that the directly experienced differences between large and small schools were, in these respects, so compelling, like the differences between a towering mountain and an ordinary hill, between a mightly river and a meandering brook.

Finally, the study found that there were social gains for students in small schools. Barker and Gump (1964:202) concluded: "A school should be small enough that students are not redundant." Ultimately, Conant's ideas took hold in America, thus over the past 20 years, comprehensive high schools have been the prominent 
organizational pattern for 15,407 surveyed high schools (Abramowitz et al., 1978). Although comprehensive high schools are intended to provide socially integrated education, equality of opportunity, a basic education, and an understanding of democratic principles, three major studies of the past decade reported that they have alienated some high school youth and are in need of change. The studies include: (1) Youth: Transition to Adulthood (1974) by the President's Science Advisory Committee (James Coleman, Chairman), (2) The Education of Adolescents (1973) by the National Panel on High Schools and Adolescent Education (John Henry Martin, Chairman), and (3) The Reform of Secondary Education (1974) by the National Commission on the Reform of Secondary Education, Charles F. Kettering Foundation (B. Frank Brown, Chairman). What were the recomended areas for reform? The three studies advocated: (1) dispersing youth into the world of work for earlier quality experiences, (2) employing individualized learning programs and flexible schedules to develop and respond to individual student's talents and needs, (3) restructuring larger schools into smaller schools or units which incorporate alternative programs, (4) modernizing and updating traditional curricula with a career, aesthetic, media, and global education, and (5) effecting changes in governance systems so that students can be more active in the decision making processes and policy development for their schools. These suggested reforms in secondary comprehensive schools will be discussed in detail in later sections of this dissertation. 
To this point, we have examined how the comprehensive high school was instituted as the prominent organizational theme in secondary schools. A discussion of the types or categories of high schools that are found in cities begins next.

\section{A FUNCTIONAL TYPOLOGY OF SECONDARY SCHOOLS}

Although the comprehensive model has been the predominant form of secondary school organization, variations of that pattern do exist. Following themes of Conant (1959) and Havighurst (1966), secondary schools can be classified according to their educational purpose or function (see Figure 1). What are the types of secondary schools? Conant and Havighurst described the comprehensive high school and the specialized high school, Type 1 and Type 2 respectively (see Figure 1).

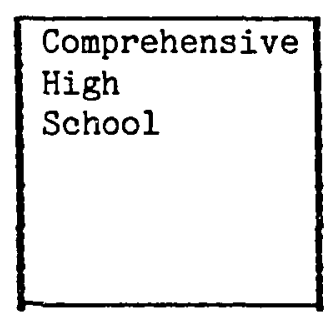

Type 1

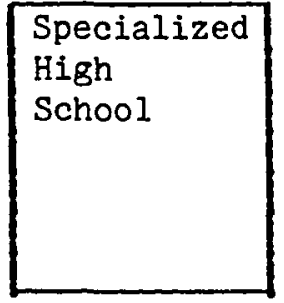

Type 2

\begin{tabular}{l} 
Comprehensive \\
High \\
School \\
\hline School- \\
Within-a- \\
School
\end{tabular}

Type 3

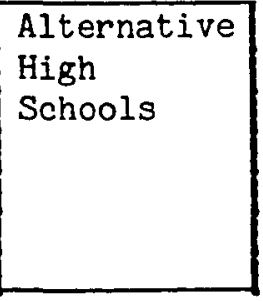

Type 4

Figure 1. An example of the functional types of secondary schools.

However, the educational literature also revealed comprehensive high schools with schools-within-a-school and alternative schools, thus Type 3 and Type 4 should also be acknowledged (Education By Choice, 1975; Nelsen, 1975; Parker, 1971; St. Germain, Carten, and Meland, 1974; Sulack, 1975; Trent, 1981; Tyack, 1974). 
What are the differences between the four types of school organizations? Let us begin that examination. As we saw earlier, Conant explicated the ingredients of comprehensive high schools, which have been the predominant kind in America. The comprehensive high school with a school-within-a-school is a related type. Schools-within-a-school are alternative programs with goals, technologies, and curricula that differ from traditional programs, often serving disaffected students with low academic achievement, poor attendance records, behavioral and attitudinal difficulties, and discipline problems. School-within-a-school (SWS) programs are housed often in the larger high school building or located in a wing of the comprehensive high school facility (St. Germain, Carten, and Meland, 1975; Nelsen, 1975; Trent, 1981).

The goals set for SWS programs vary from those of the traditional high school. For example, Nelsen noted affected goals, such as changing students' attitudes toward school, were central to the SWS program at Madison High School in Portland, Oregon. Likewise, Trent (1981:27) described the affective domains of concern for the Andrew Jackson Academy SWS program in Queens, New York:

The Academy is trying to offer a small but realistic solution to some of Jackson's problems. It can be called an alternative form of education because it offers a program that is uniquely different from the program of the high school. The flexible scheduling, variety of courses, close studentteacher relations, recognition of different student personalities and learning styles, as well as flexible teaching methods, mark the Academy as a program that is beneficial and rewarding to students who would otherwise find school a disappointing and discouraging experience. 
SWS program technologies are different from traditional ones. That is, individualized self-paced learning, contracting, flexible scheduling, pass/fail grading systems, as well as activity-centered and project-oriented learning are technologies of SWS programs.

Some students volunteer for participation in SWS programs (Education By Choice, 1975; Sulack, 1975; Trent, 1981), and others are referred or ordered to SWS programs by the courts (St. Germain et al., 1975). However, not all SWS programs focus on disaffected students. In 1974 in Quincy, Illinois there were seven SWS programs offered for 1,500 eleventh and twelfth graders at one school, Quincy Senior High II (Education By Choice, 1975). With parental consent, students chose the educational environment best suited to their educational needs and individual talents. The options included: (1) The Traditional School, (2) The Flexible School, (3) Project to Individualize Education School, (4) The Fine Arts School, (5) Career School, (6) Work Study School, and (7) Special Education School (Education By Choice, 1975:630). Seckington (1973) has described yet another variation of the SWS program in the British educational system. Under the house system, large comprehensive high schools are organized into smaller house units of 120 to 200 pupils. The house system was established to serve social rather than academic goals. Its objective is to allow students the opportunity to develop close interpersonal relations with teachers and other students in their house. Students return to the main student body for classes and the high school offers a traditional curriculum, despite the house emphasis on social relations and deemphasis of large student body size. 
Another example of an SWS program that does not serve troubled students is located in the Denver, Colorado metropolitan area in the Jefferson County Public School District. It offers an interdisciplinary program, ALTEX, in several of the senior high schools for seniors who have completed their required course work for graduation. Students develop and initiate projects in community service, personal growth, social issues, and creativity areas. They also engage in a wide variety of urban, rural, and wilderness experiences. For instance, they have been involved in river rafting excursions, trips to Mexico, and participation in the World Conference for Peace in Boulder, Colorado.

The specialized high school is a third type of secondary school (see Figure 1). Many existed before the consolidation of secondary schools into the comprehensive high school. Prior to consolidation, specialized schools varied according to the academic or vocational curricula they emphasized. Like those of the past, existing high schools offer curricula with intensive courses of study in specialized areas including traditional academic subjects, such as the arts and humanities and the natural and physical sciences, as well as various vocational and skilled trade areas.

The Seattle Public Schools provided examples of specialized high schools. During the 1981-1982 school year, they presented the following Senior High Options: (1) Advanced Placement Option for academically-accelerated students, (2) Humanities Option, (3) Marine, Enviornmental and Health Science Option, (4) Mass Media Communications Option, (5) Multi-Arts Option, (6) Business Administration Option, and 
(7) Horizon Option for gifted and talented students (Seattle Public Schools Booklet, Administrative and Service Center, 1980-1981). Similar to the Seattle School District, the Philadelphia Public Schools in its magnet plan entitled "Acres of Diamonds," offers numerous specialized programs for senior high students in 14 areas: (1) Business: Bartram High-Commercial Magnet Program, (2) Vocational: Bak Area Vocational Technical School, (3) Academic Prep: Central High School (all male), Philadelphia High School for Girls, (4) Humanities and Arts: Creative and Performing Arts High School, Overbrook High-Scholars, Fine Arts, Music Magnet Programs, (5) Basic Skills: Filter Academic Plus, (6) Competency Based Mode: Franklin Learning Center, (7) Social Science: Germantown High Social Studies Magnet Program, School for Human Services, School for all Ages, (8) Engineering and Medical Sciences: Northeast High Aerospace Magnet Program, (9) Career Development: Alney High Career Academy, Randolph Skills Center, Swenson Skills Center, (10) Communications: William Penn High Communications Magnet Program, (1i) Agriculture: Saul School of Agricultural Sciences, (12) Foreign Languages: South Philadelphia High Foreign Language Program, (13) Mathematics and Sciences: University City High Foreign Language Program, and (14) Aviation: West Philadelphia High Aviation Magnet Program (Thirtieth Educational Conference of the Philadelphia Home and School Council, Acres of Diamonds in the Philadelphia Public Schools, 1978). Parker (1971) discussed yet another example of specialized schools, the "Opportunity School" or specialized school for delinquents, potential dropouts, and truants. In the Sacramento 
Unified District in 1970, there were 210 students in such a school, with two-thirds of the student population reportedly returning to their home schools by graduation time. This Sacramento high school's goals included rehabilitating and returning students to their home school as soon as possible. Teaching positive attitudes toward work and study, upgrading academic achievement, and preparing students for the world of work were other primary goals of this school described by Parker (1971:40).

Another example of a troubled youth specialized school is found in the Seattle public school system. Project Interchange School enrolls students who are dropouts or have behavior problems:

The program for Project Interchange School is designed to meet the needs of junior high and high school students who have dropped out, who have been suspended from schools, who have been identified by their present school as having high drop out potential, or students looking for an alternative to the traditional school. The program is designed to provide individualized instruction to meet a wide variety of student ability levels. All classes meet requirements for high school graduation or help students pass the GED examination. (Seattle Public Schools Booklet, 1980-1981:40)

A variety of specialized schools have been noted here. In order to meet youth needs, Coleman (1974) suggested that public school systems include more, rather than fewer, specialized high schools in their districts. Coleman (1974:153) argued that the concentrated curriculum plus the desegregation experience and attraction of the student population from a larger geographical area were the advantages of specialized high schools:

In many areas where the supposed benefits of comprehensiveness have been lost, the advantages of moving toward deliberate specialization in school purpose will probably outweigh the disadvantages. The advantases lie in the greater encouragement 
of intense concentration on an activity that can occur in specialized schools. Specialized schools have a clearer mission, more restricted focus, and they can attract students and faculty of appropriate and mutually-reenforcing interest. For example, they can concentrate on excellence in music, art, performing arts, science, humanistic studies, or different industry sectors (medical services, educational services, printing and publishing trades, broadcast media). And there are other advantages. A school specializing in one major area of study can draw students from a larger geographical base that commits all neighborhood youth to the one public school. Such a school can set administrative policies that encourage representatives from various social groups.

Finally, alternative high schools, a fourth type of secondary school organizational structure, have been formed within and outside the public school system (See Figure 1). We will forego a discussion of alternative schools at this point because they will be examined in Part III of this study.

The previous review demonstrates that conventional secondary schools vary in their educational function and structure. In addition, they differ importantly in terms of their socio-economic and geographical location in the city. That discussion is taken up below.

THE SOCIOECONOMIC-GEOGRAPHICAL PATTERNING OF SECONDARY SCHOOLS

Although conventional public high schools are organized by their educational function, they can also be classified according to urban housing patterns, geographical zones, and socioeconomic status (Binzen, 1970; Conant, 1961; Havighurst, 1966; Havighurst, Smith, and Wilder, 1970; Lightfoot, 1978; Ornstein, Levine, and Wilkerson, 1975). The observations to follow will detail the ways high schools, based on their socioeconomic status and geographical location, differ according 
to their goals, technologies, formal structures, informal structures, and ecological influences. Let us begin that examination.

In general, recent studies (Binzen, 1970; Conant, 1961; Havighurst, 1966; Havighurst, Smith, and Wilder, 1970; Lightfoot, 1978; Ornstein, Levine, and Wilkerson, 1975), have shown that the organizational characteristics of high schools vary according to their socioeconomic status and geographical location in a city (see Figure 2). For example, as previously noted, Conant (1961) in Slums and Suburbs found that slum and suburban schools differ according to their goals and financial resources. That is, the primary goal set for suburban schools is to prepare students for college, for 80 percent of suburban school graduates were entering college (Conant, 1961). In slum schools, with as many as 50 percent of the students dropping out before graduation, the primary goal set is to equip students with job and vocational skills in preparation for their immediate employment upon leaving school.

There are different school organizational typological themes. First, Havighurst (1966) proposed a typology which categorizes high schools by their internal workings. He characterized schools by variables such as: (1) the attitudes of the school professionals, (2) the relationships between parents and the school, (3) the frequency of violence in a school, (4) the type of curriculum utilized, and (5) the availability of teaching materials and other educational resources. Nevertheless, although he based his school categories on the description of the internal workings of various schools, Havighurst's school taxonomy followed a socioeconomic theme. In a later study, 


\begin{tabular}{|c|c|c|c|c|c|}
\hline & Coals & Technologies & $\begin{array}{l}\text { Formal } \\
\text { Structure }\end{array}$ & $\begin{array}{l}\text { Informal } \\
\text { Structure }\end{array}$ & Ecological Influences \\
\hline $\begin{array}{l}1 . \\
\text { High } \\
\text { Status } \\
\text { Schools }\end{array}$ & $\begin{array}{l}\text {-Prepare youth for } \\
\text { ollege (Conant, 1966; } \\
\text { Lightfoot, 1978) } \\
\text { - inculturate youth with } \\
\text { the values of the dami- } \\
\text { society (Jacobs, 1971) } \\
\text {-offer social integration } \\
\text { for diverse student } \\
\text { bodies (Havighurst, 1966) }\end{array}$ & $\begin{array}{l}\text {-Financial resources can } \\
\text { be double inmer city } \\
\text { schools (Conant, 1961) } \\
\text {-Curriculum academic } \\
\text { (Mickelson, 1980) } \\
\text { Textbooks above grade } \\
\text { level (Havighurst, 1966) } \\
\text { +50\% reading soores } \\
\text { (Lightfoot, 1978) }\end{array}$ & $\begin{array}{l}\text {-Formal } \\
\text { bureaunratic } \\
\text { adm. model } \\
\text { (Lightfoot) }\end{array}$ & $\begin{array}{l}\text {-Students } \\
\text { cooperative } \\
\text { - Youth culture } \\
\text { influential } \\
\text { (Ornstein } \\
\text { et al., 1975) }\end{array}$ & $\begin{array}{l}\text {-Student bodies consist } \\
\text { of high income, upper } \\
\text { middle, and middle } \\
\text { income students } \\
\text {-36 of the total public } \\
\text { school population } \\
\text { (Lightfoot, 1978) }\end{array}$ \\
\hline $\begin{array}{l}2 . \\
\text { Main } \\
\text { Line } \\
\text { Schools }\end{array}$ & $\begin{array}{l}\text {-Uhold the status quo } \\
\text {-fhe middle class values } \\
\text { orientation (IIghtfoot, } \\
\text { 1978) } \\
\text { - Prepare youth for college } \\
\text { (Havighurst, 1966) }\end{array}$ & $\begin{array}{l}\text { - Acadenic curriculum } \\
\text { (Havighurst, 1966) } \\
\text {-Reading scares in 45-51\% } \\
\text {-Class sizes } 25-30 \\
\text { students (Lightfoot, } \\
\text { 1978) }\end{array}$ & $\begin{array}{l}\text {-Same as High } \\
\text { Status Schools }\end{array}$ & $\begin{array}{l}\text {-Same as High } \\
\text { Status Schools }\end{array}$ & \\
\hline $\begin{array}{l}\text { 3. } \\
\text { White } \\
\text { Working } \\
\text { Class } \\
\text { Schools }\end{array}$ & $\begin{array}{l}\text {-Uphold the status quo } \\
\text { and keep peace } \\
\text {-Teach basic skills, } \\
\text { give homework } \\
\text { frepare youth for world } \\
\text { of work (Binzen 1970; } \\
\text { Havighumst, 196;; } \\
\text { Lightfoot, 1978) }\end{array}$ & $\begin{array}{l}\text {-Acadenic tracking system } \\
\text { present (1havighurst, 1966) } \\
\text {-Class sizes } 30-35 \text { students } \\
\text {-Reading soores } 30-40 \% \\
\text { (Lightfoot, 1978) } \\
\text {-General and vocational } \\
\text { ampiculum (Havighurst, } \\
\text { 1966) }\end{array}$ & $\begin{array}{l}\text {-Bureaucratic } \\
\text { adm. structure } \\
\text { (Binzen, 1970) }\end{array}$ & $\begin{array}{l}\text {-Individual } \\
\text { effort valued } \\
\text {-Students are } \\
\text { scmetimes } \\
\text { openly hostile } \\
\text { (Gavighurst, } \\
\text { 1966) }\end{array}$ & $\begin{array}{l}\text {-Working class, lower } \\
\text { middle class, and upper } \\
\text { lower class students } \\
\text {-20\% of the public } \\
\text { school population } \\
\text { (Binzen, 1970; } \\
\text { Lightfoot, 1978) }\end{array}$ \\
\hline $\begin{array}{l}4 . \\
\text { Trans- } \\
\text { itary } \\
\text { Schools }\end{array}$ & & $\begin{array}{l}\text {-Inservices of intergroup be- } \\
\text { havior necessary for inte- } \\
\text { grated staffs and student } \\
\text { bodies (Lightfoot, 1978) }\end{array}$ & & $\begin{array}{l}\text { - Integrated } \\
\text { student bodies } \\
\text { but volatile } \\
\text { (Lightfoot) }\end{array}$ & $\begin{array}{l}\text {-10\% of public school pop } \\
\text { ulation (Lightfoot, } 1978 \\
\text { - Manging neighbosthoods } \\
\text { (Lightfoot, 1978) }\end{array}$ \\
\hline $\begin{array}{l}5 . \\
\text { Inner- } \\
\text { City } \\
\text { Schools }\end{array}$ & $\begin{array}{l}\text { - Ecucation for social } \\
\text { change and upward social } \\
\text { mobility (Ornstein et } \\
\text { al., 1975) } \\
\text {-Prepare youth with job } \\
\text { skllils for employment } \\
\text { following school exit } \\
\text { (Mickelson, 1980) }\end{array}$ & $\begin{array}{l}\text {-Academic and vocational } \\
\text { curriculum (Omstein et al.) } \\
\text { - Class sizes } 30-50 \text { students } \\
\text {-Textbooks below grade level } \\
\text {-Reading scores between 5- } \\
\text { 20\% (Lightfoot, 1978) } \\
\text { - Special compensatary } \\
\text { exucation programs }\end{array}$ & $\begin{array}{l}\text { - Bureaucratic } \\
\text { acm. structure } \\
\text {-Regimentation } \\
\text { (Conant, 1961) }\end{array}$ & $\begin{array}{l}\text { - High dropout } \\
\text { rates, aliena- } \\
\text { tion (Lifhtfoot, } \\
\text { 1978) } \\
\text {-Strang subcul- } \\
\text { tural influence } \\
\text { (Havighurst, } \\
\text { 1966) }\end{array}$ & $\begin{array}{l}\text {-Parents politically } \\
\text { coalesce for quality } \\
\text { education (Smith and } \\
\text { MoGrail, 1969) } \\
\text {-Parental support } \\
\text { divided (Ornstein, } \\
\text { et al., 1975) }\end{array}$ \\
\hline
\end{tabular}

Figure 2. An example of the organizational characteristics of different socioeconomic high school types 
after surveying 45 cities with populations over 300,000 , he added the ethnic composition of a student body as a variable for high school typologies (Havighurst, Smith, and Wilder, 1970).

The school typologies developed by Lightfoot (1978) and Ornstein, Levine, and Wilkerson (1975) elaborated detailed categories of schools organized by housing patterns. Guided by a concentric zone theory of school organizations, Lightfoot (1975:45) listed schools as: (1) Inner-City Schools, (2) Transitory Schools, (3) Common-Man Schools, (4) Main-Line Schools, and (5) High Status Schools. Lightfoot (1978:47) noted that not all cities followed a concentric zone pattern: "Some follow a section zone approach or a multiple nuclei approach. Chicago represents a concentric zone pattern, while Los Angeles represents the multiple nuclei pattern."

Like Lightfoot (1978), Ornstein et al. (1975) based their types of schools on factors such as the geographical location in the city and socioeconomic composition of student bodies. Their typology included the following schools: (1) Inner City Schools, (2) White Working Class Schools, and (3) Upper Middle Class Schools.

With a somewhat different perspective, Peter Binzen (1970), in his ethnographic study of middle class America, Whitetown, U.S.A., clearly described the attitudes, values, and state of affairs of working class schools. He compared whitetown or the working class schools with inner city schools in the Philadelphia area. Although he did not set out to develop a school typology, his description is pertinent to this discussion, and therefore, is included here. 
The commentary which follows includes a brief explanation of the types of secondary school organizations depicted in Figure 2, as wel.1 as the organizational characteristics of each school type, as outlined by the theorists reviewed.

Consider, first, High Status Schools. This socioeconomic type listed in Figure 2 is generally located in the outer edges of the city, in the newest housing developments, or suburban neighborhoods. Preparing youth for college entrance is the primary goal set for this school type (Conant, 1961). Conant (1966:141) pointed out the pressure in suburban schools of some overambitious parents in steering unable students toward college careers: "The main problem in wealthy suburban schools is to guide the parent whose college ambitions outrun his child's abilities toward a realistic picture of the kind of college his child is suited for." Havighurst (1966:90) argued that parents' aspirations for their children were more inclusive than simply that of gaining college entrance:

What parents desire in the education of their children is a kind of school which stimulates children to do well academically; encourages them to finj.sh high school and go to college; and offers something useful and interesting for children from all kinds of families.

Furthermore, Mickelson (1980) commented on the different types of goals set for schools. She examined and compared Beverly Hills High School (high status school) and Morningside High School (working class school), both located in California. She investigated the claim of Bowles and Gintis (1976) that the educational system integrates youth into the economic system through a structured correspondence between the social relations of the school and the means of 
production. Mickelson's (1980:100) findings support the Bowles and

Gintis argument that the two schools have organizational structures

which prepare students to become different types of workers:

The evidence suggests that the social relations and the value and attitude content of Beverly Hills High School's internal organization, curriculum, vocational education program, and extracurricular activities tend to socialize students to the social relations of higher levels of the division of labor. The opposite was found at Morningside. The internal organization, curriculum, vocation education program, and extracurricular activities tend to socialize students for success as workers.

Finally, another goal held by parents for suburban high schools, was listed by Jacobs (1971:100) after he conducted a sociological observational study of 1,600 high school students, namely, to have their children enculturated with the values of the dominant society. A second organizational feature of High Status Schools, technologies, parallels the goals of these schools. For example, the curriculum is highly academic and complementary of a college preparation goal (Conant, 1961). Specifically, the curriculum at the elite high school described by Mickelson (1980:88) was open, flexible, and stimulating:

The nature of the curriculum in elite and suburban communities tends to be innovative, flexible, and conducive to preparing students for higher education. For example, the alternative school movement is most successful in middle-class communities where the ambiguity, the innovation, the flexibility of the learning experiences reflects the social relations of middle-class parents' work experience.

Because a large majority of graduates of these schools are college-bound, textbooks are often found to be one to two years above grade level. Standardized test scores report marks above the fiftieth 
percentile in reading. These schools have class sizes of 10 to 25 students, new school facilities, and innovative equipment. Parents often provide the finances for extra programs and resources unavailable through school district allocations (Havighurst, 1966; Lightfoot, 1978).

Mickelson (1980) described the technologies of one High Status School, Beverly Hills High School as nearly ideal from a teacher's point of view. The student-teacher ratio at the elite school was 9:1. The school enrolled 2,535 students in 1976 and reported a per pupil expenditure of $\$ 2,129$ (Mickelson, 1980:85). On the other hand, the technologies employed at Morningside High School, a working class school, were described in less glowing terms. This school enrolled 1,800 students, reported a per pupil expenditure of $\$ 1,300$ in 1976 and had a student-teacher ratio of 19.78:1 (Mickelson, 1980:86). The Beverly Hills' campus was open and unpoliced, students self-scheduled their courses, modular scheduling was present, and a dress code did not exist (Mickelson, 1980:86-87).

Contrary to Mickelson's portrayal of one High Status School, Jacobs (1971) insisted that overcrowding, lack of space, lack of privacy, and shortages of school personnel were problems of suburban high schools, and possible causes of the deprivation and deviance among students attending the schools described in his sociological observational study.

An examination of the formal structure of High Status Schools found that these school types utilize standardized bureaucratic procedures (Lightfoot, 1978). Regarding a fourth element of school 
organizations, informal structures, High Status Schools have been reported to include these characteristics: (1) segregated student bodies and staffs, (2) a stable teacher group with a low turnover rate, (3) low absenteeism, truancy, and dropout rates (1-5 percent), (4) students exhibit positive, respectful attitudes toward teachers, and (5) little or no fighting exists among students (Havighurst, 1966; Lightfoot, 1978).

Students are said to be highly motivated and cooperative in these schools, although the youth culture is alleged to have a strong influence on students (Ornstein, Levine, and Wilkerson, 1975). For many students, the values of the youth subculture are viewed as more legitimate than those emphasized by the school. Ornstein et al. claimed that the traditional High Status School exists in a contradictory state because students are socialized for independence but also for conformity to the values of the dominant culture. In point of fact, the authors explained that students in High Status Schools are volicing a concern for the process of secondary education, whereas in the past, emphasis was on the end product--that is, gaining college entrance. This quest for a quality education was described by Ornstein et al. $(1975: 16-17)$ in the following terms:

The alienation of many upper-middle-class students in the suburban or suburban-type high school is an unprecedented mixture of earnestness and playfulness, of individuality and identity confusion, or moral relativism and social commitment. In particular, much of what is central in the situation of middle-class youth can be summarized by noting the shift that has been occurring from concern for products to concern for process. When religious and scientific belief-systems lose much of their power to generate unquestioned acceptance of predetermined goals, when technological productivity lifts the burden of fear that the future will bring recurrent famine and 
starvation, when social change uproots people from primary communities and places them in impersonal bureaucratic settings, and when mass media provide images and knowledge of a new universe of diverse activities and pleasures to be sampled and indulged in, instrumental preoccupation with the future gives way to expressive concern for the quality of experience in the here and now. Although the schools traditionally have provided opportunities for expressive as well as instrumental behaviors, institutional emphasis on the instrumental (for example, academic competition looking toward college admissions) historically increased just the middle-class students were becoming less willing to ignore or forego expressive satisfactions. Students in the middle-class school, in such circumstances, tend to view the school as a repressive force rather than an institution authentically concerned with their interests and motivations.

Finally, Ornstein et al. pointed out ecological influences or possible sources of alienation that are markedly characteristic of High Status communities. First, the "unreality of the suburban environment" was described (Ornstein et al., 1975:14). The cloistered environment of the suburbs was pictured as being unreal and inauthentic as it was only a partial representation of the American social setting. Homogenous neighborhoods with a serene and protective environment lose out to the influence of the youth culture, which offered more credible, exciting, and authentic experiences, even if such practices were sometimes drug related.

Relative affluence was a second source of alienation depicted (Ornstein et al., 1975). Affluent students are less likely to be convinced of the necessity of schooling success than their inner-city counterparts. For example, the High Status School students need not strive for success in school as do inner-city youth, in that upward social mobility is theirs without effort. 
A "surfeit of opportunities" is a third source of alienation characterized by Ornstein et al. (1975:14). Because High Status School students are exposed to a limitless number of career possibilities, an identity crisis may occur for many of them. This identity crisis could be reduced or aggravated by the high school organization. "Intellectual acuity" is a fourth source of alienation, according to Ornstein et al. (1975:15). Middle class and upper class youth have never before been as aware of the gap between social ideals and social reality as today. The mass media, advanced communication systems, and growing cultural consciousness have affected this awareness.

A final source of alienation is "socialization for independence" (Ornstein et al., 1975:15). The authors charged that parents and schools socialize students in a contradictory fashion. On the one hand, both parents and teachers expect students to be individuals and endeavor to motivate them as individuals to face the world, while on the other hand, they then prepare them to work in highly bureaucratically-structured employment environments. Additionally, there are ecological factors impacting upon High Status Schools (Havighurst, 1956; Lightfoot, 1978). First, the socioeconomic composition of the student bodies consists of high income, upper middle income, and middle income students. These schools comprise roughly 5 percent of the total public school population. Second, parents are highly involved in the progress of their children and overambitious for them in some cases (Conant, 1961; Havighurst, 1966; Lightfoot, 1978; Ornstein, Levine, and Wilkerson, 1975). 
Perhaps the suburban school has been painted as an ideal type by the media (Ornstein et al., 1975). Bernstein (1967) and Wynne (1977) have offered a view of the suburban school that is not congruent with that put forth by Havighurst (1966) and Lightfoot (1978). Bernstein (1967:14), an urban educator, argued that the problems of the suburban school parallel those of the inner-city school:

Therefore the problems of urban educators are also to a large extent those of education in the suburbs. Why, indeed, should we expect them to be different? The suburbs do not breed angelic human beings. Their high schools also have retarded readers, truants, behavioral deviants, products of broken homes, and narcotic users. In fact, some inner city high schools are better scholastically and in behavior than certain suburban schools, where drinking, premature pregnancies, and poor performance make teaching as hard as in the presumably "tough" city schools. However the ratio of social problems is lower in the suburbs than in city public schools . . The urban-suburban dichotomy is breaking down because the poor and deprived live in the suburbs these days too, in order to serve the rich and privileged, generating problems in the suburban schools formerly associated only with city schools. Hence and henceforth in speaking of urban education we will simultaneously be speaking of suburban education also.

To summarize this section, conflicting reports about the nature of

High Status Schools have been put forth by various authors.

A second type of school, Main Line Schools (see Figure 2) is

located in the zone next to high status schools (Lightfoot, 1978). These institutions uphold the status quo, stress a middle class values orientation, and also prepare youth for college. Their curriculum is academic with class sizes averaging between 25 and 30 students. Reading scores of these students are reported in the $45-51$ percentile (Havighurst, 1966; Lightfoot, 1978). There is little mention of these 
schools in the literature because their organzational characteristics are for the most part comparable to High Status Schools.

White Working Class Schools is a third type of school (see Figure 2), found in the central city and working class suburban neighborhoods (Havighurst, 1966). These schools were called CommonMan Schools By Havighurst (1966) and Lightfoot (1978).

The parents of students in this school type hold different educational goals. They expect the school to: (1) uphold the status quo and keep peace, (2) teach basic skills, stress memorization, and assign homework, and also, (3) prepare youth for the world of work (Binzen, 1970; Havighurst, 1966; Lightfoot, 1978). Additionally, the school's socialization process is intended to stress values different from other school types. That is, unlike inner-city parents, the working class parents do not formally organize for school reform issues because they believe in individual effort rather than political organizations (Ornstein et al., 1975). Based on this ethnographic study of one east coast city, Binzen (1970) concluded that these schools are most successful at assimilating and controlling white immigrants who intend to prosper in the American social and economic system. Due to such mainstream social attitudes, the white working class parents do not demand quality education because, in part, they do not "make waves" with school administration and they do not want to be equated with rebelling minorities and Blacks (Ornstein et al., 1975:24).

To expand upon this point, among middle class Americans, it is considered a disgrace to accept welfare, support, or public 
assistance, thus individuals are expected to "plug along" (Binzen, 1979:62). These parents also do not rally for quality education because of value emphasis upon individual effort, thus, they are reluctant to engage in group efforts. For example, on a school application level, endeavors to enhance political consciousness through civic education in secondary schools might be appropriate in certain school types, but in working class schools, such efforts would be futile because of the predominant emphasis upon individual effort (Ornstein et al., 1975:27). In particular, the whitetowners in Philadelphia complained of reverse discrimination, and due to their assimilationist point of view, fought social change espoused by Black community coalitions (Binzen, 1970).

Steinitz, King, Solomon, and Shapiro (1973) conducted in-depth interviewing of 100 high school seniors in three working class communities in order to investigate the value of individual effort. They researched the types of changes youth experience as they go through ideological questioning. The research of Steinitz et al. (1973:336) was grounded upon the assumption that individualism was a strongly held value and political coalitions were viewed with skepticism:

\footnotetext{
- . we did anticipate that many of them would be experiencing considerable conflict between their desires to pursue an individualistic, upwardly mobile "good life" and their desires to contribute to the reduction of the inequalities between their class of origin and the rest of the society. We thought that they would be actively searching for ways to integrate their personal goals with their visions of a more just society and we wanted to chart the ways in which they were interpreting and responding to this press for integration.
} 
Steinitz et al.'s interview schedule included questions about students' personal worlds and their opinions concerning America's strengths and weaknesses. The findings of the study supported the assertion that working class persons value individual efforts. The study found that: (1) in all three communities, the personal goals of the student took precedence over soncern for societal issues, (2) students believed in upward mobility, (3) two of the three represented communities had students who "wished to avoid personal participation in public issues" (Steinitz et al., 1973:354), (4) two of the communities had students who viewed the present social order as unjust, and (5) one community's students were more willing to be politically involved. According to Steinitz et al. (1973:355) these students believed in the effort of the individual:

But they had seen the benefits individual efforts can attain. They were not ready to give them up when they would be the next beneficiaries of the affluence of American society. Deprived of their own past, this did not strike them as unjust.

Also, research findings demonstrated that interviewed students were aware of the inequalities of resources, power, and opportunity in America. Even so, they believed they would attain self-set goals. Students lacked a sense of collective identification, and in addition, working class youth who were involved in organized social action groups were vulnerable because they had to sacrifice their already scarce opportunities to earn money. Further, they had to sacrifice their individual identities, self pursuits, and peer support if they became involved in political activism. Thus, the findings of the Steinitz et al. study paralled the polltical values stated by 
Whitetowners. That is, individual effort is valued over political

organization for social and school reform (Binzen, 1970).

The technological characteristics of these schools are also

distinct from those of the other school types. Binzen (1970:56)

described a school:

The Harvard School is dimly illuminated. In one room, when I was there, a lone light bulb (it appeared to be sixty watts) dangled from an eight-foot cord that ran from the high ceiling to a point just above the teacher's desk. The building is a rabbit warren of little closets and rooms tucked planlessly here and there off corridors. You encounter the dusty auditorium by surprise on the third story. There is one toilet seat per floor. There is one play yard.

An elevated line linking Charlestown to downtown Boston, five minutes away, rattles nearby. The school sits back from a busy commercial street and heavy trucks trundle past all day long. (The trucks run within six feet of the living room of a Charleston resident who has an important job in the Boston city government. Like so many Whitetowners, he's proud of the old place and is damned if he will move.)

Class size runs between 30-35 students in working class schools. Lightfoot (1978:46) optimistically estimated reading scores in the 30-40 percentile. In an earlier report, Binzen (1970:72) described a group of elementary students from this type of school as falling into the bottom ten percentile nationally in reading. Havighurst (1966) disclosed that below grade level textbooks are used in them. He also described four ability tracks exercised in two central high schools. The tracks or ability groups utilized in both schools included Basic, Essential, Regular, and Honors (Havighurst, 1966:96). The High Status Schools did not have a Basic track. Havighurst (1966:97) argued that many of the students in the working class school were in the lowest tracks: "School $\mathrm{C}$ had 65 percent of its ninth graders in Basic or Essential English, and 75 percent in Basic or Essential Mathematics." 
Like High Status Schools, the formal administrative structure of these schools is bureaucratic. The principals work diligently for resources but their hands are tied with a top heavy bureaucracy (Binzen, 1970). Additionally, the Whitetowners complicated this situation for school administrators because they were unwilling to admit their need for extra services and programs. In addition to poor facilities, teachers do not have high expectations for students and have formal rather than interpersonal relations with students. However, the teacher group is stable with as many as 95 percent in 1969 in Chicago being certified and tenured (Binzen, 1970). The informal structure of this school type is distinct. Havighurst (1966) asserted that a wide range of student and parent attitudes exist toward teachers. Students' hostility is exhibited in physical forms of confrontation. The student subculture has a significant influence in these schools:

Children with discipline problems may be leaders for some students and sometimes upset academic classroom situations . . . Students strongly influenced by peer group. Behavior and dress patterned almost entirely on models offered by movie or T.V. Many have no identification with future adult roles. (Havighurst, 1966:95)

The working class, lower middle class, and upper lower class attend these schools, accounting for 20 percent of the public school population (Binzen, 1970; Lightfoot, 1978).

A fourth type of school, Transitory Schools, is located in the geographial area between the inner-city and white working class zones (Lightfoot, 1978). In this zone, housing patterns are in the process of changing. In addition to changing housing patterns, Lightfoot 
(1978:44) argued that these schools potentially are explosive because of "enforced desegregation, community militancy, and increasing minority enrollments."

Because the student bodies and staffs of these schools are highly integrated, inservice training on intergroup behavior is necessary to discuss problems and work out solutions together (Lightfoot, 1978). Ten percent of the public school population attend these schools (Lightfoot, 1978).

The final type of school in Figure 2, Inner-City Schools, is located in the inner most geographical zone, closest to the core area of the city. The lower middle and lower class parents of children in these schools hold two general goals for the education of those children. Education is expected to be a vehicle for social change, as well as the best route for upward social mobility (Binzen, 1970; Ornstein et al., 1975).

Unlike working class schools, the parents of inner city school students are likely to be politically organized and to insist on quality education in their schools. Smith and McGrail (1969) explained the desire of inner-city parents to control their schools and be directly involved in the decision-making process. First, parents are active participants because they view the schools as "the vehicle to the good life for their children" (Smith and McGrail, 1969:2). Furthermore, parents in inner-city areas feel relatively powerless in a highly competitive and technological society, thus involvement in their schools helps them feel politically effective. 
Smith and McGrail (1969:4) argued that inner-city students are positively affected by parents' involvement in school:

1. The great potential value of this kind of citizen concern is that it tends to foster educational achievement and aspiration in students.

2. An increase in the competence levels of currently deprived ethnic minorities should go a long way toward fostering integration and equality of opportunity in our nation.

Reviewing the technological characteristics of these schools, it was reported that class sizes range from 30-50 students. Textbooks are one to two years below grade level (Lightfoot, 1978). In the 1960's and 1970's, a diverse curriculum, both academic and vocational, was obtained as inner-city parents coalesced for relevant and quality education. Concerning the course offerings and programs of these schools, Havighurst (1966:93) commented: "Curriculum does not fit students' needs." Ornstein et al. claimed that the curriculum utilized in the inner-city schools, with a middle class language and experience base, is irrelevant to students and 20 years out of date. Special compensatory programs, such as Title I, funded by the federal government, provide special programs for inner-city youth deficient in basic skill development. On the national level, Lightfoot (1978) recorded reading scores between the 5-20 percentile for students in these schools. Ornstein et al. (1975:25) reported the median achievement by seventh grade as three to four years below grade level.

The formal structure of inner-city schools is different from the other school types. Conant (1961:23) described the regimentation present in inner-city schools: 
In contrast to what one hears about "blackboard jungles," I think I am fairly safe in saying that the outward manifestations of discipline, order, and formal dress are found to a greater degree in the well-run slum schools of a city than they are in the wealthier sections of the same city. The contrast is especially noticeable between city slum schools and wealthy suburban schools, where informality in dress, deportment, and classroom procedure is the rule. I doubt that many suburban parents would stand for the regimentation and formal discipline meted out in many slum schools. It is not accidental that that part of the progressive movement in education which rebelled against formalism and authoritarianism found root in the suburban and private school.

The informal structure of this school type is also unique. Dropout rates are close to 50 percent in some schools (Conant, 1961; Lightfoot, 1978). Havighurst (1966) noted a high incidence of violence, fighting, profanity, and hostility. The student subculture is a strong influence on students: "Students heavily influenced by an alienated peer group. Many students influenced by delinquent adolescent and adult models. Many have hostility toward widen society and little identification with future adult roles" (Havighurst, $1966: 95)$

Smith and McGrail (1969) argued that community control and parental involvement in the schools would guarantee that more relevant decisions would be made for youths, thus enhancing the educational experience for inner-city youtns. Smith and McGrail (1969:5) proposed that negative behaviors could be reduced: "In addition, community participation is a positive answer to many of the overt behavior problems plaguing our urban schools such as poor discipline, truancy, absenteeism, and general hostility or indifference to the schools." Parents who endeavor to convince their children of the advantages of the legitimate avenues of schooling compete against the 
attractiveness of the immediate gratification and benefits of street life. Some parents are supportive but many are apathetic toward the school's structure (Ornstein et al., 1975).

The preceding two sections of this chapter illustrated that conventional high schools are not alike but vary by their educational purposes (Figure 1) and socioeconomic status and geographical location in a city (Figure 2). Figure 2 demonstrated that the organizational characteristics of high schools differ by their socioeconomic status. For example, the goals set by people for inner-city schools are different than the goals of high status schools. This discussion has briefly outlined two possible typologies or classification schemes of secondary schools. The next chapter will discuss the organizational characteristics of comprehensive high schools in greater depth and detail. Before taking up that analysis, the challenges leveled against secondary public high schools are presented for a point of reference from which to measure these schools.

CRITICISMS OF THE CONVENTIONAL SECONDARY SCHOOL ORGANIZATION

What are some of the major criticisms raised by theorists (Brown, 1973: Coleman, 1974; Martin, 1974) against secondary school organizations? A brief portrayal of challenges facing secondary schools should provide a benchmark as the organizational characteristics of these school structures are probed in depth in the next chapters. 
Some of the criticisms are the following:

1. Changes in the developmental patterns of youth have not been recognized by high schools. Physiologically, adolescents experience puberty one to two years earlier than did previous generations. According to Piaget, between 12 and 15 years of age, adolescents reach the final stage of cognitive development, which is the intellectual stage. Psychosocially, youth in American society are seeking a personal identity and are establishing their independence. In all of these developmental processes, individual youngsters experience growth at different rates. For example, one might reach adolescence physiologically at age 14 and the final stage of cognitive development at age 15, yet another might attain the same stages of development at ages 12 and 13 .

In addition, media in our technological and post-industrial society influence youths' experiences, value systems, and moral development. However, theorists charge that youth institutions, like high schools, have not responded to the changes in the developmental patterns of today's students (Brown, 1973; Coleman et al., 1974; Martin et al., 1974; Weinstock, 1973). Similarly, Katz (1971) and Tyack (1974) argued that for 40 years high schools have continued to educate youths utilizing chronological age grouping and the same instructional technologies. In summary, the charge has been made that schools have stood still despite the changes in developmental patterns and the vast difference in rates of individual growth, for any given developmental stage. 
2. High schools reflect segregation policies and engage in a custodial role which may cause isolation, dependency, and the alienation of youth. Youngsters are segregated in high schools by age, race, and aca!demic ability. They are deprived of valuable interpersonal social experiences and role relations with different age groups of people such as the very young, working adults, and the retired elderly (Coleman, 1974). Due to the credential society, rising levels of formal schooling cause the prolongation of adolescence and dependency problems for youth (Carnegie Council, 1979).

3. High schools employ alienating and irrelevant goals and technologies. Examining school goals, Etzioni (1981) studied secondary school organizations and asserted that they do not prepare youth for the world of work; but instead, they exclude youth from worthwhile work experiences. His major proposed goals for high schools encompasses moral development and character building. The character building process he outlined includes preparation for the adult world of work and active citizenry in a democratic society. He proposed a plan for students to spend one year in national service, in either civilian job or military service. In theory, this experience would help youths discover and struggle with diverse values and build character (Etzioni, 1981).

Etzioni also voiced a concern for the values that were being transmitted by mass media to youths--violence, sex, and excessive consumerism, for example. Put differently, he viewed the proposal of one year of national service as a way of giving youngsters a break 
between high school and college, providing them with a chance to mature, and allowing them the opportunity to share values with others and the real world.

In three major reports concerning secondary schools published in the last decade, Brown (1973), Coleman (1974), and Martin (1974) recomended that high schools emphasize and plan a work experience in the curriculum, allowing credit for such encounters. Also, Greenberg (1977) and Schaefer and Polk (1967) maintained that worthwhile work and schooling experiences would have a positive effect on the societal problem of delinquency.

Finally, the Carnegie Council (1979) argued that high schools provide a poor transition for youths to adulthood, in part because youths have little contact with the workplace and human service organizations. Longer years of schooling cause them to feel dependent at a time when they seek independence and personal identity (Carnegie Council, 1979).

4. The assimilationist's point of view does not serve the urban poor well, but causes alienation in many cases. Under the assimilationist's value system, Katz (1981) claimed that society and existing social problems have not been reformed or resolved. With a point of view different from Katz's, Clift (1976) an urban educator, optimistically noted that schools have performed a competent job teaching reading, writing, and arithmetic, however, he suggested that social problems needed more attention than they have received. Furthermore, Silberman (1970) insisted that the schools have not been the great equalizer of opportunity that Conant (1967) proposed, 
clearly challenging the assimilationist's point of view. Rist (i973) asserted that a primary goal of schools is social control, not social change. He argued that the schools have sorted and maintained the urban poor to the lowest tracks. Silberman (1970) insisted that values of dominance and subordination are imposed on the urban school population.

Radical scholars Bowles and Gintis (1976) asserted that the schools employ sorting processes and uphoid status quo goals for socialization for conformity because they are under the control of the capitalist economic system. In other words, they argued that even though the present schooling structure produces an inferior product, it supplies workers for the industrial reserve army and upholds the capitalist system. Some students are placed in success-oriented tracks and others in unsuccessful tracks, reflecting the class system of capitalism.

While Bowles and Gintis proposed school reform through massive change from a capitalist system to a socialist one, other theorists offered clinical reforms of the present structure to solve the problems caused by the assimilationist's value system. A report prepared by the Task Force on Urban Education in 1969 entitled Schools of the Urban Crisis stressed the need for integrating multicultural values in the curriculum materials of the public schools. Perel and Vairo (1969) argued that the contemporary urban population, unlike earlier immigrant populations, is alienated from schools. These authors proposed that a pluralistic value system would aid in relieving and alleviating student alienation. 
The four preceding charges or challenges will be examined in greater detail in the summary section of the next chapter. Let us now turn to an in-depth review of the goals, technologies, and formal and informal structures of conventional high schools. This review will help to answer questions such as: On what level are goals made for high schools? What are the relations between teachers and students? Are the same instructional methods of 40 years ago still utilized? How formally structured is the administration of high schools? That matter is discussed next. 


\section{CHAPTER III}

\section{COMPREHENSIVE HIGH SCHOOLS: AN EXAMINATION OF ORGANIZATIONAL CHARACTERISTICS}

This chapter examines the organizational characteristics of public comprehensive schools: goals, technologies, formal structures, informal structures, and ecological influences. Goals are presented first.

\section{GOALS}

Educational goals are set on four levels: national, state, district, and individual school building. First, let us examine national goals. A discussion of nationally stated secondary educational goals could begin with the Cardinal Principles of Secondary Education, issued by the National Education Association in 1918. They were:

1. Good health.

2. Command of fundamental processes.

3. Worthy home membership.

4. Vocational efficiency.

5. Good citizenship.

6. Worthy use of leisure time.

7. Ethical character.

These early goals addressed various developmental areas, that is, the moral, biological, socio-cultural, and cognitive maturation of students. 
More recently, in 1971, the National Education Association's Center for the Study of Instruction offered the report Schools for the 70's and Beyond: A Call to Action which disclosed a major theme of "humaneness" for schools. In particular, the study maintained that schools could address controversial social problems that surfaced in the $1960^{\prime} \mathrm{s}$, such as the Vietnam War, poverty, over-population, birth control, pollution, urban problems, and the ecology (National Education Association, 1971:11). The study contended that social problems could be solved in schools, although it also argued that a differentiation between social engineering and social education would have to be made.

To expand upon this point, an historical perspective on the role of schools in the socialization process might be undertaken to illustrate the distinction between social education and social engineering. Tyack (1974:13) has charged that since the 1900's, schools have acted as a sorting device, processing lower and middle-income groups of students into the vocational tracks to supply the unskilled labor for the economy of those times:

Since 1900, Ralph W. Tyler pointed out, our economy has shifted from one in which 5 percent of the population was needed in professional or highly skilled occupations and 60 percent in unskilled work to the reverse; today, 60 percent of the work force earns its living in professional and skilled occupations, and the economy can absorb only 5 percent of the work force in unskilled jobs.

Katz (1971) supported Tyack's argument. He asserted that schools benefit the well-to-do, not the poor. Stated differently, high status or affluent students are tracked into highest academic levels leading to professional occupations. Thus, the sorting of students into 
academic tracks is a form of social engineering. By contrast, social education involves a systematic effort to promote an awareness of social problems and the discussion of possible solutions. The National Education Association (1971) study claimed that social education would be effective in solving social problems in the long run.

Returning to a point made earlier, the National Education Association (1971:16-17) argued for a national liberal education whose primary goal would be humaneness. In particular, the National Education Association (1971:16-17) advocated humaneness as an educational theme that would: first, teach men and women to be humane to themselves and others; second, prepare them to live; and third, place making a living in a secondary area of emphasis:

Our power has distracted us from our purpose. That purpose is man, and the central problem facing American society appears to be man's inhumanity to others--and to himself. . . Machinery is to serve man. And a liberal education, goes the old formula, does not teach a man how to make a living, but how to live.. But now, perhaps for the first time in human history, a society has built the machinery to place enough--enough food, enough clothing, enough shelter--within the reach of all its citizens, to put making a living in second place and living in first.

The state level is a second sphere where educational goals are set. For example, the Colorado State Board of Education adopted a statement of educational priorities on July 8, 1982. Goals are noted in the areas of Accountability and Accreditation, Alliance for Public Education, Educational Leadership, Teacher Education, Student Responsibility and Citizenship, and Statewide Library Network (Colorado State Board of Education, 1982:1). While set on the state 
level, the initiatives set forth by this particular board of education were made for the individual school building and for school districts. For example, under Accountability and Accreditation, the board maintained it would:

Implement district accountability and accreditation programs at the building level. Emphasis will be given to increasing public involvement, district evaluation of educational programs and student competency, reporting to the public, development of long-range plans by schools and school districts, and to strengthening the leadership effectiveness of the school principal. (Colorado State Board of Education Educational Priorities, 1982-1984)

Also, allocations were made concerning efforts to involve the business community and parents in the educational experience. Programs and policies to affect and emphasize students' self concepts, community relations, and citizenship responsibilities were included in this document, as well as technical provisions for an elaborate library network and other special programs. Finally, teacher education needs in the areas of competency testing and teacher shortage projections were named as need themes.

School districts also set educational goals. Let us examine the district goals of the Jefferson County Public Schools, located in Denver, Colorado. A special report of the district goals for 1978 was prepared by the central office's Department of Communication Services. The Board of Education approved the goals proposed by the administrators and SIPC (School Improvement Process Council). The SIPC Council is composed of parents, nonparent taxpayers, and school staff members (Special Report of the Jefferson County Schools, 1978:1). 
Five major goal areas are included in the district statement:

Mastering basic skills for continued learning, developing a sense of responsibility, developing a student's unique talents and sense of self-worth, preparing students to cope with change, and developing skills and attitudes necessary to earn a living and function as a contributing member of society (Special Report, The Jefferson County Public Schools, 1978:1).

Goal categories listed by the Jefferson County School District contained areas of moral, cognitive, and social development. Furthermore, the outlined goals included development of the individual in areas of self-concept, creativity, character building, and citizenship. In addition, 23 general learning objectives were developed for the 5 major goal areas approved by the Jefferson County School District. Also, this school district drafted an annual set of operation objectives for the formal structure or administration:

In addition to these educational goals and learning objectives, the Board of Education on a yearly basis adopts a set of operation objectives for the school district. These objectives focus on specific areas such as instruction, administration, management, and communication. School district coordinators also work on an annual basis to establish objectives in support of the overall educational goals of the Jefferson County Public Schools. (Special Report, The Jefferson County Public Schools, 1978:3)

Finally, goals are set at the individual school building level. Figure 2 in Chapter II illustrated that schools, differentiated by socio-economic status, hold different goals for various social status groups. For example, high status or high income schools stress goals which center on preparing students for college and socializing them for conformity. On the other hand, inner-city schools espouse goals which uphold education for social change and social mobility. 
Educational theorists (Giles, 1977; Marburger, 1980; This We Believe, 1975) have promoted the necessity of goal setting at the individual level for reasons which encompass: (1) lessening tension upon staffs, (2) representing the many views of a diverse society, and (3) cultivating quality education through shared power and decision-making. On this point, Giles, a researcher from the Department of Educational Studies at Oxford, conducted four case studies of comprehensive high schools in England, Wales, and the United States. The relationship between the four different schools' organizational characteristics and effect on discipline was studied. One U.S. high school included in the study, "Centreville," was located in an industrial city in Ohio. Giles found that a school philosophy, particularly in discipline matters, helped to relieve staff tensions. Compared to English schools, the author found that American high schools were more likely to have a stated school philosophy. Giles (1977:219-220) argued for the value of a school philosophy:

Yet, to take just one example, how can a participatory or democratic approach to school management be successful if the staff are divided or indifferent? Or if you favour traditionalist authoritarianism can you succeed if radicallyminded staff are working up plots with sixth-formers? If only schools would hammer out their aims and philosophies, make them explicit and readily available in printed form, then a whole new area of choice would be opened up to teachers, parents and pupils. Like-minded staff would gravitate to schools where their enthusiasms and talents could be fully deployed, but to make this happen perhaps there would have to be a more rational and less frustrating system of staff appointments than the present mad scramble of the blind applying for the unknown. 
The National Association of Secondary School Principals (1975:6), in its report Secondary Schools in a Changing Society: This We Believe, argued that each secondary school needed to establish specific building goals:

The National Association of Secondary School Principals believes that a new emphasis must be placed upon the consensual function of secondary schools. Schools need to assume the leadership for gaining a certain public agreement about the purpose of secondary education. The many viewpoints expressed about the objectives and priorities of secondary education must be blended in each community to provide common ground for school action.

The Association asserted that consensus on goals would allow diverse interest groups an equal chance for representation and would provide each individual school the opportunity to develop specific and unique goals, rather than loity district and state goals applied to all schools.

Malburger also promoted goal setting on the individual building level in order that parents and concerned community persons share power, thus providing decisions specific to an explicit subset of the public school clientele. He advocated planning at the individual level, with each school initiating a school council for shared decision-making among all interested parties, insuring quality education and less apathy by consumers as the end result.

\section{Participatory Goal Setting}

This section deals with the question: who should set schools goals? A subsequent section of this chapter investigates the existing power structure in the administration of schools. Concerning the 
question of who should set goals, numerous educational authorities (Abramowitz et al., 1978; Brown, 1973; Etzioini, 1981; Giles, 1977; NASSP, 1975; and Timpane et al., 1976) have urged that educational goals be decided in a participatory manner by school administrators, teachers, parents, students, and non-parent community members. Consistent with this emphasis, Brown (1973) insisted that participatory goal setting would lessen the gap and hostility between the general public and educational professionals. Similarly, Etzioni (1981) contended that goals reached with parent groups in consensus would be more effective guideposts in schools, compared to district level, generally-stated goals set for all schools.

Various plans have been proposed concerning school goal-setting. For example, Wynne (1977) detailed a plan to construct a school-withina-school with the objective of building a strong sense of community in which adults, in particular, would pre-determine educational goals. In his plan, Wynne excluded students from the decision-making process. Educational theorists generally advocate that parents, students, and interested community persons join educational professionals in school goal setting endeavors. Accordingly, cooperative goal setting is one quality school indicator detailed by Howard (1978). Following this in-depth analysis of conventional high schools, Chapter III, in part, will examine the results of some effective and quality school studies. 
Preferred Secondary School Goals

A review of major studies (Abramowitz et al., 1978; Brown et al., 1973; Carnegie Council, 1979; Martin et al., 1974; National Educational Association, 1971; Rutter et al., 1979) suggested that four major goals have been stressed by educational theorists: basic skill education, humanism, transition to adulthood and the community, and individual responsibility. An explication of these four goal areas follows.

First, various theorists emphasized a general or basic education for students. Some experts held this to be the primary goal for schools (Abramowitz et al., 1978; Etzioni, 1981; Schaefer and Polk, 1967; Shaw, 1975). Recently, this country has witnessed widespread criticism on the state of affairs of the public educational system. In particular, the competence of teachers to teach basic skills to students has been challenged. One reaction by teachers and parents to these charges has been the fundamentalist or back-to-the-basics movement first initiated in the $1950^{\prime} \mathrm{s}$ by the Council for Basic Education, and then again in the mid $70^{\prime} \mathrm{s}$, on the elementary level for the most part. The goals of the fundamentalist movement includes more than basic skill development, involving as well assimilation or melting pot values: $\mathbf{n}$. . rewarding of achievement, and inculcation of traditional. value . . " (Shaw, 1975:39). Henry Myers, a board member of the Pasadena Unified School District, enunciated goals for fundamental schools that would instill pride in students, a feeling of self-worth, and a basic skills education (Shaw, 1975). Shaw (1975:34) 
summarized this public school phenomenon: "Their patriotism seems not so much blind devotion to America as an appreciation of its values and heritage."

Another reaction to the basic skills charge of the media has been the establishment of The Council for Basic Education, located in Washington, D.C. A nonprofit organization comprised of parents, teachers, administrators, legislators, and others concerned with basic skill education, this council stresses one goal for education, namely, the teaching and learning of basic subjects: English (including reading, writing, speech and literature), Mathematics, History, Science, Foreign Languages and the Arts. According to a list compiled by this organization, alternative fundamental schools are located in 21 states. Because they offer parents a "choice" within the public school system, these schools are considered alternatives.

In principle, the fundamental school movement is not limited to elementary students. Abramowitz et al. (1978:11) conducted a survey of 2,000 public high schools in rural (52 percent), suburban (28 percent), and urban (20 percent) areas which included 13 percent of the United States public secondary schools. The average size of school represented in this study was 1,000 (Abramowitz et al., 1978:12). The survey was a joint project of NIE (National Institute of Education) and NASSP (National Association of Secondary School Principals). Although rural schools made up the majority of the represented schools, principals involved in this survey reported "teaching the basic skills" as the number one preferred goal for their school, wherever located (Abramowitz et al., 1978:51). 
Similarly, Schaefer and Polk (1967) and Etzioni (1981)

emphasized basic skill development. However, these theorists spoke of this goal in combination with other aims and goals. For example, Schaefer and Polk (1967:224) discussed general or basic education in a "whole student" context:

We assume that all children and youth must be given those skills, attitudes, and values that will enable them to perform adult activities and meet adult obligations. Public education must ensure the maximum development of general knowledge, intellectual competence, psychological stability, social skills, and social awareness so that each new generation will be enlightened, individually strong, yet socially and civically responsible.

A basic education was only part of four themes they outlined:

"General Education for Adulthood, Education for Work, Maximum Development of Talent, and Rehabilitative Education" (Schaefer and Polk, 1967:224-225). Somewhat differently, Etzioni (1981) argues that public schools should teach basic skills in conjunction with moral education and character-building for future adult and citizenry careers.

Humanism is a second theme which prevails in the educational literature of the 1970's. The National Education Association, in Schools for the 70 's, charged that schocls must become more responsive to youth's needs. Broadly speaking, the terms humane and humanism refer to the policies and procedures employed in school organizations to promote the dignity and worth of men and women and their capacities for self-realization. Humanism in the schools includes intellectual development as only part of the whole person. 
Consistent with this emphasis, Perel and Vairo (1969) and Silberman (1971) argued for a holistic education. In particular, these authors joined the National Education Association (1971) and insisted that emotional, social, aesthetic, spiritual, and physical development should accompany the intellectual learning presently found in secondary schools. Silberman (1971:208) explained how schools should be changed:

Schools can be humane and still educate well. They can be genuinely concerned with gaiety and joy and individual growth and fulfillment without sacrificing concern for intellectual discipline and development. They can be simultaneously childcentered and subject--or knowledge--centered. They can stress esthetic and moral education without weakening the three R's.

Abramowitz et al. (1978:52) found that 33 percent of the surveyed principals considered "developing esthetic appreciation" as the seventh most important educational goal. Additionally, Cusick (1981) and Etzioni (1981) stressed the development of a "sense of community" in successful schools with humane climates. For example, Cusick argued that schools are already individualized, specialized, and diversified, giving the example of one high school that offers 31 English courses. Cusick (1981:5) delineates the following factors which are crucial in effective schools, referring to the findings of the Rutter et al. (1979) study of London secondary schools:

It concluded that students performed in those schools where the students resembled a group with common norms and expectations, and where teachers planned together, supported one another, and held mutual expectations for student behavior.

Because schools play an important role in the socialization and preparation of youth for adulthood, due partially to prolonged school 
careers, the assertions that schools must first become more humane, and second, that they must recognize the "whole" youth, cannot be denied. The ways in which schools have become more humane, effective, or quality schools will be discussed in greater depth later. Now let us turn to a third area of goal recommendations.

A third area of goal recommendation concerns secondary schools preparing youths for successful transition to adulthood. The transition of youths to adulthood involves preparation for college, for employment and the world of work, for citizenship and character building, and for a changing society.

Frank Brown et al. (1973) in a study funded by the Kettering Foundation, The Reform of Secondary Education: A Report to the Public and the Profession, directly examined the high school as a social institution and outlined 35 need areas. Sources of data included regional hearing reports and surveys of national panels of teachers, parents, students, and administrators. A rationale for the improvement of the high school followed each of the 35 recommendations. Suggestions are made to increase the relevancy of the educational process of youths and prepare them for worthwhile adulthood.

Also, Martin et al. (1974) of the National Panel on High Schools and Adolescent Education, in Report of the National Panel on High Schools and Adolescent Education completed for the U.S. Office of Education, present six structural and conceptual changes needed for the reformation of high schools. First, they assert that adolescents should be educated to become full and responsible members of society. A school climate that recognizes individual differences is a second 
recommendation. Preparing youth for familial and work roles, as well as more school and community integration, are the third and fourth recommendations. Teaching of effective decision-making is another suggestion, and finally, the promotion of aesthetic experiences and knowledge of media influences is the sixth goal advised by the panel. All of these goal suggestions are advanced with the aim of providing youths with skills for a successful transition to active citizenship in the world of work and the community.

A second area of preparation for a successful transition is the matter of college entrance. College preparation was one priority set forth by Conant (1959) in his organizational goals for the comprehensive high schoocl. More receritly, the Abramowitz et al. study listed preparing students for the college as one of the seven very important educational goals identified by 54 percent of the sampled principals. In that particular study, that goal ranked sixth in a list of seven most important goals (Abramowitz et al., 1978:98).

Preparing youths for the world of work is an educational goal often cited in the educational literature (Abramowitz et al., 1978; Brown et al., 1973; Carnegie Council, 1979; Coleman et al., 1974; Jackson, 1978; Martin et al., 1974; Schaerer and Polk, 1967). For example, the Carnegie Council on Policy Studies in Higher Education, in Giving Youth a Better Chance, stress the need for attention to the non-academic or non-college bound student. The Council argues that youth manpower and other employment programs are of ten initiated for high school dropouts, but in fact, in-school youths not headed for college require work preparation too. 
Because of the changing nature of the technological world in which youths now live, certain aspects of the industrial society demand consideration by educators and are listed by the Carnegie Council (1979). First, the transition from schools to employment is more abrupt in today's society, unlike early times when work was carried on at a parent's home, shop, or farm. Fewer youths follow the career or occupation of their parents and they have a wider variety of choice or "surfeit of opportunities" (Ornstein et al., 1975). Second, the Carnegie Council (1979:16-17) maintains that schooling is

prolonged for longer periods of time and the entrance of youths into the workplace is extended:

We have greatly prolonged youth--the period from adolescence to adulthood. He have created what might be called "compulsory youth" $=-$ a substantial time between dependence and independence, a twilight zone of uncertainty and ambiguity of status. There are some good explanations of why this period is now longer; among them, in particular, is that biological maturity comes earlier and full acceptance by the institutions of the adult world comes later. And it does take more time than in earlier days to accumulate job skills; to try out the market to see what it wants and what the young person realistically has to offer; to make decisions about lifestyle as well as vocation; to decide on geographical location and possible life companions. We have created a new stage of young adulthood.

Third, in industrial society, entrance into the world of work is accompanied by less moral support from primary group members. Because contemporary youths are generally unattached and single, have exited schools, and are experiencing increasing detachment from family members, they are for the most part alone in this transition. In summary, Abramowitz et al. (1978:52) found that "preparing students for work" was rank ordered fourth in importance for seven 
measured educational goals and of the surveyed principals, 67 percent reported this goal to be very important and it was rank-ordered higher than "preparing students for college." Specifically, the Conference Report of the National Committee on Secondary Education, sponsored by the National Association of Secondary School Principals (NASSP), in American Youth in the Mid-Seventies (1972:97) focused on work as a viable part of astion learning for youths and argued that credit should be given for valuable work experiences: "Action-Learning experience is a useful and desirable educative experience for all kinds of youth, and should be integrated into the total educational program of a community."

Let us now turn to a fourth subarea of transition to adulthood, moral character-building and preparation of citizenship skills. Etzioni (1981:65) maintains that character-building is a responsibility of the schools and is more important than teaching basic skills:

We ask schools to attend to a very large variety of missions with fewer resources and fewer rights than in the past, and the result is that the schools are overloaded and very often misdirected because they do not perceive that the number one issue is not to teach reading and writing but to help teach character building.

Etzioni's proposal for one year of youth service is briefly presented in Chapter II. He promotes such a notion so that youths would be sufficiently prepared, both as citizens and employees, for the adult world.

Like Etzioni, Jesse Jackson (1978) advocates an education to build character and to develop minds. He calls upon students to 
challenge themselves and make the schooling system work for them. Jackson (1978:193s) does not suggest school reform, rather, he directed students to challenge themselves and utilize the schools to their advantage: "They must know that it is not their aptitude but their attitude that will determine their altitude."

In a broader context than Jackson, Clift (1976) views educational institutions as social problem solvers. Nonetheless, Clift (1976:43) charges that the schools have not yet prepared youths as citizens to deal with social issues adequately:

Traditionally the American public schools has achieved the expected amount of success in teaching the fundamentals, or the three R's. But the public school has never done as well as it should have in achieving the goals Horace Mann, John Dewey, Henry Bode, George Counts, William Childs, and other progressive educators sought. It has not discharged adequately its responsibility in preparing citizens for a democratic society. It has not imbued citizens with the ideals that are consistent with democracy. It has not prepared citizens to deal with the issues and problems that confront society.

Abramowitz et al. (1978) found that "developing high moral standards and citizenship" was the second most important educational goal of the seven measured goals. Over 80 percent of the principals responded that this goal was very important, second only to "teaching the basic skills" (Abramowitz, 1978:52).

Changes in school governance procedures has been suggested to give students an active role and "hands on" experience in the democratic process (Brown, 1973; Martin, 1974). In particular, Brown (1973) and Martin (1974) propose significant changes in school governance in order to involve students in deciding administrative matters and policies for their schools. The two reports advocate 
participatory and shared decision-making, involving community members, parents, administrators, and students.

Finally, preparation for a changing society is a transition goal for youths presented by theorists (NASSP, 1975; Schools of the Urban Crisis, 1969). The NASSP document Secondary Schools in a Changing Society: This We Believe (1975:1) argues that society has changed and the school structure must be reformed to reflect these alterations:

The clear social trend of recent years has been for increased individual choice and personal freedom. Among the forces fueling this movement are these: (1) a broadened legal interpretation of constitutional rights, (2) a strong thrust for equality of sex and race, (3) a growing affluence which released economic constraints upon choice, (4) rearing practices which focuses upon the needs and demand of the growing child, (5) an erosion of family stability, (6) an increased allegiance to individual options as against social obligations, (7) a public mood to experiment, to replace tradition and social custom with personal lifestyle.

This document argues that America is now composed of a pluralistic society with diverse values.

Additionally, The Schools of the Urban Crisis (1969) claimed that American schools operate with an assimilationist's perspective which must be altered to recognize the present mixed culture. Specifically, these studies (NASSP, 1975; Schools of the Urban Crisis, 1959) charged that students need to be educated with the knowledge that society is changing and the school technologies and procedures that were effective and appropriate a decade ago are not necessarily applicable now.

Finally, a fourth goal area which is cited throughout the literature (Abramowitz et al., 1978; Brown, 1973; Coleman, 1974; Martin, 1974) is the need for the development of the individual's 
talents, responsibility for learning, and respect for others. In the Abramowitz et al. study, "teaching students to get along with others" and "developing individual responsibility for own learning program" are ranked third and fifth, respectively, among the seven goals listed. Over half of the principals considered them to be very important (Abramowitz et al., 1978:98).

As early as 1967, Schaefer and Polk (1967:225) wrote that the schools should develop the talents of the individual:

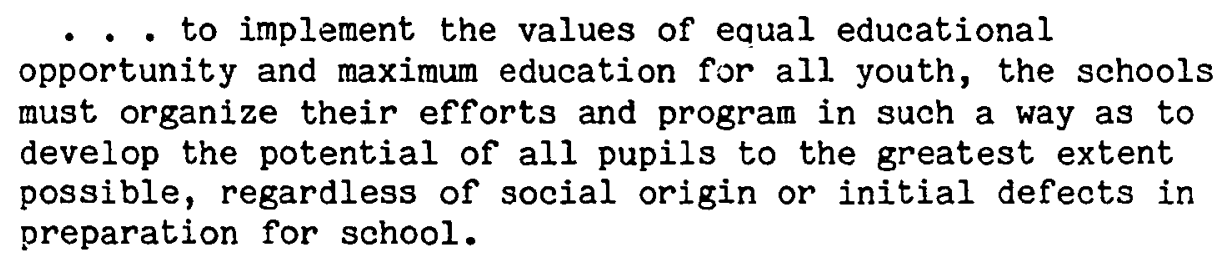

Furthermore, Coleman, Brown, and Martin advocate a policy of disperson for youths. This recommendation means that youths would be dispersed into the workplace at earlier ages in order that schooling and working would be an integrated experience. Such a policy would require that schools adopt policies of individualization and flexibility. In particular, Coleman recommended that schools foster policies to promote individual initiative through intense project development and management of one's affairs.

TECHNOLOGIES OF CONVENTIONAL HIGH SCHOOLS

This section deals with the technologies utiiized by conventional secondary public schools over the past decade. Technologies of a school organization are defined as the instructional practices, approaches, and programs employed to reach set goals. 
Figure 2 in Chapter II outlined a geographical patterning of conventional high schools, drawing distinctions between the divergent technologies various socioeconomic school types apply. Technologies employed in conventional high schools will now be examined in depth.

The inventory of school techniques is nearly limitless. A review of the literature disclosed the following to be the most central to this discussion: curriculum, school size, and academic tracking. Curriculum in high schools is examined first.

\section{Curriculum}

The first order of business is to define the term curriculum. For our purposes, the curriculum will be defined as a set of courses offered by an educational institution. Also, scheduling practices and the matter of who makes curriculur decisions are included in this discussion.

What is the state of affairs of high school curricula? Buser and Manlove (1969), Abramowitz et al. (1978), and Tubbs and Beane (1981) have presented the curricula of conventional public schools, drawn from national surveys. The Buser and Manlove study consisted of a follow-up study of a survey first initiated by Buser and Humm (1970) in 1965. In 1969, questionnaires were sent to 271 public North Central high schools in 19 states and responses were compared to the 1965 survey. Similarly, the Tubbs and Beane study compared data collected in 1974 and 1979 in an attempt to measure the current status of high school curricula. In their study, 500 randomly selected high 
schools were surveyed. As previously discussed, Abramowitz et al. (1978) canvassed the opinions of 1,448 principals in their national study.

As in Abramowitz et al., in the Tubbs and Beane study the opinions of prinsipals from rural high schools were overrepresented. Buser and Manlove categorized the schools in their study by faculty size, while the Abramowitz et al. study classified them by the national region of their location.

What does the typical high school curricula include? The course of study is comprehensive and subject or department centered with department heads. Abramowitz et al. (1978:15) found all surveyed schools offering comprehensive curricula that included academic and vocational courses:

Virtually all the high schools in our sample provide a standard academic curriculum, with courses in biology, chemistry, physics, and a mathematics sequence through grade 12; they also require all students to take English through 11 th grade. Almost every high school also offers the usual courses for non-college-bound student: business education, homemaking, wood or machine shop and art.

Similarly, Buser and Manlove stated that 90 percent of the sampled schools were departmentally organized, even so, there was a statistically significant increase in the use of department chairpersons in small schools. For example, 68 percent of the smait schools reported the use of department heads in 1965 and 88 percent in 1969. The typical large school had a curriculum specialist and department chairperson and satisfaction with the departmental organization was reported by persons surveyed (Buser and Manlove, 
1978). Finally, the Buser and Manlove (1978:318) study concluded

that: ". . there is no discernible trend away from the traditional

departmental organization."

Tubbs and Beane (1981:215) found subject-centered curriculum arrangements in both the 1974 and 1979 surveys and they describe the practice:

As with the 1974 respondents, those in 1979 indicated that separate subjects, departmentalization, and vocational preparation dominant curricular arrangements in the high school. Other arrangements such as core programs, independent study, courses deaing with social issues, and small group instruction are provided by some schools but at markedly lesser degrees than in 1974 . . . Thus while numerous suggestions have been made for change in the high school curriculum, data gathered in this study suggest a generally standardized program across schools with little variation from the historical stereotype of the subject-centered curriculum.

Somewhat differently, Abramowitz et al. (1978) present a contradictory situation concerning course offerings. On one hand, curriculum offerings had expanded to include enrichment classes, electives or options, and nonclassroom credit experiences. On the other hand, the surveyed principals report the teaching of basic skills to be their number one concern. Under continuing budget cuts, schools are offering more diversity but within limited managerial mandates. Abramowitz et al. urge the canvassing of students and teachers to obtain a clearer picture of the extent of diversity and choice being offered in high schools.

Traditional scheduling practices, with classes meeting at fixed time periods every day is the dominant pattern (Buser and Manlove, 1969; Tubbs and Beane, 1981). In one study, 87 percent of the sampled 
schools used traditional scheduling practices, and only 7 percent of the schools had modular scheduling. Of the schools which maintained modular scheduling, 70 percent were small schools, containing 40-69 teachers (Buser and Manlove, 1969:316-317). Likewise, Tubbs and Beane found that a high percentage (88.3) of the schools in the 1979 survey were applying the standard period schedule. Abramowitz et al. found 85 percent of the schools they studied with traditional periods from 35 to 60 minutes long.

A final area of curricular discussion pertains to the question of who makes curricular decisions. Tubbs and Beane (1981) find a decline in student and community involvement in the 1974 and 1979 surveys. At both times, teachers and administrators are more involved than other groups.

In summary, the national picture shows that secondary public schools continue standard scheduling practices, offer traditional comprehensive curricula with some diversity, and are subject or department-centered. Furthermore, curricular decisions are made by educational professionals. An even closer inspection of four basic subject areas (Social Studies, Science, Mathematics, and English) is undertaken in order to peer more closely at high school curricular affairs.

\section{Curriculum: Social Studies}

Two national studies have provided data on the present state of the art of Social Studies. First, Hazel Hertzberg (1981) is one of twelve consultants who participated in Project Span, funded by the 
Social Science Education Consortium located in Boulder, Colorado.

Other consultants include elementary and secondary teachers, supervisors on the school district and state level, university teachers, and professional associates. Five volumes concerning the present state of the art of Social Studies were published, including The Current: State of Social Studies, authored by Hertzberg. In 1976, the National Science Foundation funded three studies pertaining to the status of Science, Mathematics, and Social Studies education. These were initiated in order to establish an information base for policy and program decisions for pre-college education. This research consisted of a national survey of administrators (Gross, 1977), a large literature review of the various technologies and instructional practices utilized over the last 20 years, and in-depth ethnographic case studies of 11 school sites providing qualitative data on the processes of teaching the sciences at the classroom and building level. Social Studies includes History and Social Science education. Drawing particularly on the studies of Gross (1977) and Shaver, Davis, and Helburn (1979), Hertzberg (1981) lists the course offerings of Social Studies departments as including Black and Ethnic History, Women's History and Family History. Multicultural education is alleged to serve two purposes: to give students a strong and positive self-concept, and to develop respect for other people. Multicultural education is taught with the perspective of pluralism rather than assimilation as a basis for nationality (Hertzberg, 1981). In 
general, more elective courses are offered and integrated with required History classes, but nevertheless, enrollment figures in these courses overall are declining.

The situation of history is critical in both secondary and higher education institutions. Students maintain that History is irrelevant. Both secondary schools and colleges respond to the decline in interest with much experimentation in the 1970's. Hertzberg (1981:154) has reported:

In the colleges in the 1970s, there was probably more experimentation in history teaching than there had been for several decades. This trend was quite similar to developments in secondary school history, incorporating a focus on specialized topics. Renewed activity by the professional associations, classroom experimentation, and the advent of the magazine on teaching helped to create a new generation of historians with considerable interest in teaching.

Furthermore, Gross (1977) noted a national decline in the number of high schools offering U.S. History. As many as half of the students in American junior and senior high schools did not take American History or U.S. History in their ccurse of study (Gross, 1977). Gross' study revealed that of 22,737 U.S. public secondary schools (grades 7-12), 53 percent offered U.S. History and 51 percent offered World History, with 27 percent and 17 percent of the students enrolled in U.S. History and World History, respectively. Gross observed that the enrollment declines varied by school district and state.

In part, refering to the Gross (1977) study, Hertzberg (1981: 156) explains that the substitution of Social Science course offerings 
for History electives has caused an increase in Social Studies

enrollments, but overall, the enrollments in Social education have

experienced a decline:

The percentage change in high school economics was +102 percent, in sociology +175 percent, and in psychology a whopping +323 percent. These courses, however, enrolled a relatively small number of students. In grades 7-12, economics was taught in 36 percent of the schools, and it enrolled 7 percent of the students in these schools. For the same grades, sociology was also taught in 36 percent of the schools with 8 percent of their enrollments, while psychology was taught in 35 percent of these schools, with 9 percent enrolled. Other figures reported were for area studies, taught in 14 percent of the 7-12 grades with 5-14 percent enrolled, and ethnic studies, in 10 percent with 17 percent enrolled. Anthropology appeared in only 6 percent, with 5 percent enrolled, while law studies appeared in 14 percent of grades $7-12$ with 7 percent enrollment.

An examination of teaching strategies found continued use of textbooks, recitation, and the large group lecture method (Gross, 1977; Hertzberg, 1981). Recommendations made in the 1960's and early 70 's to take social education out of the classroom, to use the inquiry method, to debate controversial issues, and to apply the many new materials offered, has been heeded only to a limited extent.

Shaver, Davis, and Helburn (1979:152) have argued that the continued use of the textbook by teachers causes alienation of students :

Ironically, perhaps a major concern of social studies teachers is with student motivation--lack of student interest and dwindling willingness to do assignments just because the teacher says they are worthwhile. Despite being perplexed by student apathy, teachers generally do not make the possible connection between the lack of motivation on their students' part and their own reliance on textbook/ content based, teacher dominated instruction. 
Similarly, Fernadez, Massey, and Dornbusch's (1976) survey of students' opinions among 800 urban high school youth found that Social Studies courses are viewed as less important and interesting than other high school subjects. Also, students maintained that they were more interested in earning a grade than obtaining knowledge when taking Social Studies classes.

Surprisingly, in another study, 57 percent of the sampled teachers state that Social Studies is not an important subject (Hertzberg, 1981). Furthermore, they criticize professors and curriculum planners for not considering classroom management realities and socialization goals when calling for the utilization of new Social Studies programs and suggesting that teachers take Social studies beyond the classroom walls (Hertzberg, 1981). Gross (1977) argues that 78 percent of the sampled principals lent support to the Social Studies programs in their secondary schools. The status of Science and Mathematics is now undertaken.

\section{Curriculum: Science and Mathematics}

The work of Iris Weiss (1978) revealed the state of affairs of Science and Mathematics in secondary schools. The National Science Foundation awarded funds to the Center for Education Research and Evaluation to survey the nation's teachers, principals, superintendents, supervisors, and district program questionnaire respondents (surveyed parents). In an attempt to assess the condition of Social Studies, Mathematics, and Science education on all levels, 11,103 educators were sampled. The survey results are similar to 
those already described for Social Studies. In general, a review of the findings of the Weiss (1978: Appendix B-59) study revealed that teaching strategies demonstrate that teacher prefernece for the textbook and whole group instruction in both subject areas. For example, 73 percent and 62 percent of the teachers expressed partiality for textbook programs in Math and Science, respectively. In Math instruction, teachers used a mixed strategy approach. That is, teaching strategies included lecture (72 percent), discussion ( 69 percent), individual assignments ( 52 percent), teacher demonstrations (28 percent), and students working at chalkboard (20 percent). The mixed Science strategies for the same grade levels included discussion (52 percent), lecture ( 42 percent), individual assignments (25 percent), and students using "hands on" materials (12 percent). For the most part, this report maintained that traditional methods of teaching, primarily lecture and discussion, were the most frequent instructional arrangements.

The Weiss (1978:159) study also surveyed 18 factors that negatively affected instruction including inadequate facilities, insufficient funds for purchasing equipment and supplies, lack of materials for individual instruction, lack of student interest, inadequate student reading ability, and low enrollments in Math and Science courses.

Twenty-six percent of the Science teachers surveyed in the Weiss (1978:159) investigation referred to inadequate science facilities as a serious problem. In fact, this difficulty ranked third among 18 possible problems. Principles and district program questionnaire 
respondents insist that inadequate science facilities are a serious problem. The second most serious problem for science teachers is insufficient funds for purchasing equipment and supplies. Also, principals, district respondents, and supervisors report this difficulty as a major problem. Lack of materials for individualizing instruction is the number one problem for Science teachers and the third most serious problem for Math teachers. Lack of student interest is a fourth factor which affected instruction for secondary level students, 20 percent and 30 percent of the teachers in Science and Math, respectively, report a lack of student interest to be a serious problem. Fifth, inadequate student reading ability is a problem recorded by all groups in the survey. According to the Weiss (1978:160) findings, as many as 40 percent of the Math and Science teachers in grades 10-12 refer to this problem as very serious (Weiss, 1978:160). Finally, a seventh factor which impacted instruction, low enrollments in courses, ranks fourth among problems according to principals in schools with grades 10-12. In Math, state supervisors also report this problem to be serious.

\section{Curriculum: English}

The status of secondary English programs has not been studied comprehensively on the national level since 1968 (Squire and Applebee, 1968). However, Shuman (1981) collected forecasts for English education in the $1980^{\prime} \mathrm{s}$, and Abramowitz et al. (1978) gathered information concerning secondary requirements for English. These three documents will be used to portray the present situation of English curricula. 
In 1968, Squire and Applebee published a report on 106 high school programs with reputations for achieving outstanding results. The study was funded by the National Council of Teachers of English and was conducted by members of the English and Education Departments of the University of Illinois. Each school's program was measured through observation, individual interviews, group meetings with teachers and students, and questionnaires. The schools represented the best English programs in the 45 sampled states. Squire and Applebee (1968:v) maintained that all types of high schools were represented: "Although schools were selected largely for their reputation in English, many of their programs and practices are not unlike those in schools throughout the nation."

In an attempt to forecast and discuss the issues and ideas that English departments would confront in the $80^{\prime} \mathrm{s}$, Shuman (1981) collected papers from English professors and elementary and secondary teachers. The Abramowitz et al. (1978) study, reviewed in other sections of this thesis, represented a national survey of secondary school principals and included data on English curricula.

What does the course content involve? First, Abramowitz et al. commented on the extent that English courses were required. Aìramowitz et al. (1978:74) stated that 99.1 percent of tenth graders, 95.9 percent of eleventh graders, and 65.0 percent of twelfth graders were required to take a full year of English. In the area of English course content, Squire and Applebee stated that Literature, Composition, Language, and other courses were emphasized in classroom teaching 52.2 percent, 13.5 percent, and 18.6 percent of the time, 
respectively. That is, Literature was taught in the classroom over half of the class time allocated. A delineation of other courses and the time included: Speech, 4.9 percent; Reading, 4.5 percent; Mass Media, 1.3 percent; no content, 0.8 percent; other, 7.1 percent (Squire \& Applebee, 1968). The authors claimed that the amount of time devoted to various content areas fluctuated according to the ability group being taught. For example, students in the college preparatory track received more literature time, while the lower tracked students spent more time working on grammar and writing mechanics.

Another content area which has received more notice in English publications is reading. Palmer (1981:57) discussed the goals English teachers should have when teaching reading:

Instead of letting students become passive indentifiers of letters and words, English teachers of the $80^{\circ} \mathrm{s}$ must encourage them to become active searchers for meaning during reading. We will also need to help students expedite this process. Instead of perpetuating instruction in reading with a set oi discrete and fragmented skills, we must help students go directly from graphic language to meaning-without getting needlessly bogged down in the process.

Theodore Hipple (1981) made forecasts for future English courses. He argued that the "back to the basics" movement caused an overall decline in English electives but predicted a return to electives in the $80^{\prime} \mathrm{s}$ with more caution and limitations than in the 70's. Another prognosis made by Hipple was that more instruction and courses for English teachers would be supported by universities, due in part to falling college enrollments and stronger teacher unions. Finally, Hipple (1981:29) asserted that more alternatives will be offered to English students: 
In sum, more teachers in the $80^{\prime} \mathrm{s}$ will give more students more options about more of the literature being studied. The lock-step beat--Act II for tomorrow, Act III for nexi Monday-that 11 must march to in unison will not disappear, nor should it, but the classroom in which lots of different students are doing lots of different things at the same time will be much more in evidence.

Teaching strategies were surveyed by Squire and Applebee (1968). Generally, findings indicated that traditional approaches to teaching English were being used in the late $60^{\prime} \mathrm{s}$, that is, lecture and recitation were the dominant modes of teaching, used 21.1 percent and 22.2 percent of the time, respectively. Other methods reported by Squire and Applebee (1968:45) included: discussion, 19.5 percent; student presentation, 14.3 percent; socratic questioning, 2.2 percent; group work, 1.9 percent; audio-visual, 1.6 percent; other, 6.8 percent. Textbooks were reported to be a strength of a good English program in the Squire and Applebee (1968:24) study:

Also characteristic of outstanding English programs is an adequate supply of books and learning materials. A rich collection of textbooks in every classroom, a well-siocked, accessible library, supplementary books and learning resources, and classroom book collections add substantially to the effectiveness of any program; when these are inadequate or unavailable, the quality of instruction must suffer.

Shuman (1981) advocates that a new perspective, pluralism, be implemented in the teaching of English in the $70^{\prime} \mathrm{s}$ and $80^{\prime} \mathrm{s}$. The pluralism perspective reflects a respect and appreclation for all people, their language, and their cultural patterns. Shuman (1981:11) emphasizes this need:

- . ways of reaching the diverse clientele of today's educational institutions, elaborating on how to benefit from all that a pluralistic society has to offer without allowing the pluralism of that society to be divisive to its members. 
Teachers' and students' opinions concerning English programs were gathered by Squire and Applebee (1968). Teachers maintained that strengths of English programs centered about the following: (1) they have freedom from administrative supervision and are involved in goal setting; (2) they claimed that their quality staff affected the English program in their school in positive ways. Weaknesses noted by teachers included: (1) the practice of ability grouping or tracking in some schools, (2) problems with articulating defined objectives, (3) a lack of skill and content sequence, and (4) adverse teaching conditions having a demoralizing affect on programs in some schools. Squire and Applebee (1968:24) found that teaching load was another weakness reported by sampled teachers:

\footnotetext{
- - average pupil-teacher ratios in excess of 150 , five classes per teacher, committee assignments, lack of preparation periods; yet in one fourth of the schools a deliberate attempt has been made to conform to the general standards recommended by the National Council of Teachers of English and the Commission on English of the College Entrance Examination Board. Where efforts were being made to restrict loads to four classes, totalling not more than 100 pupils, with time for paper grading, conferences, and preparation, morale seemed higher and instruction better. Although factors such as the quality of the staff, the leadership in the department, and the resources available were sometimes more obvious in their efforts, a substantial number of observers agreed that load remained a critical factor in the overall excellence of the program.

Reflecting different points of view, students suggested changes
} in language, composition, and reading, in that order. Language, interpreted as writing mechanics and grammar, was cited by students as being too tedious and boring. They felt that the literature and composition areas of their programs were adequate but could be improved. In particular, students recommended an increase in creative 
writing exercises in composition classes. In reading, students asked for more variety and an abundance of books. The lowest tracked students expressed negative attitudes toward too much drill, workbook assignments, grammar and writing exercises, and they also stated a desire for more literature.

Concerning research in English curricula areas, an updated national study would be appropriate so that speculation about the current scene could be validated. Specifically, O'Donnell (1981:159) called for a cooperative research attempt between classroom teachers and university researchers to solve problems in English, particularly the lack of sequence and he asserted:

Cooperative efforts involving scholars who have mastered their discipline and are knowledgeable about research design and data analysis and classroom teachers who understand the purposes and techniques of meaningful research can move us toward solutions to the problems that have remained unsolved. Perhaps research developments in the decade of the $80^{\prime} \mathrm{s}$ will move in that direction.

In summary, the reviewed studies demonstrate that the four basic subjects (Social Studies, Science, Mathematics, and English) have not changed significantly in curriculum content. Traditional course contents were still the norm, with some experimentation taking place in Social Studies and English. All four subject areas maintain conventional teaching strategies. Extensive national studies are needed to assess the current status of these subjects in order to ascertain the answers to questions such as: what are students' opinions concerning the course content of English electives, whether mixed teaching strategies are utilized in the four basic subjects, what percent of high school students in upper division Math and 
Science course are female and minorities, what is the scope and sequence of English courses offered across the United States. Another facet of public high schools, namely large school size, is now discussed.

\section{School Size}

Comprehensive high schools of 750 students were advocated by Conant (1967) for reasons which included financial efficiency. There is not universal agreement on how large or small schools should be. Scholars (Allen and Greenbérger, 1978; Barker and Gump, 1964; Barone, 1980; Beckner and O'Neal, 1980; Brimm and Hanson, 1980; Garbarino, 1978, 1980; Miller, 1970) have agreed that there are intangible and unmeasurable benefits for students in smaller, less comprehensive high schools. For example, large school size may be one variable which contributes to vandalism, school crime, and delinquency (Allen and Greenberger, 1978; Garbarino, 1978, 1980). Garbarino argues that academically and socially marginal students in large schools are less likely to be involved in extracurricular activities or social involvement which can complement academic achievement or school success.

Barker and Gump (1964) studied the effects of size upon the behavior and experience of students in a three-year longitudinal study of 13 high schools. Barker and Gump (1964:62) found that there were insignificant differences in the variety and richness of large and small schools:

The extent of which school size was related to the richness of offerings depended upon the measure of richness employed. The variety of index, which reflects only major degrees of 
diversity among settings, showed relatively little richness difference between large and small schools. When heterogenity within varieties was investigated, it was found that large schools provided about four times as many kinds of athletic settings and twice as many kinds of academic settings as the smallest schools. In general, the smaller schools managed to sustain a large proportion of the types of offerings provided by the larger schools.

In effect, the authors maintained that the social life in small schools was significantly different from that in the larger schools. Students in the smaller school.s were twice as likely to be involved in extracurricular activities. Also, students in smaller schools participated in a broader variety of extracurricular activities. Finally, a larger portion of students in small schools held positions of importance and responsibility. Their findings led Barker and Gump (1964:114) to comment:

The question might be raised: Which school size provided the "better" nonclass experience for its Junior inhabitants? To the extent that one believes that the satisfactions related to competence, challenge, activity, and group affiliation are better than those related to vicarious enjoyment and to large entity affiliation--to this extent, small school Juniors reported better experiences than did large school Juniors.

Small schools have been advocated by theorists (Barone, 1980; Beckner and 0'Neal, 1980; Brimm and Hanson, 1980; Garbarino, 1980; Miller, 1970) for other reasons as well. For example, Barone (1980), Beckner and O'Neal (1980), and Brimm and Hanson (1980) list less bureaucratization, more interpersonal interaction between students and teachers, easier implementation of new programs and ideas, better community and school board relations, fewer discipline problems, more individualization for student needs, a stronger sense of belonging, and shared values and goals as some of the benefits of smaller schools. 
Miller (1970) in The Oregon Small Schools Program examined the way rural and small schools were organized effectively and flexibly to meet the needs of students. Twenty-four percent of the state's 218 high schools were represented and analyzed in this three-year project. Small school benefits, not previously mentioned, included learning packets, flexible scheduling, no age grading, guidance and career education improvement, more choices in Language Arts, classes by phone, exploratory programs, and six-year high schools.

A study by Cullers, Hughes, and McGreal (1973) stood in contradiction to the writings of investigators who favor small schools. They focused on the relationship of leadership style and student satisfaction. Six public high schools in Illinois were investigated in two studies. The first study (Cullers, Hughes, and McGreal, 1973:159) utilized the Likert Profile of a School Questionnaire. The six principals of the schools and a random sample of teachers were surveyed in order to determine administrative style. A second study used a random sample to question students from each of the six high schools about school satisfaction. Their responses were analyzed by school size; two schools were categorized as small ( 800 students or less, two as medium ( 801 to 2,000 students), and two as large (over 2,000 students).

The findings of this study were contrary to the results of Barker and Gump, that is, students in the small schools reported more dissatisfaction with school. In particular, small school students exhibited a significant difference in interpersonal relations, academic pressure, rules and regulations, and activities and resources 
(Cullers, Hughes, and McGreal, 1973:161). In effect, small schools had authoritarian administrative styles, leading the authors to argue that variables such as administrative style may have an effect on students, independent of the school size variable.

Brimm and Hanson (1980) list financial problems, limited educational experiences, homogeneous student populations, heavily-focused college preparation curricula, and teacher isolation as drawbacks and weaknesses of small schools.

A final point concerns the optimal or most appropriate size for high schools. Various opinions exist on this subject (Coleman, 1974; Kozberg and Winegar, 1981). For example, Kozberg and Winegar (1981:566) suggest that school size be reduced but they state that 1,200 students is a manageable figure:

We define small in relation to the principal's ability to really know the students--their first names, last names, siblings, home life, after-school activities, special interests. There is no substitute for such knowledge. With a well-developed memory, the average principal should know at least $50 \%$ of the student body. Therefore, we define small schools as those with enrollments not larger than 1,100 to 1,200 students.

Coleman (1974) recommends smaller schools for similar reasons as Kozberg and Winegar (1981), namely, better interpersonal relations between students and staff. But, Coleman (1974:155) suggests an optimal schools size of 500 students:

Also, when a high school is larger than about 500 students, teachers no longer know the names of students they do not teach, and the principal no longer knows students by name. At about a thousand students, the principal becomes unable to distinguish whether a particular young person belongs to his school. 
Garbarino (1980:29) also discusses the complexity of the school size

debate and argues for the benefits of smaller schools:

The issues of school size provide a good illustration of the complex interaction of psychological, social structural, and historical forces in shaping the adolescent experience. The trends toward insreased retention of students for ever longer periods of schooling, the increased importance of minimal academic competence among "marginal" students, the decreased support systems promoting social control, and the increased size of schools form a kind of conspiracy against youth and, ultimately, the larger society. Small schools have become anachronistic at the same time that the need for them to promote social identity has grown markedly. In this case, the differences do make a difference.

Garbarino (1980:21) also maintains that research in the area of school

size is futile because there are no small public high schools left:

Burkhead (1967) said, for example, that in Chicago during 1961-1962 the range of high schools size was 620-4,085, with the average being 2,184 . Since virtually all the schools were in the large category, it is no wonder that little of the variance in educational outcomes (e.g., dropout rate) was attributable to school size. One can only demonstrate significant effects where the variance is substantive. In this respect, large schools--like television--have become so nearly universal that it is very difficult to find a meaning ful and ecologically valid difference to examine.

Let us now move on to another technology employed by schools, academic tracking and ability grouping.

\section{Academic Tracking}

Tracking and ability grouping by intelligence was a technology reported in half of the surveyed schools in the Abramowitz et al.

(1978) study. Among the many recommendations of the Carnegie Council (1979:24), one was that schools stop tracking students and instead, individualize programs. Two arguments against tracking are usually offered. 
The ways in which schools as social organizational structures process and sort students into academic ability groups has been studied by Hargreaves (1967) and Rist (1978), among others. Rist conducted a longitudinal study in Portland for one and a half years, observing one primary class within one classroom. In order to document the ways schools sort students into winners and losers, Rist (1978:21) recorded daily processes by which classroom practices (attitudes, values, beliefs about self and the world) were acted out. The value of using this methodology was maintained by Rist (1978:23) as :

Finally, it is only with long-term participation in a social system such as the school that one becomes aware of the subtle nuances, the brief references that have meaning only within that system, of the gaps between word and deed, and of the official notions of how the roles and tasks for various participants are defined. The privilege of sharing "inside" gossip and the personal feelings of the participants is not achieved by presenting a letter of introduction.

In effect, Rist's study supported the hypothesis that the school employed techniques that stratified children into groups of "winners" and "losers." Within the observed classroom, tracking followed a pattern of segregation based on the socioeconomic position of the student's parents. Teachers used differential treatment of students and held different academic expectations for them depending on economic status.

Hargreaves (1967) conducted a year long observational study of the way in which the social system of one all-male secondary school in northern England promoted or negated the streaming (or tracking) process at the school. Although this report is not on an American 
school, it has significant implications for a tracking discussion. Data were gathered on the school's social system through a variety of measurement techniques: student and teacher interviews, student questionnaires, and participant observations on the classroom and whole school level. The findings of Hargreaves (1967:89) demonstrated that teachers and students held varying perceptions depending on students' track placement: "The boys in lower streams not only regard the teachers less favourably, but also perceive their relationships with teachers as much less adequate." In part, this situation was due to teacher appointments for high and low tracks, based on competence and experience, putting lower-track students at a disadvantage. That is, tenured and seasoned teachers were assigned lowest-streamed boys. Hargreaves (1967:104) described this situation:

In short, the allocation of teachers to upper or lower streams on the basis of teacher competence reinforces the dominant trends of the peer group; the pupils in higher forms increase achievement and improve their relationships with teachers whom they life, and the pupils in lower streams become increasingly retarded and their relationships with teachers deteriorate to the point of mutual toleration at best and mutual hostility at worst.

The system at lumley School was one where the upper-stream subculture was characterized by values positively-oriented to teachers and school. Hargreaves (1967:164) concluded: "The boys and teachers at Lumley are products as well as components of the social system."

Other researchers (Kelly and Balch, 1971; Kelly and Pink, 1973a; Pink and Sweeney, 1978; Polk, 1969) have found that a student's position in school (academic, general, or remedial track position) was a stronger indicator of a student's commitment to school than social 
class position. They argued that rates of delinquency and school crime, involvement in extracurricular activities, orientation for educational expectations, and occupational aspirations were stronger indicators of track placement and school commitment than social class position. In other words, these investigators found that schools which employed tracking sorted students into groups of "winners" and "losers," independent of their social class position. To best the social class argument, Polk (1969), Keliy and Pink (1973a), and Ǩolly and Pink (1973b) analyzed data from a longitudinal study of adolescents in a medium-sized county in the Pacific Northwest. A random sample of sophomore males enrolled in the schools in the county in 1964 included 309 selected subjects, of which 284 returned questionnaires accounting for a 91 percent response rate. Dependent variables included social class (measured by the Hollingshead Index of Social Position and the Oregon Supplement) and school status (recorded Grade Point Average). The six related independent variables were: two measures of school involvement, two measures of extracurricular involvement, and two measures of future orientation toward educational expectations and occupational aspirations. In the Kelly and Pink (1973b:130) study, social class was associated positively with the independent variables but was not as strong a predictor as school status and they stated:

- - when contrasted against their failing peers, a much larger percentage of our academically successful seniors display positive affect, consider themselves smart, belong to clubs, value participation in clubs, expect to go to college, and aspire toward a professional occupation. (Kelly and Pink, 1973b:130) 
Additional studies (Kelly, 1976; Pink and Sweeney, 1978) investigated track placement to explore whether a sociall class bias characterized the tracking procedure. Kelly (1976) interviewed 478 Juniors and Seniors in a medium size working class community and found that curriculum assignments or track positions were not made according to race or father's occupation. Similarly, Pink and Sweeney (1978) sampled 141 seventh graders in a working class community in the Midwest and found that track placement did have an impact upon students and it was not dependent on social class, race, sex, or family size.

Why do schools employ a technology which causes some students to fail? The preceding studies concern two schools of thought on tracking but both arguments indict academic tracking for sorting students into different tracks and causing some students to fail. Moreover, unsuccessful students don't have a legitimate status in the school organization and this practice or technology of schools can increase the probability of failure for some students. Many educational theorists have urged that school organizations be altered so that nonfulfillment is not promoted through practices and procedures such as tracking to insure that the capabilities and talents of all individuals are developed. Kelly and Pink (1973a:484) also asserted that:

An important question that requires careful theoretical and empirical attention is why educators continue to type and to stratify students negatively, particularly in view of the mounting evidence suggesting that such school processes can not only seriously restrict students educational and occupational opportunities but may also play a major role in the generation of decreasing school commitment and subsequent increases in level of adolescent deviance. 
The next topic to be examined is the way in which variables work in successful combination in quality or effective schools.

\section{Effective Schools}

This discussion deals with the combinations of elements that create an environment, atmosphere, or ethos for student success. For example, technologies are interrelated to other variables which affect interpersonal relationships, school commitment, and social relations. Consistent with this emphasis on interrelated variables, educational theorists argue that variables may be combined at the individual school building level in such a way as to create a more successful school experience for youth.

Some have examined the determinants of school climates that influence the academic success of students, locus of control, and attitudes toward school at the elementary school level (Austin, 1979; Brookover and Erickson, 1969; Brookover, Schweitzer, Schneider, Beady, Flood, and Wisenbaker, 1978; Clark, Lotto, and McCarthy, 1980; Hersh, 1982). School climate was emphasized by Fox (1973:1) in the following passage :

A positive school climate is both a means and an end. A good climate makes it possible to work productively toward important goals, such as academic learning, social development, and curriculum improvement. It also makes school a good place to be, a satisfying and meaningful situation in which both adults and youth care to spend a substantial portion of their time.

The list of successful school variables presented by theorists includes: strong principal leadership, positive teacher expectations, positive parent relations, strong student self concepts, and 
agreed-upon goals. More specifically, Tornatsky, Brookover, Hathaway, Miller, Passalacqua (1980:52) list ten aspects of effective schools:

1. a clear expectation on the part of teachers that all students can be taught;

2. a corollary expectation on the part of students that they can learn;

3. a tendency on the part of staff to treat all students equivalently, rather than dividing them into homogenous groups of the "fast" and "slow";

4. an implicit or explicit adherence to mastery learning concepts (Bloom, 1976);

5. a tendency to use techniques such as group learning games (Slavin, 1977) to promote peer instruction and peer reinforcement of achievement;

6. a tendency to apply unambiguous rewards for achievement in the classroom;

7. a greater reliance on achievement test data as prescriptive for changes in classroom practices;

8. a maximization of academic engaged time (Berlinger, 1978);

9. a greater involvement of the principal in the ongoing instructional activity of the school;

10. an involvement of the parent in ways that support norms and expectations of student achievement.

Fox (1973) and Howard (1978) have provided how-to manuals for interested educators who wish to assess the climate of their school. in particular, Fox provided a checklist for schools willing to appraise their school and gave suggestions for implementing effective school elements. Howard noted and described 12 of Fox's 18 effective school determinants as they were applied to Cleveland High School in Seattle. The following results were observed: a decrease in school absenteeism from 35 to 5.6 percent, library use tripled and book loss 
decreased 70 percent, increased wins by the athletic teams, a decline in student requests including whether they would attend study hall (Howard, 1978:30). Academic success at Cleveland was indicated by the following evidence detailed by Howard (1978:31).

Sixty percent of Cleveland's graduating class now enrolis in college--up from $35 \%$ five years ago. The number of National Merit Scholarship finalists has increased by $50 \%$ in the past three years. The number of students receiving scholarships to college has increased.

Based on experience and theory, Edmonds (1982:4) found the

following elements necessary for an effective school:

The characteristics of an effective school are (1) the principal's leadership and attention to the quality of instruction; (2) a pervasive and broadly understood instructional focus; (3) an orderly, safe climate conducive to teaching and learning, (4) teacher behaviors that convey the expectation that all students are expected to obtain at. least minimum mastery; and (5) the use of measures of pupil achievement as the basis for program evaluation.

Edmonds took a "back to the basics" approach to raise students' achievement scores and create a school climate supportive for learning. Affective results were concerns of other researchers concerning effective schools but Edmonds was interested in standardized curricula, universal teacher expectations for student success, and standardized measurement instruments. He was chiefly concerned with increased student achievement and cognitive gains. Success was measured by Edmonds (1982:4-5) by the gains in mastery of skills made by both the lowest and highest social class students:

To be effective a school need not bring all students to identical levels of mastery, but it must bring an equal percentage of its highest and lowest social classes to minimum mastery. This measure of school effectiveness serves two broad purposes. First, it permits the middle class to 
establish the standard of proportionate mastery against which to judge a school's effectiveness. Second, it permits schools to be easily characterized as improving or declining as the proportion of the lowest social class demonstrating mastery rises or falls.

A closer examination of one study which analyzed the differences between effective and ineffective schools follows.

\section{Effective Schools: The Rutter Study}

The Rutter quality school study found, on the secondary school level, that individual schools did effect students differently, despite their similar economic background (Rutter, Maughan, Mortimer, Auston, and Smith, 1979). This is a report of non-American schools but it has significant implications for this discussion. Students from one burrough in London, England were followed through twelve secondary schools. The study probed for answers as to why different schools reported dissimilar examination scores, as well as attendance, misbehavior, and delinquency rates. In phase one of the study in 1970 , ten year olds who were finishing primary school and were on their way to secondary school were tested for noverbal intellectual levels and reading attainment. Family information was provided by teachers and a behavioral questionnaire was also give to the teachers of these children.

During phase two of the study in 1974, the same children were retested at age 14 or in their third year of secondary school. The same behavioral questionnaire was given to teachers to identify the number of children with behavioral and emotional problems. Also, an intelligence test and reading test were administered to the children 
in the 1970 study entering the secondary schools in South London. A comparison group of children was included from adjacent boroughs. There were 3,485 children in all: 1,998 in the comparison group and 1,487 cohort children in the original group.

Intake scores were standardized by the authors for all schools but despite this procedure, differences between the schools were not explained by intake scores. For example, the schools with the best intake scores were not the schools with the best outcomes, contrary to what might be expected.

The Rutter et al. (1979:28-29) study also focused on studying schools in depth and 12 schools were selected for the in-depth study:

They were chosen to represent the range of outcomes in terms of the findings in 1974 for third year children; and also to be representative of other obvious differences among the original twenty London schools. Thus, the twelve included both large and small schools, mixed and single-sex schools, voluntary aided (i.e., Church) and maintained schools, as well as some on single and some on split sites. All were non-selective and none had been academically selective in the past. All served London's inner city population.

Family backgrounds of the children in both study groups were reported to be similar. The nonverbal intelligence test and reading test given to both groups resulted in scores well below national averages. Students were assigned to secondary schools according to test scores, academic attainment, parental wishes, and neighborhood locations (Rutter et al., 1979:35-36).

A dual system of education existed with two degree preparations: the General Certificate of Education and the Certificate of Secondary Education. There were similarities and differences between the 
schools in the study. For example, the following statement by Rutter et al. (1979:41) exemplified the range of differences in goals:

The schools differed considerably in their educational aims, as expressed by the teaching staff. Some were firmly committed to the development of children's personalities as the most important goal whereas others saw the passing of examinations as the first requirement. In some, teachers tended to emphasize the teaching of moral codes; in others more stress was laid on making school an enjoyable and rewarding experience for the children.

A four part strategy was utilized to examine the schools' environments. First, the intake variables describing the individuals in the schools were compared. Second, the process of schooling was studied and characteristics of the school environments were examined. Third, the ways in which individual schools produced outcomes in students' academic achievement and behavior were measured. Finally, ecological influences were described.

Four strategies were utilized. First, regarding the intake variables, it was reported that children's attendance varied by the school they attended. Fifth year students showed the worst attendance rates for the age groups compared, but there were nevertheless significant differences between schools. A second intake variable was school behavior. Consistent patterns of disruptive behavior for any one group were not proven, as evidenced by the questionnaire completed by teachers. Exam scores compared for fifth year students showed statistically significant differences between schools and verbal reasoning groups (Rutter et al., 1979:85). Even allowing for verbal reasoning intake scores (intelligence scores) and parent's occupation, statistically significant differences were found between schools. 
Viewing school outcomes in this study and comparing them for students from similar social economic backgrounds, Rutter et al. (1979:93) insisted that individual schools make a difference:

As such measures included not only pupil behaviour and attainments at primary school, but also social background, it seems likely that the school variations in outcome are linked with characteristics of the schools themselves. In short, it appears that in part of inner London known to be disadvantaged in numerous ways, some schools were better able than others to foster good behaviour and attainments.

A second part of the Rutter et al. study involved an investigation of the organizational characteristics of school environments: (1) physical features, (2) administrative structures, (3) school process variables (academic emphasis, rewards and punishments, pupils' responsibilities and participation in school life, working conditions, and staff supervision), and (4) ecological variables (resource allocation, the distribution of power in society, educational ideologies, conflicts both within and between schools and political administrators, attitudes toward social control, and values attached to education by the public at large).

Two administrative features (voluntary-aid and sex composition) were linked to slightly better outcomes for schools with religious affiliation and/or mixed sex student bodies. In this study, the size of schools ( 450 to 2,000 students) did not significantly effect outcome measures nor was the age of buildings associated with better outcomes. Practices of grouping students by year, house, and academic ability did not significantly effect outcomes for any of the schools. 
This particular study did not focus on the in-depth analysis of physical and administrative variables. Rutter et al. (1979:105) found one variable which accounted for a strong relationship with outcome variables:

One concern in the present chapter has simply been to establish whether the outcome variations between the schools directly followed the lines of possible exception of the split site question, the findings clearly show that they did not, and suggest that it was possible for schools to operate effectively using a variety of administrative arrangements, and in spite of apparently unpromising premises. The most immediate obvious factors which differentiated between the schools has thus falled to offer any pointer to account for the outcome variations.

Next, school process variables were examined individually and in combination for their interrelated effects on school outcome variables. Individual school process measures were found by Rutter et al. (1979:141) to have similar effects on outcome variables although exceptions did exist:

\footnotetext{
- - we made comparisons such as between different measures of homework (as reported by teachers and by pupils, and as observed by us), between different types of reward (praise in the classroom, public praise in assemblies, etc.) and between different measures of interaction style. On the whole, different measures did produce similar findings although, as we have noted, this was not always the case.
}

Thirty nine process variables were found to have significant effects on one or more of the student outcomes (levels of attendance, children's behavior in school, delinquency, and academic attainment). Combined process correlation scores were computed for the four outcomes as follows: .92 for pupil behavior, .76 for academic achievement, .65 for attendance, and .68 for delinquency (Rutter et al., 1979: 142-143). 
Finally, ecological factors such as neighborhood features did not effect outcome variables. When balancing intake variables such as father's occupation and ability grouping, Rutter et al. (1979:159) found that ability grouping was a clearer predictor of student outcome in school. That is, students in higher academic tracks were more likely to identify with the goals and aims of the school and there was a greater chance of more positive school outcomes when there was a mix of academically successful students.

There were ten major conclusions reached in this study. First, there were differences in student outcomes in the 12 London secondary schools compared. Second, school experiences within the secondary schooling process produced outcomes at some schools that were more positive than in others. Third, the variations among the twelve compared schools remained stable over the four or five year period of the investigation. Fourth, successful schools consistently reported better outcome measures in all four areas. Furthermore, success as measured by outcome variables was not due to physical features or administrative arrangements. Sixth, these differences were due to school process variables. Seventh, intake variables did not explain school process. For example, some schools with students with low average intellectual ability scores produced successful outcomes. Eighth, intake balance was shown to affect delinquency. Ninth, Rutter et al. (1979:179) found that combined measures demonstrated a difference among schools:

- . the association between the combined measures of overall school process and each of the measures of outcome was much stronger than any of the associations with individual 
process variables. This suggests that the cumulative effect of these various social factors was considerably greater than the effect of any of the individual actions or measures may combine to create a particular ethos or set of values, attitudes and behaviors which will become characteristic of the school as a whole.

Finally, the results of this investigation by Rutter et al. (1979:179) illustrated the likelihood that school process and student outcomes are related events:

- . the total pattern of findings indicate that strong probability that the associations between school process and outcome reflect in part a causal process. In other words, to an appreciable extent children's behaviour and attitudes are shaped and influenced by their experiences at a school, and, in particular, by the qualities of the school as a social institution.

In summary, this study supported the argument that individual schools, despite their locations in improvished neighborhoods, can make a difference in students' academic and social performance in school.

The Rutter et al. study has been criticized (Acton, 1980).

However, it was one major inquiry lending support to the effective school argument and thus has been presented in detail here. Some concluding remarks about effective schools will be presented in Chapter IV which enumerates propositions about organizational features of public high schools. An examination of the formal structures of conventional high schools is presented next.

FORMAL STRUCTURES

This section deals with two questions concerning the formal structure of secondary public schools. First, who makes decisions affecting the policies and practices of secondary schools? The second 
question is: to what degree does the formal structure of the secondary school control its participants?

Tyack and Hansat (1980) have observed that during the nineteenth century, the common school spread across America through private, grass roots, and decentralized efforts on the part of the public. However, the twentieth century belief by the public in science and technology led to educational centralization in which the administrative structure was bureaucratized. The public was removed from the decision-making practices concerning schooling until the late 1960 's and early 1970's.

One community's attempts to be involved in the decision-making processes of their schools has been described by Gittell (1972) and Levine (1969). Inner-city parents from New York City felt the larger school had grown too impersonal to deal effectively with the special needs of their children. Promises to integrate black and white neighborhoods in a new school, Intermediate 201, were not kept by the school district's central administration. This breach of trust was the catalyst for this neighborhood's community control movement. Parents were unsatisfied with the school district's attempts to decentralize the district or to offer integrated school experiences. Also, they were discontented with the inferior end products they felt schools were producing. For example, Levine (1969:12) detailed the ineffectual education inner-city parents asserted their children were receiving:

Their reading and arithmetic levels were declining ( 85 percent of Negro and Puerto Rican children in the city were reading below grade), dropouts were increasing and the numbers 
entering college showed no significant improvement. At the same time, various plans for school integration which has been designed to raise the level of nonwhite educational achievement (open enrollment, Princeton Plan Pairing, rezoning, better site selection, educational parks, educational cluster) had all failed, the result of a combination of white resistance, the changing ethnic composition of the city, and the vacillation and ambivalence of the central Board of putting these plans into effect.

In effect, minority parents wanted a direct voice in the decision-making practices of their schools in New York City. Later, middle class and professional reformers joined the inner-city group in an attempt to improve and provide quality education through community control. At one point in the struggle, when parents of the inner-city community of Harlem refused to send their children to Intermediate 201, the president of the Ford Foundation, McGeorge Bundy, entered the picture. Subsequently, the foundation funded three experimental community-controlled, decentralized school districts. Partially in an endeavor to receive additional state aid, the foundation and $\mathrm{Mr}$. Bundy joined Mayor Lindsey and a special committee to prepare a plan to decentralize the New York City School System into five smaller districts. The panel drew up a plan that would have divided the school district into 30 to 60 independent community school districts. According to Levine $(1969: 19)$, each school district would have had elected community school boards ". . with the authority to hire and fire local personnel, determine curriculum policy, select textbooks, and formulate (but not raise) a district budget." The recommendations of this panel would have shifted decision-making powers from the central school administration and school board to community members on the local level. 
A power struggle ensued between the community coalition for decentralization and the teachers of the New York City schools, represented by the United Federation of Teachers. The teachers felt their professionalism was threatened by organized community groups and their union succeeded in sabotaging the decentralization and community control plan of Mayor Lindsey and panel by staging a city-wide strike until their demands were met.

Parent groups in communities elsewhere have coalesced for more community control, but the involvement has consisted of participatory, advisory, and token roles for the most part (Cohen, 1978; Cortin, Main, Swanson, 1969; Davies, 1976; Fagan, 1973; Fischer, 1979; Gittell, 1972; Jenkins, 1976; Levine, 1969; Morgan, 1980; Thornburg, 1981). One example of ineffectual participation has been presented by Fischer (1979). In 1973, the Florida legislature mandated that advisory parent groups be formed for the 67 county school districts. In a study of 140 members of such groups, Fischer found that the advisory groups had not participated effectively in budget committees or teacher/administrator evaluations. The committee members maintained that they had indirect decision-making powers and had exercised their opinions in advisory capacities. Fischer argued that it is not sufficient to open the door to parent advisory groups, rather educators should instruct parents on all sides of educational issues so that the latter can participate effectively in decision making.

Similarly, Jenkins (1976) investigated the extent of community participation in decision-making in 35 elementary, junior, and senior 
high schools in Los Angeles. Principals, the advisory council chairpersons, as well as community, student, and teacher representatives on the advisory councils were interviewed. The findings indicated that principals thought community input was acceptable as long as community members were kept in indirect, ineffective, and advisory positions. Citizens involved with advisory councils in the Jenkins (1976:30) study reported that their role was: ". . minimal, having no meaningful involvement in decision making, and was generally ineffective." These same citizens insisted that principals and district administrators were protective of their right to make final decisions. On the other hand, Thornburg (1981) sampled 202 respondents from secondary schools to measure parental involvement in the schools. Twenty one principals, 59 teachers, 62 parents, and 60 students were interviewed about their actual and preferred involvement in school decisions. Unlike Jenkins' findings, teachers and principals claimed that they wanted more parental involvement in their schools. Parental involvement was categorized according to levels of support, volunteering, and decision making. Although principals and teachers asserted that they wanted more parental involvement in decision-making, they did not distinguish between token, advisory, and effective participation. Thornburg (1981:153) called for in-depth research in the area of parental involvement in decision-making processes:

A study of more specific parental attitudes is needed to examine why parents do not want to be involved. Educators 
should take a closer look at the secondary schools that have successful models for parent involvement and begin considering some alternatives for their schools.

In summary, educational experts have insisted that no significant power shifts have occurred in school decision making. Indeed, a greater concentration of power over decision making by educational professionals (i.e., principals, teachers, central office administrators, boards of education) has apparently occurred in recent years. Earlier, it was recommended that schools' goals be made through a participatory effort by parents, teachers, administrators, students, and interested community members on each individual school level. Marburger (1980), Ianni (1979), and Howard (1978) have suggested that decisions be a shared effort of all members of schooling institutions. Ianni insisted that student involvement in, rather than exclusion from, the governance systems and decision-making practices would lessen student tension in schools. Similarly, Howard (1978:103) listed a seven-step problem-solving process where members would be included in the decision-making processes of the school:

A good school is a place where everyone learns and everyone teaches. It is also a place where everyone helps to solve problems. By involving lots of people in making the school a better place the administrator improves morale, raises selfesteem, and reduces discipline problems.

Finally, Marburger (1980) advocated that decision-making processes for educational policies be a shared project with parents to insure a quality education for consumers. He supported planning at the individual school level with a school council for shared power between all components. 
A second question posed by this chapter is: to what degree does the formal structure of the secondary public school control its organizational participants? Schmiedeck (1979) claimed that modern organizational procedures, modeled after big business operations, do not allow adolescents close interpersonal relationships with teachers and other students and that there is a clash between human needs and organizational efficiency in large high schools.

Some theorists (Deal and Celotti, 1980; Hollister, 1979) have argued that teachers and principals use the formal bureaucratic structure of the schools to ward off overinvolved parents. Also, they have asserted that teachers are relatively autonomous, fending off the recommendations of superintendents, central office administrators, the community, and even the principal. But, how tightly controlled are the schools? What is the function of the school administrators? This discussion presents the basic parameters of the issue of whether the formal structure of schools is tightly-bound as in a business or loosely-structured, as numerous theorists maintain.

Principals are reported to be the major decision makers in the high schools surveyed in the studies of Abramowitz et al. (1978), Marburger (1980), and Tubbs and Beane (1981). In particular, Deal and Celotti (1980:471) studied the ways administrators influence classroom instruction and working relationships among teachers. They conducted a three-year study funded by the National Institute of Education with the assumption that the organizational cohesion taken for granted by many school administrators is an illusion. The study involved 34 school districts in the San Francisco Bay area, representing a range 
of district sizes, wealth, and locations. The sampled population consisted of 103 elementary schools with varying-sized teaching staffs ( 4 to 30 ). Although the study dealt with elementary schools, the results have implications for this discussion of the formal structure of secondary schools.

Superintendents, principals, and teachers were interviewed concerning such matters as district policies, relationships between the community and the district, instructional patterns, characteristics of the building, classroom organization, and instructional techniques and approaches. The prevalence of team-teaching and individualized instruction was noted and it was assumed that their presence signals organizational or administrative patterns characteristic of the community.

The researchers found teacher teaming was affected by open space and individualized instruction caused more teachers to pair together. Team teaching was unaffected by district policies, comunity climate, or school policies that stressed team teaching. Deal and Celotti (1981:472) found that individualized instruction was a matter of teacher preference and was independent of variables such as community composition, building policies, and district policies:

Finally, with the exception of the effects of California's ECE program, classroom instruction appears to be independent of environment pressures: community ethnic and socioeconomic characteristics, and the influence of teachers organizations of Title I funding. Although many external funding sources are designed to affect directly the patterns included in the index of individualized instruction, the analyses did not show such effects. Environmental pressures may produce other changes but do not seem to affect material variation, student grouping, or pacing. 
Thus, the Deal and Celotti (1981:472) study found that teachers are autonomous, at least in instructional matters and the assumption that there are three levels of educational organizations (district, school, and classroom) operating independently of each other was upheld by the results of this study:

The results portray the classroom as a relatively autonomous unit, its instructional or organizational characteristics shielded from formal influence by the community, district office, principal--or even the teacher next door . . . Rather, the lack of consensus was interpreted as further evidence supporting the view that patterns of organization in schools and districts are more disconnected than previously thought. Educational organizations appear to consist (at least around instructional matters) of a loose collection of individuals, units, or levels, each performing activities independently--as segmental units buffeted from one another.

In part, these results supported Lortie's (1977) claim that schools are complex, interdependent, and interrelated organizations but also simple organizations because they are a collection of single and individual classrooms.

The Deal and Celotti study (1981:472) has implications for schools, namely, the principal should not tighten up formal control if the instructional techniques of teachers are to be effective, but he or she should take care of simpler custodial building issues such as ordering supplies and managing the cafeteria to allow the school to run sroothly:

But instructional activities do not seem to be effectively coordinated through formal channels. For administrators who approach subordinates or superiors assuming that schools operate on a business or industrial logic, one can predict conflict, personal tension or disillusionment, and reduced administrative effectiveness. 
Generally, Meyer and Rowan (1977) found similar results when examining the formal structures of organizations. These authors conducted investigations funded by the National Institute of Education at the Stanford Center for Research and Development in Teaching. Their work supported the position that organizations in postindustrial society through their formal structures, uphold institutional myths about their environments. That is, the formal structures of institutions exist for matters of legitimacy and rationality and to establish relational networks with other institutions.

This role of the formal structure in a bureaucratic organization stands in contrast to its original definition. It had been theorized that the function of the formal structure in a bureaucracy is to define, maintain, and regulate the purposes, positions, policies, and procedures of that particular institution. The Loose-Coupling theory asserts that the formal structure of organizations exists with rules as myths to appease outside environmental influences. The reader might ask, what then are the implications of this alternate administrative theory?

The Abramowitz et al. study established a hierarchy in the decision-making positions of various school participants, a power pattern which we have discussed in previous sections of this chapter. School officials held the highest ranks in the decision-making hierarchy. Abramowitz et al. (1978:40-41) presented theoretical models of bureaucratic and loose-coupling administrative systems and more specifically, they discussed how principals' participation in decision-making matters should charge: 
The roles of individual principals would be broad, rather than specialized. Principals would have to serve as managers in response to State, district, and Federal agency requirements; as ambassadors to parents and students; and as colleagues to their fellow professionals.

As can be seen, the Abramowitz et al. (1978) study presented and supported the loose-coupling theory as a possibility for understanding the formal structure of schools. Also, Deal and Celotti discussed some implications from their study which are noteworthy. On the simplest level, if teachers are autonomous units, as the Deal and Celotti (1981:472) study found, the administration should take care of custodial building issues and leave instructional decision making up to teachers:

But instructional activities do not seem to be effectively coordinated through formal channels. For administrators who approach subordinates or superiors assuming that schools operate on a business or industrial logic, one can predict conflict, personal tension or disillusionment, and reduced administrative effectiveness.

Some weaknesses of the loose-coupling theory were pinpointed by Deal and Celotti. Teacher loneliness and isolation can be an outcome of such a formal structure. Conflict can arise when agreed-upon policies have not been formulated by administrators and teachers. A reduction in local community and administrative control concerning teacher decision-making implies that teachers will be operating without a system of checks and balances. Administrators may misuse the formal structure to ward off ecological and parental influences. Finally, a potential misuse of the myths and ceremony of the formal structure revolves around administrators using their influence to decide what goes on in the classroom. 
Considering the strengths and weaknesses of the 1oose-coupling theory, Meyer and Rowan (1977:360) supported it because of the potential benefits from this type of formal structure:

No position is taken here on the overall social effectiveness of isomorphic and loosely coupled organizations. To some extent such structures buffer activity from efficiency criteria and produce ineffectiveness. On the other hand, by binding participants to act in good faith, and to adhere to the larger rationalities of the wider structure, they may maximize long-run effectiveness. It should not be assumed that the creation of microscopic rationalities in the daily activity of workers effects social ends more efficiently than commitment to larger institutional claims and purposes.

Concluding remarks about formal structures will be presented in Chapter IV which presents propositions about conventional high school organizational features. A discussion of the informal structures of schools is presented next.

\section{INFORMAL STRUCTURES}

Teachers, supporting staff, and parents are examples of subcultures or groups within the school that act to reinforce the goals, rules, and purposes of any given school. This section will focus primarily on the student subculture in that the influence of parents and other subcultural groups has been discussed in earlier sections of Part II. In particular, two issues concerning the student subculture within the large comprehensive high school organization will be discussed. First, student power or the position of youth in the authority hierarchy of the schools will be delineated. A second issue concerns identified characteristics of the youth subculture and the dominance the subculture exercises upon the socialization of youth 
in schooling institutions. Let us first examine the position of youth in the decision-making process of the formal structure.

The political scene involving students in the late $1960^{\prime} \mathrm{s}$ was more of an activist one than in the late 1970's (Strauss, 1974). Strauss claimed that there were more than 2,000 political outbursts in secondary schools during the 1968-1969 school year. For example, Strauss (1974:370) claimed that students protested about such issues as Vietnam, race relations, dress codes, and school discipline. The reader might ask what has happened to the political activism that students demonstrated in the late 1960's.

Generally, an examination of student involvement in the decisionmaking practices of schools shows a picture of post $1960^{\prime} \mathrm{s}$ decline to traditional lower rates of participation (Dodson, 1970; Long, 1980; Tubbs and Beane, 1981; Weinstock, 1973). Students are "on the bottom of the totem pole" in the hierarchy of decision-makers in schools (Abramowitz et al., 1978; Marburger, 1980). On this point, a 10.8 percent decline in student influence in curriculum planning between 1974 and 1979 was found in the Tubbs and Beane study. While the students were reported to have more involvement than the board of education and citizenship groups, they lost power or failed to exercise it at a greater rate than the other two groups. According to the findings of this study, the board of education had a gain in their control (3.7 percent); although citizens reported a 1.2 percent decline in authority. While commenting on the schools in White Plains, New York, Dodson (1979:34) argued that training in schools is for dependency, that is, teaching students their place is: 
The school is a kind of charity operation run for the minority population who are powerless. The fact of the business, if you saw the school as a social system, a case could be made that its input is all the children of all the people; its output is people who know their place. Its chief function is teaching people their place.

In addition, Weinstock (1973:17) insisted that high schools operated

with a custodial function of policing students:

That cardinal offense, leaving the school building during unscheduled hours, prompted one Airlie House participant to remark, "The high school is the only institution in the United States, except the prison, where they count the inmates seven times a day to make sure no one has escaped."

The preparation of students in American secondary schools for political life has been commented upon by various theorists (Dodson, 1970; Strauss, 1974; Weinstock, 1973). Utilizing a conceptual framework from social science research, Strauss noted two conceptions of political education at the high school level. The first considered the student as agency object, or as raw material to be socialized by the school. This particular socializing function of the school has been criticized as being contradictory to the principles of democracy because students are subjected to hierarchical bureaucratic school organizations and are treated as children. The school, in this view, works to instill democratic ideals in its citizenry through indoctrination techniques such as civic courses which offer prepolitical experiences to be acted out in future adult situations. In agency-object schools, students are taught democratic ideals but they do not live out such practices.

In arena-actors schools, students learn democratic processes by experiencing and practicing them. They are treated like adults in 
these schools and are allowed and encouraged to be politically active and share in decision-making practices. Strauss pointed out that both perspectives acknowledge that the American high school is charged with the development of young citizens who are prepared to function with the norms and values of a democratic society. The two schools differ significantly in the means by which political preparation is acquired and in the way students are assumed to be children or adults.

In a previous section on curriculum, we found that the social studies education curriculum has been broadened, with social science electives as a response to educational reform cries in the early 1970's. However, due to financial cutbacks as well as student dissatisfaction and decline in enrollments in social education classes, social science curriculua have returned to a more traditional and conservative course of study. Textbooks, large group lectures, and recitation of facts are the instructional techniques utilized by teachers. While in the 1970 's classes were offered in Black and ethnic history, women's history, and family history, social science education in the American high school has usually operated from the perspective of the student as agency-object, as noted by Strauss (1974). That is, students are taught democratic principles in social studies classes but are not given the opportunity to apply learned skills.

Long (1980) randomly sampled 269 students from two inner-city high schools in Hartford, Connecticut in May, 1976 and investigated the feelings of powerlessness and political alienation among urban adolescents. The majority of the sample was female (64 percent 
female, 36 percent male), with a mixed ethnic population represented (44 percent Blacks, 44 percent Whites, 11 percent Hispanics). It should be acknowledged that this study used a weak measurement instrument. That is, the questionnaire was written with a negative and biased perspective on the political system and numerous leading questions. Many items in the long (1980:33) questionnaire were confusing as they asked the respondents to react to more than one issue in a single question, e.g., "For the most part, the government serves the interests of a few organized groups, such as business or labor, and isn't very concerned about the needs of people like my parents and me."

The Long study measured adolescents' responses to seven dimensions of political alienation, discussed the intercorrelations of the different dimensions, and finally, analyzed the effect of adolescents' attributes on these measures of political alienation. A brief summary of the findings stated that over 50 percent of the sampled students felt powerless and alienated from the political process. The average intercorrelation of the political alienation indicators was 0.65 , but a factor analysis of the seven dimensions revealed that two factors explained most of the variance. Students claimed the most dissatisfaction with the performance of the political system, and second, they were skeptical of their chances to affect the political system by their behavior.

A third set of findings of this study has particular implications for educators in preparing students for active citizenry. That is, this study found three determinants of alienation. First, 
the students responded that they felt the political system

discriminates by race and social economic class. Second, students

felt threatened by the political system and finally, their preparation in classical democratic theory led them to hold idealized expectations for the political system. Long (1980:41) implied that educators'

responses to the findings of this study would be to teach the realities of the political process as it functions in America, not as

\section{it is intended to operate:}

Thus, it might be argued that any attempt to diminish adolescents' feelings of disaffection from the political system, assuming such an attempt were successful, would be status-quo oriented and would conflict markedly with the apparent political beliefs held by contemporary adolescents.

Dodson (1970) and Wilhelms (1979) professed a belief in students

that went beyond the agency-object perspective of treating students as

children. Wilhelms (1979:88) studied the attendance problems at

Westside High School, a suburban high school in Omaha, Nebraska and

complimented the students he observed with the following statements:

I have said that today's students are calmly independent and stand in no great awe of authority figures; that administrators, counselors, and teachers have to earn their own personal acceptance and respect. But the other side of that coin is even more important. When teachers or officials have gained that acceptance, when they are known for competence, square shooting and a reasonable sense of humor--they can expect fine treatment in return. The students' manner may be free and easy, but it has a basis for respect. Cooperation comes naturally. There is a decent thoughtfulness. Altogether, it seems to me that while this generation hates repression--simply will not tolerate it--it responds generously to freedom. And when it is offered responsibility, it lives up to it.

Similarly, Dodson proclaimed a deep faith in the youths in American high schools and advocated that schools move beyond present student governments to new power structures. He charged that student 
governments are nothing more than popularity contests. The new structure he supported would redistribute power to the extent that students could challenge the power patterns of existing school organizations. Also, Weinstock (1973) called for shared decision making so that students would be more involved in the policies that affect their education, would experience the process of choice, and would take responsibility for their own education. Effective student governing bodies do exist in some American secondary schools. Staples High School in Westport, Connecticut established a Student Governing Board in the early 1970's which was a joint effort at shared decision-making between ten students and ten adults (Calkins, 1974). The ten students represented 1,900 students. The following list reported by Calkins (1974:17-19) includes a number of the changes which the Staples Governing Board established in an effort to humanize their school:

-elimination of "tracking" in all subjects. -elimination of all bells. -elimination of homerooms and systematic attendance taking on a daily basis.

-provision of a system of shared responsibility between the home and school for attendance and progress.

-elimination of mandatory study halls.

-creation of option areas for serious and quiet study, talkstudy tutorials, smoking, and blowing off steam.

-opening up the cafeteria as a coffee and doughnut shop for breakfast and provision for pretzel stands, soda machines and snack machines.

-elimination of detentions and detention hall. 
-provision for a suspension review board of students and faculty as an initial step in eliminating suspension.

-provision of complete freedom of campus and buildings as long as classes and rights of others were not interfered with.

-initiation of an open-ended schedule for all students that permitted them to come when their first class begins and leave when the last class was over.

The preceding list of changes demonstrates that students in large high schools can participate in affecting significant modifications in school administrative matters.

Another example of students being involved in formal administrative matters has been described in Barsalou, Killinger, and Thompson (1979). The student government at San Mateo High School in California sponsored a student evaluation of teachers and the program received an 80 percent response rate from teachers the second year it was instituted. The authors emphasized the importance of student input in such a process and concluded that it is an area that needs more research.

In summary, it can be concluded that students have lost power or have failed to exercise it in the decision-making practices of the formal administrative structure although there are cases of individual schools reporting effective cooperative efforts in central administrative issues. Some have argued that students should become more active in experiencing democratic principles rather than just being taught democratic ideals. Let us now turn to a discussion of the characteristics of the student subculture. 
The challenge has been made that high schools segregate youths and prolong their period of dependence (Carnegie Council, 1979; Coleman, 1974). Coleman (1974) and Martin (1974) charged that such segregation processes cause youths to depend on their own peer groups, and accordingly, the youth culture is socializing youths to a greater extent than primary institutions such as the family and school. These issues will be examined in the section which follows, beginning with a discussion of the characteristics of the youths subculture, followed by a clarification of some of the issues surrounding the challenges that have been made by Coleman and Martin.

The first order of business is to define the term youth. The conception of youths put forth by Kenneth Kenniston is identified in Coleman (1974:112) as those persons in high school, experiencing adolescence, but not yet attaining independent status.

In general, Coleman (1974:113-115) adolescence is distinguished by an "inwardlookingness." Three factors have exacerbated this process of "inwardlookingness" for youths of the present generation. First, because of the baby boom of the post World War II period, the youth population is one of the largest it has ever been although it is declining. Second, because of the rising educational aspirations of youths, caused in part by the credential society, youths spend. more time in school and are segregated from the larger population for a longer period of time than in previous generations (Coleman, 1974). This segregation causes dependency on the schooling institution and other youths. Finally, youths have experienced greater economic 
affluence than past generations and are able to support their inwardlookingness to more of an extent than in other areas.

"Physic Attainment" has been identified by Coleman (1974:115116) as a second element of the youth culture. The need to be close and attached to other adolescents is not a phenomenon peculiar to the present generation but it is a growing need because of the weakening of the nuclear family with each generation.

The third element identified by Coleman (1974:118) is the "Drive Toward Autonomy" or independence. Coleman (1974:118) explains that young persons who challenge adults and authority figures are held in high regard by their peers: "Youth are a subordinate nation, and any youth that can stand up to adults is regarded with a certain amount of respect, awe, and admiration." Coleman has claimed that mass media, particularly movies, radio, and newspapers have identified youths as alienated and deviant. They have allowed the diverse opinions of youths to be resounded and represented to the larger culture and population.

A fourth element of the youth subculture indicated by Coleman (1974) is a "Concern for the underdog," emanating from an anticompetitive and sympathetic ethic and idealism often found among youths. Finally, "Interest in Change" is an element of the youth culture (Coleman, 1974:124). The occupational status achievement system is at the base of this characteristic. That is, occupational status is achieved in this generation and is not ascribed by birth rights as in other generations. In this situation, youths have less 
invested in the economic system and social order and they opt for change while older persons have more to gain by promoting the status quo and thus resist change.

In sum, Coleman (1974:125) has contended that youth has been forced into a subculture which they have difficulty leaving: ". . having been forced to create and live within a youth subculture, many youth are reluctant to leave it, reluctant to become assimilated into the adult culture from which they have so long been segregated." Timpane et al. (1976) did not put much weight upon the Coleman and Martin proposal concerning the youth subculture's characteristics and socialization influence on other youths. First, they argued that there were no national surveys or evidence which demonstrate value differences between youths and their parents. They contend that a distinct youth culture of the magnitude that Coleman and Martin claim had implications for cultural transmission and cultural continuity. Timpane et al. argued that if the characteristics described by Coleman and Martin were significant enough to transmit values then the youth subculture would be a stronger socializing influence than the home or school. Timpane et al. maintained that youth-adult differences were in manners and tastes, not in basic values. They upheld that the characteristics of youth, identified by Coleman and Martin are not strong enough at this point in time to be contended with by the schools as a significant and serious socializing influence. Studies to date have not proven otherwise.

This account of the youth subculture has implications for secondary school organizations. Educators need an awareness of the 
distinct characteristics of their development so that educational experiences will be planned relevantly and appropriately. The youth culture is not to be feared but it can be understood for its preference in matters of taste and manners. Schooling experiences that are worthwhile and relevant will recognize the potential influence the youth culture holds for socializing its own. On this point, agreeing with Coleman (1974) Kozberg and Winegar (1981:566) have described their reform attempts with South Boston High School and asserted their belief in the possible socializing influences of the youth culture in large schools: "As school populations rise above 1,200 , the primary agents of socialization become increasingly the students themselves."

A final organizational characteristic of schools, ecological influences, is addressed briefly below.

\section{ECOLOGICAL INFLUENCES}

A fifth characteristic or element of an organization is ecological influences. School organizations have inner and outer forces to consider in planning change. For example, inner forces within the school such as teachers, principals, and other primary participants must be considered and dealt with directly in order to plan change while the larger system, the ecosystem includes the community.

Some examples of external, or ecological influences that impact upon the schools include resource allocations, values for education by the larger society, social control attitudes, educational ideologies, 
and political moods and movements. As a case-in-point, passage of

Proposition 13 of California has consequences for service delivery in schools, namely substantial cutbacks which eliminate certain programs. A delineation of summary statements concerning secondary school organizations based on the studies that have been reviewed is now undertaken. 
CHAPTER IV

SUMMARY STATEMENTS: THE STATUS OF CONVENTIONAL SECONDARY SCHOOL ORGANIZATIONS

Chapter III reviewed studies presenting various components of school organizations. In this chapter, the general findings of the literature concerning conventional secondary high school organizational characteristics will be delineated. Second, the challenges and charges listed against high schools in Chapter 2 are addressed by the findings of the literature reviewed.

CONVENTIONAL SECONDARY PUBLIC SCHOOLS SUMMARY STATEMENTS

Fifteen statements emerge from the literature reviewed:

1. Historically we find that comprehensive high schools are the predominant pattern instituted in this country following World War II. Conant (1959) has identified six principles on which they are based.

2. Secondary high schools can be classified in two ways: first, by their educational function or purpose (Conant, 1959; Germain, Carten, and Meland, 1975; Havighurst, 1966; Trent, 1981; Tyack, 1974); and second, by their socioeconomic status and geographical location (Binzen, 1970; Havighurst, Smith, and Wilder, 1970; Lightfoot, 1978; Ornstein, Levine, and Wilkerson, 1975). Various school types are categorized by different organizational characteristics (see Figure 2).

3. Goals for conventional high schools are instituted on four general levels including: national, state, district, and individual school building (Colorado State Board of Education, 1982; Giles, 1977; Marburger, 1980; National Education Association, 1971; Special Report of the 
Jefferson County Schools, 1978). Educational theorists (Abramowitz et al., 1978; Brown, 1973; Giles, 1977; Marburger, 1980; NASSP, 1975) have asserted that schools are more effective if goals are set in a participatory matter on the individual school building level.

4. On a national level, curricula in secondary public schools continue to involve standard scheduling practices, traditional course offerings with some experimentation in electives, and are subject or department-centered (Abramowitz et al., 1978; Buser and Manlove, 1969; Tubbs and Beane, 1981).

5. A review of Social Studies curricula in particular finds it in a state of crisis. Enrollments are declining (Gross, 1977) despite experimentation with electives (Gross, 1977; Shaver, Davis and Helburn, 1979; Hertzburg, 1981). Traditional teaching strategies have continued the use of textbooks, the method of recitation, and the large group lecture teaching technique (Gross, 1977; Hertzburg, 1981). Students voice less interest in Social Studies compared with other subjects (Fernadez, Massey, and Dornbusch, 1976). Principals are more supportive of Social Studies programs than are teachers (Gross, 1977; Hertzberg, 1981).

6. Mathematics and Science curricula are in a similar state as Social Studies. That is, traditional teaching strategies are used and include textbooks and whole group instruction (Weiss, 1978).

7. Concerning English curricula, traditional teaching approaches continue as the most frequent mode: lecture and recitation as well as the use of textbooks (Squire and Applebee, 1968). Ability grouping is practiced and English course content varies according to the group instructed (Squire and Applebee, 1968). Currently, Shuman (1981) had maintained that English is taught with the pluralistic perspective. Reading has a new emphasis in the English curriculum (Palmer, 1981). Hipple (1981) has forecasted a return to more electives in the 1980's but with caution and discretion due to the "back to the basics" movement. Finally, O'Donneli (1981) has called for cooperative research endeavors between universities and secondary school organizations to investigate problems. 
8. Controversy exists over another technology, school size. Some theorists (Brown, 1973; Coleman, 1974; Martin, 1974) have advised the division of large comprehensive schools be divided into smaller, more manageable, and interpersonal units. On the other hand, some (Culler, Hughes, and McGrail, 1973; Brimm and Hanson, 1980) have supported large school size. The findings of the studies reviewed here were inconclusive concerning school size.

9. Academic tracking, a school technology, apparently is utilized in about half of the schools (Abramowitz et al., 1978). Some experts (Hargreaves, 1967; Ianni, 1978; Rist, 1973) have suggested that school organizations eliminate this technology that sorts students into tracks of winners and losers.

10. Some theorists (Fox, 1973; Howard, 1978; Rutter et al., 1979) have argued that schools can organize elements in successful combinations to create an atmosphere, ethos, and environment for student success. Howard (1978) and Rutter et al. (1979) presented specific examples, using quantitative and qualitative data, to document effective and quality secondary schools.

11. Efforts by communities to gain control of decision making processes in schools have resulted in only advisory roles being allocated to community members (Coleman, 1978; Gittell, 1972; Jenkins, 1976; Levine, 1969; Morgan, 1980). Educational authority remains in the hands of educational professionals. Some theorists (Marburger, 1980; Ianni, 1979; Howard, 1978) have suggested that decisions be a shared effort of all members of a schooling institution.

12. Principals are the primary decision-makers in high schools depending on the category of decisions (Abramowitz et al., 1978; Marburger, 1980; Tubbs and Beane, 1981). Regarding instructional decisions, Leal and Celotti (1980) found in their investigation of elementary schools that teachers were autonomous, independent of principals and other administrative influences. Similarly, Meyer and Rowan (1977) contended that formal structures of institutions exist for matters of legitimacy, rationality, and relational networking with other institutions.

13. Students have lost power in influencing and deciding school matters (Dodson, 1970; Long, 1980; Tubbs and Beane, 1981; Weinstock, 1973). Students feel powerless 
in today's political system (Long, 1980). New governance structures have been recommended to redistribute power so as to involve students in the decision-making process (Dodson, 1970; Weinstock, 1973).

14. There are discernible characteristics of the youth subculture (Coleman, 1974). Timpane et al. (1976) argued that the differences between youth and adults are not in values but in manners and tastes. Youths are segregated from society, but Timpane et al. (1976) maintained that all age groups are segregated to some extent and that this separation can be a positive experience for youths working toward autonomy.

15. There are numerous external or ecological influences impacting upon schools. Because a list of these variables could be endless, this analysis made mention of some of these factors.

CONVENTIONAL SECONDARY PUBLIC SCHOOL CONCLUDING STATEMENTS

What are the charges that have been leveled against conventional high schools?

First, educational theorists (Brown, 1973; Coleman, 1974; Martin, 1974; Weinstock, 1973) have asserted that school institutions have not responded to changes in youth's developmental stages. In particular, Katz (1971) and Tyack (1974) have insisted that for 40 years, high schools have continued to educate youths, utilizing chronological age grouping and the same instructional technologies. That is, for the most part, reviewed studies revealed evidence to support the fact that conventional secondary schools continue to employ the same technologies as utilized 20 to 40 years ago, despite some experimentation. For example, efforts to update course contents have been reported in Social Studies and English, but overall, 
traditional teaching strategies and course content have not changed radically in secondary schools to recognize youth's developmental patterns and other needs.

Second, some theorists (Carnegie Council, 1979; Coleman, 1974) have insisted that high schools reflect segregation policies and engage in a custodial role which may cause isolation, dependency, and the alienation of youth. Two technologies which might partially alleviare this situation are alternative credential forms and work experiences. Alternative credential forms have been proposed by Bachman et al. (1967), Brown (1973), Coleman (1974), Martin (1974), and NASSP (1972). Brown, Coleman, and Martin claimed that schools should grant credit for out-of-school experience. The NASSF (1972) suggested that a wide variety of credit with various evaluation measures be instituted in schools to meet the needs of individual students. At the same time, the Abramowitz et al. (1978:77) study reported that 83.5 percent of the schools use an $A-B-C-D-F$ grading system with few grading options.

Bachman, Kahn, Mednick, Davidson, and Johnson (1967) have insisted that alternative credential forms be offered, arguing that schoois are too ambitious in their attempts to monopolize the socialization of youth and they also called for more realistic goals for youngsters in the schools. Their longitudinal study investigated the effect of environmental influences on 2,200 tenth grade boys in public U.S. schools. The findings supported the social class argument and suggested that schools should be let "off the hook," that is, 
society expects too much in the socializing process of adolescents. This study suggested that schools stop their anti-dropout campaign, move to alternative credential forms, shift away from graded years of schooling, and offer more options within the schooling enterprise. Numerous studies have emphasized the importance of worthwhile work experiences being integrated with the secondary curricula (Brown, 1973; Carnegie Council, 1979; Coleman, 1974; NASSP, 1972). Sixty-five percent of the schools in one sample had an off-campus work experience or occupational training program (Abramowitz et al., 1978:17), while 75 percent of the schools had a career information center and vocational education funding (Abramowitz et al., 1978:23).

Work adventures have been recommended on the high school level for various reasons. The Carnegie Council advocated them in order that students: (1) will have an opportunity to develop good work habits, (2) will be able to ease the transition from high school to the labor market, and (3) will be able to experiment with a variety of job areas. The Carnegie Council was implicit in its emphasis on aiding youths to make a successful transition from high school to the world of work. In the past, preparation for work was the responsibility of the family but that situation has changed. Thus, for a smoother transition from school to the world of work, the Carnegie Council proposed that high schools provide work experiences. In addition, Brown and Coleman advocated that schooling and employment institutions not be divorced entities, rather, adolescents should be dispersed earlier for such worthwhile adventures. 
Coleman (1974:135) addressed the reasons why youths in the

schools are segregated from other segments of the population:

It appears to us that the benefits of age integration of youth with children in relations involving responsibility far outweigh the benefits of age segregation. We do not mean to imply that there should never be age homogenous settings, whether social or intellectual. But the relative absence of settings involving age integration with role relations that include responsibility of youth constitute a serious and increasing gap in the experience that society owes its youth. Thus we believe that future environments for growth should include settings in which older youth can have responsibility for the young to provide an opportunity that is largely missing for youth in today's society.

Thus, Coleman recommended less age segregation and more age integration in the schools. He also argued for the self-development of youth and their need for productive activity. Like Etzioni (1981), he proposed alternating school and work. His proposal went beyond career education, calling for a semester of work followed by a semester of school, involving all students, both college prepatory and vocational education students. Major goals of this experience would be interdependent activity and interaction with people. Learning a skill would not be the primary goals of this enterprise (Coleman, 1974).

This brief review reveals that work experiences have been advocated for two purposes: to aid high school students in a successful transition from school to the world of work, and to provide them with real involvement with responsible interdependent activity. The Abramowitz et al. (1978) survey noted that the majority of responding high schools to their survey contain a work experience in their curricula. The goals and scope of those programs would be worth future research. 
A third criticism of secondary schools is that they employ goals and technologies which are alienating and irrelevant to youth. Schools employ traditional teaching strategies and operate with academic tracking practices that sort some students into the "loser" category. A review of school scheduling practices illustrates this point. As noted in Chapter III, Abramowitz et al. reported that 93.3 percent of the high schools sampled utilize a traditional scheduling system of 35-60 minute periods. The second most frequent system is modular scheduling with 10-30 minute periods, recorded in 2.4 percent of the schools (Abramowitz et al., 1978:70). In a predominantly rural sample (58.8 percent), Tubbs and Beane (1981) found the traditional scheduling system in use in 88.3 percent of the responding schools. This study revealed a larger variety of scheduling practices than Abramowitz et al. (1978), with the following types: block-time, 10 percent; daycycle, 11.7 percent; flexible-modular, 3.1 percent (Tubbs and Beane, 1981:206). Experimentation with scheduling practices has benefits for students. In particular, Kier (1973) and Shockless (1973) detailed two scheduling experiments in separate high school sites. Kier, the principal of Yorktown High School in Arlington, Virginia described a simple scheme which extended the school day by two periods. The flexibility in scheduling caused more student satisfaction. Forty percent of the teachers insisted that attendance was less of a problem than in the preceding year. On the other hand, Shockless (1973:85) outlines the benefits of modular scheduling for students at New 
Milford High School in New Jersey: "The purpose of unscheduled time is to instill in the student not only the desire to learn on his own, but to accept more responsibility for decisions relevant to his education." Parenthetically, Coleman proposed an alternative schedule of interchanging semesters of work and study, which if implemented, would require a year-round schedule.

Fourth, the charge has been made that secondary schools utilize an assimilationist's point of view which can cause student alienation. Although this situation may have changed somewhat in recent years, a close examination of Social Studies and English curricula found that they are now taught with a pluralistic perspective.

Finally, brief note might be taken of recommendations for future research concerning conventional secondary schools' organizational arrangements. There are numerous areas which need further in-depth research. For example, why haven't English curricula been studied on a national level for 15 years? Why haven't traditional instructional practices been changed? Are students satisfied with conventional procedures? Have their opinions been canvassed? From the studies reviewed, it appears that the organizational characteristics of secondary public schools need in-depth, current, and ongoing research to continually evaluate pclicies and procedures in order to affect change where appropriate. 
PART III

ALTERNATIVE SCHOOLS: EDUCATIONAL ORGANIZATIONS OF CHOICE 
CHAPTER V

\section{ALTERNATIVE SCHDOLS: AN OVERVIEW}

Currently, alternative schools are distinguished by key characteristics such as: broader student choice, comprehensive goal setting, innovative curricula and teaching strategies, close interpersonal relations between students and teachers, diffuse roles rather than formal ones, student satisfaction, innovative school governance practices resulting in improved attendance, and elimination of school vandalism and violence (Arnove and Strout, 1980; Duke and Muzio, 1978; Fantini, 1973, 1974; Moore, 1978; Raywid, 1982). Alternative schools continue to exist, if not thrive, despite the inhospitable political and economic times.

Community members frequently hold misconceptions concerning alternative schools including views that: (1) they exist for misfit students and teachers, (2) students do not learn basic skills but learn through "doing their own thing," (3) they are loosely organized and do not have comprehensive goals and objectives, (4) students are not held responsible for their actions, (5) teachers have no expectations for students' progress, (6) students are labeled and isolated from other students and the larger society, (7) these schools cost more, and (8) students do not learn anything but just "hang out" and smoke cigarettes (Arnove and Strout, 1980; Barr, 1981; Deal and Nolan, 1978a; Ornstein and Levine, 1981). 
Part Three of this thesis will respond to some of these myths and will summarize the way alternative schools are organized differently from traditional schools to effect students' learning. First, Chapter $\mathrm{V}$ defines alternative schooling and presents two alternative school typologies. Chapter VI offers a literature overview of the organizational characteristics of alternative schools. Finally, Chapter VII presents propositions concerning alternative schools. Additionally, the charges leveled against secondary schools will be examined by a summary of the alternative literature reviewed. We now begin the discussion of alternative schooling.

\section{ORIGINS}

Historically, a debate exists over the origin of alternative schools (Arnove and Strout, 1978; Deal and Nolan, 1978a; Krahl, 1977; Moore, 1978; Raywid, 1981b, 1982). Deal and Nolan (1978a) claim that alternative school themes are rooted in The Progressive Education movement of the $1920^{\prime} \mathrm{s}$, associated with John Dewey. Deal and Nolan (1978a:31) 1ist some of those themes as:

-The individual student's needs and experiences as a beginning point (i.e., personalization of education).

-The teacher as advisor.

-The school as a social community--education is seen as a social activity: active rather than passive learning.

-A variety of learning resources, especially using those of the local community.

-Skills as a means, not an end.

-Student participation in at least some of the major decision making of the school. 
-The individuality of both students and teachers.

Deal and Nolan (1978a) join other theorists (Arnove and Strout, 1978; Krahl, 1977; Raywid, 1981b) in claiming that alternative schools were initiated in public school systems (there have always been private and parochial alternatives) in the early 1960's. Two explanations are given for the evolution of alternative schools. First, they are a spin-off of the free schools model (Sumnerhill type schools, A. S. Neill, 1960) established in the private sector in the early 1960's (Arnove and Strout, 1978; Deal and Nolan, 1978a). Second, the social themes of the 1960's (numanism, egalitarianism, participatory decision making) spawned educational alternatives in the public sector.

The sources of the alternative schools conception are significant. Alternative schools initiated by parents, community members, and school board members within the public schools system have predictably been more viable than schools instituted in the private sector (Arnove and Strout, 1978; Collins, 1980; Moore, 1978). The demise of Adams High School, an alternative public secondary school in Portland, Oregon was due in part to its creation by seven Harvard graduate students, rather than by local community persons. Collins (1980) has stated: "In creating an alternative learning environment, start small and add on gradually. In the process, involve the community in the design of the program. Before that, ask the community if it even want the program" (The Sunday Oregonian, May 25, 1980).

Ideologically, alternative schools originated for two reasons. First, they were influenced by anti-establishment and counter culture 
sentiments with the supposition that they would be exemplary models to replace traditional schooling. Raywid (1981b:551) stated: "Most viewed their programs as the kind of reform desperately needed by all education."

In the mid seventies, advocates of alternative schools offered a second line of thought, arguing that they were experimenting with different organizational arrangements in an attempt to find better ways to educate children. Alternative education was moving away from a monolithic system toward diversified ways of educating youths (Barr, 1981; Deal and Nolan, 1978a; Ornstein and Levine, 1981; Raywid, 1981b). Eut, Fantini (1973:15) warns against belittlement of other alternative or conventional schools: "Such deliberations only lead to ill feelings among professionals and laymen alike, threatening the cooperative spirit of alternative education."

Currently, many educational theorists (Barr, 1981; Nolan, 1978; Raywid, 1981b; Smith, 1981) view alternative schools as the last chance for reforming public education. Barr (1981:571) has portrayed alternative schools as a catalyst and model to influence reforms in comprehensive high schools.

In summary, alternative schools can be traced back to The Progressive Movement of the $1920^{\prime} \mathrm{s}$, with a recent version being the free schools of the 1960 's. Alternative schools originated to replace the monolithic one best system of conventional schools but now exist to offer choice or diversity to a pluralistic student population. Let us now examine the definitions of alternative schooling. 
THE MATTER OF A DEFINITION

There is little agreement on definitions of alternative schooling. Some theorists emphasize distinct school features: providing alternative learning experiences from conventional high schools (Ornstein and Levine, 1981; Smith, 1981), choice for families in a community at no extra cost (Barr, 1981; Smith, 1981), less bureaucratized formal structures (Deal and Nolan, 1978b) and separateness from traditional school units (Raywid, 1982). Moore (1978) was critical of attempts to define alternatives and insisted that no single definition could accommodate the assortment of programs which advertise themselves as options. In point of fact, Barr (1981) asserts that there are 150 alternative types of schools. Because Ornstein and Levine (1981) define alternatives as all schools which offer learning opportunities different from traditional programs, then magnet schools, parochial schools, street academies, storefront schools, and schools without walls can all be included in a definition. Also, by this definition, in-classroom and subunits (such as schools within schools and magnet programs) presented by Moore (1978), could be considered alternatives.

With a somewhat different perspective, Barr (1981:571) discussed alternative schools in terms of the assumptions they make about learners:

But if the terminology is confusing, the concept of alternatives is based on a rather simple, straightforward set of assumptions: Different people learn in different ways. It is important not simply to match learners with teachers but to develop an educational system in which parents, students, and teachers can choose the type of program they believe to be in their best interests. 
Arnove and Strout (1978:80) proposed that the term "alternative" was politically sensitive and should be changed to "option":

If everything is an "alternative" there is also a trend toward dropping the term altogether because it has become politically sensitive--opposed by minorities who see the programs as devices to isolate their children and hinder integration efforts, and by conservatives who cannot free the term from its association with the political and social disruption of the sixties.

For now, let us say that a universal definition of alternative schools has not yet been reached, although in a subsequent section of this chapter, Raywid's (1982) differentiation between alternative and optional schools will provide the reader a clearer picture of the distinction. Now we will examine the growth of the alternative school movement.

THE GROWTH OF ALTERNATIVE SCHOOLS

Alternative schools have experienced impressive growth since the early 1970's and demonstrate few signs of abating (Arnove and Strout, 1978; Barr, 1975; Raywid, 1981b, 1982; Wolfe et al., 1974). One of the first national alternative schools surveys, conducted by the International Consortium for Options in Public Education, disclosed that there were only 25 public alternative schools in the U.S. in 1969 but by the fall of 1973, there were 464 in 35 states (Barr, 1975:2). Wolfe et al. (1974) conducted a national survey through the National Aiternative Schools Program at the University of Massachusetts, Amherst and identified 600 alternative programs, 85 percent of which were in the public school system. Furthermore, Barr (1975) revealed that by December 1976, alternative schools reached over 500,000 
students in 3,000 public schools on the elementary and secondary level. An estimated three million students were enrolled in alternative schools, with 80 percent of the nation's largest school districts (25,000 or more registered students) containing alternative schools of some type (Raywid, 1981b).

In the most extensive national study to date, Raywid (1982) described the locations of the nation's public secondary alternative schools. The survey, Project on Alternatives in Education, was partially funded by the National Institute of Education and investigated high school organizations with the purpose of encouraging reform through research. The first phase of the Eight Year Study involved: (1) identifying alternative schools on the secondary level $(2,500$ were located), and (2) analyzing a survey of 1,200 responding schools concerning their organizational features.

This study found the heaviest concentrations of alternative programs in three states: California, New York, and Washington. Michigan, Illinois, and Oregon also had proportionately large concentrations of alternative programs (Raywid, 1982:6). However, while Florida and Texas also grew in the number of alternative programs, they were of the punitive or in-school suspension type (Raywid, 1982:6). The West Coast, East Coast, and Great Lakes areas reported the most numerous pockets of alternative schools while the Southern states and Rocky Mountain and Plains states had fewer alternative programs than the other parts of the U.S. (Raywid, 1962:7). Site locations for alternative schools had spread to the suburbs and new alternative programs were most frequently located there. 
Additionally, most alternative schools were apparently stabilized. Raywid (1982:7) maintained that over half of the programs were at least six years old:

We also found evidence for concluding that alternatives are not the fly-by-night or short-lived structures some have claimed. A seventh of the programs responding to our survey were established before 1970; a third were established between 1971 and 1975; 44 percent began between 1976 and 1980; and 7 percent are new programs starting in 1981 or early 1982. This means that approximately half of our responding programs were at least six years old--which suggests durability for individual programs, as well as continuing growth for the alternatives movement in general.

In effect, alternative programs have continued to grow and spread. Entire schoool districts in Seattle, Philadelphia, and New York have diversified secondary education and organized all their programs as schools of option (Raywid, 1982; Seattle Public Schools Booklet, 1980-1981; Thirtieth Educational Conference of the Philadelphia Home and School Council, 1978). Overall, alternative programs have experienced a steady growth pattern since the early 1970's.

\section{ALTERNATIVE SCHOOL TYPOLOGIES}

General and broad alternative school types include: open schools, minischools, schools without walls, learning centers, continuation schools, schools within schools, magnet schools, community schools, bilingual schools, environmental schools, performing arts schools, Montessori schools, and fundamental schools (Carnegie Council, 1979; Barr, 1975; National Consortium for Options in Public Education, 1972; National School Board Association, 1976). Alternative schools run the gamut of learning models from Summerhill 
education, open education, individual instruction, experimental learning, fundamental "back to the basics" education, and behavior modification. Some theorists (Arnove and Strout, 1978; Barr, 1975; Raywid, 1982) have reported changes in the types of alternative schools that were being initiated in the mid-seventies. Increases occurred in learning centers, continuation schools, schools within schools, and fundamental schools. In particular, Barr (1975) disclosed these gains in the findings of the second national study on alternative schools. Schools without walls decreased from 22 percent to 6 percent of the reported public school options from the first national study of alternative schools initiated by the National Consortium on Options in Education in 1973 to the time of the Raywid (1982) study. Open schools dropped from 20 percent to 15 percent of the number of recorded alternative schools (Arnove and Strout, 1978). Earlier, Barr (1975) has argued that the creation of fundamental schools is hardly a backlash by the cormunity against present educational systems and insists that they are not here to stay. Nevertheless, although they are predominantly established on the elementary school level, fundamental schools have experienced considerable growth (Shaw, 1975).

Classification schemes based on a review of the educational literature point out that there are variations in the degrees of alternative patterns (Anglin, 1979; Deal and Nolan, 1978b; Fantini, 1974; Moore, 1978). For example, Deal and Nolan (1978b) discliss four structural models of schools distinguished by their organizational features: traditional schools, "do your own thing" schools, 
revolutionary schools, and negotiation schools (p. 37) Fantini (1974) notes seven school types and depicts each by the range of learner choice. For example, in free schools the learner has broad range of choices but experiences guidance from teachers. Standard or traditional schools have formal organizational structures, monolithic and standardized academic programs, and limited learner choices (Fantini, 1974:65). The Anglin (1979) classification scheme included The Traditional School, The Systems School, and The Open School and categorized schools by the extent of teacher decision-making powers and the assumptions made about learners. Moore (1978) proposed an unidimensional typology of alternative schools, distinguishing them according to their variance from traditional schools. Moore (1978:3) suggested that alternative schools should be analyzed on a case by case basis rather than sorted into specific, contrived and mutually-exclusive categories.

Some theorists (Ornstein and Levine, 1981: National School Board Association, 1976; Raywid, 1982) drew a distinction between alternative schools and schools of option. Schools created by school systems to service special needs populations (i.e., pregnant teenagers, disaffected youth, returning dropouts, and behaviorally disruptive youth) are considered option schools. Magnet schools, fundamental schools, and vocational schools are option or specialpurpose schools which attract students because of specialized programs and curricula emphasis. On the other hand, alternative schools are divergent and unique from traditional school strustures. They move beyond curricular specializations, and with heterogerious student 
populations, they utilize innovative organizational combirations to effect educational improvement and reform (Raywid, 1982).

A second typology concerned the levels on which alternative and option programs were instituted (Arnove and Strout, 1978; Barr, 1975; Collins, 1980, Crabtree, 1975; Dunn, 1981; Fantini, 1973; Gillies, 1981; Kaplan, 1981; MacNab and Weiland, 1980; Moore, 1978; National Consortium for Options in Public Education, 1972; National School Boards Association, 1976, Perry, 1980; Raywid, 1982; Rosenbaum and Presser, 1978; Seattle Public Schools Booklet, 1980; Thirtieth Educational Conference of the Philadelphia Home and School Council, 1978; Yates, Saunders, and Watkins, 1980). Figure 3 identifies these levels: (1) the classroom level, (2) subunits in comprehensive high schools such as schools within schools, (3) the

Level 1 Level 2

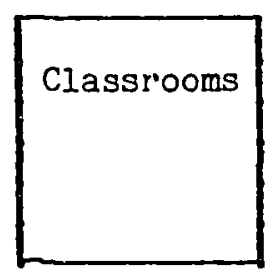

Level 3

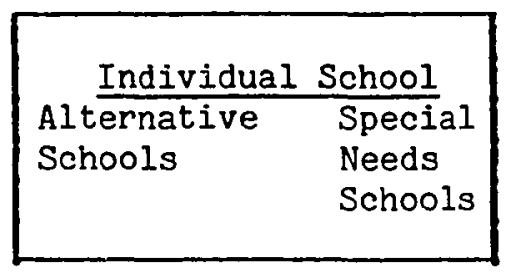

Level 4 Alternative Systems

Figure 3. An example of the levels of alternative education programs.

individual, separate school building level, encompassing alternative and option or special needs school programs, and (4) alternative school systems.

Moore (1978:3) details two examples of alternative classroom units (Level 1, Figure 3): the Affective Education Program in Philadelphia and the Open Corridor Project in New York's Upper West 
Side. Raywid (1982:29) reported that 8 percent of the 1,200 programs she surveyed were course offerings within the conventional high school.

A second level of alternative education is within subunits of cconventional high schools. Some authors (Dunn, 1981; Education by Choice, 1975; Gillies, 1981; Nelsen, 1975; St. Germain, Carten, and Meland, 1975; Sulack, 1975) have described various school-within-aschool programs. For the most part, they are small, enrolling between 40-115 students. Madison Prep, a school within a school (SWS) program in New York City had 20 students, one teacher, a teaching aide, and a social worker. Hold Youth, a pilot study which began in 1974 with 42 students in the Denver Public School System expanded to include 500 students with SWS programs in 9 junior highs and 5 senior highs (The Denver Post, April 12, 1981:33).

These programs are voluntary, although teachers, counselors, and parents act to influence students to choose various SWS programs. Disaffected youth with behavior, attendance, drug, alcohol, and attitude problems are among the students in the SWS programs described (Gillies, 1981; Nelsen, 1981; St. Germain et al., 1975; Sulack, 1975). A student profile of one SWS program was offered by St. Germain et al. (1975:637):

Focus is a school within a school for approximately 75 boys and girls in grades 10-12 who have average intellectual ability, low academic achievement, low self-concept, a negative attitude toward school, high drop-out potential, poor social development, a high rate of court referrals, and a high rate of school discipline referrals and suspensions. The overall goals of the Focus program are to reduce student dissaffection with school and learning, to improve each student's background of basic skills, and to provide a classroom atmosphere that will contribute to feelings of selfconfidence and concern for others. 
Unlike individual option schools for disaffected youth, the SWS programs reported here enrolled no mandated or court-ordered students. Examining the organizational characteristics of these SWS programs, the goals include: (1) reducing disaffection with school, (2) improving basic skills, (3) making learning more enjoyable, and (4) cultivating positive growth in self concept (Gillies, 1981; Nelson, 1975; St. Germain et al., 1975; Sulack, 1975; Trent, 1981). Specifically, Sulack (1975) reported that punctuality and regular attendance were empahsized in the SWS program at Anaheim High in Anaheim, California.

The instructional technologies employed by SWS programs are a significant point of departure from conventional education programs. They are: (1) more individual and group learning, (2) students are teachers, (3) attendance at nearby colleges, (4) flexible scheduling and curriculum, (5) individualized learning, (6) more student decision making and planning of programs, and (7) activity and project centered learning (Nelson, 1975; St. Germain et al., 1975; Sulack, 1975; Trent, 1981).

The staffs at the reviewed SWS programs were small, varying from three to five teachers. Some faculties included counselors, aides, and paraprofessionals. The degree of autonomy from the conventional school administration varied from program to program (Moore, 1978). Trent (1981:27) described a positive relationship between the SWS staff and the high school administration at Andrew Jackson Academy, a SWS program of Andrew Jackson High School in Cambria Heights, Queens. 
The high school administrators are very cooperative because they realize that the Academy provides a solution to certain problems faced by the main school: discipline, truancy and disaffected students. Teachers and students are enthusiastic because the program allows them to develop and use teaching and learning methods not feasible in the main high school. Parents are satisfied because many of their formerly disinterested teenagers are now highly motivated to continue and complete their education.

Close interpersonal relations are fostered by the small size of SWS programs (Education by Choice, 1975; Nelsen, 1975; St. Germain, Carten, and Meland, 1975; Sulack, 1975; Trent, 1981). Advisory systems such as the "Family" were planned at Alexander Ramsey Senior High School in Minnesota to develop the affective realm of a student's self concept, interpersonal relations, and human relations (St. Germain, Carten, and Meland, 1975).

Quantitative indicators of the success of SWS programs are decreased office referrals, fewer school suspensions, less days absent, increased academic achievement, and increased credits (Nelsen, 1975; St. Germain et al., 1975; Sulack, 1975). Similarly, in affective realms, SWS programs have measured student gains in areas of improved attitude toward school, improved self concept, and enriched interpersonal relations (Nelsen, 1975; St. Germain et al., 1975; Sulack, 1975).

Consistent with this emphasis on success in SWS programs, Sulack (1975) disclosed that only 7 percent of the original 115 students in the SWS program at Anaheim High School (California) requested transfers back to the regular conventional program. In addition, Nelsen $(1975: 631)$ stressed the benefits of the Focus program at Madison High School in Portland, Oregon: 
It must be noted that the most important day-to-day targets of FOCUS are in the affective realm. This is not to say that cognitive outcomes are not valued. However, the program's greatest thrust has been toward such areas as valuing, selfimage, and interpersonal relations. It has been encouraging, therefore, to find that respectable academic improvement has occurred with most program students, albeit as a by-product of basically affective activities. These results, considered along with markedly improved student attitudes and attendance, substantiate the Focus belief that if a student's feelings of self-doubt, inadequacy, and detachment are encountered and resolved, significant academic growth can be expected.

The minischool design at Quincy High School in Quincy, Illinois, funded under Title III of the Elementary and Secondary Education Act, was unique and offered seven SWS programs in one conventional high school. The programs included: The Traditional School, The Flexible School, The Project to Individualize Education School, The Fine Arts School, Career School, Work Study School, and Special Education School (Education by Choice, 1975; Fantini, 1973). The school assumed that learners have an individual style and they offered the seven mini-programs as choices for students and parents. The SWS programs at Quincy offered advantageous program features as small size, more interpersonal interaction, a humane environment, and decentralized decision making and choice (Fantini, 1973:14).

Alternative programs also exist on the individual school building level (see Level 3, Figure 3). In the discussion to follow, alternative schools and option schools will be considered as different types (Ornstein and Levine, 1981, National School Board Association, 1976; Raywid, 1982). Specific examples of alternative and option schools will make the distinction clearer. 
On an extreme end of the continuum, schools without walls were a distinct departure point of alternative schools. There is a decline in the number of this school type. Between the 1973 national alternative study and the 1975 study, Barr (1975) recorded a decrease from 22 percent to 6 percent of the total alternative school population. Raywid (1982) found only 1 percent of the alternatives to be schools without walls.

Parkway School of Philadelphia was the first and most widely known school without walls. Other schools without walls originated in various cities and are modeled after the Parkway School: Chicago Metro School in 1970, St. Paul Open School in 1971, Louisville Brown School in 1972, and New York City's City-as-School in 1972 (Arnove and Strout, 1978; Crabtree, 1975; Ford Foundation, 1974; Silberman, 1970). Originating in 1969 with 143 students, the Parkway School was conceived by the Philadelphia Board of Education and funded by the Ford Foundation (Silberman, 1970:350). Enrollment was expanded to 500 students in the 1969-70 school year and to 850 students by 1973 (Ford Foundation, 1974). The school lacked a standard facility as the city itself was its classroom. The Ford Foundation (1974:7) reported that it did have central headquarters on the second floor of an old building in downtown Philadelphia:

The "classroom" of Philadelphia's Parkway Program spread out from the two-mile-long Benjamin Franklin Parkway, the site of many of Philadelphia's scientific and cultural institutions. The entire city 's both Parkway's campus and its curriculum. The program has no school building as such. Classes are held in city and state facilities, hospitals, businesses and educational institutions, private homes, churches, and offices. 
Students were taught basic skills and other academic subjects, but Bremer, the program director of Parkway, insisted that teaching students how to live and survive was more important than teaching them a high school curricula which has outdated itself.

There were four parts to the curriculum at Parkway. First, students were offered courses by the Parkway staff. These courses were constantly changing as students and teachers felt it necessary to make such changes. Second, there were institutional offerings so that students could immediately experience the relevancy of what they were learning in school and the connection with realities in the community. Silberman (1970:351) explained that this experience with many of the institutions on the Benjamin Franklin Parkway included various formats:

The offering may be a formal course, a work-study program, a research assistantship or apprenticeship, or simply a chance to hang around and watch, or to participate in the institution's activities in any way the student or the cooperating "teacher" may see fit.

The list of institutions which contributed to Parkway included: the Philadelphia Zoo; the Franklin Institute; the Museum of Art; the Insurance Company of North America; Smith, Kline \& French; the local television station KYW; The Philadelphia Bulletin and the Inquirer; the Police Department and District Attorney's office; and the Philadelphia Chapter of the American Civil Liberties Union (Silberman, $1970: 351)$.

A third phase of the curriculum encouraged youths to work at one of the institutions previously mentioned. Also, basic skills were learned in tutorial groups which met for two hours, three times a week. Grades and class rankings were not awarded, but pass and no 
pass evaluations were utilized. Students planned their own education but with consequences and responsibility for their decisions.

Students were responsible for their programs, as the school was run by all school menbers through town meetings and management committees. The small size was expected to foster quality relationships in the learning community which included teachers and students. The school was fully accredited and per pupil expenditures were the same as other Philadelphia schools.

The Ford Foundation (1974) presented two problems of the Parkway School. First, there was difficulty in finding qualified and dedicated teachers to work at the school. Second, students were expected to be responsible for their education at this school and many were not. However, the Ford Foundation (1974:7) explained that the school successfully fostered this responsibility in many students:

Out of some 52,000 high school students in Philadelphia, more than 2,000 apply for the 200 spaces available at Parkway each year. Seventy-five percent of Parkway's students are chosen by lottery, and 25 percent are referred by their local high schools to achieve a racial, economic, and geographical balance.

The Village School, an example of a second type of alternative school, is located in Great Neck, New York (Kaplan, 1981). It is an open alternative school. Unlike the Parkway School, this school is more centrally contained through work experiences, community service, and apprenticeships are contracted with the outside community. The Village School was approved over ten years ago by the Great Neck School Board at the urging of parents. It is small, with five faculty members and 60 students. 
Different objectives were set by this school. That is, the process of schooling was emphasized rather than the end product or outcome. The creativity, imagination, and positive development of self-concept is stressed. Furthermore, the quality of each individual student's education is valued.

Various technologies are utilized in the learning process and included observation and participation, experimental or action learning, individualized programs, tutorial programs, college and adult education classes, and domestic and foreign travel (Kaplan, 1981:22). The curriculum is flexible and changed according to teacher and student interest. There are no grades awarded or standardized tests administered. Students write narrative self-evaluations twice a year which also serve as their high school transcripts.

Teachers are versatile and flexible, often teaching out of their certified areas, and each is the advisor to one-fifth of the students. Also, they are head of a committee.

Similar to Parkway, this school is self-governing. Students and teachers hold equal voting powers. Kaplan (1981:23) explains that conflicts are worked out in executive committees, with working committees assigned when necessary.

Following the schools without walls trend, open schools declined from 20 percent to 15 percent of alternative programs in the 1973 and 1975 national studies (Barr, 1975:4-5).

Let us now turn to a description of several option schools. There are various types of option schools, as has previously been 
indicated. Two option schools deserve special mention, those for: (1) disruptive and disaffected youth, and (2) gifted and talented youth in a magnet school. Hess Junior High School (a fictitious name) was located in a neighborhood in a Northeast city which was racially changing and becoming predominantly black. The school had a reputation of being inferior academically with fewer education resources than its whiter counterpart in the same district. The local school board approved a plan which called for Hess to attract talented students by offering an enriched special education curriculum. Rosenbaum and Presser (1978) used unobtrusive measures and observation techniques to study the first year of the implemented magnet plan. Presser, a senior from Yale, was placed at the school as a journalism teacher for three classes, two days a week for three months (Rosenbaum and Presser, 1978:159). The goal of the magnet program was to attract whites into a predominantly black school without causing violence. All whites (400) who applied for the program were accepted. Black students were accepted according to their academic talent interest areas. Unlike whites, not all black student applicants were enrolled. The school's racial balance was $70 / 30$ of whites to black students. Rosenbaum and Presser $(1978: 160)$ explained that innovative instructional technologies were planned: "The plan called for a multitude of special programs: interdisciplinary teaching, modules, individualized instruction, increased self-reliance, team teaching, broad and extensive course offerings, and parent input." 
Hess was not the complete success story it claimed to be, with numerous misconceptions and conceptual problems surrounding it. First, despite the overt objective of such a school plan, which was to desegregate its student body, the integration intent was never acknowledged openly to the student body. Instead, the school dwelt on the talent and uniqueness of each student. Rosenbaum and Presser (1978:168) observed that the student body was integrated but the talent classes were not:

Although the blacks constitute 30 percent of the school student body, their percentage only resembles this figure in three talents: art, instrumental music, and drama. Blacks are overrepresented in the other non-academic talents, and they are underrepresented in all three academic talents.

Also, in non-talent classes there were three paces offered: the fast program, the intensive program, and the regular program. In one English class that was examined closely, four out of eight students in the regular program were black students. Rosenbaum and Presser (1978) explained that the individualization of course work which had been promised could have alleviated such internal tracking.

A second problem was that Hess had promised special teachers for this school but reopened with the original Hess staff. This was due in part to the teacher's union. The Hess teachers opened the magnet school with only a three-hour lecture on teaching talented students. Also, they did not receive the special equipment they had been promised for the new talent programs.

A third shortcoming of the program concerned the loss of black students through the emphasis on the talent plan, rather than upon 
the original goal which was integration. Rosenbaum and Presser

(1978:182) explained the situation:

The talent emphasis in the Hess plan was meant to upgrade the school's academic image and to distract parents' attention from the potential stigma that might have accompanied integration. It did draw whites to the school, and it created an initial enthusiasm. But many teachers began to perceive talent as the central aim of the school and to perceive many blacks as inappropriate for the school, and they stopped trying to integrate blacks into classroom activities. The talent idea became transformed into the myth that talent was primary.

offering only clinical reform in technological areas, this option school even lost sight of its primary goals.

Two option schools for troublesome youth, Forgotten Ones High School in an unidentified Northeast urban area and Huntsville Alternative School in Alabama (Perry, 1980; Yates, Saunders, and Watkins, 1980) have been studied. Perry (1980) used participant observation techniques and interviews to gather data on Forgotten Ones High School where he was the principal. Yates and Saunders provide an insider's point of view as they were teachers at Huntsville Alternative High School and doctoral students at the University of Alabama where Watkins was a professor. Their study is descriptive. The two schools vary in their organizational arrangements. For example, the goals and philosophy at Forgotten Ones High School are not clearly stated but are said to be understood by all staff and students. The unspoken philosophy involves cultivating responsibility for one's own actions. The assumption is made that the standard or conventional model of schooling failed these youth. A three-part plan includes reducing the emphasis on student control, communicating support, and individualizing instruction to provide success for youth. 
On the other hand, Yates et al. (1980:712) asserted that a concisely stated philosophy for the Huntsville Alternative High School is based on Maslow's hierarchy of basic needs.

The technologies of these two option schools utilize unconventional teaching methods. For example, at Forgotten Ones High School, teachers individualize instruction in 60 percent of the classes so that students' progress is self-paced. Other teachers at that school develop worksheets so that learning is relevant and understood by this particular target population. Teachers work to create a relaxed school environment. Similarly, teachers at Huntsville Alternative High School individualize education, vary large and small group instruction, and employ student and teacher contracts. The use of contracts is intended to reach Maslow's highest level of needs (security, social, esteem and self-actualization) of self actualization. Also, the staff creates a humane environment at the school, reportedly by cooking breakfast and lunch for students and eating family-style with them (Yates et al., 1980:712). They also attend to a clothing bank and teach personal hygiene. Furthermore, staff join in recreational activities with youngsters.

Both schools have a counseling and advisory component. Additionally, both recognize the importance of the individual and work to develop the students' self concepts. While Forgotten Ones High School is free from central office constraints, neither school has a shared governance system. 
Forgotten Ones High School began with 326 assigned students and was so successful that the central office planned to double the enrollment the following year. According to Perry $(1980: 476)$ this school claims the following students' social adjustment gains: (1) subjective judgments indicated a calm school environment; (2) on the School Morale Survey, the school scored higher than the other conventional high school in the district; (3) thirteen of fifteen interviewed students preferred to stay at Forgotten Ones High School; (4) absenteeism dropped from 27 percent to 15 percent; and (5) the tardy rate declined from 32 percent to 4 percent. Success measures for the Huntsville students were not presented. These students are prepared to return to their home schools and this is the implied success measure.

A fourth kind of alternative education is of fered on a system level (see Figure 3). That is, alternative education is provided in public schooi systems from first grade through twelfth grade. Berkeley, Minneapolis, Seattle, and Philadelphia are among such school districts (Fantini, 1973; Moore, 1978).

The student population of alternative schools is examined next.

\section{ALTERNATIVE SCHOOL POPULATIONS}

Barr (1981) reports that about five percent of the public school population attend alternative programs. What type of student chooses this different way of schooling? more (1978:7) found that no generalization could be made about students or teachers in alternative schools: "What is clear from the literature on schools across the 
country, then, is that they serve an enormous variety of students: all classes, races, religions, academic background, aptitudes, and interests."

Alternative school students are a smorgasbord of gifted students, dropouts, pregnant teenagers, disruptive youth, students from different cultures, students interested in a multitude of careers, the artistically talented, and troubled youth (Arnove and Strout, 1980; Barr, 1981). Duke and Muzio (1978:469) found that 8 of 19 alternative school evaluations they reviewed were schools for students with behavior problems.

Drawing a distinction between alternative and option programs, Raywid (1982:12) states that the majority of new schools are being instituted for the special needs of disruptive and troubled youth:

In any event, student dissatisfaction, apathy, and underachievement explain the beginnings of a number of today's alternative schools: 69 percent of our respondents report that a majority of their entering students are functioning below local achievement norms; and 62 percent report that their entrants have presented behavioral problems at their previous schools.

The racial balance of alternative schools reflects those of their district. Examining social class, 38 percent of the schools report no particular class predominating. But, in 37 percent of the schools in the Raywid (1982:13) study, three-fifths of the students are lower class; 24 percent report middle class background with the same three-fifths representation; and, 1 percent are youth from upper class families:

It thus appears that more than a third of public alternative schools are mixed, rather than single-class schools; almost an equal number are distinctively "working class" schools: and a 
fourth are middle class schools. But again, whether this reflects more or less stratification than other schools in the same area is not known.

Thus, the students in alternative programs are of a mixed bag, with proportionately more disruptive students but overall not unlike their conventional school counterparts.

These reports challenge the myth that alternative schools exist for misfit students. All types of students attend alternative schools. The stereotype that long-haired-"hippie-typen" kids attend these schools is unsupported by the literature reviewed. 
CHAPTER VI

ORGANIZATIONAL CHARACTERISTICS OF ALTERNATIVE SCHOOLS

The purpose of this chapter is to analyze the organizational characteristics of alternative schools, providing the reader with insights into their different organizational patterns. First, the goals of alternative schools are reviewed.

GOALS

Historically, the objective of alternative schools, exemplified by free schools, centered on creating a model to replace conventional schooling (Raywid, 1981b). In the mid 1970's, goals of alternative schools changed to emphasize group awareness and individual responsibility. More recently, alternative schools provide alternatives and choices to the monolithicc, one best system of centralized bureaucratic schooling (Raywid, 1981b; Tyack, 1974).

The freedom and independence of the student as an individual is a primary assumption of alternative schools. Alternative schools' educators make significantly different assumptions about youth. For example, the founders of alternative schools stated that youth are different, that school personnel do not know a great deal about the learning process, and therefore, schools should tailor programs to the individual, utilizing a variety of teaching strategies (Anglin, 1979; 
Raywid, 1981b). In particular, Anglin (1979) differentiates between the presuppositions made about learners in traditional schools and alternative schools. Conventional school arrangements imply that students are uniform, that teachers know how and what to teach students, and therefore, efficiency and mass production are guiding principles of the standard bureaucratic formal structure (Anglin, 1979).

One widespread myth about alternative schools concerns the stereotype that they are "hippie schools," in which youngsters "do their own thing," and basic skills are not taught or learned (Moore, 1978). Some theorists (Arnove and Strout, 1980; Duke and Muzio, 1978; Fantini, 1973, 1974; Moore, 1978; Raywid, 1983; Wolfe et al., 1974) have spoken to this misconception. In the most recent national survey, Raywid (1982:21) found that 79 percent of the respondents stated that their school emphasized basic skills including "reading, writing, computation." Earlier, in the national Alternative Schools Program national survey, Wolfe et al. (1974) maintained that 75 percent of the experimental schools listed basic skills as a major program emphasis. They found that basic skills were often individualized with more time spent on their development. In particular, fundamental schools and continuation schools accentuated basic skill development (Moore, 1978). Responsibility is a goal of alternative programs (Crabtree, 1975; Ford Foundation, 1974; Silberman, 1970; Yates et al., 1980). Students learn that freedom and choice entail responsibility. For 
example, Crabtree (1975:615) explained that responsibility is a primary lesson at Chicago's Metro School Without Walls.

There are numerous other goals set in alternative schools, including vocational/career skills, life long learning skills, human relations skills, academic achievement, social skills, individual talent development, preparation for societal roles, nurturing of physical and emotional development, and survival skills (Arnove and Strout, 1980; Collins, 1980; Fantini, 1973; Moore, 1978; Nolan, 1978). Raywid (1982) views differences among alternative schools goals, particularly by curriculur emphasis, site location, size, and academic achievement. First, examining curricula concentration, the Raywid (1982:21) study found that 65 percent of the programs specializing in college preparation had basic skills as a primary focus. Learning skills and vocational/career skills were stressed by 53 percent and 45 percent of the alternative schools surveyed, respectively. Second, alternative schools located in urban areas concentrated primarily on vocational/career skills while their suburban counterparts emphasized human relation skills. Third, size of alternative schools was found to effect goals. Larger alternative schools held goals similar to conventional high schools, which included vocational/career skills, learning skills, and school skills (Raywid, 1982:22). Less emphasis was given to human relations skills in the larger alternative schools. Fourth, the achievement level of entering students at alternative schools influenced skill priorities. For example, Raywid (1982:22) found that schools with students with academic achievement levels below grade level showed goal emphasis in the order of: basic skills, 
human relations' skills, and vocational/career skills. But, schools where students' achievement norms were above grade level emphasized the following skills, in order of priority: learning skills, problem-solving skills, and basic skills. According to Raywid (1982:14), schools of choice are four times more likely to stress learning how-to-learn than no-choice alternative schools. An option school for disruptive youth is more likely to spend time on basic skill development and behavioral modification techniques to award appropriate behavior so that students can return quickly to their home school. On the other hand, an open alternative school, while emphasizing basic skills, is more likely to spend school time turning students on to the excitement of learning so that they would be life long learners.

In summary, Case (1981:555) insists that clearly-stated goals and a clear school philosophy are among the ingredients or characteristics of a successful alternative school: "Only a clear concept of philosophy and goals, serving as the single most important standard by which to evaluate all decisions, can prevent alternatives from either reverting to the practices of the traditional schools or floundering." Alternative schools need goals and a philosophy to define what the program supports, for processing interpersonal relations, for making educational decisions, and for protecting the program from external influences. Case (1981) explains that the demise of numerous alternative programs is due to the lack of clearly defined goals and a school philosophy. 
Although there are no questions directed specifically to the philosophies of alternative schools, goal orientations are indicated in the Raywid (1982) survey. Myths 2, 3, and 4 identified in the introduction of Part III were addressed by this discussion. First, in response to the myth that students do not learn basic skills, 79 percent of the schools responded that it was a primary goal (Raywid, 1982). Second, students are held responsible for their actions as choice-with-responsibility is another major emphasis of numerous alternative programs (Crabtree, 1975; Nolan, 1978). Myth 3 asserted that alternative schools do not have comprehensive goals and objectives, but the Raywid (1982) survey suggested that alternative schools have clear curricular orientations, skill emphasis, and preferred learning activities.

\section{TECHNOLOGIES}

Alternative schools go beyond utilizing curricula and instructional methods to encourage learning on the part of individual youth, making use of: (1) a humane school climate (Case, 1981; Collins, 1980; Ford Foundation, 1974; Moore, 1978; Silberman, 1970), (2) smaller school size (Arnove and Strout, 1980; Barr, 1981; Deal and Nolan, 1978b; Duke and Muzio, 1978; Fantini, 1973; Kozberg and Winegar, 1981; Raywid, 1980, 1982; Smith, Gregory, and Pugh, 1981), (3) similar per pupil expenditures (Case, 1981; Duke and Muzio, 1978; Fantini, 1973, 1974; Raywid, 1982), (4) flexible organizational arrangements and the ability to change (Anglin, 1979; Duke and Muzio, 1978; Moore, 1978; Raywid, 1980, 1981b), (5) unconventional grading 
systems (Ford Foundation, 1974; Kaplan, 1981; Nolan, 1978; Silberman, 1970; Trent, 1981), (6) career orientation and work opportunities (Arnove and Strout, 1980; Gibbons, 1974; Raywid, 1982), and (7) extended field trips (Raywid, 1982).

The following section will discuss: (1) the relationship between alternative technologies and their assumptions about learners, and (2) the numerous technologies employed. In the preceding section, a review of the assumptions that alternative schools have made about learners is presented by Anglin (1979) and Raywid (1981) which is that school personnel do not know a great deal about the learning process, and therefore, schools should tallor programs to the individual, utilizing a variety of teaching strategies. Barr (1981), Kozberg and Winegar (1981), and Smith et al. (1981) support this claim. Barr (1981:573) offered this presupposition:

Now a decade of documentation, research, and evaluation had proven them right. We now know that people learn in different ways; when schools are able to develop programs designed to meet individual needs, impressive gains occur. We now know that all children do not need 50-minute classes and standard textbooks; some do not even need teachers. Some students need a desk, visual aids, dictionaries, and libraries; others do not. Some students need rigorous structure to learn; others demand maximum flexibility.

Alternative schools capitalize on the uniqueness and individuality of learners and organize their technologies appropriately to aid in the learning process.

\section{Curriculum}

Some alternative programs are organized around one major theme such as Science, Business, Fine Arts, Mathematics, Vocational 
Education, and College Preparation (Moore, 1978). Specialized schools of this nature are discussed in Part II of this dissertation (see Figure 1). Magnet schools are a similar type of specialized school, designed to attract students for an intensive curriculum theme (Rosenbaum and Presser, 1978).

Schools-without-walls organize their curriculum around a central design which is the city as classroom (Moore, 1978:8). Another example is the career education focus in one Appalachian project where juniors and seniors spent 80 percent of their time at work experiences. Moore (1978:9) explains that this opportunity is intended to enable students to make wiser career choices. Students at the Lab School of Boston in the first semester of the 1976-77 school year choose curriculum themes of Life Cycles or Environmental Discovery. At the Lower Kensington Environmental Center at Philadelphia, students study urban ecology as well as basic skills and other academic subjects (Moore, 1978:4) Half of the schools in the Raywid (1982) study report curricula specialization and the other half reveal a general diploma or college preparation curricula. Other alternative schools report a career orientation, comunity service, and work opportunity as an integral feature of their curricula (Arnove and Strout, 1980; Gibbons, 1974; Raywid, 1982).

Recently, Raywid (1982:21) found that of schools with specialities in curricula, 68 percent are in career and vocational preparation and 33 percent are in college preparation. It appeared that the academic achievement level of students determines curricula in specialized schools. Overall, the national survey finds curriculum 
and content as the third most distinctive element of the responding alternative programs. Raywid (1982:19) states that teacher and student interaction patterns and instructional arrangements are more distinctive departure points. These matters will be taken up in later sections or this paper.

Finally, there are alternative programs which offer a variety of courses, of which many are interdisciplinary, encompassing perspectives in sociology, psychology, history, art, and philosophy (Moore, 1978).

\section{Teaching Strategies}

Alternative schools utilize numerous instructional strategies to affect learning: individualized instruction, discussion, independent study, some lecturing, films, guest speakers, simulation games, frequent field trips, group study, experimental learning, multi-age and multi-grade level learning, peer teaching, peer tutoring, extended field trips, intervisitations between alternative schools, action learning, heterogenous grouping, work opportunities, community service experiences, and learning contracts (Arnove and Strout, 1980; Fantini, 1973; Gibbons, 1974; Moore, 1978; Raywid, 1982).

Fifty-seven percent of the respondents in the Raywid (1982:21) national survey reported that instructional methods are a major point of emphasis in their program (Raywid, 1982:21). Independent study is disclosed to be the most frequent mode of study in 57 percent of the schools. Also, administrators of alternative schools maintain that 
individualized instruction affects success for all students and eliminates the tracking and ability grouping of students (Arnove and Strout, 1980; Moore, 1978).

Extended field trips are instituted in programs so that students can experience domestic and foreign travel, community living, and the group process. A community service component is reported in 31 percent of the schools in the Raywid (1982:21) study.

Parrett (1981) finds little disparity in instructional practices between conventional and alternative schools in his comparative study of five states. He gathered the opinions of 76 teachers and 1,506 students concerning their rank ordering of 36 instructional techniques. He found that teachers in conventional schools are utilizing similar instructional practices to those of teachers in alternative schools. Both sets of teachers claim that they are involving students in decision making. However, student replies contradict the involvement findings. That is, students state that they feel they are not making decisions about learning objectives or the means to obtain predetermined goals.

Teachers in alternative schools more of ten used community resources, teacher-prepared materials for individualized instruction, and contract learning. Parrett $(1981: 603)$ found that teachers in alternative schools are more involved with the problems and concerns of students. He concludes that instructiona]. strategies are not the determining variable explaining the measured differences between the two school types. Rather, Parrett (1981:603) calculates that such variables as school size, student/teacher ratio, and administrative 
organization are more decisive in explaining the differences than teacher attitudes toward instructional strategies.

$\underline{\text { Size }}$

Alternative schools are small (Arnove and Strout, 1980; Barr, 1981; Deal and Nolan, 1978; Duke and Muzio, 1978; Nolan, 1978; Raywid, 1981a, 1982; Smith, 1981). The Raywid (1982:10) national survey indicates that one third of all alternative schools enroll 50 students or less; one half have 100 students; and 69 percent have enrollments of 200 students or less. There appears to be a size distinction by geographical location within the metropolitan area. Urban alternative schools, located in central city areas, are inclined to be larger than suburban ones. Seventeen percent of urban alternative schools are larger in size than suburban alternative schools. Suburban schools are small as two thirds enroll 100 or less pupils. Raywid (1982:10) states that only 43 percent of the urban schools disclose schools of 100 or less pupils.

Some theorists (Arnove and Strout, 1980; Barr; 1981; Berger, 1974; Fantini, 1973; Kozberg and Winegar, 1981; McPartland and McDill, 1975; Nolan, 1978, Raywid, 1981a; Smith, 1981) claim that there is a positive correlation betwen smaller school size and students' affective gains. For example, small school size is correlated with reduced school vandalism, violence, and disruptions (Arnove and Strout, 1980; Berger, 1974; McPartland and McDill, 1975; Smith, 1981). In addition, small school size is said to be advantageous because of: (1) the distinct atmosphere created (Raywid, 1981a; Smith, 1981), (2) 
the individual treatment afforded students (Arnove and Strout, 1980) (3) the increased interaction allowed teachers and pupils (Arnove and Strout, 1980; Kozberg and Winegar, 1981), (4) the reduction of students' feelings of anonymity and powerlessness (Fantini, 1973; Kozberg and Winegar, 1981), (5) the steps toward humanization and decentralization (Fantini, 1973), and (6) the invitation for students to be involved in academic functions, school governance, and extracurricular activities (Kozberg and Winegar, 1981; Nolan, 1978).

\section{$\underline{\text { Cost }}$}

In the Raywid (1982) national study, 62 percent of the responding alternative schools report operating costs at or below local school board allocations. One third of the responding suburban alternative schools have greater per pupil expenditures than other local conventional schools in the district. Forty percent of the urban alternatives surveyed have greater per pupil expenditures than other district high school programs. Urban magnet schools operate on a higher per pupil expenditure because of greater transportation and equipment costs (Raywid, 1982:16). Duke and Muzio (1978) found that 2 of the 19 schools in their review had operational expenses less than other local schools.

Half of the vocational and career programs in alternative schools are more costly than conventional schools because specialization in curricula areas is more expensive. The Raywid (1982:17) study finds that alternative schools with target populations for lower class and low achievers are also more expensive. 
How do alternative schools manage to make do with scarce funds, considering their small size? They spend their allocations differently, thus, they often hire another staff person in preference to a new piece of science equipment. Students interested in athletics, for example, join their sister conventional high schools, thus saving alternative schools considerable extracurricular expenses (Case, 1981; Fantini, 1973).

Some theorists (Case, 1981; Fantini, 1973; Ford Foundation, 1974) urge that alternative schools be under the funding control of the local school board in order to survive. In the past, alternative schools were financed by federal, state, and local governmental grants, private funds, charitable contributions, and fund raising activities (Case, 1981; Duke and Muzio, 1978). But, Case (1981:556) insists that funding under the local school district is one of the five critical components for alternative school legitimacy: "However, schools that survived made the transition at some point from this so-called soft money to hard money--most frequently, general funding under the control of the local school board."

Myth 7 noted in the Introduction of Part III stated that alternative schools cost more, but the facts do not uphold that charge. That is, 62 percent of the schools are operating with per pupil expenditures equal to or less than those in the wider districts in which they were contained (Raywid, 1982). Magnet schools and other schools of option cost more than alternative schools according to the Raywid (1982) national survey. 
Grading

Alternative schools evaluate students' academic and social

progress in various ways. The list of techniques includes: (1)

student-written evaluations; (2) student-written transcripts; (3)

student/teacher conferences; and (4) end-of-the-term evaluations of

teachers, students, and courses (Ford Foundation, 1974; Kaplan, 1981;

Nolan, 1978; Silberman, 1970). At the Parkway School Without Walls in

Philadelphia, pass and no pass evaluations are awarded (Silberman,

1970). At the Village School, an open alternative school in Great

Neck, New York, there are no grades awarded or standardized

administrative tests given according to Kaplan's (1981:23) account:

There are no grades given at the school and no standardized tests. Students do not get class rankings. Students evaluated their own effort and achievement. They submit two selfevaluations, one at midyear, the other in June. There are narrative descriptions of the students' activities, responses to courses, and the students' views of their succesess and failures in coming to grips with their own education. These evaluations serve as the basis for their final high school transcripts. The transcripts comprise 10 to 20 typewritten pages, describing and evaluating classes students have taker, activities in which they have participated and their intellectual and personal growth.

Many alternative schools utilize evaluation processes discussed here although some schools still uphold standardized grading practices.

Evaluation, Flexibility and Change

Program evaluations are a way of life in alternative schools (Anglin, 1979; Duke and Muzio, 1978; Moore, 1978; Raywid, 1980, 1981a). Eight-five percent of the respondents in the most current national study disclose regular formal evaluations of their school, with 89 percent of those from outside evaluators (Raywid, 1982:16). 
Sixty-seven percent of the respondents in the Raywid (1982) study indicated that they evaluate their own programs.

Historically, evaluation has been a necessary component because many alternative schools began with seed money from private and public grants. Because of their unusual autonomy from central administrative offices, continued evaluation efforts of alternative schools are often monitoring attempts.

Because they are genuinely interested in achieving their goals and revamping their programs when necessary, alternative schools entertain evaluation efforts. Flexibility and change are a resilt of the ongoing evaluation of alternative programs (Case, 1981).

Effects on alternative schools have been difficult to measure, especially with descriptive data, because of the changing nature of these schools. Duke and Muzio (1978:456-466) argued:

The data, though, must be regarded with some caution, since alternative schools change with great frequency. What was true of a program in September may not be true in May. Descriptive data tend to "freeze" a school at one point in time and create the impression that it is stable. Alternative school observers are quick to point out, however, that these innovative ventures are "organic" and constantly evolving.

\section{Free Choice}

A key ingredient or innovative technology of alternative schools is free choice (Collins, 1980; Fantini, 1973; Gregory and Smith, 1983; Ornstein and Levine, 1981; Raywid, 1981a, 1982; Smith, Gregory and Pugh, 1981). One reason for the demise of Adams High School in Portland, Oregon is that students $(1,200)$ were assigned to Adams and did not freely elect to attend the experimental school (Collins, 1980). 
Some theorists (Fantini, 1973; Ornstein and Levine, 1981;

Raywid, 1981a) promote alternative schools so that parents can choose the best education for their children. Raywid (1981a) claims that free choice helps students, parents, and teachers overcome feelings of powerlessness and alienation.

Returning to a point made earlier, some authors (Gregory and Smith, 1983; Raywid, 1982; Smith, Gregory, and Pugh, 1981) maintain that free choice is the decisive feature of alternative schools and that variables such as size, informality, curriculum specialization, and school climate are interdependent but not as significant as this key dimension. Raywid (1982:14) claims this emphasis in the following statement: "Irrespective of what happens within the school, say some, the idea that one has chosen it--and can "unchoose"--is alone enough to produce special ties and effects."

In point of fact, 79 percent of the responding schools in the Raywid (1982:14) survey are schools of choice and 85 percent of the teachers at schools of choice are there voluntarily. Student choices within alternative schools vary according to the program. For example, the argument could be made that back to the basics schools have limited choices for students within their programs compared to open schools.

The technologies employed by alternative schools, the assumptions they make about learners, their formal and informal structures all interact to produce a different school climate or schooling experience for students and teachers. This matter will be discussed later, but first, the formal structures of alternative schools is examined. 
ALTERNATIVE SCHOOL FORMAL STRUCTURES

The formal structure of the school is defined as the roles of students, administrators, teachers, and parents. As in Part II, this discussion will address two questions: (1) who makes decisions affecting the policies and practices of alternative schools, and (2) to what degree does the formal structure of the alternative school control the participants of its organization? A response to the first question must begin with a literature review of the governance system of alternative schools.

\section{Governance}

Governance systems initiated in alternative schools depart from the student council system of conventional high schools (Chesler, 1978; Collins, 1980; Moore, 1978; Nolan, 1978; Raywid, 1980, 1981; Wasserman, 1976). In part, they follow the model rooted at Summerhill and other free schools in the private sector (Barr, 1981; Neill, 1960).

Governance systems in many alternative schools are called town meetings, all school meetings, student-staff meetings, and all school governance meetings. Some theorists (Chesler, 1978; Nolan, 1978; Wasserman, 1976) elaborate on case studies of particular alternative schools. For example, Nolan reports on the governance system of a school-within-a-school program at Rosalyn High School in New York. A rotating chairperson is utilized. Standing committees include the College Committee, Budget Committee, and Resource Committee. Temporary committees are enlisted when appropriate. Committee 
membership is voluntary but consists of student and staff persons. The whole school takes part in voting on issues and the majority rules.

Wasserman (1976) outlines the governance procedures of a schoolwithin-a-school program in Cambridge High and Latin School in Massachusetts. Participation in the governance system is an essential ingredient of this school's attempts to integrate Kohlberg's concept of a Just Community School. The plan incorporates Sccial Studies and English curricula with moral discussions and a governance system based on a participatory democratic model. The agenda for governance meetings is decided in advance by staff and students in advisory meetings and a democracy class. Wasserman (1976:205) explains that discussion in small groups of 12 or less is employed at governance meetings so that students are directly involved in issues, learn to articulate their opinions, and are exposed to high levels of moral development and reasoning.

On a broader level, Chesler (1978) reported on the research efforts of a group of investigators who examined six alternative high schools in the East in order to provide models for change in secondary public schools. White and interracially mixed schools were studied. Teams of three to six adults and students spent five days at the six sites gathering data including interview responses, questionnaire responses of all school particiants, observations of all parts of the schools, and school documents.

There were numerous gains by students from their involvement in school governance, including an enhanced sense of competency and self 
esteem, lower anxiety, a heightened commitment to learning, improvement of communication and interpersonal skills, and improved decision-making skills (Chesler, 1978; Tjosvold, 1978).

Nolan insists that, with time and instruction, students can learn governing skills. Students experience adults in a different light, namely as sources of expertise and assistance rather than as authority figures. Wasserman (1978) acclaims the higher levels of intellectual and moral development that the experience with governance systems allows students.

Governance systems in alternative schools have not been found to be problem free (Collins, 1980; Moore, 1978; Nolan, 1978; Raywid, 1982; Wasserman, 1976). Some alternative schools do not have a governance system but they do have some decision making by participants (Moore, 1978). Raywid (1980) argues that alternative schools need a place where participants can air their feelings about the program. She also found that the alternative schools with the largest degree of autonomy had students who were very active in decision making.

Nolan (1978) and Wasserman (1976) point to problems of governance systems. First, alternative schools must be small so that students and staffs can effectively debate and vote on issues. Second, student-run schools are not found to meet the needs of all students and teachers, thus policies to redirect such students is recommended. Third, if governance systems are weighed down with administrative issues then they are often times viewed as boring by students. These problems did not uniformly apply to all individual 
alternative schools. That is, a particular alternative school with an effective governance system might be free of the problems outlined by the theorists reviewed.

Raywid (1982:16) found that governance in alternative schools has changed from earlier participatory democratic models to an educationally oriented model involving teachers and students in planning. Explanations for this shift include: (1) preference for informal arrangements over more time-consuming formal structures, and (2) many alternative schools have, over time, reached program designs which are suitable for participants and no longer necessitate formal governance structures. Only 23 percent of the schools surveyed in the Raywid (1982:30) study responded that decision making is a distinct feature of their program.

These findings can be directly related to Myths 6 and 3 in the Introduction of Part III. For example, the formal structure of alternative schools is different from that of conventional high schools and directly involves and includes youths. Students are assumed to be individuals who are treated as adults and are given the opportunity and responsibility to make direct decisions about their educational programs and governance systems. Also, alternative schools employ individual instruction and numerous other learning techniques to untrack students and allow them to progress at their own rate. In addition, the small size of alternative schools works to diminish the cliques typically of larger conventional high schools. Myth 6 is not upheld by research findings, as alternative schools work to untrack students, involving them in decision-making practices, and treating them as individuals. 
The governance systems of alternative schools suggest different roles for participants which is discussed next.

\section{Administrators in Alternative Schools}

The governance systems and organizational patterning of alternative schools involve a different role for school administrators than the one played by conventional school administrators. Their role is diffused and not neatly defined (Nolan, 1978; Raywid, 1982; Wasserman, 1976; Wolfe et al., 1974). For example, Wolfe et al. (1974) found one principal who performed custodial and janitorial duties as well as directing the program. Fantini (1974) recommended that alternative school principals be centrai planners, bringing together students, parents, teachers, and community people. Raywid (1980) advocated that the role of the administrator be a shared position so that programs would not collapse with the departure of a charismatic leader. Nolan (1978) described a principalship which was a shared position. Wasserman (1976) advocated a revolving administrator, appointed monthly.

The traditional role of the administrator is altered, with principals being in closer contact with students, teachers, and the classroom. In essence, they are closer to the experiences that brought them into education initially. Findings of the Raywid (1982:24) study revealed that 20 percent of the responding schools function without a principal. This fact lends support to Wasserman's (1976:214) proposition that alternative schools operate under a different formal pattern: "Thus the conventional administrative 
pyramid has been replaced by a flexible structure which encourages the authentic sharing of authority, power, and responsibility."

\section{Teachers in Alternative Schools}

Teachers are the backbone of alternative schools and central to their programs (Arnove and Strout, 1980; Duke and Muzio, 1978; Perry, 1980; Raywid, 1982; Wasserman, 1976). Going beyond the role of information disseminator, teachers must be willing to interact with students and support them (Duke and Muzio, 1978; Perry, 1980). Three of the four most distinct features of alternative schools in the Raywid (1982:19) survey are teacher related, emphasizing the impact of teachers rather than curriculum. The three departures from conventional schools relating to teachers were: Teacher-student interaction, instructional methods, and teacher roles.

What do alternative school teachers look like? Are they the bearded, liberal, denim-dressed persons stereotyped as such in conventional educational circles? Moore (1978) found that no generalizations could be made about alternative school teachers, although he observed subtle differences. They tended to be slightly younger, had less teaching experience, finished fewer years of graduate school, and were less likely to be married than were teachers in conventional schools. These differences were not significant enough to conclude that there are predictable differences between conventional and alternative school teacher types. Moore (1978) found that alternative school teachers relate informally with students, frequently on a first name basis. 
Similar to administrators of alternative schools, teachers have a demanding and diffused role (Arnove and Strout, 1980; Raywid, 1982). Because of small staffs, teachers share jobs and responsibilities and perform multiple functions. Due to the value that, alternative schools place on the individual, teachers often work extra hours and weekends, aiding students. For example, on extended field trips, teachers are responsible for students on a 24-hour basis.

Teachers have a positive effect on students in alternative schools. Their close interaction and caring for students causes them to feel better about their schooling experience, produces lowered vandalism rates, and brings improvement for students with negative behavioral histories (Arnove and Strout, 1980; Barr, 1980; Perry, 1980; Raywid, 1980; Wasserman, 1976). Arnove and Strout (1980:457) explain these experiences in the following manner:

While disruptive students rate teachers in their former schools in negative terms, they also tend to rate the teachers in the alternative schools as the single most important factor affecting their positive feelings about these programs. Whereas teachers in conventional schools are viewed as being more concerned with lesson plans and getting paid than meeting the needs of students, they are viewed in the alternative programs as confidents and friends, people students can turn to when they are in trouble or feel upset.

There are "burnout" problems for teachers at alternative schools because of the degree of involvement and other demands (Arnove and Strout, 1980; Raywid, 1980). Sabbaticals have been recommended to relieve the strain of teaching at alternative schools (Raywid, 1980). Often, teachers seek alternative schools as a way to individualize instruction for students and escape the formalities of slowly changing conventional school structures and they report high morale despite the 
pressing demands on their time (Raywid, 1982). High morale is due to the experience of success with students and their programs, the ownership of alternative programs and the ability to change ingredients when necessary, and the degree of professionalism demonstrated by attendance at outside workshops and other career activities (Raywid, 1982).

Alternative school teachers play a novel role: their job is complex, responsibility is shared, and professional satisfaction is reported.

Myths 1 and 5 in the Introduction of Part III have been explored by these data. For example, Moore (1978) maintained that there were no generalizations that could be made about alternative teacher types. They are not misfits and not significantly different from their counterparts in conventional schools. Raywid (1982) reports that alternative school teachers employ whatever technologies are necessary to effect student success, thus teachers expect and work for success with their students.

The two questions posed at the beginning of this discussion of formal structure have been answered. It is found that decision making is a collaborative effort in alternative schools, involving all participants in school governance meetings. Alternative schools with no governance systems report some student decision making, particularly in matters of educational planning. Second, because of the small size of alternative programs and the governance system, roles are diffused and responsibilities are shared. The formal structure is informal and nontraditional. The examination of the informal 
structure of alternative schools is examined next, beginning with the advisory component of these schools, followed by the affective and standardized gains of these schools structures.

INFORMAL STRUCTURE OF ALTERNATIVE SCHOOLS

\section{$\underline{\text { Advisory Systems }}$}

The advisory system at alternative schools differs from the once-a-year or crisis visits to the counselor typical of large conventional high schools. Weekly advisory meetings of small groups of students and a teacher or staff member exist to establish personal relationships between students and their advisor, to discuss social and academic problems, to initiate issues for governance meetings, to understand the various functions and components of their schools, and to report on academic and social progress (Kaplan, 1981; Perry, 1980; St. Germain et al., 1975; Yates et al., 1980). Variations of advisory systems allow student responsibility and ownership of the school's programs to be fostered through this weekly check in and update of problems and progress. Advisory systems are the heart of alternative programs, establishing a dialogue between students and their advisor about the importance of the individual's needs and aspirations.

\section{Student Gains}

Some theorists (Ford Foundation, 1974; Duke and Muzio, 1978; Gregory and Smith, 1983; Moore, 1978; St. Germain, Carten, and Meland, 1975) have claimed that alternative schools are doing at least as well as conventional schools in academic preparation. For example, the 
Ford Foundation found that alternative school students perform as well as their conventional school counterparts in cognitive development. Alternative school students from the attendance area of their conventional high schools were tested and interviewed in depth along with their conventional school counterparts, with the alternative students demonstrating superior results in academic and affective areas (Gregory and Smith, 1983). A Statements About School (SAS) testing instrument and a range of achievement scores for both schools yielded the measurement differences of the two school types (Gregory and Smith, 1983). Similarly, Perry (1980:476) reports that alternative school students scored higher on the Schools Morale Survey than did conventional high school students in the Northeast urban district.

Student success is also maintained in areas of improved self-concept, increased credits, increased academic achievement, decreased discipline referrals, decreased school suspensions, better school attendance, and a declining tardy rate (Kaplan, 1981; St. Germain et al., 1975; Nelsen, 1975; Sulack, 1975; Perry, 1980; Raywid, 1982). For example, in the case studies presented previously, the following results were reported for alternative schools on student attendance: (1) increased attendance rates at four evaluated schoolwithin-a-school programs; (2) 70 percent of the students at the Focus Program at Madison High School in Portland, Oregon became better attenders (Nelsen, 1975:631); (3) 75 percent of the students who finished one year of the school-within-a-school alternative program at Anaheim (California) High School increased their attendance rate 
(Sulack, 1975); (4) the absenteeism dropped from 27 percent to 15 percent and the tardy rate declined from 32 percent to 4 percent at Forgotten Ones Alternative School (Perry, 1980:476). Raywid (1982:17) states that 81 percent of the surveyed schools claim attendance increases and 38 percent of them report sharp increases in attendance. Eighty-nine percent of the schools of options for dropouts and behavioral problems have increases in attendance with 46 percent demonstrating sharp increases (Raywid, 1982:17). Eighteen percent of the schools maintain no change in attendance rates and 1 percent indicate a decrease (Raywid, 1982:17). Increased attendance rates are viewed as strong indicators of students' conmitment to their alternative programs.

The satisfaction of one student from one open high school program in Great Neck, New York is captured in the following quote presented by Kaplan (1981:23):

Before I came to the Village School I was bored, nonchalant, frustrated, unhappy with myself and repressed. Bored of classes that didn't interest me, nonchalant because there was no way I saw that I could change anything, lonely in a crowd of 1,000 strangers, frustrated because I couldn't learn what I felt I wanted to, and repressed because of it. I came to the Village School quiet, without self-confidence and with many fears. I had never had any say in what happened to me and the new pressures and responsibilities seemed almost unbearable. I listened a lot and tried to feel out the school and where I belonged in it. Slowly, I began to notice the enthusiasm that was flowing all around me. People were involved with their education, their own school and other people in the school. I guess it was contagious because I caught it. I then began to spend a lot of time in my room, lecturing myself and crying at my stupidity and my faults. What came out of it was more than worthwhile. I needed that time to face myself, my failures and my successes. I realized that from that point on I had no one but myuself to blame when things go wrong and myself to congratulate when things go right. Life is not 
without its boredom or loneliness now that I'm in the Village School. But it is overwhelmingly filled with excitement for what I'm doing and a feeling of knowing that tomorrow $I$ may be doing something else . . just as rewarding.

Smith, Gregory, and Pugh (1981) developed the SAS (Statement About Schools) Inventory. It is based on Maslow's hierarchy of needs (Security, Social, Esteem, and Self-Actualization) and assesses now well a school satisfied students' needs, measured by students' and teachers' opinions. The study included 7 alternative and 6 conventional high schools in 4 states and 459 students and 104 teachers from alternative schools, 622 students and 379 teachers from conventional schools.

The SAS Inventory was completed twice by students and teachers. The first score measured their actual attitudes about their school, while the second score quantified their opinions of their ideal school situation. An Adjusted Needs Satisfication score for each person sampled was computed by Smith et al. (1981:5610 and these scores were compared in the study.

The hypothesis tested was that choice, variety, and environmental characteristics of alternative programs would make students in them more satisfied. Although the surveyed alternative schools included a "back to the basics" school, the lowest scoring alternative school scored higher than the highest scoring conventional high school. Security, the first level of the needs, was the only one on which no significant difference between the two school types turned up. Students from alternative versus conventional schools differed significantly on the three higher level needs. According to this 
survey, alternative schools were meeting students' needs on the three higher levels (Social, Esteem, and Self-Actualization), measured by students' opinions.

In a more recent study of Gregory and Smith (1983), the SAS was used to survey a larger school population involving 44 schools in 14 states: 24 alternative high schools paired with 20 of their sister conventional high schools. According to the results, three groups (alternative school teachers, conventional school teachers, and students from conventional schools) desired more control and order in their schools. Students in alternative schools were satisfied with the order and structure of their programs. Conventional school teachers indicated that they felt they were meeting security needs at a competent level. Students from conventional schools indicated that schools were not meeting those needs.

In Social Needs, the actual scores from the lowest alternative school were equal to those from the highest conventional school. There was no overlap in scores between the two teacher types as Gregory and Smith (1983:8-9) report: "Thus, both alternative school teachers and students are experiencing school as a warmer, friendlier place than are the teachers and students in the larger, more impersonal conventional schools."

In Esteem Needs, there was a significant difference between alternative schools and conventional schools in the actual scores of their students, although with ideal scores Gregory and Smith (1983:8-9) reported some overlap between the four types; "In general, both al.ternative school students and teachers describe themselves as 
being more satisfied with their school settings than do their conventional school counterparts." In Self-Actualization needs assessment, the actual scores of students and teachers in alternative schools exceeded their conventional high school counterparts by one to two standard deviations.

The conclusions of the Gregory and Smith (1983:10) study are that: (1) while the school types overlapped on the Security Needs assessment, alternative schools were superior when meeting higher level needs; and, (2) alternative students were more satisfied with the climate of their schools.

\section{Alternative Schools as Effective Schools}

School climate, effective schools, and quality school indicators are discussed in Part II. A warm climate is defined as one of the 12 indicators of a quality or effective school (Colorado Department of Education, May, 1982). In the following discussion, the term effective school will be used to stand for all the factors which combine to produce a healthy and successful school.

The Rutter et al. (1979) investigation of 12 secondary schools in London found that students with comparable backgrounds were effected differently by the various secondary schooling institutions they attended. That is, school experiences within the secondary schooling process produced more positive outcomes at some schools than others.

Some theorists (Arnove and Strout, 1980; Case, 1981; Perry, 1980; Raywid, 1981a, 1982; Smith, 1981; Swidler, 1976) have claimed 
that alternative schools are effective in creating a unique and distinct atmosphere and environment. For example, utilizing a School Climate scale, Case (1981) found that after its first five months, Project 12, an alternative school in Tulsa, was rated higher by students than their previous schools, in all cases. The scale by Case (1981:557) included measurement in three areas: (1) students' feeling of power; (2) extent of caring in the school; and (3) the extent to which the curriculum meets the individual needs and provides success. Case (1981) and Raywid (1982) portrayed different schooling experiences for alternative school participants. Administrator's roles are diffused and administrators are in closer contact with students than administrators in conventional schools. Teachers experience less "burnout" despite the extra demands of their job because teaching in an alternative school is rejuvenating (Case, 1981). Teachers collaborate more over diverse and multiple tasks and responsibilities. Jobs are awarded by talent and preference. Parents, students and peers in alternative schools expect nothing less than success from teachers working with individual students. Numerous technologies, teaching strategies, and learning styles are employed to effect a student's success. Also, teachers are often advisors and counselors to students. Teachers feel close to students and other staff members. Because their input is integral to changing components of the school, teachers are responsible and express ownership for their programs. Teachers in alternative schools are also reported to be professionally active (Raywid, 1982). 
Students feel warmth, trust, and care in the school climate of their alternative programs and find the work stimulating and challenging. They have close interpersonal friendships with other students and adults, cliques are less prominent, and students acquire friends from many backgrounds. The feel powerful and effective in decision-making matters concerning their personal educational agendas, as well as that of the alternative school program. Raywid (1982:25) concludes that students in alternative schools are successful because: "The combination--of the sense of personal efficacy, choice, and success--is the way many explain the new levels of achievement often reached by alternative school students."

Myths 6 and 8 identified in the Introduction of Part III claim that alternative schools isolate students and that they do not learn anything at these schooling institutions. Through technologies such as apprenticeships, work experiences, community service components, and extended field trips students are exposed to and integrated with the larger society outside of the school community (Raywid, 1982). Also, studies (Duke and Muzio, 1978; Ford Foundation, 1974; Gregory and Smith, 1983; Moore, 1978; Raywid, 1982; St. Germain et al., 1975) have maintained that alternative schools are doing as well as conventional high schools in their social and academic preparation of youths. Gregory and Smith (1983) found that alternative school students performed in a superior way to their sister conventional high school student body on tests measuring academic and affective gains. Overall, alternative schools demonstrate healthy and stimulating school climates. Raywid (1982:25) argued that alternative schools are 
places for "turned on" teachers and students. A brief discussion of the ecological influences upon alternative schools is presented next.

ECOLOGICAL INFLUENCES

As in Part II, the ecological influences on secondary schools will only be briefly mentioned. The ecological influences on alternative schools are similar as those of conventional high schools. In addition, alternative schools either protect themselves from the political and economic shifts in the country or perish. Alternative schools are many times parent initiated and this aids their survival (Case, 1981; Raywid,, 1982; Smith, 1981). Because of their distinct administrative arrangements and free choice status, alternative schools exist in a volatile political environment. Collins (1980) argued that a poor public image contributed to the termination of Adams High School in Portland, Oregon. Oftentimes, alternative schools are misunderstood by community persons but because many have been initiated, in part, under the public school system and have operated on a similar per pupil expenditure as conventional high schools, alternative schools have survived.

A SUMMARY: SCHOOL REFORM AND ALTERNATIVE SCHOOLING

Alternative schools are viewed as the model for reforming public education (Barr, 1981; Nolan, 1978; Raywid, 1981b, 1982; Smith, 1981). The initiation of alternative schools is a step away from the monolithic educational system toward a diversified system of educational alternatives (Barr, 1981; Fantini, 1973, 1974). Also, alternative 
schools act, in part, as safety valves for comprehensive high schools, serving troubled, disaffected, and special needs students (Nolan, 1978). Third, various alternative school organizational arrangements, such as the advisory system, have potential for impacting conventional high schools so that the latter might be more successful in dealing with students (Barr, 1981; Nolan, 1978).

Generally, alternative schools offer innovations in educational reform in the areas of: (1) advancing pluralism, diversity, and equal educational opportunity through choice; (2) decentralizing the formal structures of schools; (3) localizing aspects of curricula for special needs and target populations; (4) involving community members in planning, operating, and evaluating public schools; (5) and, reducing school violence, vandalism, and disruption (Arnove and Strout, 1978; Barr, 1981; Raywid, 1981a, 1982).

Summary propositions about alternative schools are presented in the following chapter. 
CHAPTER VII

THE STATUS OF ALTERNATIVE SECONDARY SCHOOL ORGANIZATIONS: SUMMARY STATEMENTS

\begin{abstract}
Chapters $\mathrm{V}$ and $\mathrm{VI}$ reviewed various components of alternative school organizations. Chapter VII will delineate summary statements concerning the ways alternative schools are organized. The challenges and charges leveled against secondary school organizations will also be addressed. However, before presenting those statements, 26 summary conclusions are offered.
\end{abstract}

ALTERNATIVE SCHOOL SUMMARY STATEMENTS

(1) Historically, alternative schools are rooted in the Progressive Education movement of the 1920's and the free schools of the early 1960's (Arnove and Strout, 1978; Deal and Nolan, 1978a; Raywid, 1982). A debate persists on the actual beginnings of this school type. Ideologically, alternative schools originated for two reasons: (1) to replace traditional models, (2) to move from monolithic system of one best way to education youth, in order to offer options or choices of diverse educational models to consumers (Barr, 1981; Deal and Nolan, 1978a; Raywid, 181b).

(2) Some theorists (Arnove and Strout, 1978; Collins, 1980; Moore, 1978) maintain that alternative schools initiated in the public system by parents, teachers, students, and community persons are the most viable ones.

(3) Because of the wide range of alternative schools offered, a universal definition of alternative education has not been reached (Moore, 1978). But, a distinction between alternative schools and schools option is drawn by Raywid (1982). 
(4) Alternative schools continue to grow in numbers despite the conservative political and economic conditions of the early 1980's (Barr, 1975; Raywid, 1982; Wolfe et al., 1974).

(5) Two classification schemes of alternative school types have been developed. A first strategy categorizes schools in terms of how markedly their organizational characteristics separate them from traditional school organizations (Anglin, 1979; Deal and Nolan, 1978b; Fantini, 1974; Moore, 1978). A second classification theme identifies the levels of alternative school operation.

(6) Student populations of alternative schools are from all sectors of society or a mixed bag. No generalizations can be made about the youths who chose alternative schooling (Moore, 1978; Raywid, 1982).

(7) Alternative schools began with the intention of providing a model to replace traditional schooling. This goal changed to emphasize group awareness and the individual. Presently, challenging the monolithic system of educating, alternative schools present themselves as diverse choices for the parents seeking other ways to educate their children (Raywid, 1981b; Tyack, 1974).

(8) Alternatives operate on the assumption that students are individuals with different needs. Numerous teaching strategies are employed to assist these individuals in the learning process (Anglin, 1979; Raywid, 1981b).

(9) Seventy-nine percent of the alternative schools in one current national survey report that basic skill development is a primary goal of their program (Raywid, 1982).

(10) Teaching a sense of responsibility is a fundamental goal of alternative programs (Crabtree, 1975; Ford Foundation, 1974; Yates et al., 1980). Other goals include: vocational career skills, life long learning skills, human relations skills, academic achievement, social skills, individual talent development, preparation for societal roles, nuturing of physical and emotional development, and survival skills (Colling, 1980: Arnove and Strout, 1980; Fantini, 1973, 1974; Moore, 1978; Nolan, 1978). Goals of alternative programs are ranked by factors such as school location, curricular emphasis, and student body needs (Raywid, 1982).

(11) Clearly stated goals and a school philosophy are essentiaf for the survival of an alternative school (Case, 1981).

(12) Various curricular designs are used by alternative programs. There are alternative programs organized around 
a curricular theme (Moore, 1978; Rosenbaum and Presser, 1978). Some schools specialize in career and vocational preparation and college preparations (Raywid, 1982). Schools without walls organize their curriculum around a central design which is the city as a classroom (Moore, 1978). A career orientation, community service component, and work opportunity are ingegral features of some alternative schools (Arnove and Strout, 1980; Gibbons, 1974; Raywid, 1982). Curricular specialization depends on the needs of the student body at a particular program. Curriculum content is the third most distinct feature of programs responding to a recent national survey (Raywid, 1982).

(13) Numerous instructional strategies are employed by alternative schools. Independent study, individual instriaction, extended field trips, and community service experiences were disclosed as the most frequent strategies employed by alternative schools (Raywid, 1982).

(14) Alternative schools are small (Arnove and Strout, 1980; Deal and Nolan, 1978b; Duke and Muzio, 1978; Raywid, 1982; Smith, 1981). Small school size affects students' success and contributes to creating a warmer school climate (Raywid, 1981a; Smith, 1981).

(15) Sixty-two percent of the schools in a recent national survey operated at or below district expenditures set for other schools (Raywid, 1982).

(16) A variety of grading and evaluation systems is employed by alternative schools (Ford Foundation, 1974; Kaplan, 1981; Nolan, 1978; Silberman, 1970).

(17) Due to continuing and ongoing evaluations of alternative schools, they are flexible and constantly changing their organizational arrangements (Duke and Muzio, 1978; Moore, 1978; Raywid, 1980, 1981a).

(18) A key ingredient of alternative schools is free choice. Seventy-nine percent of the alternative programs in the Raywid (1982) study were schools of free choice.

(19) Alternative programs show different administrative arrangements which include all members of the school involved in school governance meetings (Chesler, 1978; Moore, 19'78; Nolan, 1978; Wasserman, 1976). Governance systems in alternative schools have shifted from a participatory democratic model to an educationally oriented model (Raywid, 1982). All alternative schools report some degree of student decision making (Raywid, 1982). 
(20) Administrators in alternative schools experience diffused roles (Nolan, 1978; Raywid, 1982; Wasserman, 1976; Wolfe et al., 1974).

(21) Teachers in alternative schools experience more demanding roles than their conventional school counterparts. They are the main ingredient of alternative programs (Arnove and Strout, 1980; Duke and Muzio, 1978; Perry, 1980; Raywid, 1982; Wasserman, 1976).

(22) Advisory systems affect: (1) students' interpersonal relations with other students and teachers, and (2) students' commitment and ownership of the alternative program where they are enrolled (Kaplan, 1981; St. Germain et al., 1975; Yates et al., 1980).

(23) Alternative schools create student academic and affective gains at least equal to if not greater than those of conventional high schools (Ford Foundation, 1974; Duke and muzio, 1978; Gregory and Smith, 1983; More, 1978; St. Germain et al., 1975).

(24) Alternative schools are organized so that school climates are unique and distinct (Arnove and Strout, 1980; Case, 1981; Perry, 1980; Raywid, 1981a, 1982; Smith, 1981; Swidler, 1976).

(25) The ecological influences on alternative schools are similar to conventional schools although community opinion exerts an external pressure on alternative programs that could be lethal (Smith, 1981; Raywid, 1982).

(26) Alternative schools are viewed as the model for reforming public education (Barr, 1981; Nolan, 1978; Raywid, 1981b, 1982; Smith, 1981).

\section{CHARGES AGAINST SECONDARY SCHOOLS--THE ALTERNATIVE SCHOOL RESPONSE}

This section responds to charges leveled against secondary school organizations which are presented in Chapter II.

First, some theorists (Brown, 1973; Coleman, 1974; Martin, 1974; $\checkmark$ Weinstock, 1973) have asserted that schooling institutions have not responded to changes in youths' development stages. On the contrary, 
the organizational elements of alternative schools consider the needs of individual students. In particular, the assumption is made that every student is an individual with specific needs and talents. An array of instructional methods is used to address personally-set educational goals (Arnove and Strout, 1980; Fantini, 1973; Gibbons, 1974; Moore, 1978; Raywid, 1982). The whole child is central to the organization of innovative schools. That is, goals are set for providing development of all students' academic and social needs. These schools are organized to effect more than basic skill competency. Socially, alternative schools employ smaller size in order to increase teacher and student interaction (Arnove and Strout, 1980; Kozberg and Winegar, 1981). Also, smaller school size and innovative governance structures provide an environment for positive student affective gains of school commitment, personal power, and feelings of belonging (Fantini, 1973; Kozberg and Winegar, 1981; Nolan, 1978). Small school size gives students the opportunity to interact with more diverse personalities and break through social cliques that are characteristic of larger schools (Raywid, 1982). Academically, individualized instruction and independent study discourage academic tracking and negative labeling of less scholarly students (Arnove and Strout, 1978; Moore, 1978). Innovative teaching strategies provide students with opportunities to develop special interests at their own pace.

Politically, the participatory democratic governance system allows students "hands on" experience with the governmental processes of their schooling environment and knowledge of the inner workings of 
other bureaucratic organizations (Chesler, 1978; Moore, 1978; Nolan, 1978; Wasserman, 1976; Raywid, 1980, 1982). At the very least, the inclusion of students in decision making cultivates in them a sense of responsibility for their own education (Raywid, 1982).

Overall, studies (Gregory and Smith, 1983; Smith, Gregory, and Pugh, 1981) have found that alternative schools successfully reach higher level Social, Esteem, and Self Actualization needs, measured by opinions of students and teachers in alternative schools and in conventional schools.

Second, some theorists (Carnegie Council, 1979; Coleman, 1974) have argued that high schools reflect segregation policies and engage in a custodial role which may cause isolation, dependency, and the alienation of youth. This charge is unfounded for alternative schools. Alternative schools provide a structure in which individuals can discover and develop themselves. Alternative schools are subversive in the respect that they do not uphold the status quo but focus on the development of the individual. For example, they move beyond immediate academic achievement and also develop survival and life long learning skills, preparing individuals for a full and independent future (Arnove and Strout, 1980; Collins, 1980; Fantini, 1973, 1974; Moore, 1978; Nolan, 1978). For example, the Parkway School Without Walls in Philadelphia engaged the city as its learning resource and laboratory (Crabtree, 1975; Silberman, 1970). Students utilize the mass transit systems to commute to various public institutions where they are frequently involved in projects, apprenticeships, and classes. 
Schooling technologies including work opportunities, extended field trips, and community service experiences provide students with close interaction and integration with persons of all ages from the larger society. The world is the classroom for many alternative programs (Arnove and Strout, 1980; Gibbons, 1974; Raywid, 1982). To help alleviate pressure, anxiety, and competition, alternative schools employ flexible grading systems (Ford Foundation, 1974; Kaplan, 1981; Nolan, 1978; Silberman, 1970). The advisory and governance systems provide a forum for students' opinions to be aired. Because evaluations are a way of life to alternative schools, many programs apply research results to change and improve their program (Anglin, 1979; Duke and Muzio, 1978; Moore, 1978; Raywid, 1980, 1981a). Students are encouraged to become active participants in the change process.

A third charge leveled at secondary schools is that they apply goals and technologies which are alienating and irrelevant to youth. This criticism is untrue for alternative schools. They set goals and apply technologies that are relevant and applicable to the development of the whole person. Also, the needs of the individual rather than the status of the advanced, average, or low groups of students are focused upon for development.

A fourth charge has been made that secondary schools apply an assimilationist's point of view which can cause student alienation. Alternative schools have been criticized for causing segregation of special groups of students for having a staff of ideologues (Arnove and Strout, 1980; Barr, 1981). Magnet schools or schools for targeted 
groups of the conventional high school population are not alternative schools as defined by Raywid (1982), These special purpose schools do cater to homogenous groups of students. Alternative schools are not segregated but ratios reflect those of the larger district (Raywid, 1982; Wolfe et al., 1974).

Because of the off campus activities which integrate learning with all age groups of the larger society, students at alternative schools have the opportunity to associate with a broad spectrum of people. Also, within building units, because of the small community size, alternative school participants develop closer relationships with a wider variety of personalities (Raywid, 1982). Advancing pluralism and diversity is an innovation in educational reform reported by alternative schools (Arnove and Strout, 1978; Barr, 1981; Raywid, 1981a). Next, Part IV closely describes and examines the organizational features of one alternative high school. 
PART IV

MOUNTAIN OPEN HIGH SCHOOL: A CASE STUDY OF ONE ALTERNATIVE PUBLIC HIGH SCHOOL 
CHAPTER VIII

AN OVERVIEW OF MOUNTAIN OPEN HIGH SCHOOL

This study of Mountain Open High School (MOHS), located in Evergreen, Colorado was undertaken in the 1980-1981 school year, during the school's sixth year of operation. Historical documents were collected and analyzed and included (1) the original proposal for the school, (2) the Audit Committee's Task Force Reports for the first three pilot years, (3) the North Central Accreditation Team's Report during the fifth year, (4) local and metropolitan newspaper accounts of various aspects of the school, (5) MOHS' Self Study (1979-1980), and (6) other secondary sources. In addition, direct observations of the school's activities (Governance, classroom observations, Beginnings Classes, and one Extended School Trip) and in depth interviewing of 13 student volunteers provide descriptive material to supplement the information yielded in historical documents. The methodology of this case study is identified in Chapter I. The volunteer student interviewees are first, second, and third year students from four identifiable groups of MOHS students (Self Study, 1979-1980): academically stifled students from traditional schools (one volunteer), students from conventional schools (three volunteers), Open Living students from the feeder alternative K-9 program (four volunteers), and dropouts returning to school (four 
volunteers). One other student volunteer was an exchange student from Switzerland and a first year MOHS student. The 13 students were interviewed about their opinions of various MOHS organizational characteristics (see Appendix B for an interview schedule). Student interview responses are used as descriptive material and because space limitations do not allow the reporting of all replies, the quotes included in this case study represent the range of student reactions indicated in the interviews.

Part IV presents a description of MOHS' organizational characteristics. In particular, Chapter VIII presents information on history, location, and student population of MOHS and Chapter IX examines the organizational characteristics of MOHS. Finally, Chapter $X$ provides summary statements or propositions about the MOHS organization arrangements. The charges leveled against secondary school organizations are addressed by the information provided in the case study of MOHS. Third, the research questions posed by this study are answered. Finally, recommendations for future research are made.

\section{LOCATION AND PHYSICAL FACILITIES}

MOHS opened in September, 1975 in six temporary structures which provided major learning centers and classroom meeting areas. A second metal building housed the office of the principal and school secretary, the Community Learning and Volunteer Coordinator's office, a game and music room, and Munchie Central (the student-run food service). MOHS was located in close proximity to the existing Evergreen Open Living School (K-9) to take advantage of the K-12 
learning concept. MOHS also shared a gym with the other open school. MOHS is next to the Evergreen Library, within five blocks of Evergreen High School, and close to the Evergreen business community (Background Information, First Year Evaluation Mountain Open High School, April $28,1976)$

During MOHS' fourth year, Evergreen Open Living School moved to Golden, Colorado and then MOHS occupied the vacated buildings. The six temporaries were removed by the district. The newly acquired building is adequate and adaptable for MOHS needs, despite a leaky roof (Self Study, 1979-1980:IX, 2).

For the first three years MOHS was in a pilot phase and was evaluated by an Audit Committee (AC) appointed by the Jefferson County School District. AC members consisted of central office administrators, administrators of conventional high schools, community members, and a teacher and student from another alternative program. The $\mathrm{AC}$ was responsible for evaluating the pilot program and recommending it for continuation or termination. The first year AC reported that the existing facilities of MOHS were adequate, although equipment was inadequate and limited. Esthetic improvment of the building was recommended. Relocation of the school was also suggeted by the Audit Committee Report on the Mountain Open High School (May, 1976:13). "Another location would be better environmentally but might limit availability to community resources. The single Evergreen location limits the enrollment of students from other parts of the Count y." 
Jefferson County buses and vans transport students to and from the Denver metropolitan area (Audit Committee Report on the Mountain Open High School, May, 1976). The AC recommended that a satellite environment is needed to make the school more accessible district wide. The MOHS staff found it difficult to respond to these suggestions because of their desire to remain in close proximity to the Evergreen Open Living School.

The second year evaluation of the AC recognized the strides that had been made by the faculty and students of MOHS to improve the environment. In the fifth year, the North Central Accreditation Association found that the school facilities at MOHS were only adequate. It offered six recommendations in major and minor areas covering issues such as space efficiency, privacy for the counselor, safety hazards, upgrading restrooms, and student health implications (Report of Visiting Resources Team of North Central Association to Jefferson County Open High School, March, 1980:5).

Regarding the physical location and facilities of MOHS, students view the location in the mountains in a positive light despite some indicated community hardships.

The location doesn't really matter to me but I guess I like it better up here. It's excellent. The school is shaped like a round about driveway. (Interview 4/30/81)

It inspires me to come up here in the morning. I feel lucky to be able to come up here. Too bad a lot of other kids can't come up here because I'm sure they'd like it. (Interview 5/4/81a)

I think the location is good. If it was in the city I don't think I'd go. It's far away enough from everywhere else. What I like is that it is far away from the confusion. (Interview 5/ $4 / 81 \mathrm{~b})$ 
The location of the school is important because there are more options up here, like the lake, the mountains, and less pressure from the community. It is a hassle for me to ride the bus but it is nice to get into the mountains. I think it's important but if ve moved the school down to the city, the values of the school would remain the same. A lot of people in the city would like to come here but they won't ride the bus. I catch my first bus at 7:15 A.M. and then at 8:00 A.M. I pick up the MOHS bus at Warren Tech which gets me up here at 9:00 A.M. I leave here on the bus at 3:30 P.M. and get home at 5:00 P.M. in the afternoon. It is a lot of bus riding but it is worth it even though $I$ am tempted to drive. (Interview 5/4/81c)

I would hate it if the school was in Denver. I love the mountains and the wilderness. (Interview 5/11/81a)

This place is great. The building itself is shitty. I'm used to my big school but this school is alive with all the energy and everyone's thoughts. (Interview 5/11/81b)

The location is great for me. The public library is right across from us. We are centrally located and it is easy to get into Evergreen. The only problem is that kids who don't have direction go into the restaurants in town and window shop. I've left school myself and gone fishing at Evergreen Lake. (Interview $5 / 18 / 81 \mathrm{~b})$

\section{HISTORY}

During the 1974-1975 school year, a working committee of 26 students, 21 parents, 6 staff, and 2 administrators of the Open Living School $(K-9)$ in Evergreen, Colorado proposed that their system be broadened to include secondary education. The K-9 Open Living School had been in existence for five years and was within the Jefferson County Public School district, R-1 located in the Denver, Colorado metropolitan area. Alternative schools are accommodated by the Jefferson County School District in response to a report of the Alternatives in Secondary Education Advisory Committee which found that schooling choices needed to be offered for students not served by 
traditional schools (Proposal For Mountain Open High School, April, 1975:1). The warrant for alternative school proposals is provided by the Jefferson County School Board in the following statement:

Teachers, administrators, parents, and students who wish to develop alternative forms of education to better serve individual pupil needs shall be encouraged to propose programs which may be chosen by the student and his parents. Groups who wish to make proposals shall be provided the necessary guidelines for developing their proposal and shall be informed of the necessary steps for seeking approval. (Board Policy 非327.5--Alternative Education: 1).

The working committee presented a proposal which incorporated many of the key ingredients of the existing $K-9$ open school (humanistic staff, personalized instruction, community involvement in the schools, shared decision making). The proposed school was intended to complement conventional schooling, creating a total system to provide for all students' needs and was not meant to compete with other secondary schools in the district (Proposal for Mountain Open High School, April, 1975:2). The Jefferson County School Board passed the proposal for the open high school in June, 1975 (Interview $6 / 11 / 81)$

MOHS was named JCOHS (Jefferson County Open High School) during its fifth year by the School Board because of a recommendation that the school be moved to the urban areas of Denver. JCOHS is the official name of the school, although participants prefer MOHS. The school was in a pilot phase during its first three years (1975-1978). During its fifth year, by invitation of the school staff, MOHS applied for and was awarded North Central Accreditation. A concluding statement of the North Central Accreditation Team was complimentary toward MOHS: 
The team commends the Jefferson County School District for having the imagination and commitment to provide a school like Jefferson County Open High School. The school is very different from the traditional model, but it clearly provided a meaningful alternative for a substantial number of students in the district.

The team commends the staff, students, and community served by JCOHS for the same kind of imagination and commitment. The school has an excellent program that is fulfilling its promise and purpose. (Report of Visiting Resource Team of North Central Association, March, 1980:6)

Of the MOHS organizational features, the curriculum has experienced the most change until the institution of Walkabout which will be discussed in detail in subsequent chapters. The Proposal for Mountain Open High School (April 15, 1975:13) provided a curriculum that was student centered, flexible, community oriented, and with multi-strategies:

The educational program will emphasize non-grading, individualizing, self pacing and learning which is multidisciplinary. The program will require a high degree of self-discipline and responsibility on the part of the learner. The students will establish individual goals with their advisors/teachers for their planned learning experience. These could be acquired through a variety of options, such as individual and small group projects, organized classes within other Jefferson County high schools, or in area colleges, or through the use of resources in the greater Denver and mountain community. These resoures could be social or governmental organizations, service projects, experimental theatre, art organizations, senior citizen groups, environmental groups, or individual people with skills and knowledge to share.

During the first three years (1975-1978), classes were planned and taught by students and teachers, depending on their needs and interests. A variety of learning approaches was employed, including: independent study, apprenticeships, community learning experiences, on and off campus classes, and travel. The first year, the cluster 
Concept was adapted on campus in order to allow in-depth and concentrated study of one subject area for six weeks. Broad topics integrated various disciplines and included strategies such as lectures by staff persons, discussions, guest speakers, slide presentations, trips, and group member presentations. Cluster topics included: Habitat, Frontiers, Revolution in Science, Algebra, and Sexism (Addendum to Background Information, May 5, 1977:34). Curriculum was an area of concern of the first three AC teams. The teams did recognize that Jefferson County guidelines were being met and flexibility was being provided for individual student's needs. Fragmentation and student sampling of classes without in-depth study was a concern of the first two AC teams (Audit Committee Report on the Mountain Open High School, May, 1976 and June, 1977). MOHS responded with the Cluster Concept and monthly intensive courses of study.

The AC and the North Central Accreditation Teams commented that the affective realms were well cultivated at MOHS through the informal characteristic of the school and extended school trips but they suggested that academic and basic skills needed more development. MOHS used skill tests, inservices, and a learning lab to respond to the AC suggestion. The third year AC judged that the curriculum was strong in verbal learning skills and creative writing but improvement was recommended in research techniques and technical writing skills (Audit Committee Report, Third Year Evaluation, June, 1978:44).

Finally, long range planning to structure the curriculum so that students could coordinate their projects and classes more efficiently was advised by the first and second year AC teams. MOHS students 
replied that yearly planning of classes meant that the program was becoming too structured and teacher dominated (Addendum to the Background Information, May 5, 1977). During the fifth year, Walkabout was adopted at MOHS to of fer more structure to the curriculum without impeding individual student need or free choice. Walkabout will be described in Chapter IX.

STUDENT POPULATION

MOHS needed 150 students to institute their program but drew 174 students the first year with an open enrollment for all Jefferson County public secondary school students. An initial interview with prospective students, parents, and MOHS representatives aided applicants in deciding on the appropriateness of the alternative program for their educational needs (Proposal for MOHS, April 15, 1975:7). The first year Audit Committee (May, 1976:6) found that MOHS was comprised of a heterogenous student group, contrary to public perspectives concerning the student type of MOHS: "Contrary to the perception of some people interviewed in the Evergreen Community and other school people in $R-1$, the student body is not exclusively made up of potential drop-outs and trouble makers." During the first year at MOHS, 39 students were from the local comprehensive high school (Evergreen High School), 23 were from the open feeder school, 101 were from conventional high schools located throughout the school district, 4 were from private high schools in Colorado, and 7 were from out-of-state schools (Addendum to Background Information, May 5, 1977:56). The second year Audit Committee (AC) also found that the 
student population was heterogenous and from all parts of the school district. It concluded from its interviews and observations that some students were more motivated than others. In particular, students from the open feeder school were the most successful at MOHS.

Four categories of MOHS students were identified and listed: (1) dropouts and potential dropouts, (2) open school students from the feeder school, (3) academically stifled students from conventional high schools, and (4) students with social, personal, and other reasons for choosing MOHS (Addendum to Background Information, May, 1977:18). Five unofficial spaces were provided for students in emergency situations (Addendum to Background Information, May, 1977:6; Interview 6/11/81).

The first, second, and third year AC recommendations concerning the student population included: (1) continue the first-come, firstserve basis for student selection, (2) publicize the school more, possibly with a brochure, and (3) maintain initial meetings with prospective students and parents before placing their names on the waiting list.

The student volunteer interviewees offered reasons for choosing the alternative schooling:

I am in this school because of experimental learning. When I was in regular school my grades were extremely high and it was extemely boring for me in the regular school. It showed nothing. It taught me nothing and I didn't believe in the teachers and the way they taught. Another reason I can here is because I had a friend who went here so I came here and my first two years here I did extremely well. (Interview 9/19/80a)

I'm in this school to take responsibility for myself. (Interview $9 / 18 / 80 \mathrm{~b}$ ) 
At my old school, I didn't like it because everybody bothered me. It was a downer to go to school. I'd wake up dreading school. I felt like I had more enemies than friends. It is easier to get along with the teachers at MOHS. I like it that everything revolves around "trust." I do miss some of my old friends but it is less violent at MOHS. (Interview 9/19/80)

I'm a dropout and I love this school. Before I just wanted to get my GED but now this school gave me the opportunity not be be labeled a "quitter." This school is an important step for me in education. (Interview 9/16/80)

I love Mountain Open. I think it is a wonderful school. I know I'm going to learn so much because I'm already learning so much, and we haven't even started Pre-Walkabout Skills and Walkabout. Before when I didn't have a class I felt like I could sit around and veg out, and now I feel like I want to do something. I'm always writing in my journal or doing something creative like writing songs or taking classes. It's not hanging out. I've done my share of that. I think the way this school is, is just the best. It's a real logical way to have a school. (Interview 9/20/80)

I talked to Arnie about just what was happening in my life and he let me in right away. I think it's a great school but it's changing, it's always changing. I think that alternative education is the ideal program because what's happened in the past. It seems they found one method to educate and coordinate young people and they decided it worked. That's it and that's as far as we are going to go and you know certain people don't work in that system. They wind up dropping out or getting into trouble, going to jail, or going to alternative schools and alternative schools give people the opportunity to be an individual. Most of them do anyway. The way this school was set up originally, I think was as the ideal school. (Interview $9 / 25 / 80 b$ )

I started quitting school in 9 th grade because I knew they couldn't do that to me. I knew I was smarter than the diploma. To me j.t's a hoax and thought control and all these other excuses so I just dropped out and lived on the streets and accumulated a lot of experiences and travel. It was the beginning of $11 \mathrm{th}$ when I finally dropped out and checked life out, what real life really is. When I was on the streets, it was paradise. I came back to school for the Recording Studio. It's what I've always wanted to do and the other schools don't have it. I don't need to know History or Math. That's jive. I don't need anything that pollutes my sense of life, you know. We knew about this school from our friend for years and years. I was on the waiting list. I don't care if I get a diploma. I am doing Walkabout. This school is the thing. If I had been growing up on schools like 
this, I'd be three times as clear of mind as I am now. In regular schools, you have a cloudy mind because you don't know who you are. You come to a school like this and you become yourselr because you have nothing else to do. You have to take the initiative yourself to be. (Interview 9/25/80c)

I think from being in it, practically all of my life, I've pretty much learned the values of the school. The values are self-assertiveness, to be able to learn on your own, to inspire yourself. We try not to do things in the classroom but go out and find out where it's happening and experience it, instead of reading it and memorizing it. They try to teach the kids to be more independent but in a positive way. Like here at the school, some people come from a regular school and they use it in a negative way. They go off and ditch their classes and it just doesn't work for them. I think kids need to learn how to be constructive. (Interview 9/26/80)

If I didn't like it I wouldn't be here most of the time. I've only missed maybe one or two days. It takes me 45 minutes on the bus to get here. I leave here at 3:30 P.M. on the bus and I don't get home until 6:00 P.M. It's a pain. I do like the people at the school. I like the teachers a lot. They are the first teachers I've liked. They are more friendly. The other teachers would say: "___ sit your ass down and get to work." I'd just bitch back at them. Here you have the choice of learning or not learning. I don't like people telling me what to do. (Interview $10 / 31 / 80$ )

I've been in open schools since 7 th grade and I like them a lot. I don't get along well in regular schools. I don't do what I'm told. I usually do all my work. Sometimes I don't get it done on time but I always get it done. It's free here and you have a choice whether to do something. The responsibility is up to you. (Interview $10 / 31 / 80 \mathrm{~b}$ ) 
CHAPTER IX

MOUNTAIN OPEN HIGH SCHCOL'S ORGANIZATIONAL CHARACTERISTICS

Utilizing historical and archival documents and field

observations, this chapter describes the organizational

characteristics of Mountain Open High School.

MOHS'S GOALS

In general, the MOHS goals pertain to three areas: (1) self concept, (2) social and interpersonal relations, and (3) academic attainment (Canyon Courier, 9/9/76; Proposal for MOHS, April 15, 1975; Self Study, January, 1979). MOHS goals are auxiliary to and supportive of the 14 goals of the Jefferson County School District. However, MOHS maintains a distinct difference from the district in the assumptions that are made about students. MOHS recognizes the individuality of learners and it employs multiple learning strategies to achieve student-set goals (Proposal for MOHS, April 15, 1975:3). MOHS believes in involving students directly in the learning process:

The Mountain Open High School would operate in the belief that education is more a process of becoming aware of one's world, one's self, and discovering enduring relationships between the two, than it is the process of transferring knowledge from one person to another; and that this process is a highly individual and very personal one. (Proposal for MOHS, April 15, 1975:3)

MOHS also believes in the learner taking responsibility for his/her education and this fact is explained by Langberg (1983a:3): 
We think that the model of a highly structured orientation to taking responsibility for one's learning followed by a less structured period of skill development through a wide range of options and a culminating phase of independent demonstration of the ability to apply acquired skills in real world situations is a healthy alternative to a sophomore, junior, and senior year of generally unvarying passivity.

During its first year, MOHS submitted graduation requirements for students to the School Board which included five basic goals of the $R-1$ school district plus demonstration of proficiency in the skill areas of Competence, Exposure, and Experience. Some examples of these requirements included writing skills, oral speaking, math computation, community service experiences, and survival living skills (Audit Committee Report on the Mountain Open High School, May, 1976).

MOHS produced a written school organization and philosophy statement during its third year (1977-1978). The philosophy is built on the theories of Maslow, Erikson, and Kohlberg and aims to help students reach the highest levels of social, moral, and cognitive development. Components of the school philosophy include: (1) the need for the individual to grow and develop talents and capabilities, (2) an appreciation and desire for life long learning, and (3) the utilization of an assortment of strategies to affect individual learning styles at various developmental levels (Audit Conmittee Report, Third Year Evaluation, 1978:7).

The three AC evaluation efforts found that MOHS goals are compatible with the Jefferson County School District's goals. The first year AC held that MOHS provided a personalized learning situation for students and that goals were being readily implemented for the active learner. The first and second AC stated a concern for 
the unmotivated student. In particular, the first year AC recommended that MOHS adopt a stricter attendance policy, provide more curriculum structure, and increase in-school activities to involve students with one another more frequently (Audit Committee Report on the Mountain Open High School, May, 1976). MOHS responded to the unmotivated learner by adopting the Cluster Concept for in-group activites and by dropping 17 students the first year due to chronic absences (Addendum to Background Information, First Year Evaluation, May 5, 1977).

Because there was not a set of operational objectives, the first two $\mathrm{AC}$ teams maintained that there was no way to measure the extent of goal attainment. The second year AC recognized the difficulty of evaluating an alternative school by conventional standards and criteria but also emphasized the importance of MOHS providing evidence of its effectiveness:

The AC questions the adequacy of the assessment techniques in MOHS. The central office of the district should aid the school in implementing this recommendation. However, the $\mathrm{AC}$ perceives that schools in order to gain community confidence must prove the degree of their effectiveness. (The Audit Committee Report on on the Mountain Open High School, June, 1977:7)

MOHS responded by implementing a longitudinal naturalistic study to follow students periodically through the schooling process. The study was conducted by the University of Colorado and funded by the Office of Research and Evaluation of the Jefferson County Public Schools (Interview with Principal 6/11/81).

Maintaining a primary focus on the development of the individual, MOHS goals have remained stable over the first six years of its existence. However, the course of technologies employed is a 
different matter. The following description of the three phases of the MOHS program is that of its sixth year, the year of this researcher's case study. The curriculum and educational program underwent various changes and the following account indicates how it has evolved up to its sixth year (1980-1981).

\section{TECHNOLOGIES}

\section{Phase I--Beginnings}

The first two AC reports found that new students needed an intensive orientation to MOHS and during the first year, MOHS instituted a Disorientation Class for that purpose. That class is called Beginnings in the sixth year of the school.

Beginnings is the first phase of the program for a new MOHS student. Students are in Beginnings for ten weeks. They are helped to understand the school and how they as individuals may take responsibility for their own learning and education. Various activities structured by Beginnings teachers assist students to discover their strengths and talents and also provide social interaction with 12 to 15 other students for a sense of belonging to the school. Many MOHS students select the alternative school to escape the normlessness and social stereotyping of large comprehensive high schools. They report that they do not like being labeled "Jocks," "Freaks," "Hicks," or "Cowboys:"

We don't have as many people here so there is less stereotyping. We only have 160-180 people and we all know each other so why should we call each other names to identify each other? All we need to know is the personality of the other person. We don't 
label each other on the inside. A person is a person. Around here, you treat people the way you want to be treated like the Golden Rule says. (Interview 11/5/80)

In traditional schools, you're either a "Freak," "Jock," "Cowboy," or "Straight." "Straight" people are strange. It's even that way in the world. It's not that way here. They accept you for being you, not for being some "Hick," or "Freak," or whatever. They seem to understand more. They seem to understand you especially if you want to be "Straight." There are more open people here with open minds. They don't close their minds. It doesn't make any difference who you are. Maybe they are sick of it too. Because I know that I got sick of it. (Interview $11 / 14 / 80 b)$

It goes on. It happens. For me, I hardly ever stereotype people because it's one thing I tried to get out of. I can't relate to people when they only relate to one kind of person. It goes on in other schools more. (Interview 11/14/80b)

I've been stereotyped here before but it's getting better. It is changing. It doesn't happen by everybody. It's a lot worse in other schools. They're forced to do this and that and if not they're something they don't want them to be. You're either a "Jock," a "Freak," a "Cowboy," an "Outcast," or a "Square." As soon as people learn to live together, they will drop that nasty habit. (Interview 11/14/80c)

It goes on somewhat in this school. I have a tendency to stereotype people. Probably that's because what I have done. I've been stereotyped and I've stereotyped other people all of my life. I've gotten over it but still I do it every once in a while. Like I say, if there's a bunch of people together, they're a bunch of "Jocks" or they're the "Hicks." I don't stereotype people here so much as I do outside of the school. I think everybody is the same, are individuals who have their own characters and I like to be accepted for what I am and they should be accepted for who they are. Even the teachers at traditional schools do it. (Interview 11/21/80a)

I don't think it happens here. I'm really pleased with it. I think it's great. I wish I had it like that all through school. I think it works here pretty good. (Interview 11/21/80c)

Depends on whose eyes you're looking through. Everybody else doesn't think so but if you're a stereotyping kind of cat, I guess you do see it. It depends on how you look at it. I don't think it goes on here. In traditional schools you have your "Jocks," and your "Hicks," and your "Freaks," and your "Straights." Everybody here is involved in everything. Some "Freaks" are doing "Jock" things, and girls are doing boy things, and boys are doing 
girl things. How can you stereotype here because everybody here is alike, I guess. You vent your frustrations here when you get them. If you have something to say, you speak up and say it. You have more nerve here. There are less people and everybody is pretty close. Plus a lot of people come from the city to the mountains. City people love the mountains. You are allowed to be yourelf here. If you aren't then you'd have all these games going on where the "Freaks" would hate the "Jocks." There would be small tensions. Everybody is allowed to be who they are. This is a special place. There is even a waiting list. These students all party together. You come to this school for relief. Nobody has head games here, stuckupedness, ego games and all that stuff. (Interview $11 / 21 / 80$ e)

There isn't that much going on here. There are only 2 "Jocks" here anyway. There is a lot more in other schools. I used to get in fights in my old school. I'm walking down the hall and this pretty "Jock" says "Get out of the hall, you 'Freak.'" I used vuigar language with him and told him to get out of my way. I ended up decking him. (Interview 12/2/80)

This school teaches you to become aware of stereotyping and how to avoid it. It exists less here than any other school simply because of the aspects of teaching that go on here. What you learn teaches how things really are. This school nas different ideas totally. One of the amazing things about this school is that it has been going on for five years and there hasn't been a single fight here. (Interview 12/11/80a)

Beginnings' students experience two week-long trips, one to the

Wilderness and one to the inner-city of Denver. Students work in groups to plan the logistics of the two trips and also spend solo time alone on the trips for personal challenge and experience. At the end of each week, Beginnings' students write an evaluation describing what they have learned and how they felt about various Beginnings' activities.

Beginnings' students are required to attend weekly Governance meetings. They learn that they have as much political power as they are willing to take upon themselves. Beginnings gives new students the opportunity to meet each staff member, which is important in 
preparation for students' selection of their own personal advisor and for providing a positive school climate.

Observations of cne Beginnings Class were made on September 4, 1980. The class followed pre-planned activities. Three teachers and 14 students were in attendance. Teachers discussed students' feelings and concerns about the "unstructured" jobs they had participated in the previous day such as working on the park, building steps, and helping in the library. Teachers directed students through a simulation game. An explanation was given for the journal each student was expected to keep. Students wrote in these journals about the various Beginnings' activities and their feelings about what they had learned. The journal entries included writing, poetry, drawings, and other numerous documentation means. Students were given a half hour in the observed class to begin writing their first journal entries. The final activity for this class was a review of the schedule for the following week. Throughout the class, teachers kept specific questions circulating in order to keep discussions going and on track. One student made the following comment in his journal after his first week at MOHS and shared his feelings with the Beginnings' participants present:

I have come out of my shell since I came to this school. I stay up where I used to be down at my old school or not even go. I take people for what they are here. People at this school are real and not big fakes like at my other school. In other schools, people are inside themselves and big fakes. (Observation 9/4/80)

Volunteer student interviewees have positive comments about their Beginnings experiences: 
Beginnings Classes are good to take because you learn what the school is all about. It gives you a good start on your Pre-Walkabout skills. Sometimes they ramble on too much but now I wish I'd been more actively involved instead of just sitting and listening. I wish the Beginnings Trips were longer. (Interview $3 / 23 / 81 b)$

I thought it was pretty good. I gave the advisors some suggestions for improving it. It was different for me because I was dealing with freshman at 20 years old. I felt like I was between the students and teachers. It's really a nice program and it helped me learn about the school. (Interview $3 / 23 / 81 \mathrm{~h}$ )

I think it's good. We played games which some kids didn't understand. I got into it. It is supposed to tell you how to use the school. It is easier for me because $I$ have been in open schools for a long time. (Interview 3/23/81f)

Last year's Beginnings students didn't like it because they felt caged. It is like a boot camp for our school. It is a good orientation. (Interview 4/13/81b)

They're neat and they broadened my focus on this school. I didn't know that a place like this existed. It helped me to get a feel of where I was at and the possibilities for the future. It takes a long time to see how the school works. (Interview $4 / 17 / 81$ )

\section{Phase II--Pre-Walkabout}

When a student completed Beginnings, the next part of the MOHS program he or she encounters is the Pre-Walkabout phase which consists of the advisory system and Pre-Walkabout skills. The student spends approximately one to one and a half years in this part of the MOHS program.

The advisory program at MOHS is the heart of the educational program (Langberg, 1983a; Self Study of Jefferson County Open High School, January, 1977). After completing Beginnings, students choose an advisor and each teacher has approximately 20 advisees. In their first encounter, a student meets with his or her advisor and together 
they assess the student's personal, social, and academic areas of development and discuss the expectations, apprehensions, wishes, and dreams for the future of the student. During this initial meeting, advisors take notes for two reasons: (1) a teacher/advisor can calculate the ways the school and program can be of support to the student/advisee, and (2) the notes from this meeting can help the advisee measure his/her growth while at MOHS.

A second meeting of an advisee and advisor includes parents for a link between the family and school and also gives parents the opportunity to express any expectations they might have for their child's experiences at MOHS. This second meeting is arranged by the student. Parents are given the opportunity to ask questions about the functioning of the school. A support group made up of the advisee, advisor, principal, parents, and anyone else the student might want to participate can be called at any time if the need arises. That support group also attends the advisee's personal graduation ceremony, separate from the all school graduation ceremony.

Advisees attend weekly advisory group meetings with their advisors, other advisees, and often become student advisors to each other. Advisees meet with their advisors at the start of each seven week block to plan their educational program. Every advisee maintains a portfolio with his or her advisor. The contents of this portfolio include documentation of the student's progress through the second and third phases of the program, self-evaluations of every learning activity, support statements from the teacher of each activity, and other matters the student includes. 
When questioned about the advisory system at MOHS, student

interviewees' responses were supportive for that facet of the program:

is the greatest. The advisory system would be better if it was a matter freer choice. They assign you with an advisor at first but don't stress the fact that you can change. There is still choice but it is more arm-bending. (Interview 3/23/81)

The advisory system is cool. You have someone special to he]p you with your work and ask questions. I think they should have it in other schools. The kids would get more work done. (Interview $3 / 23 / 81 b)$

I think the advisory system is great but it does need more time. It is a prerequisite of this kind of school. Without it, a lot of people would be bumbling around. (Interview $3 / 23 / 81$ c)

It is the most important part of the school. If it weren't for 's patience, I'd still be a hyper, nasty kid. He's not restrictive. His philosophy is: "If you snooze, you loose." (Interview 3/23/81d)

The advisory system is good. It helps you get out your frustrations and get to know other people deep down. You can share your feelings with a lot of people. The one day advisory is good. , my advisor, and other advisees have helped me with my frustrations and I've helped other people. The group discussions are always good. I'm frightened about Walkabout and graduation. is good for me because he pushes me. The advisory system is important to the school. Our advisors are our friends, not just a counselor. (Interview $3 / 23 / 81 \mathrm{e}$ )

I think it's the backbone of the school. I picked because I knew he'd help me get ny act together. I might change advisors. You know, we have the freedom to choose and change them. You do get to know your adivsor real well. (Interview $3 / 23 / 81 f$ )

The advisory system is a good method, especially when students can choose. The teachers are also counselors with the extra responsibility. I hope it isn't too taxing for them. has been my advisor for a couple of years. I hardly ever talk to her even though I know her, trust her, and confide in her. She has been real patient with me. The advisory system should continue. (Interview 4/13/81b)

Also, Phase II of the MOHS program includes the completion of Pre-Walkabout skills. The 50 skills are clustered in 8 areas which 
include: personal, investigative, lifelong learning, citizenship, career, leisure time, consumer, and family. Students are introduced to the eight categories and given direction and assistance for completing and documenting competence in particular skills identified in Beginnings. Students spend a year to a year and a half documenting past experiences which are applicable to skills and involving themselves in activities to acquire new skills. Educational options at MOHS to complete the Pre-Walkabout skills include: classes at MOHS and other comprehensive high schools and area colleges, independent study, Extended School Trips, Community Learning apprenticeships, Skills Lab, work in the school's solar greenhouse, student run food service (Munchie Central) or recording studio, participation in the governance of the school, and Community Service.

Classes constitute roughly one-third of a student's curriculum. With a small school staff of 15 , students and community volunteers offer classes at the school also. Staff members are limited in teaching time because one third of their time is spent advising students. Students are encouraged to take classes at other high schools, community and area colleges, museums, and professional and public institutes when applicable. MOHS classes are team-taught, interdisciplinary, and experimental. They envelope a diverse range of subject areas and are offered on novice to advanced levels. Classes are intensive, meeting for two or three hours several times a week rather than once a day for a shorter period of time. Most classes are offered for one block or seven weeks. The objective of MOHS courses is to provide students with a strong basis to stimulate further independent study. 
Community Learning apprenticeships allow students the

opportunity to learn by watching and participating in someone's

career. Apprenticeships have been completed with social workers,

lawyers, teachers, cabinet makers, photographers, architects,

waitresses and waiters, physical therapists, and veterinarians

(Langberg, 1983a). Student interviewees responded to their Community

Learning experiences with the following comments:

For my Community Learning experience, I worked in a pre-school for two months. I thought I wanted to do something with children. I learned a lot and taught the teachers a lot too. After two weeks I didn't want to leave. I think it's important to do a Community Learning experience because it teaches you a lot about trades. It gets you thinking about what you want to do when you graduate from high school. (Interview 4/25/81)

In my younger grades at Open Living, I had a vet experience in 4 th grade. In 6 th grade, I worked in a grocery store. In 7 th grade, I worked with a silversmith. By the end of that apprenticeship, they were buying stuff from me. It can be a hassle because transporation can be a problem depending on where you are doing your experience. It is an important experience and a good opportunity. It can broaden your horizons. It might make you decide to get into a certain profession. It helps you understand what is going on in your community. A lot of people are getting good stuff out of it. It can turn into a hobby too. I think it's important but not as important as school trips or Walkabout. (Interview 4/25/81b)

I helped Susan in the pre-school because I like to work with little kids. I still like to work with kids. I did it because I like it. (Interview 4/25/81C)

I haven't completed a Community Learning experience for a long time but it is one of the best things we've got going at this school. You are out in the real world and you get first hand experience about society's attitude toward business. It gives you a chance to explore careers. I did a stain glass apprenticeship and worked with a professional. For me it would be a hobby but I saw what a professional had to do. I learned a lot of things and I learned that I don't want to be a professional stain glass artist. (Interview 4/25/81d)

I worked with a vet, in a greenhouse, for a modeling agency, at McNichols auditorium, and for a social worker. It has helped me 
a lot. I can see what the career can be like. The people were helpful and supportive. They have all been good experiences and they have widened my scope. I'm thinking of being a social worker or a teacher. I had a bad social worker when I was younger and he didn't help me. Transportation can be a problem because you feel bad when you can't make it sometimes. It is free labor but I learned a lot. I like to think of new Community Learning experiences I could be doing. (Interview 4/23/81)

I think it's a great experience. I learn skills and use them. I like the way it's set up. It's an important experience. I worked in a group home and found that I had to be like a mother. I learned how to cope with retarded kids. This one kid, Cory, had all types of expressions. I didn't like the home or the staff. I did write my experiences up f'or Pre-Walkabout skills. (Interview $4 / 16 / 81$ )

I've never done a Community Learning experience per se. It is great if kids haven't worked a job. A lot of things could be done and even out-of-state. I worked in Idaho Springs for the Forest Service. I've been a volunteer for Green Peace. I even wore a Santa suit and rang the bell for the Salvation Army once. (Interview 4/13/81)

Generally, students responded that Community Learning experiences were important and helpful. They did report that they had transportation problems and some did not like working without pay.

Community service is expected of MOHS students which involves doing something for someone else without expecting anything in return. Examples of this aspect of the curriculum include working with handicapped youths at the Special Olympics at the nearby recreation center, working with senior citizens, participating in a neighborhood clean-up, or volunteering service in the student run lunch program, Munchie Central.

Extended school trips are an important part of Phase II of the MOHS program. Past trips have included biking in California and visiting another alternative school; viewing of a total solar eclipse; canoeing on the Mississippi; visiting Colonial America from St. 
Augustine, Florida to Niagra Falls; attending an alternative schools conference in Santa $\mathrm{Fe}$, New Mexico and Detroit, Michigan; living with Mexican families while attending Spanish schools in Yucatan; and visiting a former exchange student in Guatemala. Trips have also been taken to Alaska, Hawail, San Francisco, Baja California, and the Boundary Waters of Northern Minnesota and Canada. Annually, MOHS sponsors a work trip to Mexico where students clean, paint, and repair a school in need (Canyon Courier, 5/20/81; Canyon Courier, 9/23/81; Langberg, 1983a; Passages, 1980).

School trips are like three classes: pre-planning, the trip itself, and post-trip activities. This researcher traveled on one three week MOHS school trip to Baja California (hereafter Baja). Two pre-trip classes for this trip were observed on January 30,1981 and February 20, 1981, although these classes were held for a seven week bluuk preceding the group's departure. During the January 30 th class, student Passage (to be explained in Phase III) activities were discussed. One student planned to film the group and another student planned to keep a journal of creative writing. Spanish lessons were held for 15 minutes at the beginning and end of each Baja class. Plans for pre-trip study were made and students volunteered to study and report on the following topics concerning Baja: geology, history, customs, whales, border customs and visas, towns and cities, botany, and sea life. During the February 20th class, Spanish lessons were again given for 15 minutes at the beginning and end of the class. The itinerary for the trip was discussed. One group leader announced that "group time" to discuss group plans and concerns would be organized 
each day on the trip. More Passages were described by students and included a study of housing and poverty in Mexico, an embroidery project, diving with the whales, study of tide pools, a proposed passage which fell through, and the assembly of dead specimens. Pre-trip planning also included housing and food arrangements, budgeting, earning trip money, and discussions of the sensitivity necessary to travel and live closely with a small group of people for an extended period of time.

MOHS school trips allow students the opportunity to discover that learning can take place outside a classroom. Exposure to other cultures, customs, and people is a second benefit of trips. A third objective includes the opportunity for independent study as well as the chance to live, interact, and work closely with a group or community for an extended period of time (Self Study, 1979).

Post-trip activities include a general report of the trip itself in Governance. A final meeting on return to the school is for a financial report, culminating group activity, and celebration. Self-evaluations are written by each student and given to one of the group leaders. Individual students give reports of their independent projects in Governance also. The individual growth of one student on the Baja trip was shared in the following self-evaluation:

I had been preparing for this trip long before I knew about it. This was a chance for me to act upon my beliefs, to challenge my strength, strength in my individuality, the strength of expressing my individuality in a group, and to test my courage. I have gained in all of these areas.

I have had the chance to be aware of my individuality and in turn accept it. 
For the first time in my life, I have felt comfortable expressing my thoughts, ideas, and acting out my individuality within a large group of people. Your allowance, __, for group consensus in decision making challenged my acceptance of individuality. I found that by truly accepting myself, I would truly accept others. I appreciate your input, keeping us focused as a group on decisions.

At times I wasn't acceptant of other people's ideas and actions, but I feel that it was a reflection on my ideas and actions of myself.

On this trip, I faced the biggest test of my courage that I have ever faced in my life. A big dream for me has been to dive with a whale. Facing this dream, to make it a reality, took a great deal of courage for me. I had only one practice salt water dive previous to my dive with the whales. Although I didn't see a whale underwater, I know by their sounds and energy that they were close. I feel satisfied in this and I'm ready to face my next dream and make it a reality. For futher comments on my dive see my logbook.

The sights I saw on this trip, the standards of living, the relationship of foreigners in a country, and their way of life has humbled me and helped me question my standards of life. I have another option to add when deciding where to place my expectations on where to live and how to live when I have a place of my own.

Thanks for your positive outlook on our situation. I helped me to stay positive, your laugh and smile.

Thank you enlightening.

Thank you for your willingness to try something new. you have helped me grow. (Student Self-Evaluation of Baja Trip, February 28, 1981 to March 20, 1981)

Student interviewees reported that trips are an important part

of the MOHS program:

Trips are most definitely important. They are the greatest thing this school has going for itself. I've been on about 8 trips. I feel a lot of personal growth from trip experiences. I felt a part of something when I came home and I was able to understand myself better. As an individual I felt a part of the school. Every trip is different although Walkabout and Trips go hand in hand. It gives Trips more possibilities. Kids really do plan their own learning when they are traveling. (Interview $4 / 13 / 81 c)$ 
I went to Santa $\mathrm{Fe}$ for the Experimental Education Conference and I liked it a lot. I learned all kinds of stuff. I had fun watching people try to camp. (Interview 4/13/81d)

This place is like a shot in the arm. It has power all its own. On trips, everyone is the same--dirty, cranky, tired, and hungry. You can relate to people as themselves. You can experience life. Trips are a really good thing as its a good way to learn through traveling. (Interview 4/17/81)

I think they are important. This school wouldn't be different from the other schools if we didn't have trips. (Interview $4 / 6 / 81)$

I'd rather go on a trip than do anything else. I love traveling. You get to know the kids and teachers better. They are good learning experiences. (Interview 4/23/81)

I think they are fun. I think you learn a lot from them. You grow and learn a lot about yourself and how people judge you. You shouldn't be too bitchy. You learn about living with a group. Sometimes you just want to get away from people so you do. I think trips are the school. They are more than being in the classroom. On trips, the whole world is our classroom. (Interview 4/25/81a)

I think trips are great. They provide good experience in planning and then doing. It is a relief when you get home even though we have a wonderful time. They teach you a lot about yourself and groups. You have to look at why things get you angry. I think it's better if you take short trips before you try a long one. I liked all the traveling on the Baja trip. I've been on the Mexico Work Trip three times. Trips are one of the best parts of the school. They can work wonders for you. Some people don't take advantage of the good experience trips provide. They are also a good way to get your Passages completed. You do learn a lot when you go to a foreign place. (Interview 4/25/81b)

Money for trips is provided by the school, the district, and the individuals traveling on the trips. Because MOHS does not compete in inter-scholastic athletics, it used that allocation to purchase and maintain two nine passenger vans. In the case of larger groups, additional vans are leased or borrowed or a school bus is used. Students pay for one third of the fuel costs for a trip and the rest of the cost is paid by the school's van account. Food costs are kept 
low by buying large quantities and in bulk. Group members prepare meals rather than eating out. Camping out or staying at other alternative schools keeps housing costs at a minimum. A student loan fund allows students to travel on trips they might otherwise miss. Through the variety of educational activites offered in Phase II of the MOHS program, students become proficient at the Pre-Walkabout skills. Although there are 50 skills, students convince their advisors that they are competent in 20 core skill areas and then move into Phase III.

\section{Phase III--Passages}

A final phase of the MOHS program is the completion of personal and challenging projects in six areas: Adventure, Career Exploration, Global Awareness/Volunteer Service, Logical Inquiry, and Practice Skills. Student projects may incorporate more than one Passage area but the MOHS guidelines require that at least one Passage must be completed by itself and one Passage area is to be accomplished in combination with one other Passage.

Students are given written guidelines for Passage proposals that include the Passage: (1) definition, (2) preparation activities, (3) Pre-Walkabout Skills, (4) proposal guidelines, and (5) documentation and evaluation suggestions (see Appendix B for an example of the Career Exploration Passage Committee Suggestions). Students are supervised closely with their first Passage proposal by their advisors but are expected to take full responsibility for proposal planning and writing thereafter. Passage proposals are submitted to Passage 
Committees which are comprised of the student's advisor, a teacher from that particular Passage area, one student who has successfully completed that Passage, one student not yet in Phase III of the MOHS program, and the student's parents. The Passage committee approves the proposal if a student's skill background is sufficient to complete the Passage and if the proposed project is challenging enough for that particular student. The approved proposal becomes a contract which includes an agreed-upon timetable for completion of the project as well as a mediur for final presentation of the Passage.

Examples of Passage projects are numerous. A student walked the Pacific Crest Trail from Mexico to Canada. He completed a study of nutrition for his Log:sal Inquiry Passage and his Adventure Passage was his actual hiking trip. Another student choreographed and videotaped a dance while involved with a dance troupe in Denver for her Creativity Passage. For his Practical Skills Passage, one student toured the country giving presentations about a methane digestion machine at various fairs and exhibitions. For his Global Awareness Passage, one student was a counselor in a foster home in New Hampshire. The student was responsible for keeping seven children aged 10 to 18 out of trouble, involved in recreation, feeding them, and he also talked to them about their various concerns and problems. After taking a stained glass class, one female student created an original stained glass window for her Creativity Passage. Two students traveled by bus to Portland, Oregon for seven weeks and lived in a downtown hotel. These two young women completed Adventure, Creativity, and Practical Skills Passages. 
One male student from MOHS traveled to England to play semiprofessional soccer and completed Adventure and Career Exploration Passages. Through this experience, the student found that he would like to go to medical school and specialize in sports medicine. A MOHS student whose family had alcohol problems finished Global Awareness and Logical Inquiry Passages by studying the effects of alcohol. A woodcarving project completed the Creativity Passage for one student who felt he was not creative. His three foot by five foot sign included the name of a visiting dance troupe and a figure of one jazz position. The sign was presented to the dance troupe on graduation day. Sewing projects completed the Practical Skills Passage for two students. One student with previous sewing experience made a three piece velveteen suit, while another student with no previous sewing experience made a tent from a kit (Langberg, 1983a; Passages, Fall, 1980; The National Commission on Resources for Youth, Inc., March, 1982).

In a letter to the editor of the local community weekly newspaper, one student asserted her feelings about students accomplishing twice as much work at MOHS compared to the local comprehensive high school:

In the five years that I have lived in Evergreen I have noticed that there is a very small percentage of stories and-or articles on Mountain Open High School (Jefferson County Open High School).

I have attended Mountain Open for three years and I find it to be a fantastic school. There certainly has to be more to write about than what $I$ have seen or read about in your paper.

Quite a few of the Evergreen residents dislike or disagree with what appears to be happening there. I think that much of this is caused by a lack of knowledge. I think that if these people were 
enlightened and knew more about the open school they would appreciate what we're doing. of course, it's not perfect, but neither is Evergreen High School.

Our little imperfections are just more obvious because of the small size of our student body. One could compare any problems with Evergreen High School and odds are that the percentages would be the same.

I don't know where so many people get the idea that we're all on drugs. Every school has drug problems and our problem is hardly one of the worst.

I happen to believe that we do twice as much work as Evergreen High School and it's not just sitting at desks looking at books or just taking notes.

Mountain Open High School has taught me to be self-sufficient, confident and ready for the Real World. I have learned to love to learn and to push past what I thought was my best.

I love the school, the ideas it holds, the staff and the students. And I would like to hear more about what's going on next year! (Canyon Courier, 6/10/81)

Before the adoption of Walkabout, the curriculum of MOHS had been criticized by the first three Audit Committees. The North Central Accreditation Team stated that Walkabout had added structure to MOHS without major upheaval of its intended philosophy of students owning their own education. Students were complimentary of the Walkabout curriculum with the exception of older students who were concerned that MOHS was becoming too structured:

The school has gone extremely downhill. There aren't as many options or things that you could be doing to be educated. It's slowly being pushed into a system. You know Walkabout. There it goes, it's already structured itself a system, something everybody else has to go by. Sure there's room that they can do things differently from everybody else but still, it's closing lots of possibilities (Interview 9/25/80b)

Walkabout is better than the old way because it gives kids more structure. There was more freedom with the old curriculum but there were problems with interest and motivation. Walkabout has more push and more focus. I don't mind it. (Interview 4/13/81c) 
Walkabout provides structure that works within the system. You need structure or you wouldn't get anything done. If I could get into it, I could forget boys, cigarettes, and my problems. It is forcing me to get organized. (Interview 4/17/81)

I think Walkabout is great. I like the set up. I like documenting my work. You can see what you accomplish. (Interview $4 / 16 / 81)$

It is hard to understand. You have to get motivated. You do just as much as the regular school but more. You aren't forced to do anything as you can do just enough to survive and get by. It allows you to personally challenge yourself. It's up to you how hard or how easy you want to make it on yourself. (Interview $4 / 23 / 81$ )

I love the Walkabout curriculum. I like the way it is set up. There are some changes which are needed but it is still new. It challenges the individual and it is not set up to stereotype us all. Your individual interests can be met. It is a lot more structured than the old curriculum and more academic. It is healthier for the individual. There is more balance than before. It puts more pressure on individuals to handle things academically. The individual has to challenge himself. With Passage Committees, the backup is good and we need feedback not pressure. I can be pushed only to a point. It depends on how you look at being pushed. In this setup, my own personal challenges can be set up. I want to challenge myself a little more and that is happening. This is a harder system to graduate under in comparison to the old curriculum. (Interview 4/25/81)

I don't understand it. In a way it's a pain in the neck. I'm not used to it. I've been in traditional schools so long that I'm used to worksheets and homework. I'm going through a transition. It might turn me on as I realize it takes time to get used to. (Interview 4/25/81b)

I think it's a really good curriculum. If you learn to cope with it, it's good for you. I took a class from and and I learned how to write skills and Passages. I found out all the different stuff I can do. You have to do everything yourself. I did one Fassage on the Baja trip and found that it was hard to write the proposal. I think it is a good system. I can explain it in 10 minutes, at least the basics. Some people go about it in the wrong way. People don't look at what they did wrong. The program will get better every year. (Interview $4 / 25 / 81 c)$

I think Walkabout is too hard for kids in high school. I think it's more college stuff. It takes a lot of will power to start Passages. I am so frustrated that I am thinking of getting my 
credits and going to summer school so I can graduate. My parents want me out of school and Walkabout is taking too long. (Interview 4/25/81d)

Other MOHS Technologies

MOHS utilizes other technologies which have not yet been described. First, all students choose freely to attend MOHS. Second, cross-age groupings is a technique applied in classes, on trips, and in various other facets of the program. Third, multi-disciplinary courses are as important as multi-aged courses and activities. Fourth, MOHS operates with a per pupil expenditure equal to larger comprehensive high schools (Audit Committee Report, May, 1976). Finally, the MOHS program is under a continual state of change, reassessment, and reorganization to improve the program (Audit Committee Report, June, 1978).

MOHS FORMAL STRUCTURE

The MOHS formal structure involves the principal, the governance system, and the teachers. The role of the principal and the evolution of his part in the history and organization of MOHS is examined next.

\section{Arnie: The Principal}

Because of the informality and emphasis on close interpersonal relations between students and staff at MOHS, the principal is addressed as Arnie rather than by his surname. Before coming to Colorado, Arnie worked for five years at the Village School in Great Neck, New York. He was involved with six students and one central administrator in the proposal and planning stages of the Village 
School. He was offered a title as principal when the Village School began but he felt that a hierarchy was not necessary for such a small school (start-up enrollment of 48 students). He found through practical experiences that because of external and internal problems, in some instances a hierarchy is needed. For example, if there were internal problems in the school which could not be resolved, a person from the central administrative offices would have to come to the school and arbitrarily resolve conflicts. In the case of external problems, Arnie felt that it would have been easier for one person to be responsible for explaining the school:

By having no hierarchy, whenever there was a need, whenever the outside world, whether it's the central administration or the community, or the Board of Education had any kind of criticism or brought any kind of pressure on the school, the school had to respond because there was nobody delegated to do it, and you can rotate things like that, but it really didn't work. Essentially what would happen is everybody would have to justify the school's existence and the result was that we were spending as much time justifying the existence as trying to exist. So I felt that one thing I learned there too was having somebody in that position as a buffer, that person takes the responsibility and allows the rest of the school to do its thing. It creates an umbrella. When it gets heavy enough, obviously you have to get everyone involved but there were a lot of times when it was a waste of energy. (Interview $6 / 11 / 81$ )

Arnie was first contacted by the Evergreen Open Living School during the time when the 10 through 12 grade component of the system was under discussion. A questionnaire was sent to the Village School and an advisee of Arnie's answered the survey and returned it to Evergreen. Later, even though the Jefferson County School Board had not approved the Open Living School's proposal for a secondary education component, the proposal committee was given support to start hiring personnel for the new school. Alternative schools throughout 
the nation were notified about the available positions. Although Arnie had lived in the Great Neck area all of his life and had taught at the Village School for five years, he financed his trip to Colorado to be interviewed for the position of leader by the Proposal Committee. After several lengthy interviews he was awarded the position. His position was titled Administrative Aide and his salary was 10 percent less than what he had originally been promised. The school district cut Arnie's salary to save on per pupil costs because of the small school size, but they compensated by giving him over-time for working a longer school year (Interview 6/11/81).

In weekly Governance meetings, major decisions affecting the school are decided by all school members. Arnie's role as principal is to take care of all administrative trivia. His major role as principal is to decide which matters are trivial and which are important enough to be sent to Governance for all-school discussion and voting. Externally, according to Jefferson County School Board Policy (非327.5) Arnie is in full charge of MOHS and directly responsible to the Mountain Area Superintendent for the high school.

\section{Governance}

During the sixth year, the MOHS school week began each Monday morning with all school Governance meetings. The purpose of these meetings include: (1) presentations of students' Passage projects, trip reports, or outside community persons' exhibits or offerings; (2) announcements; and (3) decisions after discussions of current school issues where each person has one vote in determining the running of 
the school. A student chairs each Governance meeting. Interested students learn how to prepare and run Governance in a leadership class. Governance provides the training ground for active citizenship and first hand experience on the workings of a democracy. Students learn that they have political power in their school if they are willing to accept the responsibility to use it.

Student interviewees had varied opinions about Governance:

Sometimes I don't know what to think of the Governance system. It lacks "ump." I do like the idea of school-run Governance with students and teachers. Sometimes it lacks direction and goes in circles. I go as of ten as I can hack it. I go approximately two times a month. It depends on my attitude whether I go or not. In my opinion everyone should go. I've been going for five years and sometimes they're boring and sometimes they are interesting. I think they need more pillows for people to sit on. (Interview 4/25/81a)

It's boring sometimes. I get bored so sometimes I decide not to go. I usually do go every week. I think it's neat because as a school we get to decide things instead of having the School Board decide things for us. It's important, I just get bored. (Interview $4 / 25 / 81 \mathrm{~b}$ )

I think it's boring. It could be more exciting by putting less into it. Things could be said in a briefer way. Just a few people get something out of it. Governance should only last 20 to 30 minutes. Only big issues should be discussed as it would make Governance more exciting. Announcements should be put in the minutes. I go about three times a month but that doesn't mean that I stay. Once a month I stay the whole time. It's a lot better than Student Council. In Governance everybody is involved and in Student Council everyone is uppity. (Interview 4/25/81c)

Governance has its place for those people who want to participate and listen. I've been too busy with my school work. I've only been three or four times total this year (Interview $4 / 30 / 81)$

Governance gets a lot done. Schools have problems because they don't have Governance systems like ours. All schools need it. I didn't have it until I was in the Open School. I go most Mondays because I'm usually interested in what is going on. (Interview $5 / 4 / 81 a)$ 
Governance works pretty well but a lot of people don't go. It gets messages out. A lot of people don't go and they need to go. Governance needs to be emphasized as a worthwhile thing. I think it works pretty well. I usually go every week. Sometimes discussions tend to drag on. (Interview 5/4/81b)

People are uninterested. It's boring and lasts too long. I hate it sometimes. When there is an issue to discuss it is more interesting and I am more motivated to go. It is very important to the school even if it is sometimes too boring. It is a good way to start the week and I have only missed twice all year. (Interview $5 / 1 / / 81$ )

I like Governance because I know what's happening in the school and it gives you the feeling you are doing something. (Interview $5 / 18 / 81 a$ )

I think Governance is good. Maybe they should have it on Friday afternoons too. Governance on Monday mornings breaks the ice for the week coming up. It's a way to advertise what is going on, finish Passages, bring in good speakers and community people, and learn what is going on in our school. (Interview 5/18/81b)

Governance has remained constant. The first and second year Audit Committee Reports recommended that there be more development of all people's skills for more involvement in Governance. The creation of the leadership class helps students be involved and gives Governance more structure. Attendance varies but was better in the sixth year with the inclusion of presentations instead of only business. Students like to discuss controversial issues but there aren't always things to debate (Interview with Arnie, 6/11/81).

\section{Teachers}

The duties of the MOHS staff are different from those of other Jefferson County Schools. The MOHS Proposal mandates a role where teachers will be learning facilitators and student advisors rather than information organizers and presenters (Proposal for Mountain Open High School, April, 15, 1975:14). The numerous responsibilities of 
MOHS teachers include: (1) all those of a conventional Jefferson County classroom teacher, (2) advising, (3) teaching utilizing a multitude of strategies, (4) initiating curriculum development, (5) administrating the school particularly through Governance, (6) hiring and evaluating peers, (7) promoting public relations, (8) assisting student teachers and interns, (9) serving on Passage committees, and (10) consulting in issues relating to alternative education (Audit Cormittee Repcrt, Third Year Evaluation, June, 1978). Furthermore, MOHS teachers conduct short and extended school trips locally, in the state of Colorado, throughout the United States, and to various international destinations.

The first year there were seven teaching positions, one principal, a half-time counselor, a half-time community learning coordinator, a half-time volunteer teacher coordinator, and four para-professionals. During the sixth year there was one principal, eight teachers, a full-time counselor, a full-time learning coordinator, and four para-professionals. In addition, a food service coordinator had been hired.

"Burn-out" is a problem for MOHS teachers. Provisions are made to alleviate and confront staffing demands and they include: (1) using volunteers to teach classes, (2) maintaining a full-time Community Learning coordinator, (3) having a half-time library-media person, half-time counselor, and a half-time reading specialist, (4) utilizing a hiring committee to screen applicants and inform them about the extent of the MOHS teaching commitment, (5) conducting a Peer-Self Evaluation, (6) requesting a waiver for the policy of 
relatives working in supervisory relationships (specifically, the principal's wife was teaching at MOHS and was told she was in violation of district polity after she was initially given the approval by the district), (7) establishing staffing patterns, (8) seeking an additional staff person as allocated by the Small Schools provisions, and (9) seeking assurance of aide time in the Skills Lab (Audit Committee Report, Third Year Evaluation, June, 1978). The third year $A C$ stated that due to the intense and demanding teacher roles, staffing ratios should be made in light of the MOHS program and not according to standard district policy (Audit Committee Report, Third Year Evaluation, June, 1978:43). Teacher burnout was more of a problem until the adoption of the Walkabout curriculum at MOHS (Interview with Arnie, 6/11/81).

The second year AC stated that students did not appreciate staff efforts as much as did their parents. The responses of interviewed students directly contradicted that $\mathrm{AC}$ observation:

I think it's a really good staff, partly because they are all willing to help people learn and have the ambition to learn things themselves. There is also a variation on the staff with different expectations. Some are strict, some give a student more freedom. I think the variation is good. That's why I picked __ for my advisor. He keeps me motivated. He is also a good person with a lot of support for me. Some of the staff I know better than others but that's OK. I'II have the opportunity to get to know them better. Arnie is an original. I think he is really good for this school. He helps students and staff and Arnie really stands behind us. It is neat to see that being the principal of the school hasn't over-powered him and he isn't apt to play by the rules all the time. I think that since I've been in the Open System so long, he has confidence and maybe a little bit higher expectations for me to get through with less hassles and problems. (Interview 1/22/81a)

They don't expect anything. expects me to go to my classes. I don't know what expects from me. Teachers at 
traditional schools tell you to do something. Here they get upset and talk to you when you mess up. does tell me I'm going

to make it. I don't have any expectations for myself but will soon. The staff is real together here but some expect more than others. (Interview $1 / 22 / 81 \mathrm{~b}$ )

Teachers set low expectations for me. They always want me to finish things and be less scattered. I will set new expectations for myself later, after I get settled. I can do well when I get organized as $I$ am an escape artist. (Interview 1/22/81c)

Kids make their own expectations here. The staff doesn't make any when you first come in. When I come into a class, they expect me to get into it. The expectations here are based on what you want to do. I think the whole staff is wonderful. Some are different but they will try to help you. If they don't have time for you, they find time for you. (Interview 1/22/81d)

The staff here is unique and refreshing. They are an inspiration. I have a positive attitude for my work here because of the staff. It is making me think about my future. They have given me an insight into what $I$ can do and what I should cast out. The teachers here help you go for what you want. Their awareness of individual kids is different. The teachers in traditional schools are overwhelmed by so many kids. (Interview $1 / 22 / 81$ e)

I like all the staff here. They are fantastic people. I have the highest regard for all the staff. (Interview 1/26/81a)

The staff has high expectations. If they didn't, I'd probably fail. I don't think I'd make it to graduation without their high expectations. I'm more of a leader than a follower. If I'm told to do something I don't do it. If I'm asked with a "please," I'll do it. (Interview $1 / 30 / 81 \mathrm{c}$ )

The MOHS staff was commended by two evaluation teams:

The staff again has to be commended in that they are fulfilling a significant role in the lives of the students attending Mountain Open High School as reported by the students to the observation team. From this standpoint the advisor/advisee relationship is working. (Audit Committee Report, Third Year Evaluation, June, $1978: 43$ )

All aspects of Standard $\mathrm{V}$ are met at J.C.O.H.S. Beyond simply meeting the standard, however, the team was impressed with the energy, enthusiasm, dedication, and creativity of the staff at J.C.O.H.S. The staff is a testimonial to the philosophy of the school that openness and self-acceptance do result in trust, acceptance, and high levels of productivity. (Report of Visiting Resource Team of North Central Association to Jefferson County Open High School, Evergreen, Colorado, March, 1980:3) 
INFORMAL STRUCTURES

MOHS students are involved in the total school program (Audit Committee Report, Third Year Evaluation, June, 1978). As this description of the MOHS organizational theme has indicated, students participate in: (1) Governance, (2) curriculum planning, (3) hiring committees, (4) budget committees, (5) the student-run lunch program, Munchie Central, and (6) varous other aspects of the program. Student satisfaction with MOHS is indicated by interviewees' responses throughout this case study. In addition, the feelings of other students are reported in newspaper accounts of the school. For example, self-composed transcripts of one exchange student are printed as follows.

When I first started going to Mountain Open High School, I discovered a new world in which I didn't really fit. I had been used to an extremely structured educational system throughout my years of school. The teacher was to be called "Mister" and his decisions were not to be discussed. Toward the end of the year every class became somewhat of a battlefield where students and teachers were fighting each other continually.

Living in a universe such as the one I just described didn't leave much time for the development of the individual, which didn't really matter at the time, since it was more important to get good grades than to become a person.

MOHS taught me a hard but beautiful lesson--the knowledge of the self . . There is one last thing I wish to say in this transcript: "Thank you, MOHS for showing me who I really am." (Canyon Courier, 9/23/81)

Earlier, in the discussion of Phase III of the MOHS program, the letter of a student printed in a local newspaper stated her loyalty to the school. In the Jeffco News, a newsletter for Jefferson County residents about the public sciools, one MOHS student pointed out what 
she viewed as advantages of the MOHS program: " . . the personal

attention from teachers and advisors and the opportunity for

self-motivated learning" (Jeffco News, September, 1979). During the

second year of the school, the misconception of the type of student

who attended MOHS was discussed in the following newspaper account:

"A lot of people think this is just a school for bums," said Charlie Fleming, a student from Lookout Mountain. "I mean they see that we don't sit in desks lined up in rows and we're not always in a classroom and they think it's just a place to goof off."

"That's real funny, because the object here is to teach you discipline," said Tom Early, a student from Kittredge. "But the catch is you've got to do it. No one forces you." (Rocky Mountain News, 11/2/76)

A local newsreporter asked MOHS students why they attended MOHS

and their responses were as follows:

The school is more challenging. It's challenging how I motivate myself and take care of my own education. I love the people. It's trying to do your best because you care.

In a traditional school, the administrators only care about quotas and they don't get involved with the students; it's the involvement in the school.

- - because I learn about life. I learn about ilie $\mathrm{by}$ experiencing it, by being out of the school, by setting involved with the community.

I like the people here. I like the teachers. It's an open high school. There are no cliques, no generation gaps. It prepares you more for life.

The schools I went to before were too big. The administration didn't spend much time with you. Here, the teachers care what is going on. They gear you toward going out on your own. (Canyon Courier, $9 / 16 / 81$ ) 
COMMUNITY INFLUENCES

The local community press published favorable statements about Mountain Open High School. For example, after covering a community cultural workshop sponsored by MOHS provided by a grant from the National Endowment of the Arts, a newswriter included the following comments about MOHS in an editorial:

When the dancers began to dance and the crowd of students, teachers, and passers-by become involved, I learned something. JCHOS is different in one big way--the people.

Open High students aren't afraid to get involved. When most students are hesitant to stand up and have some fun, these students are not. And that is where the learning comes in.

In the space of little more than an hour, they learned more about dancing by participating than they could ever learn from a book. They had fun, too, and I didn't see an embarrassed face in the crowd.

As I left the school and walked back to a world where things are not so casual, where people are sometimes afraid to try new things, I was sure of only one thing.

There is indeed a place in this world for a Jefferson County Open High School, and we should be proud to have it and the people associated with it in Evergreen. (Canyon Courier, 4/4/82)

Similarly, during the fifth year of MOHS, the editor of another weekly

in Evergreen described the school in complimentary terms:

The entire school is covered with bright paintings and murals that the students have created. One whole wall in the gym is covered with a gigantic mural of a whale. Arnie said there is no vandalism problem at the school. The students are proud of what they have done.

As I'm typing this, I find my mind wandering to my little brother, Jim, in Texas. I find myself constantly watching Evergreen, wishing Jim were here, wishing he could find the very best of living like I have found. 
I am wishing right now that he could attend Jefferson County open High School. I'm convinced that the students, the staff and the programs are some of the best offered anywhere. (Evergreen Today, 6/12/80)

Because of misconceptions about its program, MOHS has had public image problems within the school district and in the local community (Audit Committee Report of the Mountain Open High School, June, 1977; Audit Committee Report, Third Year Evaluation, June, 1978; Report of Visiting Resource Team of North Central Association to Jefferson County Open High School, March, 1980). The second year AC recommended that MOHS continue to work to promote a positive school image and increase communication between the school and the area superintendent. Professionals in the Jefferson County School District misunderstood the MOHS program and the second year AC called for: "Better understanding of the Mountain Open High School program by other R-1 administrators and teachers" (Audit Committee Report of the Mountain Open High School, June, 1977:28).

Misunderstandings and misconceptions of alternative school programs is a problem presented in Part III of this dissertation. MOHS has not escaped this problem. For example, the second year AC investigated the gross generalization that MOHS students abused drugs.

The second year AC found that stereotype to be unfounded:

The Audit Committee was not able to confirm charges which have been made that the student body is above average in its use of drugs, alcohol, or sexual promiscuity. The open atmosphere for communication in the school does allow for a more free discussion of these topics, but an actual incident count to support or discount such charges goes beyond the capability and charge of the Audit Committee. (Audit Committee Report on the Mountain Open High School, June, 1977:28) 
The North Central Accreditation Team stated its concern for the

lack of communication between MOHS and the school district

administration:

There seems to be some resistance to ownership and understanding of J.C.O.H.S. by above school administration. We recommend that efforts be continued to keep lines of communication open between J.C.O.H.S. and above administration and that above school administration strive for understanding and acceptance of J.C.0.H.S. as a desirable alternative to the traditional school model. (Report of Visiting Resource Team of North Central Association, March, 1980:2-3).

But, the North Central Accreditation Team also commended the MOHS

program:

The team commends the Jefferson County School District for having the imagination and commitment to provide a school like Jefferson County Open High School. The school is very different from the traditional model, but it clearly provides a meaningful alternative for a substantial number of students in the district.

The team commends the staff, students, and community served by J.C.O.H.S. for the same kind of imagination and commitment. The school has an excellent program that is fulfilling its promise and purpose. (Report of Visiting Resource Team of North Central Association, March, 1980:6)

The third year AC maintained that MOHS was a model of reform of secondary education (Interview with Arnie, 6/11/81).

Belief in MOHS was demonstrated in the school's sixth year with the award of securities estimated at $\$ 82,000$ by an anonymous donor (Canyon Courier, 1/14/81). The donor indicated his or her conviction in the affectiveness of the MOHS program with the following statement:

I hope this gift will materially enhance and enrich the program of the Jefferson Open Living High School. I have found this program both to be an outstanding educational effort and to have some of the most dedicated teachers and administrators $I$ have ever encountered. (Canyon Courier, 1/14/81) 
Arnie, the principal, commented on the reason for the generous donation: "I could speculate it is someone whose son or daughter, or grandson or graddaughter was turned around by the school, and they are grateful" (Canyon Courier, 1/14/81).

An analysis of the organizational characteristics of MOHS compared to other secondary school types is presented in the next, concluding chapter. 
CHAPTER $\mathrm{X}$

CONCLUSIONS

This final chapter has two purposes. First, the questions posed by this investigation will be answered and responded to by the evidence provided by the historical analysis and case study. Second, recommendations for future research will be made.

\section{RESPONSES TO RESEARCH QUESTIONS}

Figure 4 provides: (1) a definition of the organizational characteristics of bureaucratic structures and (2) several examples of the organizational characteristics of traditional and alternative secondary schools, and Mountain Open High School. This section restates the questions posed by this study. That matter is taken up now.

(1) What organizational model do conventional and alternative high schools utilize? Conventional and alternative secondary schools are structured according to the bureaucratic model. Alternative secondary schools follow the bureaucratic model but are distinguished by unique features and arrangements. For example, many alternative schools explicitly state that the needs of the individual student are the main focus of their program. Then, individualized learning, independent projects, and other program components are implemented which are designed to challenge the individual. 


\begin{tabular}{|c|c|c|c|c|}
\hline & $\begin{array}{c}\text { Bureaucratic } \\
\text { Organizational Theory }\end{array}$ & $\begin{array}{l}\text { Traditional } \\
\text { Secondary Public Schools }\end{array}$ & $\begin{array}{c}\text { Altermative } \\
\text { Secondary Public Schools }\end{array}$ & $\begin{array}{l}\text { Moumtain Open } \\
\text { High School }\end{array}$ \\
\hline $\begin{array}{l}0 \\
7 \\
0 \\
0 \\
0\end{array}$ & $\begin{array}{l}\text { - Central statements } \\
\text { give onganization } \\
\text { Girection } \\
\text {-Gals must be valued } \\
\text { and legitimate to } \\
\text { society }\end{array}$ & $\begin{array}{l}\text {-Vary by fumction or purpose (see } \\
\text { (see Figure 1) } \\
\text {-Vary by socioeconamic-geographical } \\
\text { location } \\
\text {-Goals set on } 4 \text { levels: mational, } \\
\text { stale, district, individul building }\end{array}$ & $\begin{array}{l}\text { - Vary acoarding to program type } \\
\text { (see Figure 3) } \\
\text {-Are set on individual program lev- } \\
\text { el, necessary for survival \& focus } \\
\text {-Assume learner individuality } \\
\text { - Basic skillis emphasis }\end{array}$ & $\begin{array}{l}\text {-Pertain to three areas: } \\
\text { self-cancept, social, } \\
\text { interpersonal relations } \\
\text {-Developonent of individual } \\
\text { primary focus } \\
\text { firitten school philosophy }\end{array}$ \\
\hline 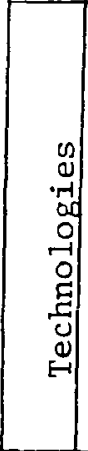 & $\begin{array}{l}\text { - Bode of prodiction } \\
\text { employed to reach } \\
\text { goals }\end{array}$ & 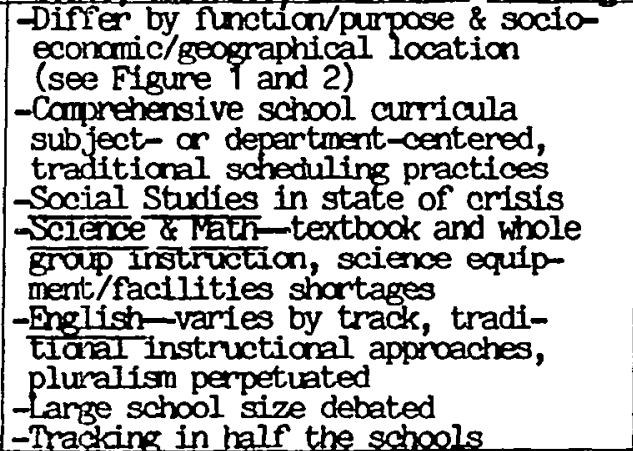 & $\begin{array}{l}\text { - ihmeraus strategies employed: } \\
\text {-supportive school climate } \\
\text { - imall school size } \\
\text { equal per pupil expenditures } \\
\text {-unoonventional grading practices } \\
\text {-career orientation, cammity } \\
\text { service, work experience } \\
\text { - Under continual reassessment and } \\
\text { evaluation } \\
\text { - Choice a key ingredient }\end{array}$ & 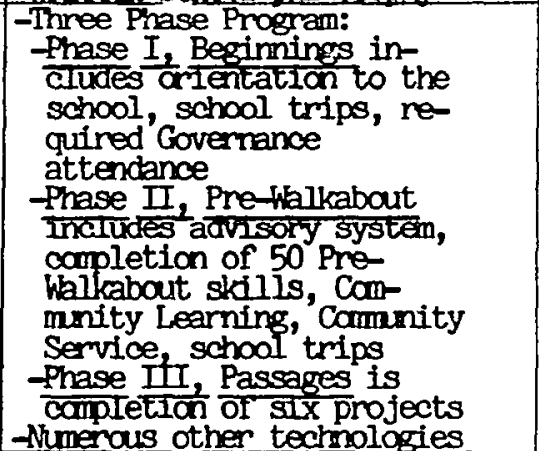 \\
\hline 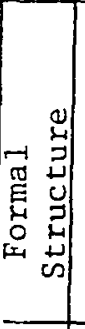 & $\begin{array}{l}\text {-Defines roles of } \\
\text { all participants, } \\
\text { how they relate to } \\
\text { one another } \\
\text {-Monitars internal } \\
\text { conformity } \\
\text {-Exists for ritual; } \\
\text { relational network } \\
\text { to rationalize modes } \\
\text { of production to out- } \\
\text { side organ"zations }\end{array}$ & $\begin{array}{l}\text { - Bureaucratic administrative } \\
\text { structure and management principles } \\
\text { adhered to (see Figure 2) } \\
\text { - Principles are major decision makers } \\
\text {-Citizens/parents attempt to gain } \\
\text { control/participate in decision } \\
\text { making but only token roles allowed } \\
\text { - Loose-coupling allows teachers } \\
\text { autonomy, teachers make } \\
\text { instructloral decisions }\end{array}$ & $\begin{array}{l}\text { Principal's role difflused and } \\
\text { not neatly defined } \\
\text {-20\% have no principal } \\
\text {-Ali school participants vote on } \\
\text { adm. matters in all-school, town } \\
\text { meetings } \\
\text {-Students leam democratic prao- } \\
\text { tices by active participation, } \\
\text { enhances self-concept, commin- } \\
\text { cation skills commitment to } \\
\text { school, \& decision-making skills }\end{array}$ & $\begin{array}{l}\text {-Prinaipal interacts informal- } \\
\text { ly w/students \& staff, } \\
\text { also a teacher } \\
\text {-Principal shares decision } \\
\text { making w/students \& staff } \\
\text {-Principal respansible to } \\
\text { school board and area } \\
\text { superintendent } \\
\text { - Covernance involves all } \\
\text { school menbers, discuss vote } \\
\text { on all adm. matters }\end{array}$ \\
\hline 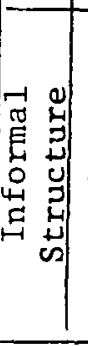 & $\begin{array}{l}\text { - Interacts w/formal } \\
\text { structure to deter- } \\
\text { mine what really } \\
\text { goes on in organ- } \\
\text { Ization } \\
\text { - Maximum efficiency in } \\
\text { production achieved } \\
\text { w/open comminication, } \\
\text { exchange of ideas } \\
\text { betwoen formal and } \\
\text { informal structures }\end{array}$ & $\begin{array}{l}\text {-Varies according to socioeconomic } \\
\text { group (see Figure 2) } \\
\text { - Student participation in decision } \\
\text { making in adm. matters declining } \\
\text { - Shared decision making in scme } \\
\text { large schools } \\
\text { - Identifiable youth subculture } \\
\text { characteristics w/socialization } \\
\text { implications } \\
\text { - Youth subulture differences in } \\
\text { manners and taste but not values }\end{array}$ & $\begin{array}{l}\text {-Teachers the backtone of alt. } \\
\text { programs } \\
\text {-Teachers and students interact } \\
\text { more closely } \\
\text {-Teachers role more demanding but } \\
\text { more satisfying } \\
\text {-Advisory svstems enhance student } \\
\text { acadenic and affective gains }\end{array}$ & $\begin{array}{l}\text { Advisory program heart of MDS; } \\
\text { fosters student commitment, } \\
\text { allows close interaction and } \\
\text { supervision of student's } \\
\text { academic and social progress } \\
\text {-Teachers perform many tasks } \\
\text { - Students participate in all } \\
\text { aspects of program including } \\
\text { curriculum planning, hiring, } \\
\text { Governance, budget decisions }\end{array}$ \\
\hline
\end{tabular}

Figure 4. Bureaucratic organizational characteristics of traditional and alternative secondary schools and Mars. 
(2) What types of conventional and alternative secondary schools exist in urban areas? Figures 1 and 2 demonstrate that conventional schools vary by their educational function or purpose. Some conventional high schools are specialized high schools but the predominant model or type is the comprehensive high school. Also, Figure 2 illustrates that traditional high schools (High Status Schools, Main Line Schools, White Working Class Schools, Transitory Schools, and Inner-City Schools) differ by their socioeconomic-geographical location in urban areas. For example, High Status Schools have had goals set by the community and educational professionals which prepare students for college and enculturate them with the values of the dominant society. On the other hand, goals set for Inner-City Schools by the community and profession include preparing youths with job skills for employment following their graduation from high school and educating students for social change and social mobility.

Alternative secondary schools vary according to their purpose as well as their level of inception (see Figures 1 and 3). Alternative school types have two purposes. A first type, schools of option, service special needs or homogenous student populations. A second type utilizes educational evaluation and research and institutes organizational arrangements to effect educational improvement and reform. Figure 3 describes the four levels of alternative programs: (1) classroom, (2) subunits like a school-within-a-school, (3) individual or separate alternative schools, and (4) alternative systems which provide alternative schooling from Kindergarten through secondary school. 
(3) What are the organizational elements of conventional and alternative secondary public schools? The left hand column of Figure 4 lists and defines the organizational characteristics of a bureaucratic organization. As bureaucratic organizations, conventional and alternative public secondary schools have goals, technologies, formal structures, and informal structures. The second and third columns of Figure 4 present several examples of the organizational characteristics of conventional and alternative secondary public schools. Figure 4 reveals some of the differences in bureaucratic organizational characteristics between traditional and alternative secondary public schools. In point of fact, the traditional schooi formal structure adheres to conventionalized and standardized bureaucratic management principles. In contrast, some alternative schools incorporate all school members when deciding administrative matters in a participatory democratic model.

(4) How do conventional and alternative high school organizations measure up to the charges leveled against secondary education? There are four charges against secondary school organizations which have been presented in depth in Parts II and III of this study. A first charge states that school organizations have not responded to changes in youths' developmental patterns. For the most part, conventional secondary schools continue to employ the same technologies as twenty to forty years ago, despite some reported experimentation. For example, efforts to update course contents have been reported in Social Studies and English, but overall, traditional 
teaching strategies and course contents have not changed radically in secondary schools to recognize youths' developmental patterns and other needs.

On the other hand, the organizational elements of alternative schools consider the needs of individual students. In some alternative schools the assumption is made that every student is an individual (see Figure 4, Alternative Secondary Public Schools, Goals). An array of instructional methods are utilized to address personallyset educational goals. The whole child is central to the organization of some alternative schools.

Socially, alternative schools employ a smaller school size in order to increase teacher and student interaction. Smaller school size and innovative governance structures provide an environment for positive student affective gains for school commitment, personal power, and a feeling of belonging. Small school size gives students the opportunity to interact with more diverse personalities and break through social cliques that are characteristic of larger schools. Academically, individualized instruction and independent study discourage academic tracking and negative labeling of less scholarly students. Multi-teaching strategies provide students with opportunities to develop special interests of their own. Politically, the participatory democratic governance system allows students "hands on" experience with the governmental processes of their schooling environment and knowledge of the inner workings of other bureaucratic organizations. At the very least, the inclusion of 
students in educational decision making cultivates a sense of responsibility for their own education.

A second charge against secondary education is that high schools reflect segregation policies of the larger society and engage in a custodial role which may cause isolation, dependency, and the alienation of youths. Two technologies for conventional schools have been suggested to partially alleviate this situation. The technologies are alternative credential forms and work experiences to ease the transition from high school to the world of work and/or higher education. Abramowitz et al. (1978) with a national survey of principals of conventional high schools found that 83.5 percent of the schools use an $A-B-C-D-F$ grading system with few grading options. Sixty-five percent of the schools in the Abramowitz study reported an off-campus work experience or occupational training program. Seventyfive percent of the schools had a career information center and vocational education funding. The goals and scope of the reported programs were not indicated and would be worth future research. Figure 2 reveals that conventional high schools differ by their socioeconomic neighborhood or location within the city. The goals, technologies, formal structures, and informal structures of the various socioeconomic neighborhoods demonstrate different organizational characteristics. Mention has already been made of the different goals for High Status Schools and Inner-City Schools. An examination of the goals of White Working Class Schools reveals that the status quo is upheld, basic skills are emphasized, homework is assigned, and youths are prepared for the world of work. A comparison 
of the informal structure of the five school types in Figure 2 demonstrates neighborhood differences. First, in Inner-City Schools a high dropout rate and alienation is reported. Also, there exists a strong subcultural influence. In White Working Class Schools, students are reported to be openly hostile but the individual student effort is valued. In High Status Schools, students or the youth culture are influential but students are cooperative.

Alternative schools provide a structure in which individuals can discover and develop themselves. Alternative schools are subversive in the respect that they do not uphold the status quo but focus on the development of the individual. For example, they move beyond academic achievement and also develop survival and life long learning skills, preparing individuals for self-actualized and independent futures. The Parkway School Without Walls in Philadelphia engaged the city as its learning resource and laboratory. Students utilize the mass transit systems to commute to various public institutions where they are frequently involved in projects, apprenticeships, and classes. Schooling technologies including work opportunities, extended field trips, and community service experiences provide students with close interaction and integration with persons of all ages from the larger society. The world is the classroom for many alternative programs.

To help alleviate pressure, anxiety, and competition, alternative schools employ flexible grading systems. Also, advisory and governance systems provide a forum for students' opinions to be aired. Because evaluations are a way of life to alternative schools, 
many programs institute reforms from research results to change and improve their programs. Students are encouraged to be active participants in the change process.

Secondary schools apply goals and technologies which are alienating and irrelevant to some youths is the third charge leveled against high schools. Conventional schools employ traditional teaching strategies and operate with academic tracking practices that sort some students into the "loser" category (see Figure 4, Traditional Secondary Public Schools, Technologies). A review of school scheduling practices illustrates this point. Abramowitz et al. (1978) found that 93.3 percent of the high schools sampled utilize a traditional scheduling system of 35-60 minute periods.

The reviewed studies of conventional schools lacked evidence to support the claim that goals were set on the individual school level. There was evidence that suggested that goals were set on the national, state, and district levels. Students in conventional high schools were not reported to be involved in the goal setting process.

Alternative schools set goals and apply technologies that are relevant and applicable to the development of the whole person. Also, the needs of the individual rather than the status of the advanced, average, or low groups of students are focused upon for development. Figure 4 demonstrates that goal setting on the individual building level is necessary for survival for alternative programs. A final charge against secondary education is that secondary schools utilize an assimilationist's point of view which causes some student alientation. Although this situation may have changed 
somewhat in recent years in conventional high schools, there was only evidence in the Social Studies and English curricula to suggest that a piuralistic perspective was being advocated in these subjects. Alternative schools have been criticized for causing segregation in magnet schools and other special needs schools. These types of schools are not alternatives which work to implement educational reform as defined by Raywid (1982). Alternative schools were not found to be segregated but they reflect ratios of the larger school district.

Because of the off campus activities which integrate learning with all age groups of the larger society, students at alternative schools have the opportunity to associate with a broad spectrum of people. Also, within building units, because of the small community size, alternative school participants develop more interpersonal relationships with a wider variety of personalities. Advancing pluralism and diversity is an innovation in educational reform reported in many alternative schools.

(5) What are the organizational characteristics of MOHS? Figure 4 presents a summary of the organizational characteristics of MOHS. The first MOHS staff spent their first staff meeting deciding on the MOHS school philosophy. The goals were set for three areas and have not significantly changed. They include development in: (1) self-concept, (2) social areas, and (3) interpersonal relations. The individual is the focus of this program. Concerning technologies, the program component which has experienced the most change is the curriculum. They now have a three phase program named Walkabout which 
includes: (1) Beginnings, (2) Pre-Walkabout, and (3) Passages. Other technologies are employed at MOHS and they include: (1) cross age grouping in all classes and activities, (2) small school size, (3) no tracking or ability grouping, (4) promotion based on mastery, (5) written evaluations, and (6) flexible scheduling. The formal structure of MOHS is unique. There is a principal but all major administrative decisions are made in all school Governance Meetings held each Monday morning. Every school participant votes equally on all important administrative issues including hiring, budgeting, and curriculum planning.

The participants (teachers and students) of the informal structure at MOHS are involved in all aspect of the MOHS program. The advisory system which is a one-on-one guidance component provides close supervision of the academic and social growth of students. MOHS teachers spend one-third of their time advising but this program component is deemed the heart of the school. See Part IV for student opinions of the advisory system at MOHS. Although the MOHS subculture (teachers and students) is reported to be involved in all aspects of the MOHS program (see Figure 4), and such participation can be taxing for all members, the cooperative effort fosters student and teacher commitment and ownership of the program.

(6) What type of alternative school is MOHS? A review of the literature found that alternative high schools have been classified in two ways. A first type, schools of option or special needs schools offer an education for homogeneous student populations. A second type of alternative school implements innovative organizationai features 
and combinations to effect educational improvement and reform. MOHS is the latter kind of alterantive school type. The right hand column on Figure 4 presents examples of the organizational characteristics of MOHS. First, goals are set which pertain to developing the whole individual and include areas of self-concept, social development, and interpersonal relations. There are goals set on the building level and there is a written school philosophy.

More than lip service is given at MOHS to the development of the individual student's social and academic areas. For example, the three phases of the Walkabout curriculum allow the development of individual students' needs. Other technologies are employed at MOHS to cultivate a waym school climate and to maximize student success and they include: (1) no age segregation, (2) written evaluations, (3) flexible scheduling, and (4) community service and work experiences. The formal structure at MOHS is non-traditional. There is a principal but his role is diffused and not neatly defined. The Governance system at MOHS if unique because it involves all school members in weekly meetings where administrative matters are discussed and voted upon by all school members. The principal at MOHS interacts closely with students and stafi persons and even teaches. Also, he has traveled on numerous school trips.

As Figure 4 indicates, the advisory system at MOHS is deemed the heart of the school. The one-on-one guidance system allows close contact between a student and his/her advisor. Advisee groups provide additional support for students and the forum to discuss their progress and problems. The advisory system supports and closely 
supervises the academic and social progress of students. The advisory system is one program component of MOHS which fosters student commitment and ownership of their school. The participants of the informal structure at MOHS (teachers and students) are involved in all aspects of their program.

(8) In what ways is MOHS similar or dissimilar to public secondary schools? MOHS is similar to traditional and alternative schools because its organizational elements are structured after the bureaucratic model (see Figure 4). MOHS is different from traditional secondary schools because of some of the following reasons.

First, in goal areas, all members of MOHS participate in goal setting and they are made on the building level. It is assumed that each student is an individual and educational experiences are planned and structured accordingly.

Second, innovative technologies at MOHS are different from traditional schools. Students are not assigned to MOHS but chose freely to attend there, coming from attendance areas throughout the public school district. The MOHS curriculum does not track students by academic and vocational ability groups but offers an educational program designed to challenge individual's talents. MOHS employs multiple instructional techniques and does not rely on a subject-centered curriculum, traditional scheduling practices, textbook instruction, and the lecture method for information dissemination. Cross-age grouping is integrated into classes and activities to eliminate age segregation. Interdisciplinary classes are presented at MOHS in order that students can examine the 
interrelatedness of events and issues. MOHS invites and engages in ongoing evaluation efforts internally and externally, reassessing and implementing beneficial program changes.

Third, the MOHS formal structure is unique. The MOHS principal has a diffused and nonauthoritarian role. Administrative matters are decided by all school members in weekly Governance meetings. With a participatory democratic model, Governance at MOHS provides a "hands on" experience for all school members.

Finally, the informal structure at MOHS is central to the program. MOHS has a one-on-one academic and social guidance component or advisory system which fosters close interpersonal relations between staff and students. The responsibilities and duties of MOHS teachers are more demanding and numerous than those of their conventional school counterparts. Students are acknowledged as important entities in the MOHS structure and they are expected to be active participants in choosing and implementing educational activities tailored to their personal needs.

MOHS is similar to the alternative school type which works to implement innovative organizational reform measures within public school districts.

There are similarities in the organizational components of conventional high schools and MOHS. First, they share a common goal which is the education of American youths. Basic skill development and preparation for adulthood is another shared goal. Both school types adhere to national, state, and local school district goals. 
In the area of school technolcgies, MOHS per pupil cost is equal to the conventional schools in its district. Standardized tests measure academic achievement and SAT tests are administered.

The formal structure of conventional schouls and MOHS are alike in the fact that principals are responsible for what goes on in the school. Finally, a shared similarity in the informal structure is the significance that teachers are the heart of the program.

Areas for future research are detailed next.

RECOMIENDATIONS FOR FUTURE RESEARCH

There are two general areas from this study which need further research. First, the specific and manageable ways that organizational arrangemenics of alternative schools can be implemented in larger conventional high schools deserves further investigation. For example, the feasibility of initiating advisory systems of smaller house units to promote social and interpersonal relations between students and teachers in comprehensive high schools is worthy of exploration. Second, another general area which deserves further research attention is the study of alternative school typologies and the documentation of the types which are experiencing the most growth.

Inquiry is needed in various areas of school organizations. First, Figure 4 notes that goals are not always set on the individual school building level in conventional schools. The effective or quality school studies argue that this level of goal setting is necessary. Future studies could compare the effects of goal setting and non-goal 
setting on a representative sample of conventional high schools to further investigate the importance of this organizational element. Second, Figure 4 reveals diversity between technologies employed in conventional schools, alternative schools, and MOHS. There are numerous teaching-learning dimensions which demand further inquiry. For example, the use of flexible scheduling and independent study in alternative schools compared to the standardized scheduling and predominant lecture method of conventional schools needs in-depth study to establish appropriate teaching and learning modes.

The leadership styles of principals needs further investigation as well as shared decision-making models and measured effects on the informal structure. The extent and impact of the student subculture influence on the socialization of high school youths has not been firmly established and is worthy of future research. In a more general sense, the effects of the organizational arrangements of conventional and alternative school types should be continually measured by gathering school participants perceived attitudes and opinions.

Finally, alternative high schools should establish communication networks with each other, conventional high schools, and the larger community to promote positive public relations. There is a lack of confidence by many community members concerning the realities of alternative schooling. Effective steps to enlighten the public about these school organizations should be advocated. 
SOURCES CONSULTED 
SOURCES CONSULTED

BOOKS AND PERIODICALS

Abramowitz, Susan, Tenebaum, Ellen, Deal, Terrence E., Stackhouse, E. Anne. High School '77: A Survey of Public Secondary School Principals. Washington, D.C.: U.S. Department of Health, Education, and Welfare, December, 1978.

Acton, T.A. Educational Criteria of Success: Some Problems in the Work of Rutter, Maughn, Mortimore, and Auston. Educational Research, June, 1980:163-169.

Allen, Vernon L., and Greenberger, David B. Aesthetic Factors in School Vandalism. In School Crime and Disruption: Prevention Models. National Institute of Education, June, 1978.

American Youth in the Mid-Seventies. Conference Report of the National Committee on Secondary Education, National Association of Secondary School Principals. Washington, D.C.: November 30 and December 1, 1972.

Anglin, Leo W. Teacher Roles and Alternative School Organizations. Educational Forum, May, 1979:438-452.

Arnove, Robert and Strout, Toby. Alternative Schools and Cultural Pluralism: Promise and Reality. Educational Research Quarterly, Winter, 1978:74-98.

- Alternative Schools for Disruptive Youth. Educational Forum, May, 1980:453-471.

Austin, Gilber R. Exemplary Schools and the Search for Effectiveness. Educational Leadership, January, 1979:10-14.

Bachman, Jerald G., Kahn, Robert L., Mednick, Martha T., Davidson, Terrence N., and Johnson, Lloyd D. Youth in Transition. Anne Arbor, Michigan: Institute for Social Research, 1967.

Bany, Mary A. and Johnson, Lois V. Educational Social Psychology. New York: MacMillan, 1975. 
Barker, Roger G. and Gump, Paul V. Big School, Small School: High School Size and Student Behavior. Stanford, California: Stanford University Press, 1964.

Barone, Orlando R. Lessons to be Learned, The Ups and Downs of Family Schools. National Association of Secondary School Principals Bulletin, October, 1980:36-40.

Barr, Robert D. Alternatives for the Eighties: A Second Decade of Development. Phi Delta Kappan, April, 1981:570-573. - The Growth of Alternative Public Schools: The 1975 ICOPE Report. Changing Schools, 12, 1975:1-10.

Barsalou, Judith M., Killinger, June E., Thompson, June E. Students Evaluation of Staff in Secondary Schools. National Association of Secondary School Principals Bulletin, 63 (Noyember), 1979:10-14.

Beckner, Weldon and $0^{\prime N}$ Neal, Linda. A New View of Smaller Schools. National Association of Secondary School Principals Bulletin, $64(438), 1980: 1-7$.

Berger, Michael. Violence in the Schools: Causes and Remedies. Bloomington, Indiana: Phi Delta Kappa Educational Foundation, 1974 .

Bernstein, Abraham. The Education of Urban Populations. New York: Random House, $1 \overline{967}$.

Bidwell, Charles E. The School as a Formal Organization. In March, James G. Handbook of Organizations. Chicago: Rand McNally \& Company, 1965.

Binzen, Peter. Whitetown, U.S.A. New York: Philadelphia Bulletin Books, 1970.

Blau, Peter Michael. Bureaucracy in Modern Society. New York: Random House, 1961.

- The Dynamics of Bureaucracy. In Amitai Etzioni, A Sociological Reader on Complex Organizations. New York: Holt, Rinehart and Winston, Inc., 1969.

Bowles, S. and Gintis, H. Schooling in Capitalist America. New York: Basic Books, Inc., 1976.

Brimm, Paul and Hanson, Donald L. The Small School: How Can It Be Improved. National Association of Secondary School Principals Bulletin, October, 1980:20-21. 
Brookover, Wilbur B. and Erickson, Edsel L. Society, Schools, and Learning. Boston: Allyn \& Bacon, Inc., 1969 .

Brookover, Wilber B., Schweitzer, John H., Schneider, Jeffrey M., Beady, Charles H., Flood, Patricia K., Wisenbaker, Joseph M. Elementary School Social Climate and School Achievement. American Educational Research Journal, Spring, 1978:301-318.

Brown, B. Frank (Chairman). The Reform of Secondary Education: A Report to the Public and the Profession. National Commission on the Reform of Secondary Education, New York: McGraw-Hill, 1973.

Buser, Robert and Humm, William L. A Study of the Organization for Instruction in Selected Schools of the North Central Association of Secondary Schools and Colleges. (Unpublished Study No. EA-002981, ERIC Clearinghouse on Educational Administration, Eugene, Oregon, 1970.)

Buser, Robert L. and Manlove, Donald C. Organization for Instruction in the Larger NCA Public High School (1965-1969). North Central Association Quarterly, 44 (1), 1969:316-319.

Calkins, James E. Are Students Involved in Deciding Crucial Issues? National Association of Secondary School Principals Bulletin, October, 1974:15-20.

Caplow, Theodore. Principles of Organizations. New York: Harcourt, Brace, \& World, Inc., 1964.

Carnegie Council on Policy Studies in Higher Education. Giving Youth a Better Chance: Options for Education, Work, and Service. San Francisco, Calif.: Josey-Bass, Inc., 1979.

Case, Barbara J. Lasting Alternatives: A Lesson in Survival. Phi Delta Kappan, April, 1981:554-557.

Chesler, John. Innovative Governance Structures in Secondary Schools. In Terrence E. Deal and Robert R. Nolan (Eds.) Alternative Schools. Chicago: Nelson-Hall, 1978.

Childe, V. Gordon. The Urban Revolution. In John Walton and Donald E. Carns, Cities in Change. Boston, Mass.: Allyn and Bacon, Inc., 1977 .

Clark, David L., Lotto, Linda S., and McCarthy, Martha M. Factors Associated With Success in Urban Elementary Schools. Phi Delta Kappan, 61 (7), 1980:467-470.

Clift, Virgil A. Organizing Metropolitan Schools. In Allan C. Ornstein and Steven I. Miller (Eds.), Policy Issues in Education. Lexington, Mass.: Lexington Books, 1976. 
Cohen, David K. Refirming School Politics. Harvard Educational Review, 48 (4), 1978:429-447.

Coleman, James (Chairman). Transition to Adulthood. Report of the Panel on Youth of the President's Science Advisory Committee, Chicago, Illinois: University of Chicago Press, 1974.

Collins, Huntley. John Adams High School: What Happened to the Experiment? The Oregonian, May 25, 1980.

Combs, Arthur W. Can Education be Relevant? In Galen J. Saylor and Joshua Smith. Removing Barriers to Humaness in the High School. Washington, D.C.: Association for Supervision and Curriculum Development, 1971:30-42.

Conant, James Bryant. Slums and Suburbs. New York: McGraw-Hill Book Company, 1961 .

- The American High School Today. New York: McGraw-Hill Company, Inc., 1959 .

- The Comprehensive High School. New York: McGraw-Hill Company, 1967.

Cortin, Edith, Main, Eleanor and Swanson, Bert E. Parents in Search of Community Influence in the Public Schools. Education and Urban Society, 4 (1), 1969:383-403.

Corwin, Ronald G. and Edelfelt, Ray A. (Eds.). Perspectives on Organizations, The School as a Social Organization. Washington, D.C.: American Association of Colleges for Teacher Education, 1977 .

Council for Basic Education, 725 Fifteenth St., N.W., Washington, D.C.

Crabtree, Mary Frances. Chicago's Metro High: Freedom, Choice, Responsibility. Phi Delta Kappan, May, 1975:624-628.

Cremin, L. The Free School Movement, A Perspective. Today's Education, September, 1974:71-75.

Cuban, Larry. To Make a Difference: Teaching in the Inner City. New York: The Free Press, 1970.

Cullers, Benjamin, Hughes, Clarence, and McGreal, Thomas. Administrative Behavior and Students Dissatisfaction: A Possible Relationship. Peabody Journal of Education, 50 (2), 1973:155-163.

Cusick, Phillip. An Rx For Our High Schools. Character, May, $1981: 1-6$. 
Davies, Don. Making Citizen Participation Work. National Elementary Principal, March, 1976:20-29.

Deal, Terrence E. and Celotti, Lynn D. How Much Influence Do (and Can) Educational Administrators Have on Classrooms? Phi Delta Kappan, 61, 1980:471-473.

Deal, Terrence E. and Nolan, Robert R. Alternative Schools: A Conceptual Map. School Review, November, 1978a:29-49. - Alternative Schools: Ideologies, Realities, Guidelines. Chicago: Nelson-Hall, 1978b.

Dodson, Don W. Student Powers as a Means to Educational Change. Integrated Education, November-December, 1970:32-39.

Doll, Russell. Categories of Elementary Schools in a Big City. Research Paper, Department of Education, University of Chicago, 1965.

Douglas, Jack D. Investigative Social Research. Beverly Hills: Sage Publications, 1976.

Drabek, Thomas E. and Haas, J. Eugene. Understanding Complex Organizations. Dubuque, Iowa: Wm. C. Brown Company, 1974.

Drake, Michael (Ed.). Applied Historical Studies, An Introductory Reader. London, England: Metheun \& Co., Ltd., 1973.

Duke, Daniel Linden and Muzio, Irene. How Effective Are Alternative Schools? Teachers College Record, February, 1978:461-483.

Dunn, Kenneth. Madison Prep: Alternative to Teenage Disaster. Educational Leadership, February, 1981:386-387.

Edmonds, Ronald R. Programs of School Improvement: An Overview. Educational Leadership, December, 1982:4-12.

Education By Choice, Phi Delta Kappan, May, 1975:629.

Etzioni, Amitai. A Bulletin Special: An Interview with Amitai Etzioni--The Real Role of the Nation's Secondary Schools. National Association of Secondary School Principals Bulletin, 65 (447), 1981:64-74.

- A Comparative Analysis of Complex Organizations. New York: Free Press, 1961 .

Fagan, Dorothy F. Community Participation in Decision Making. Educational Horizons, Fall, 1973:10-13. 
Fantini, Mario. Alternatives in the Public School. Today's Education, September, 1974:63-66.

- Education By Choice. National Association of Secondary School Principals Bulletin, 57 (374), 1973:10-19.

Fernadez, Celestino, Massey, Grace, and Dornbusch, Stanford. High School Students Perceptions of Social Studies. The Social Studies, March/April, 1976:51-57.

Fischer, Allen. Advisory Comittees--Does Anybody Want Their Advice? Educational Leadership, 37 (3), 1979:254-255.

Ford Foundation. Matters of Choice: A Ford Foundation Report on Alternative Schools. New York: Ford Foundation, 1974.

Fox, Robert S. School Climate Improvement: A Challenge to the School Administrator. Denver, Colorado: CFT Ltd., $197 \overline{73}$

Garbarino, James. Some Thoughts on Schools Size and Its Effect on Adolescent Development, Journal of Youth and Adolescent, 9 (1), 1980:19-31.

- The Human Ecology of School Crime. In School Crime and Disruption: Prevention Models. National Institute of Education, June, 1978.

Gibbons, Maurice. The New Secondary Education. Bloomington, Indiana: Phi Delta Kappan, Inc., 1976.

- Walkabout: Searching for the Right Passage From Childhood and School. Phi Delta Kappan, May, 1974:596-603.

Giles, Arthur. Organization and Discipline in the Comprehensive School. Educational Review, 30 (4), 1977:213-220.

Gillies, Fred. Distractions Disrupting in Hold Youth Classes. The Denver Post, April 13, 1981:13. - Young and Troubled . . A Second Chance. The Denver Post, April 12, 1981:33.

Gittell, Marilyn. Decentralization and Citizen Participation in Education. Public Administration Review, October, 1972.

Goffman, Erving. The Characteristics of Total Institutions. In Amitai Etzioni (Ed.), A Sociological Reader on Complex Organizations. New York: Holt, Rinehart, and Winston, Inc., 1969. 
Gouldner, Alvin W. Organizational Analysis. In Robert T. Merton, Leonard Broom, and Leonard Cottrell, Jr., (Eds.), Sociology Today. New York: Harper Torchbooks, 1959.

Greenberg, David F. Delinquency and the Age Structure of Society. Contemporary Crises, 1, 1977:189-223.

Gregory, Tom and Smith, Gerry. School Climate Findings. Changing Schools, Spring, 1983:8-11.

Gross, Neal. Some Contributions of Sociology to the Field of Education. In Ronald M. Pavalko (Ed.), Sociology of Education. Itasca, I.ll.: F. E. Peacock Publishers, Inc., 1968.

- The Sociology of Education. In Robert T. Merton, Leonard Broom and Leonard Cottrell, Jr., Sociology Today. New York: Harper \& Row Publishers, 1959.

Gross, Richard F. The State of the Social Studies in the Public Schools of the United States: Facts and Impressions of a National Survey. Social Education, March, 1977:194-205.

Guba, Egon G. Toward a Methodology of Naturalistic Inquiry in Educational Evaluation. Los Angeles: University of California, Center for the Study of Evaluation, 1978.

Hargreaves, D. H. Social Relations in a Secondary School. New York: Humanities Press, 1967.

Havighurst, Robert J. Education in Metropolitan Areas. Boston: Allyn and Bacon, Inc., 1966.

Havighurst, Robert J., Smith, Frank L., and Wilder, David E. A Profile of the Large-City High School. Washington, D.C.: National Association of Secondary School Principals, 1970.

Hersh, Richard. How Effective is Your School? Instructor, October, $1982: 34-35$.

Hertzberg, Hazel Whitman. Social Studies Reform, 1880-1980. Project SPAN, Social Studies Priorities, Practices, and Needs. Boulder, Colorado: Social Science Educational Consortium, 1981.

Hipple, Theodore W. Literature Study in the 80's: A Look at the Possibilities. In Shuman, R. Baird, Education in the $80^{\prime} \mathrm{s}$ : English. Washington, D.C.: National Education Association, 198i:20-29.

Hollister, C. David. School Bureaucracies as a Response to Parents' Demands. Urban Education, July, 1979:221-235. 
Howard, Eugene R. School Discipline Desk Book. New York: Parker Publishing Co., 1978 .

Ianni, Francis A. A Positive Note on Schools and Discipline. Educational Leadership, 37 (6), 1979:457-458.

- The Social Organization of the High School: School-Specific Aspects of School Crime. In School Crime and Disruption: Prevention Models. National Institute of Education, June, 1978.

Jackson, Jesse. In Pursuit of Equity, Ethics, and Excellence: The Challenge to Close the Gap. Phi Delta Kappan, November, 1978: 191S-193S.

Jacobs, Ruth Harriet. Focus on High Schools. Phi Delta Kappan, October, 1971:100-101.

Jencks, C. (Chairman). Inequality--A Reassessment of the Effect of Family and Schooling in America. New York: Basic Books, 1972.

Jenkins, Jeanne Kohl. Advisory Councils and Principals in Los Angeles. Integrated Education, January, 1976:27-31.

Johnson, David L. and Parker, Jackson V. Options. Phi Delta Kappan, May, 1975:624-628.

Kaplan, Judy. Observation and Participation: No Grades, No Tests. Compact, Spring, 1981:22-23.

Katz, Fred E. The School as a Complex Social Organization. Harvard Educational Review, 34 (3), 1964.

Katz, Michael B. The Irony of Early School Reform. Cambridge, Massachusetts: Harvard University Press, 1968.

Katz, Michael B. Class, Bureaucracy and Schools. New York: Praeger Publishing, 1971.

Kelly, Delos H. Analysis of the Expected Correlates of Curriculum Assignment Patterns in an American High School. Contemporary Education, 47, 1976:74-78.

- Student Perceptions, Self Concept, and Curriculum Assigriment. Urban Education, 9, 1974:257-269.

Kelly, Delos H. and Balch, Robert W. Social Origins and School Failure: A Reexamination of Cohen's Theory of Working Class Delinquency. Pacific Sociological Review, October, 1971:413-430.

Kelly, Delos H. and Pink, William T. School Commitment, Youth Rebellion, and Delinquency. Criminology, February 1973:473-485. 
Kelly, Delos H. and Pink, William T. Social Origins, School Status, and the Learning Experience. Pacific Sociological Review, January, 1973:121-134.

Kerlinger, Fred N. Foundations of Behavioral Research. New York: Holt, Rinehart and Winston, Inc., 1973.

Kier, William R. Humanizing Large Schools: One School's Experience. National Association of Secondary School Principals Bulletin, 57(373), 1973:146-150.

Kohlberg, Lawrence. The Moral Atmosphere of the School. In Norman V. Overly, The Unstudied Curriculum: Its Impact on Children. Washington, D.C.: Association for Supervision \& Curriculum Development, National Education Association, 1970.

Kozberg, Geraldine and Winegar, Jerome. The South Boston Story: Implications for Secondary Schools. Phi Delta Kappan, April, 1981:565-569.

Krah1, George B. Alternative Education: Current State of the Art. New York: Institute for Urban and Minority Education, 1977.

Langberg, Arnie. This School is the Future . . Changing Schools, Spring, 1983a:1-3.

- What's Happening in .. Jefferson County Open High School? Phi Delta Kappan, June, 1983b:736.

Levine, Naomi. Ocean Hill-Brownsville: Schools in Crisis, A Case History. New York: Popular Library, 1969.

Lightfoot, Alfred. Urban Education in Social Perspective. Chicago: Rand McNally College Publishing Company, 1978.

Lofland, John. Analyzing Social Sectings. Belmont, Calif.: Wadsworth Publishing Company, Inc., 1971. - Doing Social Life. New York: John Wiley \& Sons, 1976.

Long, Samuel. Urban Adolescents and the Political System: Dimensions of Disaffection. Theory and Research in Social Education, 8, Spring, $1980: 31-43$.

Lortie, Dan C. Two Anomalies and Three Perspectives: Some Observations on School Organization. In Ronald G. Corwin and Roy A. Edelfelt, Persuectives on Organizations, The School as a Social Organization. Washington, D.C.: American Association of Colleges for Teacher College, 1977.

MacDonald, James B. A Vision of a Humane School. In J. Galen Saylor and Joshua L. Smith, Removing Barriers to Humaness in the High School. Washington, D.C.: Association for Supervision and Curriculum Development, 1971:2-20. 
MacNab, Alexander G. and Weiland, Richard J. Earn and I.earn: An Uncommon Solution to a Familiar Problem. Phi Delta Kappan December, 1980:280-282.

Marburger, Carl L. Parents/Citizens: The Fourth Force in Education. National Association of Secondary School Principals Bulletin, January, 1980:8-11.

Martin, John Henry (Chairman). National Panel on High Schools and Adolescent Education. U.S. Office of Education, Washington, D.C., 1974.

Martindale, Don. Prefactory Remarks: The Theory of the City. In Max Weber, The City. New York: The Free Press, 1958.

McCoy, F. N. Researching and Writing in History. Berkeley, Calif.: University of California Press, 1974.

McPartland, James M. and McDill, Edward L. Research on Crime in the Schools. Baltimore, Md.: Center for Social Organization of Schools, John Hopkins University, 1975.

Merton, Robert K. Bureaucratic Structure and Personality. In Amitai Etzioni, A Sociological Reader on Complex Organizations. New York: Hoİt, Rinehart, and Winston, Inc., 1969.

Meyer, John W. and Rowan, Brian. Institutionalized Organizations: Formal Structure as Myth and Ceremony. American Journal of Sociology, 83 (2), 1977.

Mickelson, Rosalyn Arlin. Social Stratification Processes in Secondary Schools: A Comparison of Beverly Hills High School and Morningside High School. Journal of Education, 162 (4), 1980:83-112.

Miller, Donald F. The Oregon Small Schools Program. National Association of Secondary School Principals Bulletin, October, 1970:75-88.

Moore, David Thornton. Alternative Schools: A Review. New York: Institute for Urban and Minority Education, Urban Diversity Series, 53, June, 1978.

Morgan, Stanley R. Shared Governance: A Concept for Public Schools. National Association of Secondary School Principals Bulletin, January, 1980:29-33.

National Association of Secondary School Principals. Secondary Schools in a Changing Society: This We Believe. Reston, Virginia: National Association of Secondary School Principals Bulletin, 1975. 
National Association of Secondary School Principals, Conference Report on the National Committee on Secondary Education, American Youth in the Mid-Seventies. Washington, D.C.: Nov. 30 to Dec. 1,1972 .

National Commission on Excellence in Education. A Nation at Risk: The Imperative for Educational Reform. Washington, D.C.: U.S. Government Printing Office, 1983.

National Commission on Resources for Youth, Inc. New York: March, 1982.

National Consortium for Options in Public Education: Directory of Alternative Schools, Changing Schools, 8, 1972:1-18.

National Education Association, Schools of the Urban Crisis. Task Force on Urban Education Report, 1969 .

National School Boards Association, Alternative Schools. Report Number 1976-3, Evanston, Ill.: 1976.

Neill, A. S. Summerhill: A Radical Approach to Child Rearing. New York: Hart Publishing Company, 1960.

Nelsen, Ralph T. Focus: An Alternative Model that Works, Phi Delta Kappan, May, 1975:631.

Nolan, Robert R. Students Power: A Case Study. In Terrence E. Deal and Robert R. Nolan (Eds.), Alternative Schools. Chicago: Nelson-Hall, 1978:124-135.

O'Donnell, Roy C. Needed Research in the Teaching of English. In R. Baird Shuman (Ed.), Education in the 80's: English. Washington, D.C.: National Education Association, 1981:154-159.

Ornstein, Allan C. and Levine, Daniel U. Strategies for Reforming Metropolitan Schools, Urban Education, 16 (1), 1981:93-107.

Ornstein, Allan C., Levine, Daniel U., and Wilkerson, Doxey A. Reforming Metropolitan Schools. Pacific Palisades, Calif.: Goodyear Publishing Company, 1975.

Palmer, William S. Reading and the Teaching of English. In R. Baird Shuman (Ed.), Education in the 80's: English. Washington, D.C.: National Education Association, 1981:54-63.

Parker, Harold K. and Masuda, Richard. Opportunity Schools. National Association of Secondary School Principals Bulletin, 55 (354), April, 1971: $\overline{37}-\overline{45 .}$

Parrett, William H. Conventional vs. Alternative Schools: How Different Are the Teachers? Phi Delta Kappan, April, 1981. 
Parsons, Talcott. Suggestions for a Sociological Approach to the Theory of Organizations. Administrative Science Quarterly, 1 (1), 1956.

Passow, A. Henry. American Secondary Education: The Conant Influence. Reston, Virginia, National Association of Secondary School Principals, 1977.

Perel, William A. and Vario, Philip D. Urban Education: Problems and Prospects. New York: David McKay Company, Inc., 1969.

Perrow, Charles B. Organizational Anaysis: A Sociological View. Belmont, Calif.: Brooks \& Cole Publishing Company, 1970.

Perry, Roger H. Strategies for Working with Problem Students, An Organizational Perspective. Urban Education, January, 1980.

Pigors, Paul and Pigors, Faith. Case Method in Human Relations: The Incident Process. New York: McGraw-Hill Company, 1966.

Pink, William T. and Sweeney, Mary Ellen. Teacher Nomination, Deviant Career Lines, and the Management of Stigma in the Junior High School. Urban Education, 13 (3), 1978:361-380.

Polk, Kenneth. Class, Strain and Rebellion Among Adolescents. Social Problems, Fall, 1969:214-224.

Postman, Neil. The Ascent of Humanity: A Coherent Curriculum. Educational Leadership, 37 (4), 1979:300-303.

Raywid, Mary Anne, Sherin, John, Firestone, Helen, and Schelle, Ray. Keeping Afloat I: Internal Considerations. Hempstead, New York: Center for the Study of Education Alternatives, 1980.

- The Alternative Route to School Renewal. Compact, Spring, 1981a: 7-10.

- The Current Status of Schools of Choice in Public Secondary Education. Project on Alternatives in Education. Hempstead, New York: Hofstra University, 1982.

- The First Decade of Public School Alternatives. Phi Delta Kappan, April, 1981b.

Reilly, Robert T. Wind River Changes Its Course: The St. Stephen's Experience. Phi Delta Kappan, November, 1980:200-202.

Rist, Ray C. Social Class and Teacher Expectations: The SelfFulfilling Prophecy in Ghetto Education. Harvard Education Review, 40, 1970. 
Rist, Ray C. The Invisible Children: Social Integration in American Society. Cambridge: Harvard University Press, 1978.

- The Urban School: A Factory for Failure. Cambridge: The MIT Press, 1973.

Rosenbaum, James E. and Presser, Stephen. Voluntary Racial Integration in a Magnet School. School Review, 82 (2), 1978:156-186.

Rutter, Michael, Maughan, Barbar, Mortimore, Peter, Auston, Janet, Smith, Allen. Fifteen Thousand Hours: Secondary Schools and Their Effects on Children. Cambridge, Mass.: Harvard University Press, 1979.

Sackett, Gene P. Observing Behavior. Baltimore, Md.: University Park Press, 1978.

St. Germain, Richard, Carten, Roger D. and Meland, James. Roseville Faces Disaffection with Alternative High Schools. Phi Delta Kappan, May, 1975:637-638.

Schaefer, W. E. and Polk, K. Delinquency and the Schools. In Task Force Report: Juvenile Delinquency and Youth Crime, President's Commission on Law Enforcement and the Administration of Justice, Washington, D.C.: Government Printing office, 1967:222-277.

Scl.miedeck, Raoul A. Adolescent Identity Formation and the Organizational Structure of High Schools. Adolescence, 14 (53), 1979:191-196.

Seckington, Roger. Schools Within Schools. Forum for the Discussion of New Trends in Education, 17 (3), 1973:90-92.

Selznick, Philip. Foundations of the Theory of Organization. In Amitai Etzioni, A Sociological Reader on Complex Organizations. New York: Holt, Rinehart, and Winston, Inc., 1969.

Shaver, James P., Davis, O. L. Jr., Helburn, Suzanne W. The Status of Social Science Education: Impressions from Three NSF Studies. Social Education, 43, February, 1979:150-153.

Shaw, Jane S. The New Conservative Alternative. Nation's Schools \& Colleges, February, 1975:31-39.

Shockless, Daniel. Changing to Modular Flexible Scheduling. National Association of Secondary School Principals Bulletin, 57 (369), 1973:79-88.

Shuman, R. Baird (Ed.). Education in the 80's: English. Washington, D.C.: National Education Association, 1981. 
Sieber, Sam D. and Wilder, David E. The School in Society. New York: Free Press, 1973.

Silberman, Charles E. Crisis in the Classroom. New York: Random Holuse, 1970.

Silberman, Harry F. Involving the Young. Phi Delta Kappan, May, 1975:596-600.

Sjoberg, Gideon. The Preindustrial City, Past and Present. New York: The Free Press, 1960.

Smith, David Horton and McGrail, Richard F. Cormunity Control of Schools: A Review and Options. Urban and Social Change Review, 3 (1), 1969:2-9.

Smith, Gerald R., Gregory, Thomas B., and Pugh, Richard C. Meeting Student Needs: Evidence for the Superiority of Alternative Schools. Phi Delta Kappan, April, 1981.

Smith, Vernon H. Alternative Education is Here to Stay. Phi Delta Kappan, April, 1981.

Squire, James R. and Applebee, Roger K. High School English Instruction Today. New York: Appleton-Century-Crofts, 1968.

Stake, Robert E. The Case Study Method in Social Inquiry. Educational Research, February, 1978.

Steinitz, Victoria, King, Prudence, Solomon, Ellen, Shapiro, Ellen. Ideological Development in Working-Class Youth, Harvard Educational Review, 43 (3), 1973:333-361.

Straus3, George H. Two Perspectives on High School Student Politics. Youth and Society, 5(3), 1974:360-376.

Sulack, Shirley M. The Turnabout: From Boredom to Interest. Phi Delta Kappan, May, 1975:630.

Swidler, A. What Free Schools Teach. Social Problems, 1976.

Tanner, Daniel. Splitting Up the School System: Are Comprehensive High Schools Doomed? Phi Delta Kappan, October, 1979:92-97.

The Twentieth Century Fund, The Report of the Twentieth Century Fund Task Force on Federal Elementary and Secondary Education Policy, New York, 1983.

Thornburg, Kathy R. Attitudes of Secondary Principals, Teachers, Parents and Students Toward Parent Involvement in the Schools. High School Journal, 64 (4), 1981:150-153. 
Timpane, Michael, Abramowitz, Susan, Bobrow, Sue Berryman, Pascal, Anthony. Youth Policy in Transition. Santa Monica, Calif.: Rand Corporation, 1976.

Tjosvold, Dean. Limited Democratic Schools: A Social Psychological Analysis. Educational Studies, Spring, 1978:25-35.

Tornatzky, Louis, Brookover, Wilber B., Hathaway, Douglas V., Miller, Stephen K., and Passalacqua, Joseph. Changing School Climate: A Case Study in Implementation. Urban Education, 15 (1), 1980: 49-64.

Trent, Margaret. Small But Realistic. Compact, Spring, 1981:26-30.

Tubbs, Mary P. and Beane, James A. Curricular Trends and Practices in the High School: A Second Look. High School Journal, 64 (5), 1981:203-208.

Tumin, Melvin M. Schools as Social Organizations. In Ronald G. Corwin and Roy A. Edelfelt, Perspective on Organizations, The School as a Social Organization. Washington, D.C.: American Association of Colleges for Teacher Education, 1977.

Tyack, David and Hansat, Elizabeth. From Social Movement to Professional Management: An Inquiry into the Changing Character of Leadership in Public Education. American Journal of Education, 88, 1980:291-319.

Tyack, David B. The One Best System. Cambridge, Mass.: Harvard University $\overline{\text { Press, }} 1 \overline{974}$.

Udy, Stanley Jr. Administrative Rationality, Social Setting, and Organizational Development. In Amitai Etzioni, A Sociological Reader on Complex Organizations. New York: Holt, Rinehart and Winston, Inc., 1969.

- The Comparative Analysis of Organizations. In James March (Ed.), Handbook of Organizations. Chicago: Rand MeNally \& Co., 1965.

Wallar, Willard. The Sociology of Teaching. New York: John Wiley, 1932.

Wasserman, Elas R. Implementing KohIberg 's Just Community Concept in an Alternative High School. Social Education, April, 1976:203-207.

Webb, Eugene J., Campbell, Donald T., Schartz, Richard D., and Sechrest, Lee. Unobtrusive Measures. Chicago: Rand McNally \& Co., 1966. 
Weber, Max. The I'heory of Social and Economic Organization. New York: Oxford University Press, 1947.

Weinstock, Ruth. The Greening of the High School. New York: Educational Facilities Laboratories, 1973.

Weinstock, Samuel. Urban Adolescents and the Political System: Dimensions of Disaffection. Theory and Research in Social Education, Spring, 1980.

Weiss, Iris R. Report of the 1977 National Survey of Science, Mathematics, and Social Studies Education. North Carolina Research Triangle Park, Center for Educational Research and Evaluation, March 1978.

Wilhelms, Fred T. Sizing Up Today's Schools--More Pluses than Media Report, National Association of Secondary School Principals Bulletin, 63 (430), November, 1979:84-96.

Wolfe, Thomas E., Walker, Michael and Macking, Robert A. Summary of the NASP Survey, 1974. Amherst: National Alternative Schools Program, University of Massachusetts, 1974.

Wynne, Edward A. Growing Up Suburban. Austin, Texas: University of Austin Press, 1977 .

Yates, Mary Ruth, Saunders, Ron Watkins, J, Foster. A Program Based on Maslow's Hierarchy Helps Students in Trouble. Alternative Education, June, 1980:713.

DOCUMENTS

\section{Federal}

Cardinal Principals of Secondary Education, Bureau of Education Bulletin No. 35 . Washington, D.C.: Government Printing office, 1918.

Coleman, James I., Campbell, Ernest Q., Hobson, Carol J., McParland, James, Mood, Alexander M., Weinfeld, Frederic D., and York, Robert L. Equality of Educational Opportunity. U.S. Department of Health, Education, and Welfare, 1966.

National Education Association, Schools for the 70's and Beyond: A Call to Action. Center for the Study of Instruction, 1971. 
$\underline{\text { State }}$

Colorado Department of Education, School Improvement and Leadership Services Unit, May, 1982.

Department of Education, Sic te of Colorado, Colorado State Board of Education Educational Priorities 1982-1984, State office Building, Denver, Colorado 80203 .

Jefferson County Public Schools--Lakewood, Colorado

Audit Comittee Report of the Mountain Open High School, Jefferson County Public Schools, Lakewood, Colorado, June, 1977.

Audit Committee Report of the Mountain Open High School, Prepared by Appointed Members of the Jefferson County Public Schools, Maj, 1976.

Audit Committee Report, Third Year Evaluation--Mountain Open High School, Jefferson County Public Schools, Lakewood, Colorado, June, 1978.

Jeffco News. Alternative Programs Meet Individual Needs, September, 1979 .

Jefferson County Public Schools, Special Report, 1978, Department of Communications Services.

Proposal for Mountain Open High School as Approved by Jefferson County Board of Education, April 15, 1975.

Mountain Open High School

Addendum to Background Information First Year Evaluation--Mountain Open High School, prepared by Mountain Open High School Personnel, for use by 1976-1977 Audit Committee, May 5, 1977.

Passages, published by the Journalism Class of Jefferson County Open High School, Fall, 1980.

Self-Study of Jefferson County Open High School, prepared for the North Central Accreditation Team by the Jefferson County Public School Staff, January, 1979.

Other

Report of Visiting Resource Team of North Central Association to Jefferson County Open High School, Evergreen, Colorado, March, 1980. 
Seattle Public Schools Booklet, Administrative and Service Center, 1980-1981.

Thirtieth Educational Conference of the Philadelphia Home and School Council, Acres of Diamonds in the Philadelphia Public Schools, 1978 .

\section{Newspapers}

Evergreen Today. Open High School's program is highlight in Evergreen, June $12,1980$.

Canyon Courier. Cyclists head to California coast, May 20, 1981.

Canyon Courier. Letter to the Editor: Loves School, June 10, 1981.

Canyon Courier. Open High Donation Finally to be Spent, August 5, 1981 .

Canyon Courier. Open Schools Focus on Academics, September 9, 1976.

Canyon Courier. Thanks for Showing Me Who I Am, September 23, 1981.

Canyon Courier. The Open High School--Worth Examining, April 4, 1982.

Canyon Courier. Unknown Donor Gives $\$ \$ \$$, January 14, 1981.

Canyon Courier. Why Open Living School? September 16, 1981.

Interviews: $4 / 30 / 81 ; 5 / 4 / 81 \mathrm{a} ; 5 / 4 / 81 \mathrm{~b} ; 5 / 4 / 81 \mathrm{c} ; 5 / 11 / 81 \mathrm{a} ; 5 / 11 / 81 \mathrm{~b}$;

5/18/81b;9/19/80a; 9/19/80b; 9/19/80;9/16/80; 9/20/80;

9/25/80b; 9/25/80c; 9/26/80; 10/31/80; 10/31/80b; 11/5/80;

$11 / 14 / 80 \mathrm{~b} ; 11 / 14 / 80 \mathrm{~b} ; 11 / 14 / 80 \mathrm{c} ; 11 / 21 / 80 \mathrm{a} ; 11 / 21 / 80 \mathrm{~b} ; 11 / 21 / 80 \mathrm{c}$;

$11 / 21 / 80 \mathrm{e} ; 12 / 2 / 30 ; 12 / 11 / 80 \mathrm{a} ; 3 / 23 / 810 ; 3 / 23 / 81 \mathrm{c} ; 3 / 23 / 81 \mathrm{f}$;

$4 / 13 / 81 \mathrm{~b} ; 4 / 17 / 81 ; 3 / 23 / 81 ; 3 / 23 / 81 \mathrm{~b} ; 3 / 23 / 81 \mathrm{c} ; 3 / 23 / 81 \mathrm{c}$;

$3 / 23 / 81 \mathrm{f} ; 4 / 13 / 81 \mathrm{~b} ; 4 / 25 / 81 ; 4 / 25 / 81 \mathrm{~b} ; 4 / 25 / 81 \mathrm{c} ; 4 / 25 / 81 \mathrm{~d}$;

$4 / 23 / 81 ; 4 / 16 / 81 ; 4 / 13 / 81 ; 4 / 13 / 81 c ; 4 / 13 / 81 d ; 4 / 17 / 81 ; 4 / 16 / 81$;

$4 / 23 / 81 ; 4 / 25 / 81 a ; 4 / 25 / 81 b ; 9 / 25 / 80 b ; 4 / 13 / 81 \mathrm{c} ; 4 / 17 / 81$;

$4 / 16 / 81 ; 4 / 23 / 81 ; 4 / 25 / 81$; 4/24/81b; 4/25/81c; 4/24/81d;

$6 / 11 / 81 ; 4 / 25 / 81 a ; 4 / 25 / 81 b ; 4 / 25 / 81 c ; 4 / 30 / 81 ; 5 / 4 / 81 a$;

5/4/81b; 5/11/81; 5/18/81a; 5/18/81b; 1/22/81a; 1/22/81b;

$1 / 22 / 81 \mathrm{c} ; 1 / 22.81 \mathrm{~d} ; 1 / 22 / 81 \mathrm{e} ; 1 / 26 / 81 \mathrm{a} ; 1 / 30 / 81 \mathrm{c}$. 
APPENDICES 
APPENDIX A

INTERVIEW SCHEDULE OF QUESTIONS FOR THIITEEN STUDENT VOLUNTEERS EROM MOUNTAIN OPEN HIGH SCHOOL

1) Background Information and Why an Alternative School Choice

a. Tell me about yourself.

b. Tell me about your family.

c. Why did you choose an alternative school experience?

d. How long have you been in an alternative school setting?

2) Perceptions Concerning Labeling Practices

a. What is your opinion concerning the extent of social and academic labeling practices at MOHS?

b. Are terms such as "jock," "freak," "cowboy," and "hick" used at MOHS to label students?

3) Opinions Concerning the Expectations of the Staff and Principal

a. What are your perceptions concerning the expectations that the staff at MOHS hold for you?

b. What do you think of the principal, Arnie and the expectations he has for you?

4) Attitudes About Beginnings Classes and the Advisory System

a. Who is your advisor?

b. What do you think of the Advisory System at MOHS?

c. What do you think of the Beginnings Classes at MOHS?

5) Perceptions Concerning the Walkabout Curriculum, Trips, and Community Learning Experiences

a. How do you like the Walkabout Curriculum?

b. Do you understand the Walkabout Curriculum?

c. How many school trips have you been on?

d. What do you think of Trips?

e. Have you completed a Community Learning Experience? If yes, explain.

f. What do you think of Community Learning Experiences?

6) Governance System and Freedom of Choice

a. What do you think of all-school Governance Meetings?

b. How often do you attend Governance Meetings?

c. To what extent do you think freedom of choice exists at MOHS?

7) Opinions of the Physical Characteristics of MOHS

a. What do you think of the physical location of your school?

b. What do you think about the size of classes at your school?

c. What do you think about the student body size of your school? 


\author{
APPENDIX B \\ JEFFERSON COUNTY OPEN HIGH SCHOOL CAREER EXPLORATION \\ PASSAGE COMMITTEE SUGGESTIONS
}

DEFINITION

A passage in Career Exploration as an in-depth experience and/or investigation of a possible life's work. It can also be an extension of an interest or ability.

\title{
PREPARATION
}

Completing one or more of the vocational interest inventories is STRONGLY recommended before writing your proposal. These inventories are available in the counseling office.

At least one Community Learning/Service or its equivalent should be attained before attempting a Career Exploration Passage.

\section{PREWALKABOUT SKILLS}

Experiences which address the following skills should be logged in your prewalkabout notebook:
A. 4,8
B. 6
D. (any and/or all, where applicable)
C. 3,4
F. $1,2,3,4,5$
H. 3

\section{PROPOSAL}

The following information should be included in your passage proposal: your skills, past experience(s), awareness of self, values, etc., what the job requirements are (e.g., education, skills, working conditions), your physical, mental and emotional conditions.

\section{DOCUMENTATION AND EVALUATION}

A daily journal and a complete evaluation, containing a discussion of the personal relevance of the experience, are required. Other documentation should be worked out with, and approved by, your committee.

The proposal needs to follow the guidelines for passage proposals (obtain this information from your advisor or the Walkabout room).

Before doing anything in writing, it is recomended that you discuss your plans with AT LEAST your advisor and one of the members on the Career Exploration committee. 